UNIVERSIDADE DE BRASÍLIA

FACULDADE DE TECNOLOGIA

DEPARTAMENTO DE ENGENHARIA CIVIL E AMBIENTAL

\title{
MODELAGEM PARA A ROTEIRIZAÇÃO DO PROCESSO DE COLETA E TRANSPORTE DOS RESÍDUOS SÓLIDOS URBANOS
}

JOSÉ ANTONIO RODRÍGUEZ MELQUIADES

ORIENTADORA: ADELAIDA PALLAVICINI FONSECA

TESE DE DOUTORADO EM TRANSPORTES

PUBLICAÇÃO: T.D-03/2015

BRASÍLIA/DF: SETEMBRO - 2015 
UNIVERSIDADE DE BRASÍLIA

FACULDADE DE TECNOLOGIA

DEPARTAMENTO DE ENGENHARIA CIVIL E AMBIENTAL

MODELAGEM PARA A ROTEIRIZAÇÃO DO

PROCESSO DE COLETA E TRANSPORTE DOS RESÍDUOS SÓLIDOS URBANOS

JOSÉ ANTONIO RODRÍGUEZ MELQUIADES

TESE DE DOUTORADO SUBMETIDA AO DEPARTAMENTO DE ENGENHARIA CIVIL E AMBIENTAL DA FACULDADE DE TECNOLOGIA DA UNIVERSIDADE DE BRASÍLIA COMO PARTE DOS REQUISÍTOS NECESSÁRIOS PARA A OBTENÇÃO DO GRAU DE DOUTOR EM TRANSPORTES

APROVADA POR:

Prof ${ }^{\mathrm{a}}$ Adelaida Pallavicini Fonseca, D.Sc. (UnB) (Orientadora)

Prof. Paulo Cesar Marques da Silva, Dr. (UNB) (Examinador Interno)

Prof. Sérgio Ronaldo Granemann, Dr. (UNB) (Examinador Interno)

Prof. Reinaldo Crispiniano Garcia, PhD. (UNB) (Examinador Externo)

Prof. Luiz Antônio Silveira Lopes, D.Sc. (IME)

(Examinador Externo)

BRASÍLIA/DF, 4 DE SETEMBRO DE 2015 
FICHA CATALOGRÁFICA

MELQUIADES, JOSÉ ANTONIO RODRÍGUEZ

Modelagem para a roteirização do processo de coleta e transporte dos resíduos sólidos urbanos [Distrito Federal] 2015.

xiii, 145p., 210 x 297 mm (ENC/FT/UnB, Doutor, Transportes, 2015).

Tese de Doutorado - Universidade de Brasília. Faculdade de Tecnologia.

Departamento de Engenharia Civil e Ambiental.

1. Resíduos sólidos urbanos

2. Sustentabilidade urbana

3. Programação linear inteira

4. Roteirização, transporte

I. ENC/FT/UnB

II. Título (série)

\section{REFERÊNCIA BIBLIOGRÁFICA}

MELQUIADES, J. A.R. (2015). Modelagem para a roteirização do processo de coleta e transporte dos resíduos sólidos urbanos, Publicação T. D - 003/2015, Departamento de Engenharia Civil e Ambiental, Universidade de Brasília, Brasília, DF, 145p.

\section{CESSÃO DE DIREITOS}

AUTOR: José Antonio Rodríguez Melquiades.

TÍTULO: Modelagem para a roteirização do processo de coleta e transporte dos resíduos sólidos urbanos.

GRAU: Doutor $\quad$ ANO: 2015

É concedida à Universidade de Brasília permissão para reproduzir cópias desta tese de doutorado e para emprestar ou vender tais cópias somente para propósitos acadêmicos e científicos. O autor reserva outros direitos de publicação e nenhuma parte dessa tese de doutorado pode ser reproduzida sem autorização por escrito do autor.

José Antonio Rodríguez Melquiades

Calle Los Cedros 449 Huamán, Distrito Victor Larco - Ciudad Trujillo, Perù.

jrodriguezmelquiades@gmail.com 


\section{DEDICATÓRIA}

A Deus por sua eterna benção e por todos os momentos maravilhosos que me proporciona.

A minha esposa Julia Lila por seu incondicional amor e paciencia. Grande companheira da minha vida.

A meus filhos Jair André, Jairo André e Fátima Jael pela felicidade que trazem na minha vida. A meus pais Felipe e Magna que sempre incentivaram o meu interesse pela vida acadêmica.

A meu irmão Orlando Felipe por mais uma motivação.

A minha cunhada Elena por sua força e incentivo, e pelo carinho especial que da a meus fillhos.

Muito obrigado por todo. 


\section{AGRADECIMENTOS}

Agradeço à professora Adelaida Pallavicini Fonseca por ter aceitado ser minha orientadora. Por sempre se mostrar disponível e interessada em me ajudar. Grande pessoa e profissional.

Aos meus professores dos quais recebi muitos conhecimentos que fizeram possível minha formação acadêmica na UnB.

Ao Governo de Republica Federativa do Brasil, pela oportunidade dada para a realização do curso de doutorado em Transportes.

Aos grandes amigos que conheci na UnB. Como os meus amigos de Cabo Verde, Milton Jonas Monteiro e seu irmão Claudio, sempre dispostos em ajudar; a minha amiga Lucinei Tavares de Assunção, colega de grande coração e sempre disposta a contribuir com os amigos; e não posso esquecer-me de duas grandes amigas de Piauí: a Noêmia Gomes e Roméa Ribeiro. Obrigados a todos vocês.

Aos meus colegas do Departamento de Informática da Universidade Nacional de Trujillo, pelo apoio dado todo este tempo para poder realizar meus estudos na UnB. 


\title{
RESUMO
}

\section{MODELAGEM PARA A ROTEIRIZAÇÃO DO PROCESSO DE COLETA E TRANSPORTE DOS RESÍDUOS SÓLIDOS URBANOS}

\author{
Autor: José Antonio Rodríguez Melquiades \\ Orientador: Profa. Adelaida Pallavicini Fonseca, D. Sc. \\ Programa de Pós-Graduação em Transportes - Universidade de Brasília \\ Brasília, 4 de setembro de 2015
}

A pesquisa bibliográfica revela uma preocupação dos governos federais com a destinação final dos resíduos sólidos urbanos (RSU) com o objetivo de preservar a saúde da população, o meio ambiente urbano e rural. Por exemplo, no Brasil observa-se a criação da Lei 12.305/10 e, no Peru, da Lei 27.314/2000. Neste contexto e para o caso das cidades brasileiras esperava-se que, com o comando legal de desativação dos lixões até 2014, surgissem medidas que viabilizassem a coleta seletiva, reciclagem e reutilização para cerca de $80 \%$ do volume total de resíduos sólidos coletados e destinados a locais impróprios. No entanto, o que se observa é o não cumprimento das metas propostas em ambas as leis vis-àvis as metas reais dos governos locais. Infere-se que isso se deve essencialmente à falta de uma boa estrutura organizacional, gerencial e operacional dos respectivos governos capaz de atender às demandas da população. A rigor, pode-se concluir que o maior problema das cidades está na falta de uma rede logística reversa, amparada por um adequado sistema de informação gerencial e de controle operacional que, por sua vez, integre todos os participantes formais e informais, privados ou não, que atuam e trabalham com os RSU. Nesse sentido esta pesquisa tem como objetivo principal modelar e planejar uma rede logística reversa para uma região urbana, dimensionando o fluxo de RSU que será movimentado ao longo da rede, o número e capacidade das estações de coleta, das unidades produtivas e especiais necessárias para sua coleta, transporte e disposição final. Os resultados obtidos mostram ser possível realizar a modelagem matemática desse tipo de problema com baixo investimento, assim como aplicá-la em várias regiões sem necessidade de grandes mudanças no modelo proposto. 


\title{
ABSTRACT \\ MODELING FOR THE ROUTING OF THE PROCESS TO \\ COLLECTION AND TRANSPORTATION OF URBAN SOLID WASTE
}

\author{
Author: José Antonio Rodríguez Melquiades \\ Advisor: Adelaida Pallavicini Fonseca, D. Sc. \\ Graduate Program in Transportation - University of Brasilia \\ Brasilia, September, 4th, 2015
}

The literature reveals a concern of Federal Governments with the disposal of municipal solid waste (MSW) in order to preserve the health of the population, the urban and rural environment. For example, in Brazil there has been the creation of Law 12,305 / 10 and, in Peru, of Law 27,314 / 2000. In this context and for the case of Brazilian cities, it was expected that, with the legal command for the deactivation of landfills by 2014, measures would be adopted in order to enable the selective collection, recycling and reuse for about $80 \%$ of the total volume of collected solid waste and intended to inappropriate places. However, what is observed is the non compliance of the proposed goals in both laws vis-àvis the real targets of local governments. It is inferred that this is due mainly to the lack of proper organizational, managerial and operational structure of these governments able to meet the demands of the population. Rigorously, it can be concluded that the biggest problem of the cities is the lack of a reverse logistics network supported by an adequate system of managerial information and operational control which, in turn, integrates all formal and informal, private or not, participants that act and work with MSW. In this sense, this research aims to model and plan a reverse logistics network to an urban area, dimensioning the flow of MSW that will be moved along the network, the number and capacity of collection stations, and the productive and special units required for their collection, transportation and final disposal. The results show to be possible perform mathematical modeling of this problem with low investment, as well as apply it in various regions without major changes in the proposed model. 


\section{LISTA DE FIGURAS}

Figura 2.1 - Aterro sanitário de Huaycoloro 23

Figura 2.2 - Planta de mecanismo de desenvolvmento limpo ............................................. 24

Figura 2.3 - Planta elétrica para queima de biogás para gerar energia elétrica .................. 25

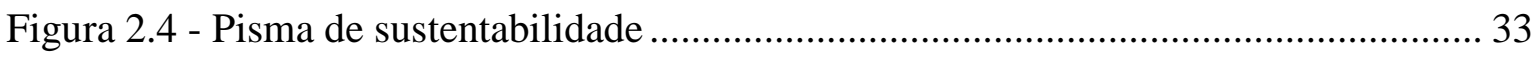

Figura 2.5 - Aspectos chave para o desenvolvimento sustentável ..................................... 34

Figura 2.6 - Logística reversa embutida no desenvolvimento sustentável .......................... 37

Figura 2.7 - Suporte de um sistema para logística urbana............................................... 39

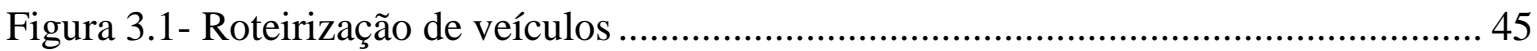

Figura 3.2- Modelo conceitual de logística reversa......................................................... 52

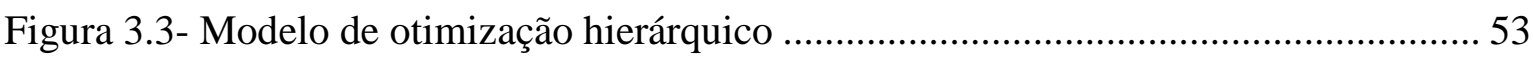

Figura 3.4 - Rede Logística Reversa A e as capacidades de oferta e/ou demanda de cada

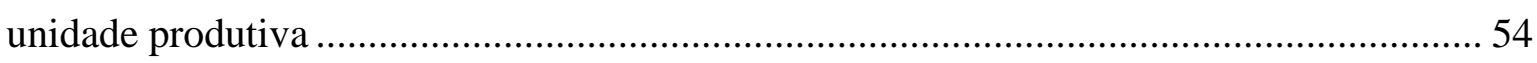

Figura 3.5 - Rede Logística Reversa A e as capacidades de oferta e/ou demanda de cada

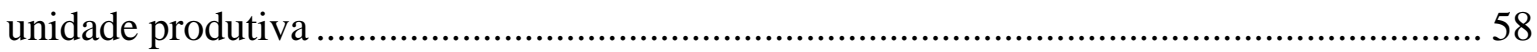

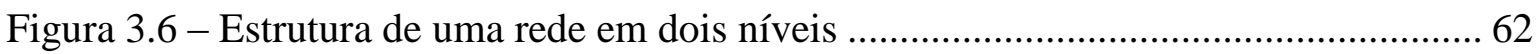

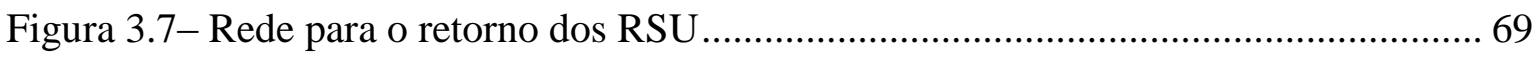

Figura 3.8 - Zona comercial de Distrito de Trujillo....................................................... 73

Figura 3.9 - Alocação dos centros especializados ........................................................... 79

Figura 3.10 - Localização das plataformas, unidades satélites e clientes ........................... 80

Figura 3.11 - Alocação dos setores e centros especializados........................................... 82

Figura 3.12 - Distribuição dos resíduos gerados nos setores do Distrito de Trujillo.......... 83

Figura 4.1-Esquema do processo de coleta e transporte de RSU ..................................... 85

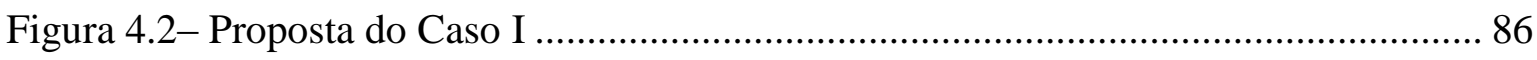

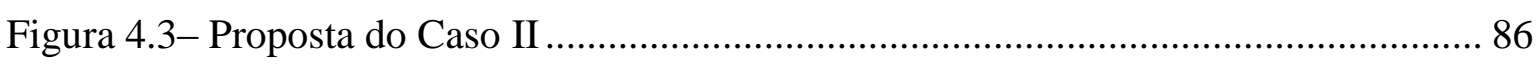

Figura 4.4- Localização geográfica do Distrito de Trujillo ............................................... 99

Figura 4.5-Zonas geradoras de RSU no Distrito de Trujillo............................................ 100

Figura 4.6 - Localização geográfica dos centros especializados no Distrito de Trujillo .. 102

Figura 4.7 - Subsetores La Merced e La Arboleda_San Eloy .......................................... 103

Figura 4.8 - Roteirização nos SubsetoresLa Merced_La Arboleda_San Eloy................... 104

Figura 4.9 - Transporte dos RSU para os centros especializados, Caso I......................... 106

Figura 4.10 - Transporte dos RSU para os centros especializados, sem centro de

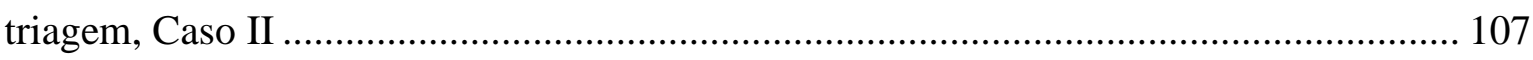


Figura 4.11 - Roteirização no Subsetor San Andrés da zona 5

Figura 4.12 - Transporte de RSU coletados no subsetor San Andrés, para os centros especializados do Distrito de Trujillo, Caso I e Caso II .. 110

Figura 4.13 - Transporte de RSU coletados no subsetor Monserrate, para os centros especializados do Distrito de Trujillo, Caso I e Caso II 


\section{LISTA DE TABELAS}

Tabela 2.1 - Geração e coleta de RSU no Brasil............................................................... 15

Tabela 2.2 - Estatística da geração, coleta e destino final dos RSU ................................... 16

Tabela 2.3 - Geração e coleta de RSU no Distrito Federal................................................. 17

Tabela 2.4 - Principais materiais de RSU coletado no Brasil .......................................... 17

Tabela 2.5 - Participação dos Municípios na coleta de RSU por tonelada coletada (Q) por

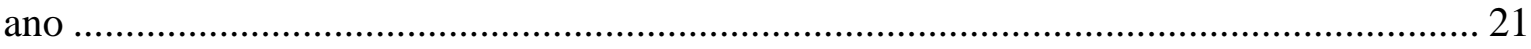

Tabela 2.6 - Participação dos Municípios na disposição final de RSU por ano.................. 21

Tabela 2.7 - Geração de RSU em Peru ................................................................................ 21

Tabela 2.8 - Geração e coleta de RSU na Província de Lima ............................................. 22

Tabela 2.9 - Quantidade de operadores autorizados para atuar na Lima Metropolitana .... 22

Tabela 2.10 - Método de Incineração de RSU em Países Desenvolvidos ............................ 30

Tabela 3.1 - Resultados obtidos no PRVC para veículos com 10 ton de capacidade ......... 75

Tabela 3.2 - Resultados obtidos no PRVC para veículos com 12 ton de capacidade......... 76

Tabela 3.3 - Resultados obtidos no PRVC para veículos com 14 ton de capacidade .......... 76

Tabela 3.4 - Quadro comparativo dos resultados das três corridas..................................... 77

Tabela 3.5 - Resultados obtidos no PRVJT para veículos com 12 ton de capacidade ....... 78

Tabela 3.6 - Resultados obtidos com o modelo de Lee J. et al.(2008) .............................. 79

Tabela 3.7 - Resultados computacionais obtidos no modelo de Sterle (2010).................... 81

Tabela 4.1 - Quantidade de residências nas zonas geradoras de RSU ................................ 98

Tabela 4.2 - Residências por classe econômica e social ...................................................... 98

Tabela 4.3- Geração de RSU nas zonas por classe social em kg/residência/dia............... 100

Tabela 4.4 - Geração de RSU por zonas ....................................................................... 101

Tabela 4.5 - Dados de geração de RSU dos subsetores La Merced e La Arboleda_San Eloy. 103

Tabela 4.6 - Resultados obtidos da Etapa 1 do processo de modelagem nos subsetores La

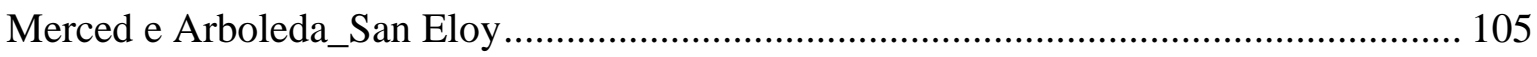

Tabela 4.7 - Resultados obtidos no subsetor San Andrés da zona 5 ............................... 109

Tabela 4.8 - Resultados obtidos no subsetor Monserrate da zona 5.............................. 112 


\section{Sumário}

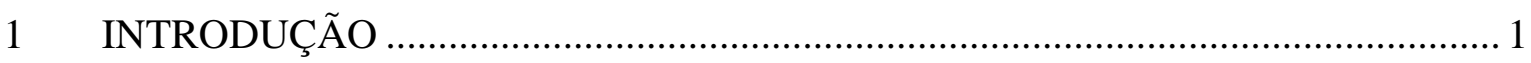

1.1 DESAFIOS BRASILEIROS NA IMPLEMENTAÇÃO DA LEI 12305/2010 …........5

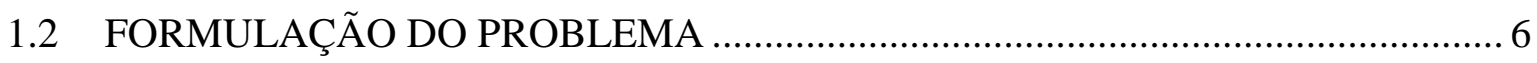

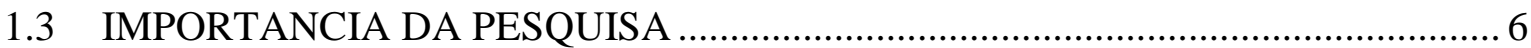

1.3.1 Estimativa de custos da coleta seletiva e destinação final ambientalmente adequada. 7

1.3.2 A riqueza do "lixo" ou os "bilhões perdidos" ......................................................... 8

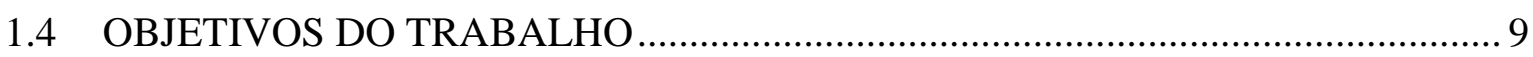

1.5 METODOLOGIA DA PESQUISA ………………………………………......... 10

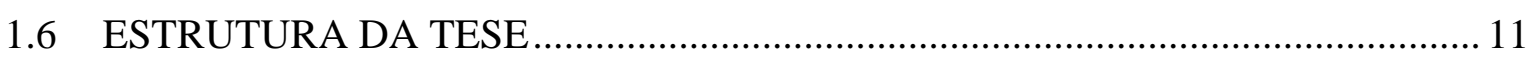

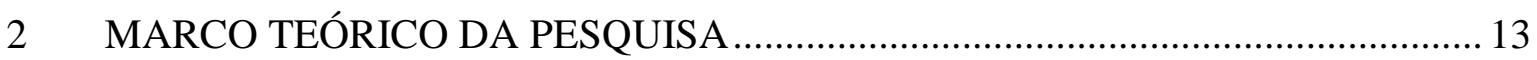

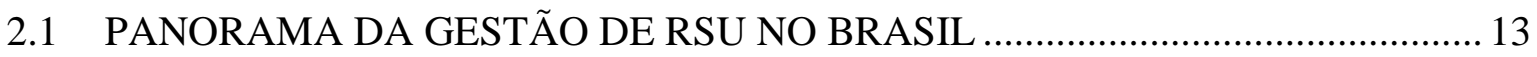

2.1.1 Diagnóstico da Situação Atual ................................................................................ 13

2.1.2 Reciclagem e Compostagem ............................................................................ 17

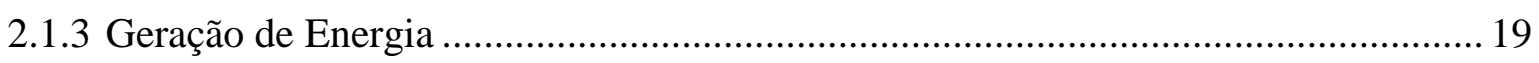

2.2 PANORAMA DOS RESÍDUOS SÓLIDOS NO PERU E A LEI 27.314/2000_........ 19

2.3 EXPERIÊNCIAS NO BRASIL NO TRATAMENTO ADEQUADO DOS RSU ....25

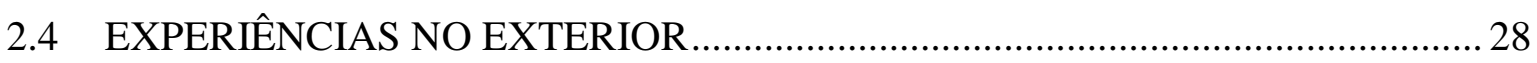

2.4.1 Tratamento e Gestão de RSU em Países Desenvolvidos ............................................. 28

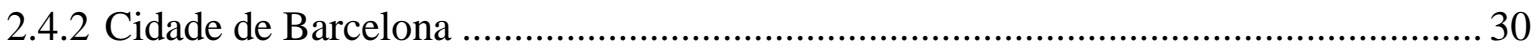

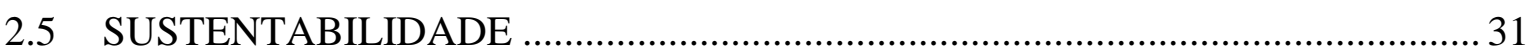

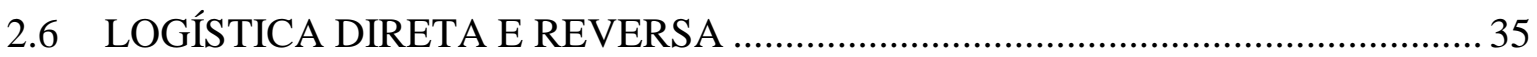

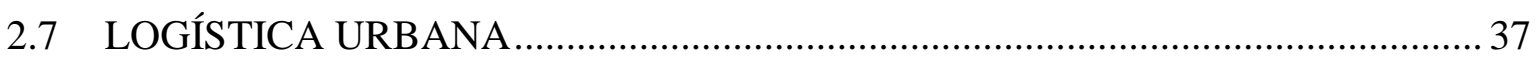

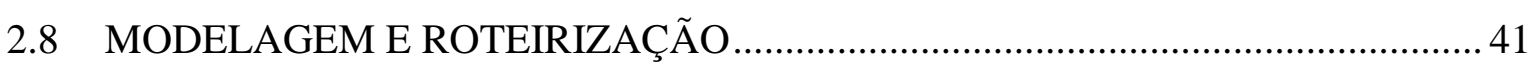

3 MODELOS UTILIZADOS EM REDES LOGISTICAS E GESTÃO DE RESÍDUOS

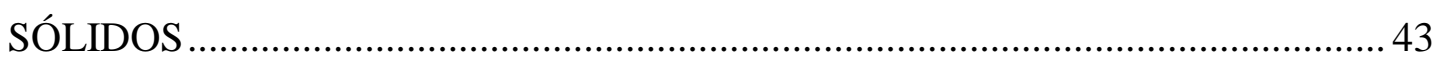

3.1 MODELOS UTILIZADOS NOS PROBLEMAS DE ROTEIRIZAÇÃO E PROGRAMAÇÃO DE VEICULOS....................................................................... 44

3.1.1 Problema de RoteirizaçãoOperando com Frota Homogênea ......................................... 47

3.1.2 Problema de Roteirização de Veículos com Janelas de Tempo ……………………..... 49

3.2 MODELOS UTILIZADOS NOS PROBLEMAS DE REDES LOGÍSTICAS ……... 51

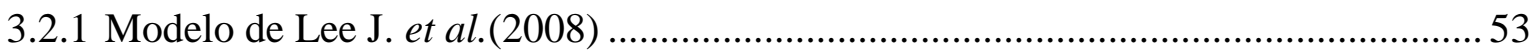

3.2.2 Modelo de Saman et al.(2009) ................................................................................ 57 
3.3 MODELOS UTILIZADOS NOS PROBLEMAS DE LOGISTICA URBANA ....... 61

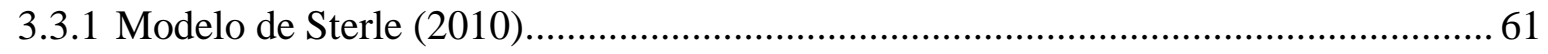

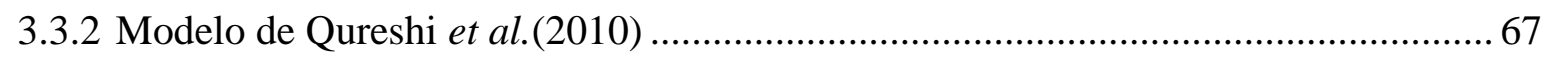

3.4 MODELODE BADRAN (2006) PARAGESTÃO DE RSU ..................................... 68

3.5 TESTEDOS MODELOS ESTUDADOS NO DISTRITO DE TRUJILLO................ 72

3.5.1 Testesdo Problema de Roteirização Operando com Frota Homogênea...................... 74

3.5.2 Testes do Problema de Roteirização de Veículos com Janelas de Tempo................. 78

3.5.3 Teste do Modelo de Logística Reversa de Lee J. etal.(2008) ................................... 78

3.5.4 Teste do Modelo de Logística Urbanade Sterle (2010) ........................................... 79

3.5.5 Teste do Modelo de Gestão de Resíduos Sólidos de Badran (2006) .......................... 81

4 PROPOSTA DE MODELAGEM PARA COLETA E TRANSPORTE DE RSU .... 84

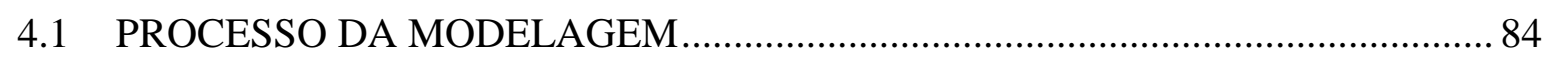

4.2 PROCESSO DE ROTEIRIZAÇÃO E SELEÇÃO DAS ESTAÇÕES DE COLETA87

4.3 TRANSPORTE DOS RSU DAS ESTAÇÕES DE COLETA SELECIONADAS ATÉ OS CENTROS ESPECIALIZADOS …................................................................ 91

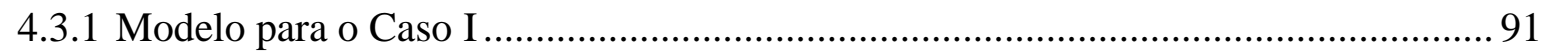

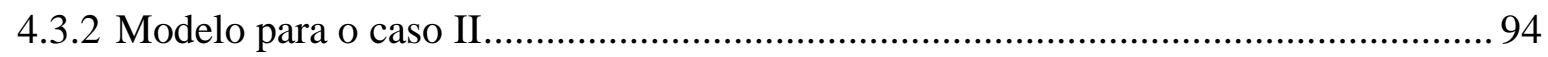

4.4 ESTUDO DE CASO PARA O DISTRITO DE TRUJILLO NO PERU ...................97

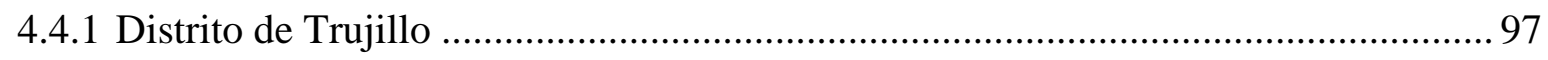

4.4.2 Etapa 1: Aplicação do Modelo PRVJT nos Subsetores La Merced e La Arboleda_San

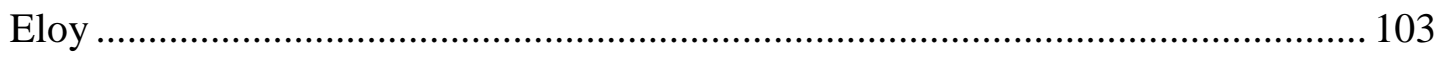

4.4.3 Etapa 2: Aplicação do Modelo de Transporte nos Subsetores La Merced e La

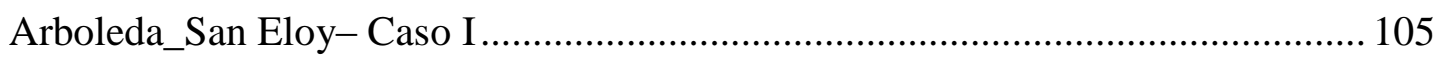

4.4.4 Etapa 2: Aplicação do Modelo de Transporte nos Subsetores La Merced e La

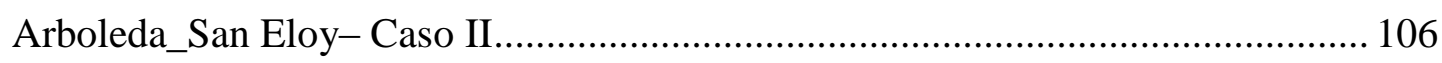

4.4.5 Teste no Subsetor San André: Aplicação das Etapas 1 e 2 (Caso I e Caso II)......... 108

4.4.6 Teste no Subsetor Monserrate: Aplicação das Etapas 1 e 2 (Caso I e Caso II) ........ 111

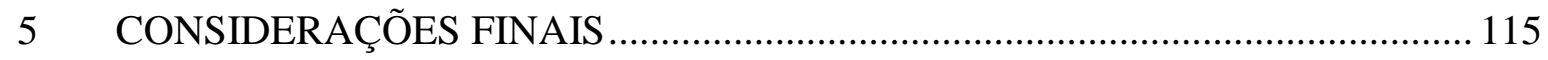

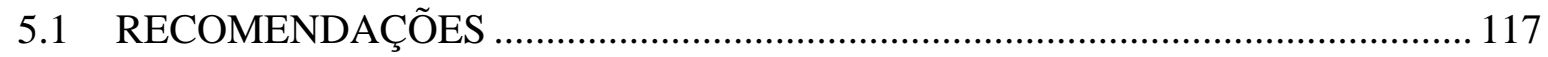

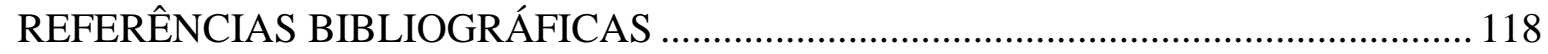

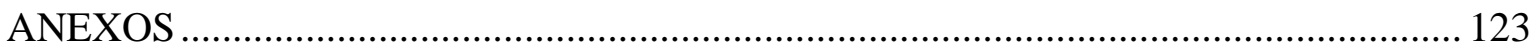

ANEXO A: Modelo de roteirização de veículos operando com frota homogênea ............ 124

ANEXO B: Modelo de roteirização de veículos com janela de tempo .............................. 125

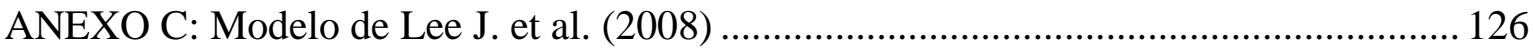


ANEXO D: Modelo de Sterle (2010)

ANEXO E: Modelo de Badran (2006)

ANEXO F: Modelo de coleta dos RSU.

ANEXO G: Modelo de transporte dos RSU coletados para centros especializados: Caso I 135

ANEXO H: Modelo de transporte dos RSU coletados para centros especializados: Caso II 138 APÊNDICE 141

APÊNDICE A: Conceitos Utilizados 142 


\section{INTRODUÇÃO}

$\mathrm{Na}$ medida em que as cidades iam crescendo, o próprio sistema urbano como um todo, ia ficando cada vez mais complexo e insuficiente para atender a forte demanda da população por serviços urbanos. As instituições responsáveis pela oferta desses serviços urbanos não têm conseguido acompanhar o ritmo de crescimento dessas demandas, já que precisam de investimentos para ampliar os serviços, de projetos inovadores que se adaptem à nova realidade da sociedade moderna e de modelos de gestão mais eficientes e eficazes que dinamizem a tomada de decisão, assim como uma participação mais proativa da comunidade e de todos os atores envolvidos de forma direta e indireta nesses serviços.

O maior problema tem sido a falta de um bom sistema de planejamento por parte dos governos locais que coordene e integre todas as atividades urbanas de forma a otimizar e racionalizar recursos. Assim, surge a questão de como controlar o próprio crescimento das cidades sob diretrizes e políticas de sustentabilidade. Essa harmonização de objetivos é difícil nos modelos de gestão atual das cidades, já que cada serviço público é gerenciado e operado separadamente.

Um exemplo claro desse problema é o serviço de transporte de pessoas e de carga que compartilham as mesmas vias e espaços em uma cidade. Observa-se nos principais centros urbanos uma forte demanda por transporte de carga e de passageiros, demanda que pressiona a demanda por infraestrutura viária como de serviços de transporte público urbano de passageiros e de transporte urbano de carga. Problema esse que vem comprometendo a mobilidade e acessibilidade nos grandes centros urbanos.

Esse fenômeno vem acontecendo desde os anos 70 nas principais metrópoles do Brasil e com maior intensidade nos anos 80 e 90, tal como mostram muitos artigos científicos apresentados nos principais anais da área de transporte no Brasil (ANPET, ANTP, Revista de Transportes, dentre outros). Sendo um tema que sempre está em debate nos principais meios de comunicação do país como também em reuniões acadêmicas e científicas (Congressos, Seminários, Workshop, etc.). No entanto, a abordagem do problema pelos gestores públicos e ainda pelos pesquisadores da área de transporte é feita separadamente, 
até a Lei de Mobilidade do Brasil dá mais destaque ao transporte de passageiros, ficando o transporte de carga resumido a poucas linhas.

Tanto a movimentação de pessoas como de mercadorias e bens são importantes e vitais para o desenvolvimento e crescimento econômico e social de uma cidade ou uma região. Assim, o bom gerenciamento dos fluxos de transporte nas cidades, principalmente naqueles núcleos urbanos mais densos, garante a mobilidade e acessibilidade da população a qualquer zona de trafego da cidade, já que melhora o nível de serviço de todo o sistema de transporte urbano da cidade (carga e passageiros) devido a uma melhor racionalização da oferta de transporte (isso inclui todos os componentes do sistema de transporte).

O transporte de carga tem certa vantagem sobre o transporte de pessoas, já que é possível intervir e influenciar nos fluxos das viagens através de um bom gerenciamento das grades horárias dos sistemas logísticos de entrega e coleta das empresas e por meio da implementação de projetos de logística urbana e definição de políticas do transporte de carga por parte dos governos locais em parceria com as empresas, transportadoras e comunidade. Vários desses projetos têm sido aplicados com bastante sucesso em várias cidades do primeiro mundo (SANTOS, 2008) trazendo ganhos a todos os atores e uma redução significativa dos impactos negativos nos principais centros urbanos.

Dentro dos serviços de transporte de carga urbano tem-se o serviço de coleta e transporte dos resíduos sólidos urbanos (RSU), que também compartilha as mesmas vias e espaços urbanos de todos os outros meios de transporte que operam em todos os centros urbanos. Sendo que este é mais crítico que o resto do serviço de transporte de carga urbano, já que lida com resíduos sólidos provenientes de várias fontes, tais como hospitais, indústrias, construção, comércios, residências, dentre outros, que podem ter uma série de componentes químicos, biológicos, etc., que manuseados, armazenados e dispostos indevidamente, podem causar sérios problemas de saúde a população e contaminação ao meio ambiente.

O problema de coleta e transporte dos RSU é um problema crítico na maioria das cidades brasileiras e peruanas, já que este serviço é feito de forma domiciliar. Os veículos coletores responsáveis percorrem uma a uma todas as vias da cidade para coletar os RSU depositados por cada residência ou prédio na calçada. Estes são dispostos em contêineres 
grandes ou pequenos dependendo das características do bairro ou da cidade, ou senão em sacolas de plásticos. Não existe uma uniformização de como os RSU devem ser colocados nas calçadas ou nos outros espaços urbanos em espera de seu recolhimento, também não existe uma fiscalização e penalização dos órgãos responsáveis para evitar a exposição aberta deles ou o manuseio de pessoas alheias ao serviço urbano de limpeza. Que em muitos casos, só complica mais a limpeza da cidade.

A acessibilidade predial na maioria das cidades já se encontra comprometida, em virtude da falta do cumprimento das normas técnicas brasileiras quanto ao desenho e construção de calçadas e passeios, assim como na disposição não padronizada dos elementos de infraestrutura de mobilidade urbana (CERNA, 2014), o problema somente se agrava com a colocação indiscriminada dos RSU (seja como for o armazenamento) nas calçadas e nas vagas de estacionamento, como apontam as pesquisas de Monteiro (2013), Oliveira (2014) e Abreu (2015).

Esses três autores levantaram a situação da coleta e transporte dos RSU nas quadras comerciais da cidade de Brasília. Um deles focou o problema no Setor Comercial Norte (MONTEIRO, 2013) e os outros dois nas quadras comerciais do Plano Piloto (ABREU, 2015; OLIVEIRA, 2014). Os diagnósticos apresentados nesses trabalhos mostram a dificuldade de gestão dos RSU na cidade. Os autores avançaram nas suas pesquisas propondo soluções para a gestão dos RSU.

Em entrevista pessoal com os responsáveis do Serviço de Limpeza Urbana do Distrito Federal (DF) no início do ano 2015, percebe-se que a situação é muito grave, não tendo a instituição, capacidade gerencial e operacional para atender aos desafios impostos na Lei de Resíduos Sólidos 12.305/2010. Outro problema sério é que a instituição não tem controle sobre a programação diária dos veículos que realizam a coleta domiciliar e transporte dos RSU nas cidades do DF, já que não existe um sistema que permita ao SLU ter essas informações em tempo real das empresas responsáveis por esse serviço.

Mas o maior problema do SLU encontra-se no "Aterro Controlado do Jóquei (Estrutural)", o qual recebe $90 \%$ dos RSU do DF, quase dois mil toneladas diárias. Ele existe há mais de 40 anos, no entanto, poucas intervenções relevantes e sérias foram feitas para o seu fechamento. O lixo levado para lá fica depositado por longos períodos descoberto e 
revirado, há presença de animais e catadores, assim este aterro é considerado um lixão, o maior da América Latina. Não existe drenagem especifica para a água de chuva que escorre levando substancias tóxicas para a rede pluvial comum. Em alguns pontos o chorume corre a céu aberto, parte é depositada em uma lagoa artificial impermeável e o resto penetra no solo. Não possui Licença Ambiental nem impermeabilização de base (REZENDE, 2006).

Com a Política Nacional de Resíduos Sólidos, que determina o fechamento de todos os lixões do país e a destinação ambiental correta dos resíduos, pode-se concluir que este aterro está na ilegalidade. Já são mais de R \$ 11 milhões em multas ambientais, só no ano 2015. O SLU considera que o "Aterro controlado do Jóquei" depois de fechado ainda vai ser um problema pelos próximos 30 anos (http://www.fatoonline.com.br, 2015).

O modelo de gestão dos Serviços de Limpeza Urbana é similar em aproximadamente todas as cidades brasileiras, sendo que a situação de acondicionamento residencial ou predial, coleta e transporte, tratamento e disposição final dos RSU, infelizmente é a mesma em quase todas as cidades, segundo dados da $\operatorname{ABRELPE}(2010,2014)$. Situação que é também parecida na maioria das cidades peruanas (Peru) como é descrito posteriormente nesta pesquisa.

Outro problema que pode ser observado em todas essas cidades é a falta de políticas mais arrojadas para um engajamento mais responsável das empresas que geram RSU, bem como a falta de programas educativos orientados para a participação mais proativa da população na coleta seletiva.

Não se pode negar que existem muitas iniciativas da população e de várias organizações não governamentais tratando de reverter essa situação, no entanto, elas não têm a infraestrutura adequada para operacionalizar várias ações da cadeia logística reversa, nem muito menos as competências e atribuições necessárias para exercer o mesmo papel que lhe cabe aos SLU.

A rigor, pode-se concluir que o maior problema que todas as cidades têm, está na falta de uma rede logística reversa que integre todos os participantes formais e informais, privados 
ou não, que atuam e trabalham com os RSU, aliada a um bom sistema de informação gerencial e de controle operacional.

\subsection{DESAFIOS BRASILEIROS NA IMPLEMENTAÇÃO DA LEI 12305/2010}

Os RSU não coletados e/ou armazenados de forma inadequada criam um cenário desafiador e permanente para os administradores públicos com consequências danosas às pessoas. Então, como resolver ou atenuar as consequências negativas dos RSU nas cidades?

Há necessidade de se implantar políticas públicas adequadas, que possibilitem saltos qualitativos, conforme já citado acima, permitindo assim migrar rapidamente dos ultrapassados aterros a céu aberto ou lixões para se alcançar os benefícios dos aterros sanitários ou sistemas integrados que reincluam os RSU na cadeia produtiva, aproveitando o seu potencial produtivo e de geração de renda, assim como o seu conteúdo energético. A Lei $\mathrm{n}^{\circ} 12.305$, é enfática neste sentido.

A construção de políticas públicas que ampliam e integram as ações do governo federal, o incentivo às cooperativas e recicladoras, facilidade de acesso a juros baixos e linhas de créditos mais acessíveis, o fomento à pesquisa são facilitadores para que todos os atores envolvidos com a questão em pauta assumam suas responsabilidades.

Desta forma, os sistemas integrados para manejo, tratamento e disposição final dos RSU que já existem em várias cidades e capitais de países desenvolvidos se tornam referência para pesquisas e justificam possíveis adaptações para a realidade brasileira com o objetivo de tornar as cidades em ambientes mais sustentáveis e competitivos.

Portanto, pode-se concluir que realmente existe uma necessidade de planejar e modelar uma rede logística reversa que atenda às necessidades de uma região urbana e que contribua com a adequada disposição dos resíduos urbanos. A partir dessa modelagem é possível estruturar o sistema organizacional, gerencial, operacional e de informação de toda a rede logística reversa, e todas as outras ações que foram elencadas acima. 


\subsection{FORMULAÇÃO DO PROBLEMA}

Como viabilizar uma rede logística reversa em regiões urbanas minimizando os custos logísticos de roteirização e de transporte dos RSU até sua disposição final?

\subsection{IMPORTANCIA DA PESQUISA}

A coleta seletiva é definida na Lei Federal 12.305/2010, como a coleta de resíduos sólidos previamente separados de acordo com a sua constituição e composição. Ainda esta coleta deve ser implementada por todos os municípios brasileiros. Em 2013, 62,1\% dos municípios registraram alguma iniciativa de coleta seletiva (MMA, PNRS, 2011).

O cenário atual revela que a coleta seletiva de materiais recicláveis é adotada tão somente em aproximadamente $18 \%$ dos municípios brasileiros e estimativas indicam que a participação dos resíduos recuperados pelos programas de coleta seletivas formais ainda é muito pequena. A reciclagem no país é mantida pela reciclagem pré-consumo e pela coleta pós-consumo informal ${ }^{1}$, conforme se pode visualizar na Tabela 1.1.

Tabela 1.1 - Estimativa da participação dos programas de coleta seletiva formal (2008)

\begin{tabular}{l|c|c|c|c}
\hline \multicolumn{1}{c|}{ (a) } & (b) & (c) & (d) & $(\mathbf{e})=(\mathbf{d} / \mathbf{c}) * \mathbf{1 0 0}$ \\
Resíduos & $\begin{array}{c}\text { Composição } \\
\text { gravimétrica dos } \\
\text { resíduos sólidos } \\
\text { urbanos coletados } \\
\text { (t/dia) }\end{array}$ & $\begin{array}{c}\text { Quantidade de } \\
\text { resíduos } \\
\text { reciclados no País } \\
\text { (mil t/ano) }\end{array}$ & $\begin{array}{c}\text { Quantidade } \\
\text { recuperada por } \\
\text { programas oficiais } \\
\text { de coleta seletiva } \\
\text { (mil t/ano) }\end{array}$ & $\begin{array}{c}\text { Participação da } \\
\text { coleta seletiva } \\
\text { formal na } \\
\text { reciclagem total } \\
(\%)\end{array}$ \\
\hline Metais & $5.293,50$ & $9.817,8$ & 72,3 & $0,7 \%$ \\
\hline Papel/papelão & $23.997,40$ & $3.827,9$ & 285,7 & $7,5 \%$ \\
\hline Plástico & $24.847,90$ & $962,0 *$ & 170,3 & $17,7 \%$ \\
\hline Vidro & $4.388,60$ & 489,0 & 50,9 & $10,4 \%$ \\
\hline
\end{tabular}

Fonte: MMA, PNRS, 2011

Pesquisas realizadas pela Abrelpe (2011 e 2014) corroboram esses dados, uma vez que do total de municípios brasileiros, 58,6\% indicaram a existência de iniciativas de coleta seletiva, que, em sua maioria consistem em disponibilizar a população pontos de entrega voluntária $(\mathrm{PEV})$ ou em celebrar parcerias com cooperativas de catadores para a execução

\footnotetext{
${ }^{1}$ Reciclagem pré-consumo: reciclagem dos resíduos gerados nos processos produtivos (MMA, PNRS, 2011).
} 
dos serviços de coleta seletiva, que não abrangem a totalidade do território ou da população do município (Tabela 1.2).

O PNRS (2011) estima entre 400 e 600 mil os catadores de materiais recicláveis e em pelo menos 1.100 organizações coletivas de catadores em funcionamento no país ${ }^{2}$. Os catadores são os maiores responsáveis pelos altos índices de reciclagem de alguns materiais, tais como latas de alumínio e papelão ${ }^{3}$.

Tabela 1.2 - Participação dos Municípios na coleta seletiva no Brasil

\begin{tabular}{l|c|c|c|c}
\hline \multirow{2}{*}{ Região } & \begin{tabular}{c} 
Iniciativa de coleta seletiva \\
(Municípios) - Abrelpe \\
\cline { 2 - 5 }
\end{tabular} & Sim (\%) & Não (\%) & \multicolumn{2}{|c}{$\begin{array}{c}\text { Valores médios por habitante/ano de recursos } \\
\text { aplicados na coleta de RSU e demais serviços de } \\
\text { limpeza urbana - Abrelpe 2011 }\end{array}$} \\
\cline { 2 - 5 } & 49,5 & 50,5 & $\begin{array}{c}\text { Coleta de RSU } \\
\text { (R\$/hab/ano) }\end{array}$ & $\begin{array}{c}\text { Demais serviços de } \\
\text { limpeza urbana } \\
\text { (R\$/hab/ano)* }\end{array}$ \\
\hline Norte & 40,4 & 59,6 & 48,24 & 74,52 \\
\hline Nordeste & 33,8 & 66,2 & 40,80 & 79,44 \\
\hline Centro-Oeste & 82,6 & 17,4 & 38,04 & 41,04 \\
\hline Sudeste & 81,9 & 18,1 & 53,28 & 90,12 \\
\hline Sul & & & 43,68 & 52,56 \\
\hline Brasil & & 47,28 & 77,16 \\
\hline
\end{tabular}

Fonte: Abrelpe, Panorama dos Resíduos Sólidos no Brasil, 2011 e Abrelpe (2014)

* Os demais serviços incluem despesas com a destinação final dos RSU e com serviços de varrição, capina, limpeza e manutenção de parques e jardins, limpeza de córregos, etc.

\subsubsection{Estimativa de custos da coleta seletiva e destinação final ambientalmente adequada.}

Estudo realizado pelo ESALQ-LOG para algumas cidades do Estado de São Paulo em 2009 indica que, em sua maioria, os custos com a disposição final dos resíduos situam-se entre $\mathrm{R} \$ 45,00$ e $\mathrm{R} \$ 55,00$ por tonelada de resíduo ${ }^{4}$.

\footnotetext{
${ }^{2}$ A imprecisão da estimativa do número de catadores, segundo o IPEA, está relacionada à sazonalidade da atividade e ao estigma da profissão que ainda prevalece.

3 www.cempres.org.br. O banco de dados do CEMPRE (Compromisso Empresarial para a Reciclagem) contém 546 organizações de catadores cadastrados distribuídas em quase todos os Estados brasileiros.

${ }^{4}$ Citado por Bartholomeu Bacchi, et al 2011, pg. 39.
} 
Embora a perspectiva seja de aumento dos custos relativos à coleta e destinação final ambientalmente adequada de resíduos sólidos, segundo a PNSB (2008), 61,4\% dos municípios brasileiros não fazem qualquer tipo de cobrança pela gestão dos resíduos sólidos. Outros $35,7 \%$ dos municípios que realizam a cobrança por meio de taxas para financiar os custos associados à gestão de resíduos sólidos a fazem associada à cobrança do IPTU (Taxa de Limpeza Urbana), dificultando o desenvolvimento de técnicas e de projetos economicamente viáveis para o tratamento de sólidos.

Usualmente, nos municípios brasileiros, a taxa recolhida via IPTU, dissociada do volume de resíduo produzido pelas famílias, é rateada a partir do custo dos serviços entre os agentes demandantes desses serviços, dispersando a responsabilidade dos agentes econômicos em reduzir na fonte o volume de resíduos gerados e menosprezando o princípio do poluidor-pagador. No país, reduzido número de cidades aplicam taxas proporcionais ao volume de resíduos recolhidos, o inverso do que é adotado nos países da União Europeia que utilizam a taxa PAYT (pay-as-you-thow) ${ }^{5}$.

Em 2010, o custo médio estimado da coleta seletiva nas grandes cidades foi calculado em US\$ 204,00 (ou R\$ 367,20) por tonelada, quatro vezes maior que o custo da coleta convencional, estimada em US\$47,22 (R\$ 85,00) por tonelada nas cidades pesquisadas ${ }^{6}$. Em contrapartida, os valores aplicados na coleta de RSU no país são reduzidos frente ao custo do serviço, conforme dados apresentados na Tabela 1.2.

\subsubsection{A riqueza do "lixo" ou os "bilhões perdidos"}

Do ponto de vista da nação, Calderoni (2003) definiu uma metodologia que captura os ganhos econômicos proporcionados pela reciclagem, a partir da redução no consumo de energia, de matérias-primas, de água, e dos custos relativos ao controle ambiental e à disposição final dos resíduos. Utilizando dados da cidade de São Paulo, o referido autor

\footnotetext{
${ }^{5}$ Cobrada em função do volume ou do peso dos resíduos descartados tal mecanismo incentiva a coleta seletiva e a redução do resíduo descartado.

${ }^{6}$ A pesquisa é feita por meio de questionários enviados às prefeituras e visitas técnicas com o objetivo de identificar os municípios que possuem coleta seletiva estruturada. www.cempres.org.br.
} 
estima, em valores correntes de 1996, que o país perde por ano pelo menos R $\$ 4,6$ bilhões pela não reciclagem do $\operatorname{lixo}^{7}$ ou $0,59 \%$ do $\mathrm{PIB}^{8}$

De todo o exposto, conclui-se que o tema é bastante desafiador, pois embora a sociedade possa ter consciência da riqueza descartada cotidianamente e de potenciais ganhos econômicos, sociais e ambientais que poderiam ser auferidos, soluções abrangentes parecem caminhar a passos lentos. Em sentido contrário, os indicadores apontam avanço acelerado na produção de bens que um dia será descartado e nos custos de construção e manutenção de aterros.

É nessa perspectiva da nova legislação e do estágio pouco avançado em que se encontra em relação ao tratamento e disposição final dos resíduos que pretendesse desenvolver esta pesquisa que possa ser aplicado em distintas regiões do País. Assim, o planejamento e modelagem do sistema de logística reversa de uma área urbana é uma fase importante e estratégica para obter no futuro, ótimos resultados no processo de gerenciamento e operação do sistema.

\subsection{OBJETIVOS DO TRABALHO}

A pesquisa tem como objetivo principal modelar e planejar uma rede logística reversa para uma região urbana, dimensionando o fluxo de RSU que será movimentado ao longo da rede e determinando o número e capacidade das estações de coleta e das unidades produtivas e especiais necessárias para o atendimento dessa região, quanto a coleta, transporte e disposição final dos RSU.

Com a otimização do modelo de coleta de RSU é possível reorganizar o sistema logístico reverso de uma cidade de forma a conseguir um melhor dimensionamento da rede, com a consequente diminuição do número de veículos que circulam na cidade.

\footnotetext{
${ }^{7}$ Segundo Calderoni o cálculo está subestimado por não considerar os custos evitados pelas prefeituras com a disposição final dos resíduos.

${ }^{8}$ Para o cálculo do percentual utilizou-se o PIB de 1996, em valores correntes, em R \$778,88 bilhões e de 2011 em R\$ 4.143 bilhões, de acordo com o IBGE. O percentual sobre o PIB de 2011 resulta em R \$ 24,44 bilhões. Os custos atuais de energia, matéria prima, água, e com o controle ambiental e de disposição final provavelmente devem ter aumentado em 2011 em relação a 1996, o que poderia resultar num valor maior caso fossemos aplicar calcular a equação proposta pelo autor com os novos valores.
} 


\section{Objetivos Específicos:}

- Aplicar uma metodologia de programação linear inteira, considerada computacionalmente como um problema que pertence à classe de complexidade NP (KORTE, 2008), para solucionar o problema.

- Implementar com o software GLPK (GNU Linear Programming Kit), rodando no sistema operativo Linux, os modelos propostos, valida-los e testa-los em um caso prático.

\subsection{METODOLOGIA DA PESQUISA}

Para atingir os objetivos propostos, o desenvolvimento da pesquisa compreendeu as seguintes etapas de trabalho, a saber:

a) Análise do problema de gestão de resíduos sólidos urbanos (RSU) no Brasil e no Peru para compreender a situação atual e levantar os principais gargalos. Além disso, definir as principais variáveis de decisão para a modelagem;

b) Levantamento dos principais casos de sucesso de gestão de RSU nas cidades brasileiras, peruanas e de outros países;

c) Formulação do problema principal da pesquisa, justificando sua importância;

d) Levantamento bibliográfico dos diferentes temas necessários para elaboração da pesquisa, tais como Leis de RSU, sustentabilidade, roteirização, logística urbana, logística reversa e gestão de resíduos, dentre outros;

e) Estudo e análise dos modelos de roteirização, logística urbana e logística reversa que venham a contribuir com o estado da arte do problema formulado;

f) Estudo e análise dos métodos de solução para resolver os modelos avaliados na revisão bibliográfica, assim como os modelos que serão propostos neste estudo;

g) Investigação e estudo de softwares livres que permita o teste dos modelos estudados e a implementação dos modelos desenvolvidos na pesquisa; 
h) Testes e validação dos modelos estudados com a ferramenta computacional escolhida;

i) Planejamento do sistema de logística reversa para a sustentabilidade no contexto da logística urbana, por meio do desenvolvimento da modelagem matemática do Sistema de Coleta Seletiva (roteirização) e de Transporte dos RSU para os centros especializados para que sejam reciclados, reutilizados ou rejeitados;

j) Escolha de uma área urbana para ser utilizada como estudo de caso, tanto para os testes dos modelos estudados como dos modelos desenvolvidos;

k) Levantamento de todos os dados necessários para validação e testes dos modelos junto aos órgãos responsáveis e organizações que participam direta e indiretamente nesse campo de trabalho;

1) Levantamento de premissas e simulação de dados para rodar os programas, ou seja, muitas vezes as bases de dados reais que se encontram são incompletas e por um determinado dado não se pode rodar o programa, nesse caso, essas informações são preenchidas por meio de simulações de dados sob experiência do analista de sistema;

m) Testes e validação dos modelos desenvolvidos na cidade escolhida por meio da geração de cenários alternativos.

\subsection{ESTRUTURA DA TESE}

O presente trabalho está dividido em seis capítulos. O primeiro capítulo apresenta os aspectos gerais do tema tratado: a formulação do problema, os objetivos da pesquisa, a delimitação e a justificativa e contribuição, além da metodologia da pesquisa.

No capítulo dois é apresentado o referencial teórico, suporte do tema, contemplando os conceitos de sustentabilidade urbana, modelagem e roteirização, logística de distribuição (direita) e reversa, gestão de RSU. 
No capítulo três são estudados e programados os modelos baseados nos conceitos do capítulo dois. Estes capítulos são fonte de motivação para o desenvolvimento da tese.

O quarto capítulo trata da modelagem para o processo de coleta e transporte de resíduos sólidos nos centros urbanos, tema desta tese. Assim como, a aplicação do modelo proposto no Distrito de Trujillo, Região a Libertad, no Peru.

No quinto capítulo são apresentadas as considerações finais obtidas nesta tese. Inicialmente são apresentadas as conclusões, seguidas das recomendações para futuras investigações relacionadas ao tema em questão.

Nos anexos são apresentados os programas elaborados e no apêndice um pequeno glossário de certos termos usados nessa pesquisa. 


\section{MARCO TEÓRICO DA PESQUISA}

Nesse capítulo apresenta-se uma breve resenha do material bibliográfico pesquisado com relação aos temas abordados nessa pesquisa. Vale ressaltar que o material bibliográfico pesquisado é muito amplo, principalmente aquele que ajudou a consolidar as bases do conhecimento científico para elaborar essa tese. Como são os temas de Pesquisa Operacional, Ciências da Informação e Logística, conhecimento sem os quais fica difícil modelar e solucionar matematicamente qualquer tipo de problema de otimização.

Portanto nessa tese são abordados somente aqueles temas que ajudaram a formular o problema principal e os objetivos desse trabalho. Procurou ser bastante conciso e específico nos temas abordados pelas restrições de página que um trabalho científico deve ter, assim como na escolha dos temas que são abordados.

\subsection{PANORAMA DA GESTÃO DE RSU NO BRASIL}

Considerando o estabelecido no Art. 13 da Lei 12.305/2010 no Brasil, RSU são aqueles resíduos gerados nos domicílios e na limpeza urbana. No primeiro caso refere-se à geração de RSU pelas pessoas físicas ou jurídicas, de direito público ou privado por meio de atividades domésticas nas residências urbanas ou atividades realizadas em prédios comerciais e de prestação de serviços, dentre outros. No segundo caso, abrange os resíduos originários da varrição, limpeza de logradouros e vias públicas e outros serviços de limpeza urbana. Os RSU no Peru também são classificados de forma similar por meio do Art. 15 da Lei $\mathrm{N}^{0}$ 27314, sancionada pelo Congresso.

\subsubsection{Diagnóstico da Situação Atual}

Em 2010, segundo o IBGE, havia cerca de 190,7 milhões de habitantes, sendo 160,9 milhões (84,35\%), residentes em áreas urbanas, e 29,8 milhões (15,65\%), nas áreas rurais. Embora a taxa de crescimento populacional verificada no período de 2000/2010 tenha sido 
de $1,7 \%$, o crescimento de renda e o maior acesso ao consumo de bens duráveis pela sociedade tenderam a elevar a quantidade de resíduos gerada pela sociedade brasileira ${ }^{9}$.

Segundo o Plano Nacional de Resíduos Sólidos (PNRS, 2011), em 2008, foram coletadas 183.481,5 t/dia de RSU, ou seja, o volume médio de resíduos sólidos gerados por habitante urbano no Brasil estava próximo a $1 \mathrm{~kg} /$ habitante $/ \mathrm{dia}^{10}$. Se se considera o número de domicílios no país, estimado pelo IBGE em 67,5 milhões em 2010, tem-se a geração de quase uma tonelada de resíduos sólidos urbanos em cada um dos domicílios brasileiros por ano $^{11}$. O material orgânico constituiu pouco mais da metade do total coletado $(51,4 \%)$; o material reciclável em $31,9 \%$ e outros componentes perfazerem $16,7 \%$ do total, segundo o PNRS. A taxa de cobertura de coleta regular de resíduos sólidos alcançou, em 2009, quase $90 \%$ do total de domicílios, sendo $98 \%$ na área urbana e aproximadamente $33 \%$ dos domicílios na área rural. ${ }^{12}$

Os dados de Abrelpe (2014) mostraram que em 2012, o volume gerado foi de 201.058 t/dia de RSU, tendo um crescimento de $9,6 \%$ com relação a 2008 , quase $2,4 \%$ por ano. No ano 2013, aproximadamente gerou-se 209.280 t/dia de RSU, representando um acréscimo de 4,1\% com relação ao ano anterior, ou seja, o volume de RSU gerado por ano só vem aumentando. Tal cenário contrasta com a fragilidade da ação do poder público em oferecer alternativas para o tratamento e disposição ambientalmente adequada do volume de resíduos gerados reduzindo seu impacto no ambiente urbano.

Com relação à coleta de RSU, 181.288 t/dia foram coletadas no ano 2012 e 189.219 t/dia no ano 2013 (Tabela 2.1). Sendo que a taxa média de cobertura de coleta dos RSU nos dois anos foi praticamente igual, $90 \%$ do total de domicílios. As regiões Sudeste, Sul e CentroOeste se mantiveram acima da média nacional durante esses dois anos, 97\%, 94\% e 93\% respectivamente.

\footnotetext{
${ }^{9}$ Entre os anos de 2010 e 2011 a geração de resíduos sólidos urbanos cresceu duas vezes mais do que a população (Abrelpe, 2011). Panorama de Resíduos Sólidos Urbanos 2011, Abrelpe, pg. 123.

${ }^{10} \mathrm{O}$ volume per capita é maior nas grandes capitais (ABRELPE, 2009; PANORAMA DOS RESÍDUOS SÓLIDOS NO BRASIL).

${ }^{11}$ Estimativa feita a partir da quantidade de RSU gerada por tonelada/ano em 2011 (61,9 milhões) apresentada pelo Caderno Informativo, Recuperação Energética de Resíduos Sólidos Urbanos, Abrelpe e Plastivida, 2011.

${ }^{12}$ Essa discrepância é atenuada uma vez que o resíduo sólido produzido é tratado nas unidades domiciliares e de produção na área rural, por se constituir em sua maior parte por matéria orgânica. No entanto, essa situação tende a se alterar dado o crescente consumo de bens de consumo duráveis o que acarretará a necessidade de mudança nas estratégias de coleta nas áreas rurais por parte do poder municipal.
} 
As regiões Norte e Nordeste ficaram com $80 \%$ e $78 \%$ respectivamente, ressaltando que a região Norte decresceu em $4 \%$ sua cobertura de coleta com relação ao ano anterior, a diferença das outras regiões que tiveram um $1 \%$ de acréscimo. A região sudeste continua respondendo por $52,4 \%$ do total de RSU coletados em nível nacional. Os percentuais das demais regiões são: Nordeste (22,1\%); Sul (10,9\%); Centro-oeste $(8,2 \%)$ e Norte $(6,4 \%)$.

Tabela 2.1 - Geração e coleta de RSU no Brasil

\begin{tabular}{l|r|r|r|r}
\hline \multirow{2}{*}{\multicolumn{1}{c|}{ Região }} & \multicolumn{2}{c|}{$\begin{array}{c}\text { Geração RSU } \\
\text { (t/dia) }\end{array}$} & \multicolumn{2}{c}{$\begin{array}{c}\text { Coleta de RSU } \\
\text { (t/dia) }\end{array}$} \\
\cline { 2 - 5 } & $\mathbf{2 0 1 2}$ & $\mathbf{2 0 1 3}$ & $\mathbf{2 0 1 2}$ & $\mathbf{2 0 1 3}$ \\
\hline Norte & 13.754 & 15.169 & 11.585 & 12.178 \\
\hline Nordeste & 51.689 & 53.465 & 40.021 & 41.820 \\
\hline Centro-Oeste & 16.055 & 16.636 & 14.788 & 15.480 \\
\hline Sudeste & 98.215 & 102.088 & 95.142 & 99.119 \\
\hline Sul & 21.345 & 21.922 & 19.752 & 20.622 \\
\hline Total & 201.058 & 209.280 & 181.288 & 189.219 \\
\hline
\end{tabular}

Fonte: Abrelpe (2014)

Dos RSU coletados no Brasil em 2013 (Tabela 2.1), 58,3\% (110.232 t/dia) foram depositados em aterros sanitários, 24,3\% (46.041 t/dia) em aterros controlados e 17,4\% (32.946 t/dia) tiveram como destino final os lixões. A comparação entre a quantidade total gerada e a quantidade total coletada mostra que aproximadamente $11 \%$ (20.061 t/dia) dos RSU deixaram de ser coletadas no ano de 2013 e, por consequência, tiveram destino impróprio (Abrelpe, 2014).

Comparando os dados da Pesquisa Nacional de Saneamento Básico (PNSB), realizada pelo IBGE em 2002 com a realizada pela mesma instituição em 2010, pode-se afirmar que as cidades brasileiras tiveram uma melhoria significativa quanto a disposição final dos resíduos sólidos nesses últimos anos. Em 2002, os índices que apresentou o IBGE foram os seguintes: $13,8 \%$ das cidades utilizam aterros sanitários; $18,4 \%$ dispõem de aterros controlados; $63,6 \%$ das cidades depositam seus resíduos sólidos em depósitos a céu aberto ou mais conhecidos por lixões; e 4,2\% não informaram a destinação de seus resíduos. 
A PNSB do IBGE (2010) aponta que os municípios que contam com serviço de coleta de resíduos sólidos domiciliares, metade se destinam para lixões, 50,8\%; 22,5\% para aterros controlados e 27,7\% para aterros sanitários. Observando-se uma concentração dos lixões como destinação de resíduos sólidos nos municípios situados nas regiões Nordeste $(89,3 \%)$ e Norte $(85,5 \%)$.

Esperava-se, com o comando legal de desativação dos lixões até 2014, houvesse uma corrida contra o tempo para adotar medidas que viabilizassem a coleta seletiva, reciclagem, reutilização de resíduos sólidos para cerca de $80 \%$ do volume total de resíduos sólidos coletados que diariamente é destinado a locais impróprios, segundo o estudo acima citado. Devido aos elevados custos para a construção e manutenção de aterros sanitários e para o transporte, era de se esperar medidas no sentido de reduzir o volume dos resíduos a serem descartados, em prol da redução da quantidade de rejeitos.

Na Tabela 2.2 são apresentados dados estatísticos dos últimos seis anos a respeito de geração, coleta e disposição final dos RSU. Aqui os dados estão expressos por t/ano, diferentes aos expostos anteriormente que estão em t/dia, existindo discrepância na percentagem de crescimento da geração de RSU, principalmente do ano 2013 com relação ao ano anterior. Observa-se que no ano 2013 a geração de RSU cresceu 21,77\%.

Tabela 2.2 - Estatística da geração, coleta e destino final dos RSU

\begin{tabular}{c|c|c|c|c|c|c|c|c}
\hline Ano & $\begin{array}{c}\text { Geração de } \\
\text { RSU } \\
\text { (t /ano) }\end{array}$ & $\begin{array}{c}\text { \% de } \\
\text { cresci- } \\
\text { mento }\end{array}$ & $\begin{array}{c}\text { RSU } \\
\text { coletados } \\
\text { (t/ano) }\end{array}$ & $\begin{array}{c}\text { \% } \\
\text { Cole- } \\
\text { tado }\end{array}$ & $\begin{array}{c}\text { RSU não } \\
\text { coletado } \\
\text { (t /ano) }\end{array}$ & $\begin{array}{c}\text { Destino } \\
\text { final } \\
\text { adequado } \\
\text { (t /ano) }\end{array}$ & $\begin{array}{c}\text { \% } \\
\text { Destino } \\
\text { final } \\
\text { adequado }\end{array}$ & $\begin{array}{c}\text { Destino } \\
\text { final } \\
\text { inadequado } \\
\text { (t /ano) }\end{array}$ \\
\hline 2008 & 52.933 .296 & & 46.550 .088 & 87,9 & 6.383 .208 & 25.493 .520 & 54,8 & 21.056 .568 \\
\hline 2009 & 57.011 .136 & 7,70 & 50.258 .208 & 88,2 & 6.752 .928 & 28.555 .488 & 56,8 & 21.702 .720 \\
\hline 2010 & 60.868 .080 & 6,77 & 54.157 .896 & 89,0 & 6.710 .184 & 31.194 .948 & 57,6 & 22.962 .948 \\
\hline 2011 & 61.936 .368 & 1,76 & 55.534 .440 & 89,7 & 6.401 .928 & 32.240 .520 & 58,1 & 23.293 .920 \\
\hline 2012 & 62.730 .096 & 1.28 & 56.561 .856 & 90,2 & 6.168 .240 & 32.794 .632 & 58,0 & 23.767 .224 \\
\hline 2013 & 76.387 .200 & 21,77 & 69.064 .935 & 90,4 & 7.322 .265 & 40.234 .680 & 58,3 & 28.830 .255 \\
\hline
\end{tabular}

Fonte: Abrelpe (2010-2014)

A Tabela 2.3 mostra a geração e coleta de RSU no Distrito Federal, de acordo com a população nos anos 2012 e 2013. Nesta tabela dá para observar que no ano 2013 não foram coletados $97 \mathrm{t} / \mathrm{dia}$. 
Tabela 2.3 - Geração e coleta de RSU no Distrito Federal

\begin{tabular}{c|c|c|c|c|c|c|c}
\hline \multirow{2}{*}{ População urbana } & \multicolumn{2}{|c}{$\begin{array}{c}\text { RSU gerado } \\
\text { (t/dia) }\end{array}$} & \multicolumn{4}{|c}{ RSU coletado } \\
\cline { 5 - 8 } & & & \multicolumn{2}{|c}{$(\mathrm{kg} / \mathrm{hab} / \mathrm{dia})$} & \multicolumn{2}{|c}{$(\mathrm{t} / \mathrm{dia})$} \\
\hline 2012 & 2013 & 2012 & 2013 & 2012 & 2013 & 2012 & 2013 \\
\hline 2.648 .532 & 2.789 .761 & 4.126 & 4.423 & 1,545 & 1,551 & 4.091 & 4.326 \\
\hline
\end{tabular}

Fonte: Abrelpe (2014)

Segundo ABRELPE (2013) os RSU coletados em 2012, no Brasil, correspondem aos produtos: metais, papel, papelão, plástico, vidro e matéria orgânica. A Tabela 2.4 mostra, em percentagem, os tipos comuns de produtos coletados, além das quantidades em t /ano.

Tabela 2.4 - Principais materiais de RSU coletado no Brasil

\begin{tabular}{|c|c|c|}
\hline Material & Participação (\%) & Quantidade (t/ano) \\
\hline Metais & 2,9 & 1.640 .294 \\
\hline Papel, Papelão e TetraPak & 13,1 & 7.409 .603 \\
\hline Plástico & 13,5 & 7.635 .851 \\
\hline Vidro & 2,4 & 1.357 .484 \\
\hline Matéria orgânica & 51,4 & 29.072 .794 \\
\hline Outros & 16,7 & 9.445 .830 \\
\hline TOTAL & 100,0 & 56.561 .856 \\
\hline
\end{tabular}

Fonte: Abrelpe (2013)

Ação exercida direta ou indiretamente, na etapa de coleta, transporte, tratamento e destinação final ambientalmente adequada dos rejeitos, de acordo com os planos municipais de gestão integrada de resíduos sólidos (ações voltadas para a busca de soluções para os resíduos sólidos), tem gerado 332.777 fontes de emprego no ano 2013 (ABRELPE, 2014). Infelizmente ainda não tem o êxito esperado, pois nem todos os municípios têm participação.

\subsubsection{Reciclagem e Compostagem}

Estimativas acerca do índice de reciclagem no País variam entre 1\% e 2\% dos resíduos sólidos urbanos. Há, no entanto, estudos que apontam percentual de reciclagem de $8 \%$ dos RSU. Tais dados sinalizam que há espaço para crescimento no país do mercado de recicláveis. Para efeitos de comparação, em alguns países europeus o percentual dos RSU 
reciclados é de 39\%, na Holanda; 31\%, na Suíça; e 29\% na Dinamarca, conforme Gameiro (2011).

Alguns setores possuem considerável participação nas atividades de reciclagem, em 2009, os índices de reciclagem observada, conforme informação coletada pela Abrelpe, ${ }^{13}$ foram: 46\% papel; $47 \%$ vidro; 38\% alumínio e 56\% PET.

Apesar dos avanços acima ilustrados em determinados setores produtivos pesquisas indicam que casos de sucesso em processos integrados de coleta seletiva, triagem e reciclagem se caracterizam por coordenação centralizada, especialmente pelas prefeituras, uma vez que o mercado de materiais recicláveis ainda não apresenta dinâmica suficiente no Brasil para funcionar de forma autônoma (BARTHOLOMEU BACCHI et al, 2011).

Além da reciclagem, o tratamento de resíduos deve compreender também alternativas de uso para o resíduo orgânico, seja por meio do processo natural de composição empreendido pela natureza, seja na geração de energia nos aterros ou por incineração, dentre outros processos. Esse aproveitamento no Brasil também é bastante restrito, pois a matéria orgânica em sua maioria é encaminhada para disposição final, juntamente com os resíduos domiciliares. De acordo com o $\mathrm{PNRS}^{14}$ do total de resíduos orgânicos coletados no País, somente $1,6 \%$ é encaminhado para tratamento via compostagem. ${ }^{15}$

Outras técnicas de aproveitamento tal como a geração de energia a partir dos resíduos, a exemplo do tratamento térmico ainda é incipiente no País, ao contrário da experiência mundial, em especial países da Europa e Ásia. Esses países possuem tradição em plantas de grande escala para geração de energia a partir do tratamento de resíduos sólidos ${ }^{16}$.

Tem-se, portanto, variadas possibilidades de aproveitamento de resíduos sólidos cada qual com suas especificidades e requisitos que precisam ser avaliadas e estudadas, pois, em sua maior parte, demandam volume considerável de resíduos concentrados em um local, recursos financeiros e tecnologia apropriada.

\footnotetext{
${ }^{13}$ Abrelpe, Panorama dos Resíduos Sólidos, 2011.

${ }_{15}^{14}$ MMA, Plano Nacional de Resíduos Sólidos, pag. 16.

15 Algumas experiências de compostagem tem se disseminado em áreas urbanas, a exemplo das hortas urbanas http://conectarcomunicacao.com.br/blogettp://transformaaterra.blogspot.com.br/.

${ }^{16}$ Bartholomeu Bacchi, et al (2011). Resíduos Sólidos e os Aspectos Ambientais e Tecnológicos. Op. Cit. Pg. 138.
} 


\subsubsection{Geração de Energia}

No Brasil não se faz larga utilização da técnica de incineração controlada para obter os benefícios da cogeração, sendo esta técnica mais utilizada para resolver a disposição final de resíduos perigosos e parte dos resíduos hospitalares (RSS).

Há necessidade de investimentos em tecnologia para começar a utilizar o conteúdo energético dos RSU. Algumas iniciativas estão sendo testadas em Campo Grande - MS e Vitória - ES. Há tecnologia disponível que pode ser utilizada para a queima do lixo urbano com segurança. Os órgãos de controle ambiental e a própria sociedade devem pressionar para que novas tecnologias voltadas para a gestão de RSU sejam implantadas em médio prazo no Brasil.

Estudos mostram que em média, o lixo urbano das cidades brasileiras é composto por $65 \%$ de material orgânico (restos alimentares), $25 \%$ de papel, $5 \%$ de plástico, $2 \%$ de vidro e 3\% de metais. A partir destes dados, podemos inferir que a parte não reciclável ou os $65 \%$ de material orgânico podem ser destinados como combustível em um sistema de incineração. Tal medida não afetaria os possíveis ganhos de catadores e cooperativas recicladoras.

\subsection{PANORAMA DOS RESÍDUOS SÓLIDOS NO PERU E A LEI 27.314/2000}

No ano 2000 foi publicada a Lei Geral de Resíduos Sólidos No. 27314, a qual no Artículo 1 estabelece os direitos, obrigações, atribuições e responsabilidades da sociedade peruana para garantir a gestão dos resíduos sólidos, sujeito aos princípios de minimização, prevenção de riscos ambientais e proteção da saúde, além do bem-estar das pessoas.

A referida Lei, no Art.14º também define resíduos sólidos como substâncias, produtos ou subprodutos em estado sólido ou semissólido que são gerados pelas empresas que estão obrigadas, de acordo com o estabelecido nas normas, ao bom gerenciamento por meio de um sistema que inclua os seguintes processos: minimização de resíduos, segregação na fonte, reutilização, armazenamento, processamento, transporte, transferência e eliminação, entre outros. 
No Art.15\%, esses resíduos são classificados de acordo com sua origem em: resíduo comercial, residencial, resíduo de limpeza de espaços públicos, resíduo de hospitais, resíduos de atividades de construção, industrial, agrícolas e instalações ou atividades especiais.

Em 2004 foi publicado o Decreto Supremo 057 sobre o Regulamento da Lei Geral de Resíduos Sólidos que estabelece, no Título II, as competências na gestão dos resíduos sólidos pelos ministérios, municipalidades e outras entidades (INEI, 2014b, 2014). Também é estendido ao conjunto de atividades relativas ao gerenciamento dos resíduos sólidos. Esse cumprimento passa a ser obrigatório para as pessoas natural ou jurídica, pública ou privada em todo o país.

Atualmente, de acordo com o regulamento da Lei Geral de Resíduos Sólidos, todos os municípios devem registrar a quantidade de RSU gerado pela população, a quantidade de RSU que a prefeitura do município coleta, quanto desse RSU vai para os lixões e que quantidade está sendo reaproveitada.

Infelizmente esses dados não estão sendo levantados devidamente e em muitos casos não existem dados atualizados, principalmente nos municípios do interior do Peru. Isso deve-se a falta de recursos humanos para realizar essa atividade e basicamente a falta de estruturação de um sistema de informação gerencial que facilite o registro desses dados. Nas regiões mais desenvolvidas têm-se condições para levar os dados dos RSU como acontece com as Regiões de Lima e Trujillo.

Por essa razão, o Instituto Nacional de Estatística e Informática (INEI) no Peru, tem dificuldade de fornecer o histórico anual da quantidade total dos RSU gerados no Peru. Os dados que publica, portanto não são completos, como pode ser observado nas Tabelas 2.5 e 2.6 .

Na Tabela 2.6 mostram-se dados preocupantes com relação à boa destinação dos RSU. Isso confirma a falta de gestão dos RSU e falta de engajamento da população em programas educativos, como falta de gerenciamento para articular todas ações em prol do benefício da comunidade e de seu meio ambiente. 
Tabela 2.5 - Participação dos Municípios na coleta de RSU por tonelada coletada $(\mathrm{Q})$ por ano

\begin{tabular}{c|c|c|c|c}
\hline Ano & $\mathbf{Q}<\mathbf{3} \mathbf{t}$ & $\mathbf{3} \mathbf{t}<\mathbf{Q}<\mathbf{8} \mathbf{t}$ & $\mathbf{Q}>\mathbf{8} \mathbf{t}$ & Não fazem coleta \\
\hline 2011 & 1240 & 210 & 334 & 50 \\
\hline 2012 & 1276 & 208 & 255 & 99 \\
\hline 2013 & 1245 & 237 & 260 & 96 \\
\hline 2014 & 1247 & 225 & 278 & 88 \\
\hline
\end{tabular}

Fonte: Anuário de estadísticas ambientales (2014)

Tabela 2.6 - Participação dos Municípios na disposição final de RSU por ano

\begin{tabular}{c|c|c|c|c|c}
\hline Ano & $\begin{array}{c}\text { Aterro } \\
\text { sanitário }\end{array}$ & Lixão & $\begin{array}{c}\text { Rio, lagoa } \\
\text { ou mar }\end{array}$ & Incinerado & $\begin{array}{c}\text { Aproveitado } \\
\text { para reciclagem }\end{array}$ \\
\hline 2011 & 469 & 1229 & 67 & 354 & 295 \\
\hline 2012 & 520 & 1243 & 66 & 384 & 363 \\
\hline 2013 & 561 & 1230 & 71 & 351 & 413 \\
\hline 2014 & 554 & 1239 & 53 & 307 & 442 \\
\hline
\end{tabular}

Fonte: Anuário de estadísticas ambientales (2014)

O Ministério do Ambiente no seu informe do ano 2012 sobre resíduos sólidos (MA, 2012), fez uma estimativa de geração de RSU para os anos 2010, 2011 e 2012. Comparando com os dados históricos reais, observa-se que os resíduos gerados foram aproximadamente o dobro. Estes dados dão para supor que nos anos 2013, 2014 e 2015 a tendência foi similar. Pode-se partir do suposto que a população está tendo um maior poder de consumo. Na Tabela 2.7 somente estão expostos os dados reais.

Tabela 2.7 - Geração de RSU em Peru

\begin{tabular}{c|c}
\hline Ano & $\begin{array}{c}\text { Geração RSU } \\
\text { (kg/dia) }\end{array}$ \\
\hline 2010 & 3478937 \\
\hline 2011 & 6466885 \\
\hline 2012 & 12717808 \\
\hline
\end{tabular}

Fonte: MA (2014)

A região de Lima, incluída a cidade de Lima capital do Peru, tem dados mais atualizados sobre a quantidade de RSU gerados e coletados, devido aos estudos que fazem a Municipalidade de Lima Metropolitana e os Distritos que compõem a Província de Lima (Tabela 2.8). 
Tabela 2.8 - Geração e coleta de RSU na Província de Lima

\begin{tabular}{c|c|c|c}
\hline Ano & $\begin{array}{c}\text { Geração RSU } \\
\text { (t/ano) }\end{array}$ & $\begin{array}{c}\text { Coleta de RSU } \\
\text { (t/ano) }\end{array}$ & $\begin{array}{c}\text { RSU não coletado } \\
\text { (t/ano) }\end{array}$ \\
\hline 2008 & 2.504 .234 & 1.920 .340 & 583.894 \\
\hline 2009 & 2.636 .257 & 2.059 .684 & 576.573 \\
\hline 2010 & 2.664 .798 & 2.058 .381 & 606.417 \\
\hline 2011 & 2.503 .583 & 2.191 .989 & 311.594 \\
\hline 2012 & 2.649 .633 & 2.467 .012 & 182.621 \\
\hline 2013 & 2.759 .700 & 2.712 .257 & 47.443 \\
\hline
\end{tabular}

Fonte: Anuário de estadísticas ambientales (2014)

Na Lima Metropolitana existem muitos centros geradores de RSU, tais como hospitais, supermercados, drogarias, centros de serviços públicos, shoppings, bancos, Palácio de Governo, Congresso da República, Ministérios, Igrejas, residências, etc.

Para atender a todos esses centros, a Municipalidade trabalha com vários operadores autorizados para fazer as operações de coleta e transporte dos diferentes tipos de resíduos gerados (Tabela 2.9). Ou seja, cada um desses operadores atua somente coletando e transportando o tipo de resíduo sólido autorizado, sendo eles responsáveis pela destinação final apropriada desses resíduos.

Tabela 2.9 - Quantidade de operadores autorizados para atuar na Lima Metropolitana

\begin{tabular}{l|c|c|c|c|c|c|c}
\hline \multicolumn{1}{c|}{ Tipo de operador } & $\mathbf{2 0 0 6}$ & $\mathbf{2 0 0 7}$ & $\mathbf{2 0 0 8}$ & $\mathbf{2 0 0 9}$ & $\mathbf{2 0 1 0}$ & $\mathbf{2 0 1 1}$ & $\mathbf{2 0 1 2}$ \\
\hline Limpeza urbana & 6 & 11 & 5 & 11 & 3 & 7 & 4 \\
\hline Transporte de RS de limpeza pública & 13 & 13 & 10 & 25 & 20 & 28 & 20 \\
\hline Transporte de RS perigosos e biocontaminantes & 11 & 16 & 21 & 44 & 52 & 68 & 64 \\
\hline Transporte de RS hospitalários & - & 1 & 2 & 2 & 4 & 5 & 6 \\
\hline Transporte de RS industriais & 17 & 14 & 20 & 35 & 56 & 56 & 75 \\
\hline Transporte de resíduos de parques e jardines & 3 & 7 & 9 & 14 & 11 & 11 & 11 \\
\hline Transporte de RS de construção & 3 & 4 & 3 & 9 & 5 & 6 & 8 \\
\hline Centros de operação inicial (centro de coleta) & 1 & - & - & - & - & 0 & 0 \\
\hline Centros de operação final & 2 & 2 & 1 & 3 & 2 & 2 & 1 \\
\hline \multicolumn{1}{c|}{ Total de operadores } & 56 & 68 & 71 & 143 & 153 & 183 & 189 \\
\hline
\end{tabular}

Fonte: Anuário de estadísticas ambientales (2014) 
Por exemplo, a empresa Petramas SAC tem o serviço geral integral de coleta, transporte, tratamento e disposição final dos resíduos coletados. Para atender toda a rede a mesma conta com uma frota moderna de caminhões coletores que presta um serviço considerado de boa qualidade.

A disposição final dos resíduos é feita no aterro de Huaycoloro (Figura 2.1), considerado como um dos melhores aterros sanitários privados do mundo, segundo avaliação do Banco Mundial, que o considera um modelo que deve ser seguido em toda Latino América.

Figura 2.1 - Aterro sanitário de Huaycoloro

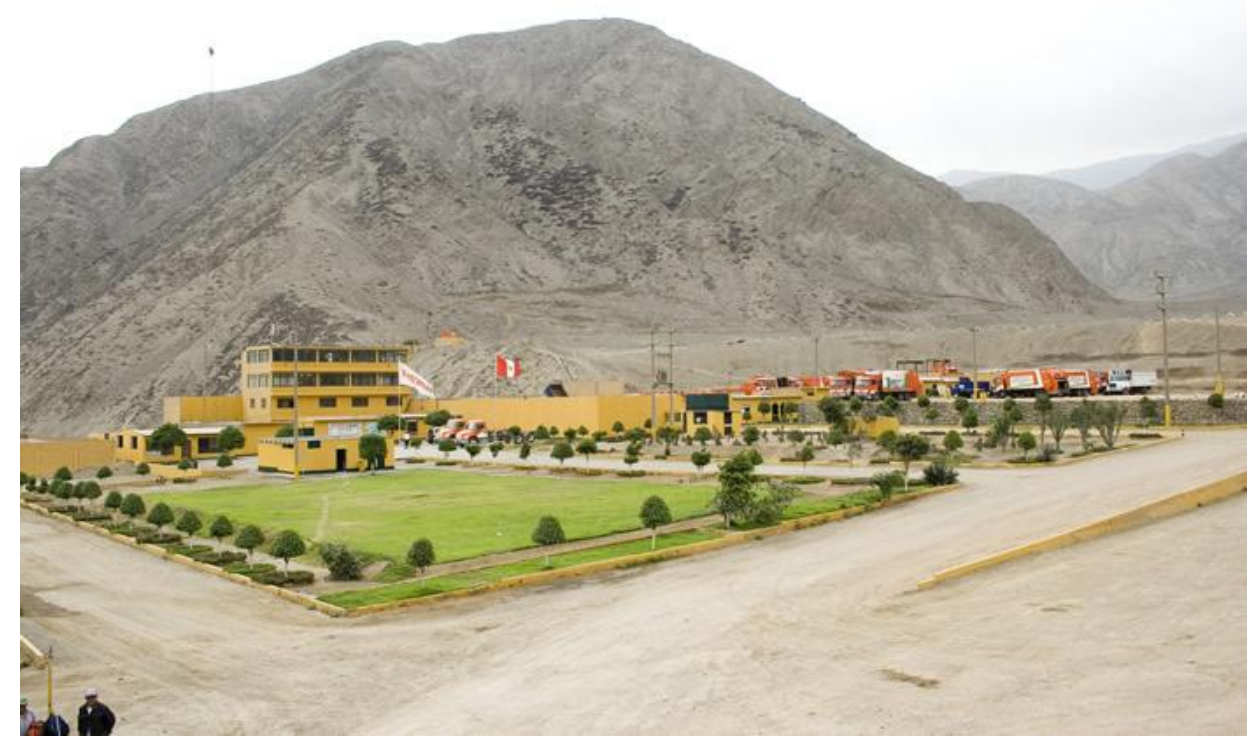

Fonte:( www.petramas.com, 2015)

Esse aterro sanitário, além de contar com a área que funciona propriamente como aterro, tem outras duas áreas, onde estão funcionando dois projetos que estão em fase de implementação:

a) O projeto de Mecanismo de Desenvolvimento Limpo - MDL (Figura 2.2) que seguindo os acordos do Protocolo de Kioto, reduz os efeitos do gás invernado, o metano CH4, "destruindo-o" até o CO2 que é 21 vezes menos nocivo. Ou seja, o objetivo é reduzir as emissões de biogás que trazem como consequência o esquentamento global. Por exemplo, com o MDL será reduzido em sete anos o 
equivalente a dois milhões de toneladas de $\mathrm{CO} 2$, contribuindo assim com a diminuição do esquentamento global no Peru e no mundo.

b) O projeto da Central Térmica de Biomassa para a geração de energia elétrica (Figura 2.3). Atualmente, $42 \%$ dos resíduos recebidos pelo aterro Huaycoloro da Lima Metropolitana é convertido em energia elétrica. Esta, por sua vez, é fornecida aos peruanos quando se tem disponível a conexão ao Sistema Elétrico Interconectado Nacional. Esse projeto, além de ser uma fonte de emprego para 2.000 trabalhadores de Petramas, gera benefício tanto para os usuários industriais quanto os domésticos que se abastecem de energia limpa, conforme aponta os acordos dos tratados internacionais do Peru na luta contra as mudanças climáticas.

Figura 2.2 - Planta de mecanismo de desenvolvimento limpo

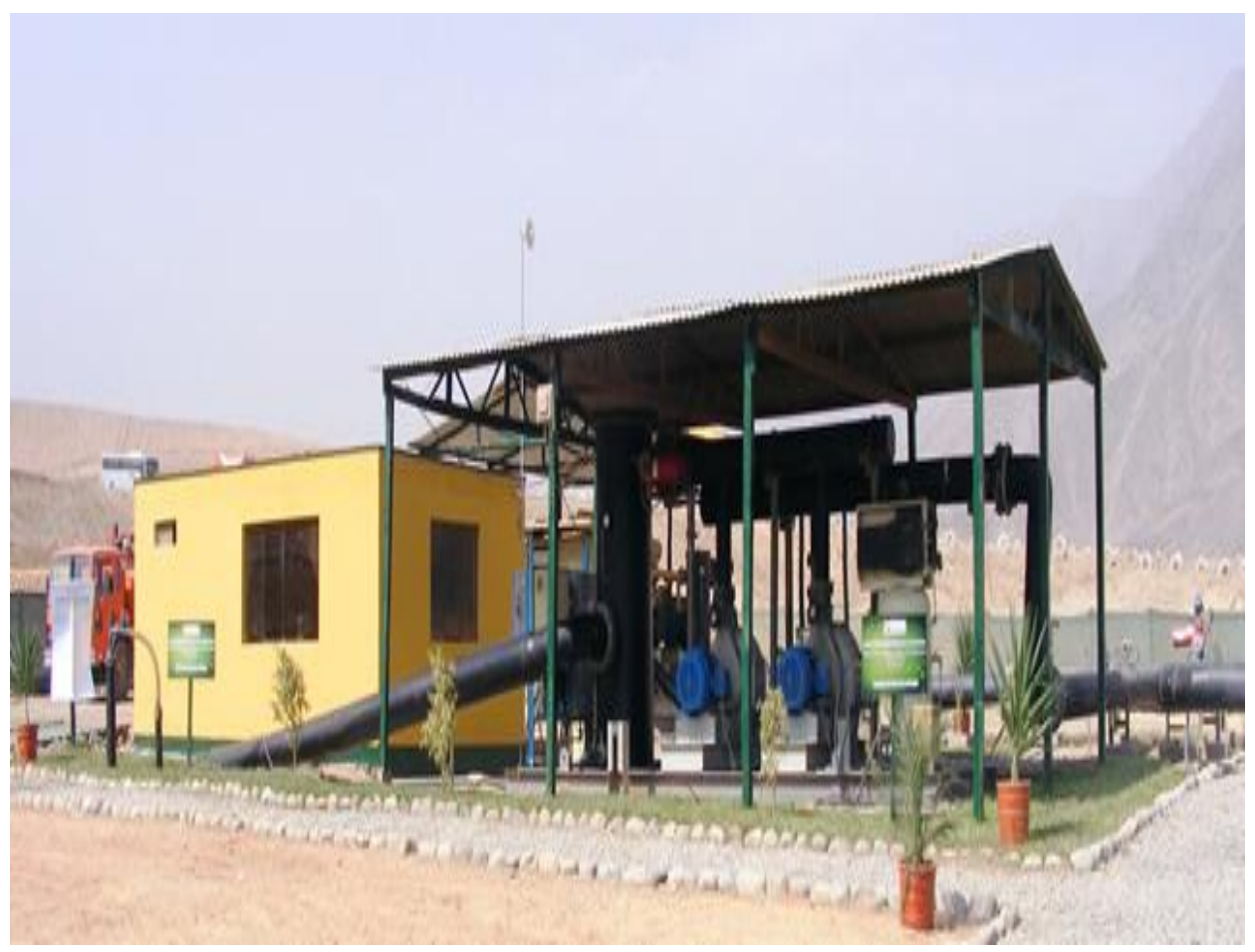

Fonte:( www.petramas.com, 2015)

É com esse modelo de gestão que a região de Lima Metropolitana está contribuindo com a sustentabilidade e redução do aquecimento global, além de gerar fontes de emprego. Ou seja, o País terceirizou o serviço de gestão por meio de operadores como a Petramas SAC e em conjunto com os governos locais estão desenvolvendo projetos para o melhor aproveitamento dos resíduos gerados. 
Figura 2.3 - Planta elétrica para queima de biogás para gerar energia elétrica

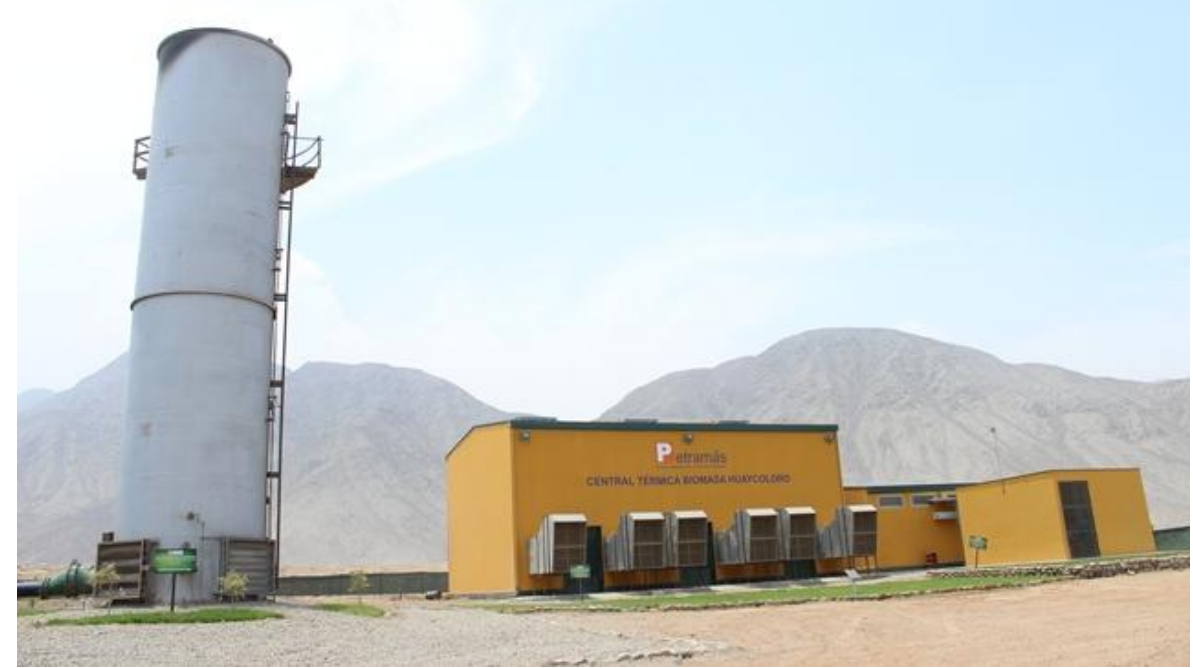

Fonte:( www.petramas.com, 2015)

\subsection{EXPERIÊNCIAS NO BRASIL NO TRATAMENTO ADEQUADO DOS RSU}

A cidade de Caxias do Sul-RS foi a primeira cidade do Brasil a implantar um sistema de coleta seletiva. O sistema começou em 1991 em toda a área central da cidade por meio de um sistema de containers e caminhões basculantes que evitam o contato dos operadores com os RSU. O sistema implantado é encontrado em algumas cidades europeias e ficou sob a responsabilidade da Companhia de Desenvolvimento de Caxias do Sul - CODECA ${ }^{17}$.

Caxias do Sul investiu forte na implantação desse sistema, de forma que hoje ela possui estrutura física e pessoal capacitado para garantir o gerenciamento e funcionalidade de todo o sistema, assim como estrutura apropriada para varrição, coleta manual e mecanizada e destinação final de todos os resíduos domiciliares gerados pela população e durante a realização de eventos. Dessa forma, estão conseguindo atualmente atingir 100\% da cidade e alcançar o índice de $15 \%$ de material reciclável sobre o total coletado, sendo um dos maiores no Brasil.

\footnotetext{
${ }^{17}$ A CODECA é uma empresa de economia mista, fundada em 1975, que executa os serviços de asseio da cidade de Caxias do Sul, na área de coleta e transporte e destinação final do lixo orgânico e seletivo, capina, varrição, construção e monitoramento do aterro sanitário.Assim, Caxias do Sul é o único município de médio e grande porte no país que detém sob responsabilidade da Administração Pública todo o processo de limpeza urbana, desde a coleta até a destinação final, compreendendo o lixo urbano, capina e varrição.
} 
Portanto, os investimentos que Caxias do Sul fez estão dando ganhos em todos os sentidos a cidade, de tal forma que hoje, é referência na reciclagem, na limpeza e embelezamento da cidade, e cidade conceito em qualidade de vida e saneamento básico. A cidade é modelo nacional na coleta e no destino final dos RSU, tendo dado um grande avanço neste conceito com a construção de seu novo: Sistema de Tratamento e Destino final dos Resíduos Domiciliares, com Aterro Sanitário, Estação de Tratamento de Chorume, Compostagem, Aproveitamento do Biogás e uma vida útil de no mínimo de 150 anos.

Antes de implantar o sistema de coleta seletiva foi realizada uma pesquisa junto à população com o intuito de identificar as áreas prioritárias que receberiam os dois tipos de containers: a) container amarelo para identificar os resíduos urbanos seletivos; e, b) container verde para os resíduos orgânicos.

No início foram instalados 1.000 containers em 270 quadras, que além da população de 80.000 moradores, recebe diariamente uma população flutuante de 200.00 pessoas. Nessa época a prefeitura de Caxias do Sul gastou por volta de R \$ 167.000 mensais, pelo aluguel dos containers e dos 4 caminhões que operavam no sistema de coleta seletiva.

Atualmente, a cidade, sempre visando o bem-estar da comunidade, conta com vários programas e $\operatorname{projetos}{ }^{18}$ que envolvem a própria comunidade e a participação de vários agentes, dentre eles estão:

- O CAPI (Central de Armazenamento e destinação de pneus inservíveis) recolhe e armazena todos os pneus da cidade. Desde 2005 já coletou 38.567 unidades, totalizando 877 toneladas.

- CALU (Central de Armazenamento e destinação de lâmpadas fluorescentes), desde 2005 já captou 137.094 unidades.

- Projeto Óleo Codeca, programa que viabiliza o destino correto do óleo usado em frituras. O material coletado é reaproveitado, sendo transformado em biocombustível ou sabão. Atende a área doméstica e estabelecimentos comerciais. Teve início em 2007 e até 2008 foram recolhidos 31.889 litros de óleo.

\footnotetext{
18 (https://caxias2014.wordpress.com/infraestrutura/limpeza-urbana/), acessado em junho de 2015.
} 
- Caminhos do Lixo, programa orientado para os estudantes, que consiste em uma visita guiada por um especialista que discursa sobre a preservação do meio ambiente com relação ao lixo gerado, a devida separação do resíduo reciclável e os prejuízos da destinação incorreta. Os estudantes percorrem um roteiro que compreende as instalações da Codeca, uma associação de reciclagem, o aterro sanitário e o museu do lixo. No período de 2005 a 2008 teve 63.367 participantes.

- Palestras de Conscientização em escolas, entidades e empresas. O seu conteúdo mostra o tratamento dado aos RSU em Caxias do Sul e ensina a separar corretamente os resíduos recicláveis do material orgânico, com o objetivo de minimizar os efeitos nocivos ao meio ambiente. No período de 2005 a 2008 foram realizadas 964 palestras.

- Projeto Reciclar na Escola, programa implantado em 2008 em conjunto com as Secretarias da Educação e do Meio Ambiente. Atinge os 37 mil alunos de escolas da rede municipal de ensino. Tem como objetivo transformar a questão do lixo em tema de sala de aula, orientando como separar e promover o correto tratamento dos materiais descartados, despertando a consciência sobre a importância da preservação do meio ambiente.

- Concursos Ambientais. Idealizados e realizados pela Codeca em parceria com a Secretaria de Educação, os projetos “A Arte de Brincar Reciclando Valores” e "Consciência Ambiental", visam incentivar os alunos das escolas municipais a valorizar e preservar o meio ambiente, respectivamente através do aproveitamento do resíduo seletivo para confecção de brinquedos e redações sobre a importância da separação do lixo.

- Projeto Troca Solidária. O Projeto tem por objetivo incentivar a prática da coleta seletiva por meio da troca de materiais recicláveis por hortigranjeiros. Aliando a preocupação ecológica à questão social, o projeto contribui para o aumento da conscientização das comunidades carentes quanto aos benefícios da coleta seletiva e da reciclagem.

- Ações Comunitárias. A CODECA participa de todas as ações comunitárias organizadas pela Administração Pública em vilas e bairros. A companhia recolhe o 
material descartado por moradores, realiza serviços de roçada e capina, faz pintura de meio-fio, limpa, conserta e constrói bocas-de-lobo.

- Lixeiras comunitárias. A CODECA implantou um programa de instalação de lixeiras comunitárias em bairros e vilas, beneficiando os moradores que não tem condições de adquiri-las. Lixeiras colocadas até dezembro de 2008: cerca de 1000 unidades.

- Lixeiras papeleiras. Com o intuito de manter a área central mais limpa, permitindo que os pedestres deem o destino correto a papéis, plásticos, latas e guardanapos, foram instaladas 200 lixeiras papeleiras. A iniciativa mantém a cidade limpa e minimiza o trabalho de varrição.

- Combate a Lixões. A CODECA mantém equipes para o controle e eliminação de lixões clandestinos. Desde 2005, foram eliminados 193 focos de depósito de lixo irregular, com o recolhimento de 1.010 toneladas de material.

- Eventos e Feiras. A CODECA participa ativamente de eventos realizados na cidade, com trabalho de consciência ambiental ou simplesmente recolhendo lixo, e mostrando seu trabalho nas áreas de preservação ambiental e desenvolvimento sustentável.

\subsection{EXPERIÊNCIAS NO EXTERIOR}

Os países desenvolvidos que apresentam território reduzido e alta densidade populacional não podem dispor de extensas áreas para implantação de aterros a céu aberto, sanitários ou controlados. Dessa forma, é possível entender que outros métodos de tratamento e disposição final dos RSU foram aperfeiçoados e implantados ao longo de décadas em número elevado em diversas cidades e capitais.

\subsubsection{Tratamento e Gestão de RSU em Países Desenvolvidos}

A utilização do lixo urbano como fonte de energia é largamente utilizada em vários países desenvolvidos. A tecnologia é denominada de Incineração controlada de RSU. Alguns 
dados mencionam que $100 \%$ do lixo urbano do Japão são incinerados em algumas de suas cidades e alcança 79\% do lixo na Suíça. Em Paris, 100\% do lixo produzido é incinerado; e, é aproveitado para o aquecimento de aproximadamente 70.000 apartamentos. Outras usinas de Incineração estão sendo instaladas em vários países do leste asiático: Coréia, Taiwan, Filipinas, Índia e China.

Um método que se sobressai, por suas vantagens econômicas e ambientais é a Incineração dos RSU com recursos de Cogeração (OLIVEIRA et al, 2006; COELHO, 2008; HENRIQUE, 2004). A incineração é conceituada como a decomposição térmica dos resíduos via oxidação (combustão), com o objetivo de reduzir o volume e a massa dos resíduos com o aproveitamento simultâneo de calor para geração de energia elétrica através de uma central termoelétrica.

A Tabela 2.10 apresenta um resumo estatístico de vários países desenvolvidos que utilizam o método de incineração, o que demonstra que é um método seguro e aceito pelas rígidas normas ambientais. A análise dos dados indica a larga utilização do método de incineração pelo Japão e França. A Suíça e Japão apresentam os maiores percentuais de incineração dos RSU.

As principais vantagens da incineração dos RSU são:

- A redução drástica da massa em até $70 \%$ e volume em até $90 \%$. As cinzas restantes podem ser destinadas para aproveitamento na fabricação de peças em concreto e aplicações em pavimentação para a construção civil;

- Esterilização dos resíduos. É possível eliminar a toxicidade e patogenicidade dos RSU, principalmente aqueles oriundos de unidades hospitalares;

- Redução do impacto ambiental. As plantas de Incineração exigem áreas menores para implantação de unidades de aproveitamento energético, reduzindo a possibilidade de contaminação ambiental permanente ou por acidentes, como ocorrem em aterros controlados, sanitários ou lixões; 
- Recuperação de energia. É possível aproveitar o poder calorífico dos RSU para geração de calor para aquecimento ou geração de frio através de sistemas de resfriamento por absorção. Simultaneamente, pode-se gerar energia elétrica.

Tabela 2.10 - Método de Incineração de RSU em Países Desenvolvidos

\begin{tabular}{c|c|c|c|c|c}
\hline PAÍ́ & $\begin{array}{c}\text { POPULAÇÃO } \\
\text { (MILHÖES) }\end{array}$ & $\begin{array}{c}\text { RSU } \\
\text { (MILHÕES } \\
\text { TON/ANO) }\end{array}$ & $\begin{array}{c}\text { RSU } \\
(\mathbf{K g} \\
\text { dia/hab) }\end{array}$ & $\begin{array}{c}\mathbf{N}^{\mathbf{0}} \\
\text { INCINERADORES }\end{array}$ & $\begin{array}{c}\text { \% } \\
\text { INCINERA } \\
\text { DO }\end{array}$ \\
\hline Suíça & 7 & 2,9 & 1,13 & 29 & 79 \\
\hline Japão & 123 & 44,5 & 0,99 & 1893 & 72 \\
\hline Dinamarca & 5 & 2,6 & 1,42 & 32 & 65 \\
\hline Suécia & 9 & 2,7 & 0,82 & 21 & 59 \\
\hline França & 56 & 18,5 & 0,90 & 100 & 41 \\
\hline Holanda & 15 & 7,1 & 1,29 & 9 & 39 \\
\hline Alemanha & 61 & 40,5 & 1,81 & 51 & 22 \\
\hline
\end{tabular}

Fonte: ASME (American Society of Mechanical Engineers) ${ }^{19}$

\subsubsection{Cidade de Barcelona}

O sistema de coleta de RSU, implantado em Barcelona a partir de 1992, utiliza um gigantesco sistema de tubulação enterrado a, pelo menos, cinco metros da superfície. Trata-se de um grande sistema de sucção, que aspira o lixo de hora em hora, dia e noite, o ano inteiro. Os sacos de RSU se deslocam a 70 quilômetros por hora embaixo da terra.

O destino final é um Centro de coleta, geralmente instalado na periferia da cidade. $\mathrm{O}$ lixo entra diretamente em um container, que depois de cheio é transportado para uma usina de triagem, ainda mais afastada da cidade. Plásticos, latas e papel são reciclados. O lixo orgânico vira combustível para mover turbinas que produzem eletricidade.

Nos últimos 18 anos, a prefeitura de Barcelona vem investindo sistematicamente na instalação desses tubos subterrâneos, conforme cita a reportagem de uma série especial sobre o tratamento de RSU em diferentes cidades do mundo ${ }^{20}$.

\footnotetext{
${ }^{19} \mathrm{http}$ ://asmedigitalcollection.asme.org/journals.aspx, acessado em junho 2010.

${ }^{20}$ Empresa ENVAC de recolhimento de Lixo (detalhes do funcionamento do sistema), acesso 2013.
} 
O extenso sistema de tubulação subterrânea, que foi implantado ao longo dos anos, é complexo devido às intervenções de infraestrutura necessárias nas regiões urbanas. Contudo, os resultados obtidos são visíveis. A população reconhece que a região da cidade onde o sistema é implantado se torna mais limpa, com menos lixo espalhado pelas vias urbanas.

Pontos de coleta, com desenho atual, permitem que a população faça parte importante no ciclo do processo, ou seja, inicie o descarte seletivo dos RSU através de escotilhas seletivas para os três tipos diferentes de lixo permitidos: plásticos, latas e papel. O lixo orgânico vira combustível para mover turbinas que produzem eletricidade em uma central termoelétrica.

O sistema de coleta subterrânea de RSU foi bem aceito pela população de Barcelona, tanto que os novos prédios de apartamentos construídos nas últimas duas décadas já têm o sistema instalado internamente. Os moradores nem precisam mais descer com os sacos até a rua: $70 \%$ do lixo na capital da Catalunha já é recolhido dessa forma.

Supostamente, em alguns anos, Barcelona inteira não terá mais nenhum caminhão de coleta de lixo circulando pela cidade. Esse sistema, embora exija investimento elevado em infraestrutura inicialmente, ao longo do tempo, tem como retorno o aumento da qualidade de vida da população e melhoria da mobilidade urbana, pois centenas de caminhões coletores já foram retiradas das vias urbanas, reduzindo dessa forma, a poluição ambiental.

O sistema se tornou uma referência de tecnologia aplicada e praticamente já foi implantado em quase uma centena de cidades na Europa. O sistema de coleta subterrânea da cidade de Barcelona é extremamente didático como demonstração real de que a tecnologia aplicada às necessidades da população pode trazer como vantagens a população, no que se relaciona a qualidade de vida e novas oportunidades.

\subsection{SUSTENTABILIDADE}

A configuração, característica, jurisdição administrativa, relações economicas, sociais e ambientais de um espaço urbano é definida pela população e pela função que ela desenvolve em uma área geográfica ou região (BUGLIARELLO,2006). Assim, as cidades 
são sistemas dinâmicos que interagem continua e constantemente com seu meio ambiente, acompanhando as características, perfil, cultura e ritmo de desenvolvimento econômico e social de sua população. Onde os meios de transportes jogam um papel importante nesse ritmo de desenvolvimento das cidades, já que eles tem como função principal relacionar os fatores populacionais com os fatores uso do solo.

Antes dos anos 60, na maioria das regiões brasileiras existia um certo equilibrio entre a população rural e a população urbana, sendo que a primeira, em termos de porcentagem era maior, a relação era de $60 \%$ a $40 \%$. Essa relação era importante porque ajudava a manter, de forma natural, uma certa sustentabilidade urbana e rural, sem muita intervenção e esforço das entidades responsáveis pela preservação dos recursos naturais e do meio ambiente como um todo.

A partir dos anos 60, deu-se uma mudança do perfil da população, esta praticamente se tornou urbana. Esse crescimento não planejado, foi afetando a dinâmica das cidades em todos os aspectos, gerando uma forte demanda no consumo de serviços básicos, principalmente no que se refere a consumo de alimentos, água, energia, saneamento, etc. Essa demanda impulsionou o mercado de ofertas desses produtos, que a sua vez demandou o fornecimento de matérias primas, gerando-se ao longo dos anos uma série de cadeias produtivas, comerciais e logísticas.

Em todo esse processo de demanda e ofertas de produtos gera-se resíduos solidos de todo tipo e género: industrial, químico, farmaceútico, de construção, aliménticio, hospitalar, etc. Residuos que durante muitas décadas foram jogados indiscriminadamente ao meio ambiente sem a devida supervisão e fiscalização dos governos locais, estaduais e federais. Assim, estes resíduos somados ao esgotamento dos recursos naturais e a falta de preservação do meio ambiente só fez aumentar a crise de sustentabilidade do meio ambiente urbano e rural.

A rigor, pode-se concluir que devido à extração sem responsabilidade dos recursos naturais para produção e geração da atual diversidade de produtos sem o devido planejamento, preservação e conservação do meio ambiente onde encontram-se inseridos está gerando consequências, tais como, impactos globais diretos e indiretos sob a atmósfera, hidrósfera, 
geosfera e biosfera. Problemas esses que na atualidade estão conduzindo ao esgotamento desses recursos em certas regiões do planeta (AGUDELO et al, 2011).

De acordo com Valentin (2000), a sustentabilidade deve ser analisada sob varios critérios: ambiental, economico, social e institucional. Todos esses critérios tem que ser tratado sob uma visão sistêmica e com o mesmo nível de importância. Deste modo, a sustentabilidade urbana passou a ser um dos temas mais importante da sociedade moderna e pauta dos governantes, tornando-se assim, um dos objetivos mais desejados, pois todos tem interesse em melhorar a qualidade de vida das comunidades.

Bugliarello (2006); Tanguay et al. (2010); Agudelo et al (2011) estabeleceram formalmente o significado e a importância da sustentabilidade e o desenvolvimento sustentável nas cidades, tendo como alvo procurar o bem estar dos cidadãos por meio da boa gestão dos recursos disponíveis. Assim, a eficiência no gerenciamento dos recursos disponíveis é essencial para manter o equilíbrio no ecossistema e deve ser parte do planejamento e da sustentabilidade urbana, já que o desenvolvimento urbano sustentavel é um desafio crucial (AGUDELO et al, 2011). Desde a visão de McDonald e Patterson (2007) apud Agudelo et al (2011) pode-se considerar a questão mais significativa nos tempos atuais e futuros

Atualmente os pesquisadores estão formalizando os conceitos referidos à sustentabilidade $\mathrm{e}$ ao desenvolvimento sustentável em 5 pilares, como se observa na Figura 2.4.

Figura 2.4 - Prisma de sustentabilidade

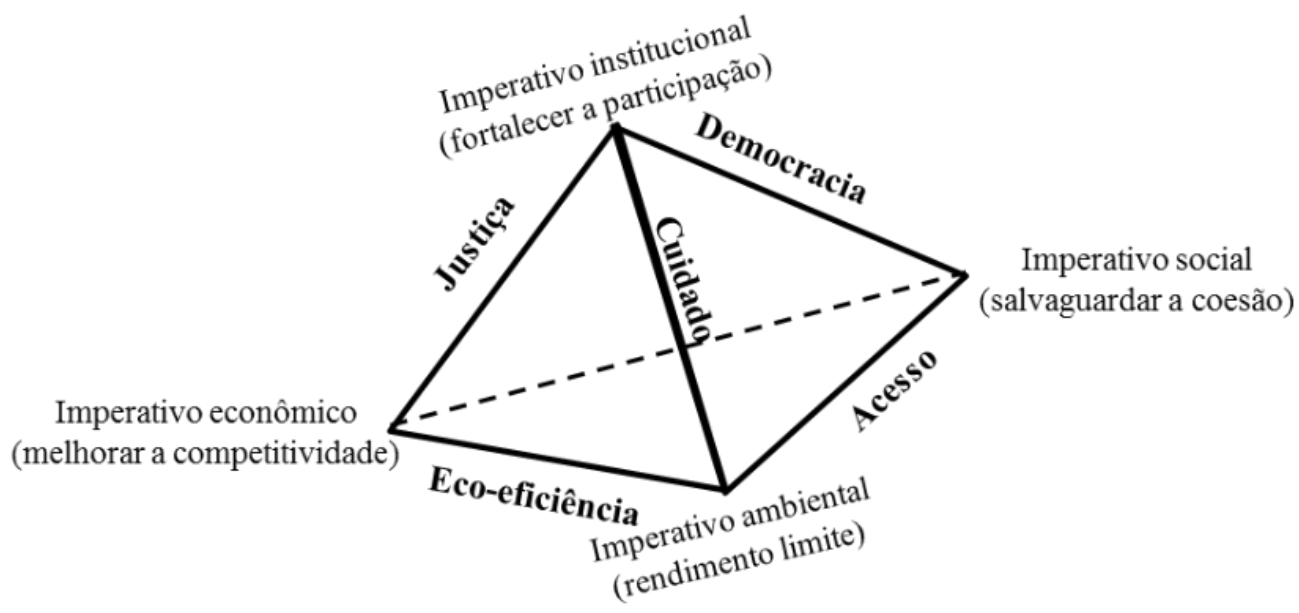

Fonte: Valentin (2000) 
Segundo Bugliarello (2006):

”a sustentabilidade é supervivência, pois os desafios técnicos (ex. criação de aterros sanitários); os desafios socioeconômicos (ex. emprego, moradia e serviços essenciais); a relação entre o transporte e uso do solo; a elaboração de políticas eficazes para promover o desenvolvimento tem que ser superados".

O desenvolvimento sustentável, (Figura 2.5), estará garantido se considerar três aspectos fundamentais: econômico, social e ambiental, onde a interseção destes aspectos garante a qualidade de vida no espaço urbano e o equilíbrio nas classes sociais em procura do bem estar (TANGUAY et al, 2010).

Para manter a sustentabilidade no meio urbano e rural tem que ser tratado o problema dos resíduos sólidos em todos os aspectos. Assim, Ghose et al (2006) comenta que todo sistema de gestão de RSU deve incluir as seguintes opções: coleta de resíduos e transporte até sua disposição final; recuperação de recursos através do processamento e tratamento dos resíduos; transporte de resíduos sem recuperação de recursos; e a eliminação dos resíduos em aterros sanitários controlados.

Com a análise dos artigos pesquisados pode-se dizer que para manter as cidades sustentáveis, além de gerenciar estrategicamente os recursos disponíveis, os governos devem apresentar programas de conciência ambiental para a população, para que assim os sistemas de gestão de RSU para a coleta e transporte seja um sucesso, e portanto possam melhorar a qualidade de vida nas grandes cidades. Propostas isoladas não garantem a solução dos atuais problemas das cidades.

Figura 2.5 - Aspectos chave para o desenvolvimento sustentável

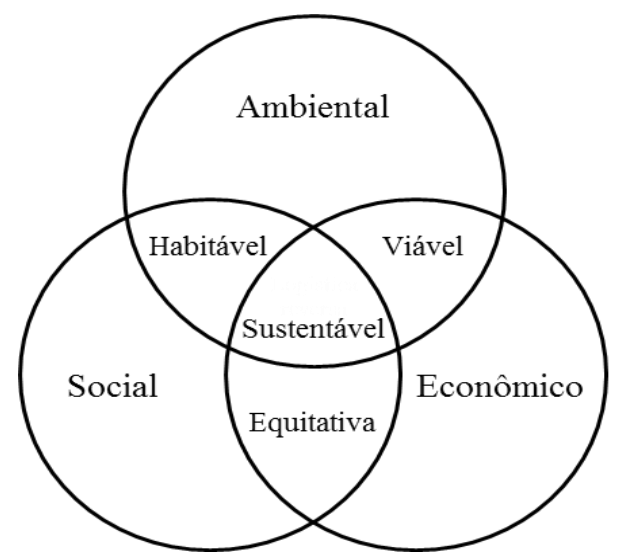

Fonte: Tanguay et al (2010) 
No entanto, tem alguns autores como, Zhang et al (2010) que argumentam que a coleta, o transporte, o tratamento e a disposição dos RSU, em particular os resíduos gerados nos centros urbanos médios e grandes, tornam-se um problema relativamente difícil de resolver.

\subsection{LOGÍSTICA DIRETA E REVERSA}

Ghiani et al (2004) entendem que:

"À logística trata do planejamento e controle dos fluxos de materiais e informações relacionadas nas organizações, tanto nos setores público e privado. Ainda, sua missão é fazer a entrega dos produtos certos, no local certo e na hora certa, otimizando os custos operacionais totais do processo satisfazendo um determinado conjunto de restrições ou condições".

Segundo De Brito (2003), é difícil de traçar com precisão a denominação do termo, mas termos como canais reversos ou fluxo reverso já eram conhecidos na literatura na década dos anos setenta.

Nos anos 90 foram apresentadas definições gerais as quais vem sendo melhoradas. Dekker et al (2003) apresenta uma melhora na definição de logística reversa, sendo

"o processo de planejamento, implementação e controle dos fluxos de matérias-primas, em processos de inventários e bens acabados, desde o ponto de fabricação, distribuição ou uso, para o ponto de recuperação ou de eliminação".

Mas, como esta definição não faz menção aos pontos de consumo e de origem, então deixa a possibilidade de acrescentar a ideia que bens não consumidos podem voltar ao processo produtivo ou para um ponto de recuperação.

Com o intuito de estabelecer os fundamentos da logística reversa, De Brito (2003) apresenta uma proposta baseada em quatro perspectivas, que segundo ele devem ter respostas tais como: por que os produtos retornam?, que é o que está sendo retornado à empresa?, como funciona a logística reversa na prática? e, quem está executando as atividades de logística reversa? 
A primeira questão pode ser respondida sob duas visões: do ponto de vista da empresa e e do ponto de vista do cliente. Da ótica do cliente, os produtos que não funcionam ou já foram usados, devem ser devolvidos ou descartados e voltar para fábrica de origem. Da ótica da empresa produtora, este problema pode ser categorizado em três fatores: econômico, ambiental e consciência ambiental.

Do fator econômico, se as empresas estão recebendo os produtos que não funcionam ou que já foram usados, então elas podem criar uma linha de reciclagem ou analisar sua disposição ambientalmente correta, de forma que traga retorno econômico à empresa. Com relação as leis ambientais, pode-se ressaltar que os governos estão sancionando leis que estabelecem a responsabilidade pelo descarte final do produto pós-consumo no produtor, sendo esta uma responsabilidade compartilhada com o consumidor. Sendo aqui acionado o terceiro fator, a consciência ambiental, o desenvolvimento sustentável somente será possível se os consumidores estiverem envolvidos na logística reversa.

Na segunda questão é importante ter conhecimento da composição, da deterioração e do uso de padrões do produto que vai voltar, para saber que procedimentos deverão ser tomados. Com relação à terceira questao é importante entender e conhecer como funciona na prática as diferentes etapas da logística reversa: coleta; processos de seleção e classificação dos produtos coletados, manufatura, reciclagem e disposição final. E saber que atores participam em cada uma dessas etapas, que seria a quarta questão a ser respondida.

A Lei 12.305/2010, no seu capítulo II, Art. 30 inciso XII apresenta sua própria definição de logística reversa como:

\footnotetext{
"Instrumento de desenvolvimento econômico e social caracterizado por um conjunto de ações, procedimientos e meios destinados a viabilizar a coleta e a restituição dos resíduos sólidos ao setor empresarial, para reaproveitamento, em seu ciclo ou em outros ciclos produtivos, ou outra destinação final ambientalmente adequada".
}

Ainda, a contribuição à sustentabilidade da logística reversa (LEITE, 2003) se dá na medida em que:

“o objetivo econômico da implementação da logística reversa de pós-consumo pode ser entendido como a motivação, para a obtenção de resultados financeiros por meio de economias obtidas nas operações industriais, principalmente pelo aproveitamento de 
matérias-primas secundárias, provenientes dos canais reversos de reciclagem, ou de revalorizações mercadológicas nos canais reversos de reuso e de remanufatura"

Portanto, o planejamento e implementação de sistemas logísticos para as atividades de coleta, triagem e processamento para assegurar uma recuperação sustentável, tem ganhado cada vez mais importância na busca pela sustentabilidade nas cidades. Podendo-se concluir que este tipo de logística é parte do desenvolvimento sustentável e, portanto, ajuda no processo de minimizar as contaminações no meio ambiente (Figura 2.6).

Devido ao interesse na preservação do meio ambiente, Saman et al. (2009) apresentam em seu trabalho a importância da logística reversa na indústria, dizendo que o bom planejamento da rede reversa traz mais lucro para a empresa. Infelizmente, alguns empresários não acreditam muito nessa afirmação; outros que acreditam, no entanto, não sabem como implantar uma rede reversa. Ainda, os que chegam a estabelecer uma rede reversa não conseguem um total apoio do governo e da sociedade, o que gera as relações informais do mercado de lixo, sem normas e regras que regulamente e proteja ao elo mais fraco desse mercado informal.

Figura 2.6 - Logística reversa embutida no desenvolvimento sustentável

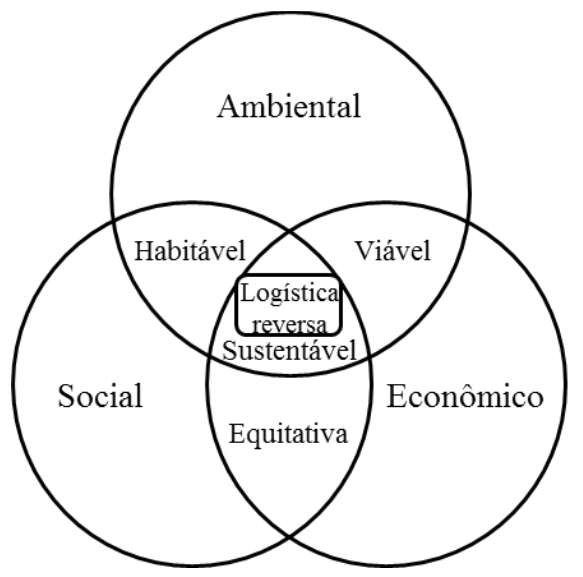

Fonte: Adaptação de Tanguay et al (2010)

\subsection{LOGÍSTICA URBANA}

Além das pesquisas sobre o acelerado crescimento da população urbana $\mathrm{e}$, consequentemente, maiores necessidades para satisfazer e se manter a sustentabilidade 
urbana, surge a logística urbana como estratégia para melhorar a qualidade de vida das comunidades no espaço urbano (DA SILVA, 2004). Essa necessidade é motivo de preocupação das autoridades federais e municipais, devido as possíveis contaminações que podem ser geradas nas operações de transporte de carga urbana, especialmente na manipulação de produtos que apresentam riscos à saúde.

Inicialmente, o conceito de logística urbana foi aplicado nas atividades de transporte de passageiros e de carga (TOLEDO, 2005). No entanto, o conceito de city logistics era mais amplo e bem fundamentado, pois além da logística urbana também considerava os problemas de congestionamento e suas externalidades (poluição, ruído e outros fatores) nas cidades, sendo seu objetivo minimizar a contaminação e procurar o bem-estar no ambiente urbano (TANIGUCHI, 2001).

O conceito de logística urbana evoluiu de tal forma, que atualmente não existe nenhuma distinção entre esses conceitos. Assim, a comunidade acadêmica formalizou o conceito de city logistics como logística urbana. Mais ainda tem muito questionamento com a definição clara de logística urbana.

Os municípios tentam controlar os impactos negativos (congestionamento, poluição do ar, ruído, etc.) que o transporte produz como consequência do crescimento do número de veículos de carga e de passageiros, veículos particulares e veículos coletores de resíduos sólidos nas áreas urbanas e metropolitanas.

Neste contexto, e considerando o interesse pela proteção do ambiente urbano, as estratégias de logística urbana procuram diminuir os impactos negativos do transporte urbano, sem penalizar as diversas atividades econômicas, sociais, administrativas, culturais, turísticas, etc. da cidade (BENJELLOUN et al, 2010). Assim, a logística urbana e logística reversa são estratégias importantes da sustentabilidade urbana.

Segundo Taniguchi et al (2001), o suporte de um sistema para a logística urbana é aquele que está baseado na sustentabilidade, mobilidade e qualidade de vida, considerando os valores sociais. A sustentabilidade está relacionada à minimização dos impactos ambientais produzidos pelo consumo de bens e serviços e à minimização do consumo de energia. A mobilidade refere-se aos requerimentos básicos para transporte de mercadorias 
no espaço urbano e a qualidade de vida a um ambiente melhor para a comunidade (Figura 2.7).

Depois da formalização da logística urbana, diversas propostas qualitativas e poucas propostas quantitativas foram feitas baseadas no suporte do sistema para a logística urbana. As propostas quantitativas baseadas nas técnicas de pesquisa operacional e ciência da computação ajudam na modelagem e solução dos problemas no mundo real. Ainda, segundo Crainic et al (2009) para a pesquisa operacional e a ciência do transporte, a logística urbana constitui um descobrimento e uma oportunidade em termos de desenvolvimento de metodologias e de impactos sociais.

Figura 2.7 - Suporte de um sistema para logística urbana

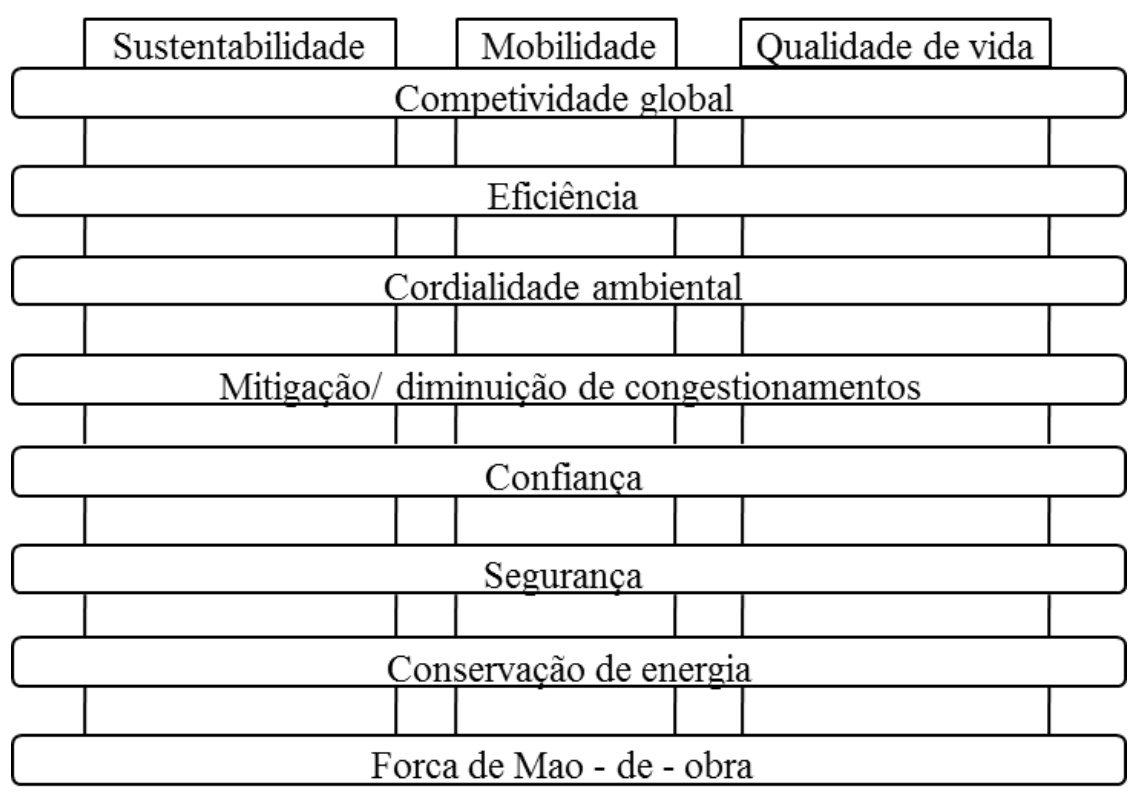

Fonte: Taniguchi et al. (2001) apud Da Silva (2004)

A logística orientada para o abastecimento das cidades tem o objetivo de aperfeiçoar o processo do transporte da carga urbana de diversos produtos, desde a fábrica até os consumidores com desenvolvimento econômico. Ainda, contribui com a melhoria das condições ambientais, minimizando a poluição, fazendo-a mais sustentável. Por isso é fundamental que o planejamento logístico nas cidades de médio e grande porte seja coordenado pelos setores público e privado, responsáveis pela estrutura da cidade e dos serviços, respectivamente. 
Pode-se observar no contexto da logística urbana, o interesse na diminuição da contaminação ambiental na procura da sustentabilidade urbana. Assim, medidas relacionadas com a infraestrutura da rede, além das características dos veículos de transporte nas cidades são fundamentais e devem ser monitoradas com a ajuda de tecnologia de ponta.

Considerando os conceitos e artigos discutidos nas primeiras seções deste capítulo, pode-se dizer que o sistema logístico urbano é a formalização das ideias qualitativas sobre o desenvolvimento sustentável e da logística urbana. Assim, a base teórica da logística urbana estabelecida em Taniguchi et al (2001) está contribuindo no desenvolvimento de novas propostas orientadas para uma melhor gestão das atividades logísticas nas cidades, tendo como objetivo a diminuição dos impactos ambientais gerados pela mesma população através das suas atividades, principalmente, a geração de lixo doméstico dos produtos pósconsumo distribuídos nas cidades.

Pesquisas atuais centradas em modelos quantitativos tais como os de Tamagawa (2010), usando o modelo multi-agente (modelo de aprendizagem e modelo de roteirização), apresenta uma metodologia para avaliar a logística urbana de acordo com o comportamento dos cidadãos. Outra nova proposta de sistema de logística urbana baseado no modelo de roteirização de dois níveis com mais de um depósito é discutido em (CRAINIC et al, 2010; CRAINIC et al, 2011).

Para garantir a sustentabilidade urbana e a proteção do meio ambiente sem afetar as gerações futuras, a comunidade acadêmica está apresentando novas propostas para melhorar o bem-estar da população urbana (MAROUDAS, 2011). Os métodos quantitativos constituem uma proposta, sendo que a etapa de modelagem baseada na programação linear inteira binária ou mista está sendo uma metodologia muito importante.

Ainda, como os problemas baseados no desenho da rede tem grande complexidade computacional, a ciência da computação está contribuindo através dos algoritmos metaheurísticos em particular os algoritmos genéticos e simulated annealing para a solução destes tipos de problemas. Com esta ajuda as autoridades municipais têm o suporte para o processo de tomada de decisões no gerenciamento das cidades. 


\subsection{MODELAGEM E ROTEIRIZAÇÃO}

A modelagem matemática é uma alternativa para expressar formalmente fatos reais que podem ajudar no processo da tomada de decisões. A modelagem permite a simulação de processos e de cenários com a introdução de índices de desempenho que permitam quantificar os custos e benefícios da implementação do sistema, a melhoria da sustentabilidade urbana e por suposto os índices de poluição nas grandes cidades e seu impacto em todo o meio ambiente.

Os problemas de gerenciamento de resíduos fizeram com que os pesquisadores começassem a desenvolver novos modelos matemáticos - computacionais, com o intuito de contribuir no processo de gestão dos resíduos sólidos gerados pelos cidadãos das cidades médias e de grande porte.

Elwany et al (2007) apresentam uma classificação das técnicas de modelagem e dos métodos de solução empregados no desenho de redes de logística. A classificação dividese em:

(1) Técnicas de modelagem: São classificadas de acordo com o tipo de fluxo (redes diretas e redes reversas); o tipo de modelo (programação linear inteira binária ou mista e programação não linear); a função objetivo que pode ser simples, múltipla, econômica e ambiental.

(2) Técnicas de solução: Usadas de acordo com o tipo de modelo; com as variáveis de decisão e as restrições (condições). As técnicas são as seguintes:

(2.1) Algoritmos exatos: Ajudam a obter soluções exatas ou ótimas, mas somente é possível para problemas com uma quantidade pequena de dados, ou seja, para problemas de tamanho limitado.

(2.2) Algoritmos heurísticos: São técnicas de aproximação que ajudam a obter melhores soluções para os problemas de otimização, mas são não ótimas. Isso acontece quando os problemas são de grande complexidade computacional, ou seja, pertencem à classe de problemas NP-Difícil. 
(2.3) Metaheurísticas: Método computacional que otimiza um problema iterativamente, fazendo uma melhor exploração no espaço de soluções com o intuito de melhorar uma solução candidato em relação a uma medida dada, mas não garante obter uma solução ótima. Em geral obtêm-se melhores resultados que as heurísticas, mas as soluções são encontradas em maior tempo de processamento. Na logística, as metaheurísticas conhecidas são os algoritmos genéticos, simulated annealing e pesquisa tabu.

O problema de roteirização de veículos (OMBUKI et al, 2006; YEUN et al, 2008) e suas variantes tem ganhado muito interesse na comunidade acadêmica. $\mathrm{O}$ intuito de ficar mais perto à realidade mediante a modelagem matemática, faz que tenham sido desenvolvidos novos modelos de otimização (SUNGUR et al, 2006; SUBRAMANIAN, 2010).

A roteirização é computacionalmente de grande complexidade e existem algoritmos metaheurísticos que ajudam a obter soluções para grandes cenários em tempo aceitável (NAGY, 2007). A roteirização procura obter as melhores rotas para atender a determinados clientes, minimizando o custo ou tempo de viagem com uma frota homogênea ou heterogênea com capacidades conhecidas. Cada cliente é atendido exatamente uma vez.

Portanto, a modelagem matemática passou a ser uma ferramenta importante e crucial para expressar formalmente problemas reais, procurando encontrar soluções ótimas ou viáveis que possam ajudar no processo de tomada de decisões e, em certa medida, fazer uso dos recursos de forma eficiente e principalmente conseguir a redução de custos com a otimização do transporte de carga na distribuição e coleta de mercadorias e bens.

Assim, as representações matemáticas dos problemas logísticos de distribuição e coleta estão ficando mais difíceis de serem estruturadas, já que os especialistas sempre buscam agregar o maior número de variáveis para ter uma melhor representatividade da situação real. Como consequência a solução desses modelos tornou-se, também, um desafio para os mesmos (TAKAI, 2009). 


\section{MODELOS UTILIZADOS EM REDES LOGISTICAS E GESTÃO DE RESÍDUOS SÓLIDOS}

Neste capítulo apresenta-se um levantamento do estado da arte dos principais modelos matemáticos utilizados na estruturação de redes logísticas, de forma geral, e na gestão de resíduos sólidos. Assim, fez-se uma seleção daqueles modelos que podem vir a contribuir com os objetivos do trabalho. O processo de seleção compreendeu os seguintes passos:

a) Revisão bibliográfica sobre modelos matemáticos relacionados ao tema de tese;

b) Compreender e entender claramente a proposta de cada modelo e suas técnicas de solução;

c) Analisar os requerimentos de dados para executar o modelo;

d) Procurar uma base de dados existentes nos diferentes agentes envolvidos na logística e gestão de resíduos sólidos;

e) Avaliar uma ferramenta computacional que permitisse executar o modelo e simular várias soluções;

f) Analisar os cenários simulados.

Devido à complexidade de uma série de modelos utilizados na literatura cientifica para estruturar redes logísticas, otimizar rotas e, sistemas de distribuição e coleta com vários pontos de origens e destinos e pontos de triagens, buscou-se aqueles modelos mais simplificados que fossem factíveis de serem programados e validados.

Vale ressaltar que a literatura é muito vasta quanto a esse tema, no entanto, nem todos os modelos podem ser testados, já que, muitas vezes apresentam alguma incompatibilidade, como conflito nas restrições, ou falta de alguma, ou talvez falta alguma hipótese ou premissa que ajude a definir melhor o modelo. Alguns modelos somente podem ser utilizados para casos teóricos com um número limitado de restrições e variáveis. Para casos reais, com um número maior de variáveis, são inviáveis. Para esses casos, a bibliografia apresenta vários algoritmos de solução, conhecidos como metaheurísticas. 
Diante desse quadro, observou-se que era importante contar com uma ferramenta computacional que possibilitasse a execução dos modelos selecionados e fosse de baixo custo, preferencialmente não tivesse nenhum custo. Assim, realizou-se uma busca intensiva de softwares livres na Internet. Observou-se que existem vários softwares livres na rede, mais nem todos são acessíveis e compreensíveis de serem usados, nem de trabalhar com um determinado número de variáveis.

Depois de uma intensa busca e de passar por vários testes, chegou-se à conclusão que a melhor ferramenta computacional para ser utilizada era o software GLPK (MAKHORIM, 2008). O GLPK mostrou-se uma ferramenta muito pratica quanto a sua capacidade de execução dos algoritmos testados e de trabalhar com um número bastante considerável de variáveis e dados de entrada.

\subsection{MODELOS UTILIZADOS NOS PROBLEMAS DE ROTEIRIZAÇÃO E PROGRAMAÇÃO DE VEICULOS}

Um sistema de roteirização pode ser considerado como um conjunto organizado de meios que objetiva o atendimento de demandas localizadas nos arcos ou nos vértices de alguma rede de transportes. O sistema de roteirização, como qualquer sistema operacional, pode ser decomposto, sob a ótica da operação, em três partes a saber: estratégica, tática e operacional (MARTEL, 2008).

Uma solução para o problema de roteirização de veículos (PRV) que seja capaz de modelar situações reais que afetam principalmente a indústria, o comercio, o setor de serviços, a segurança, a saúde pública, o lazer, dentre outros e, que possa ser implementado num sistema computacional, fornecendo uma série de cenários alternativos, é uma grande contribuição, já que possibilita diversas aplicações práticas (GHIANI et al, 2004).

A ideia básica do problema de roteirização consiste em visitar uma serie de clientes ao menor custo possível, atendendo a todas as imposições e premissas do problema. Assumindo-se que não existam restrições (tempo, número de veículos etc.) o PRV pode ser interpretado como o problema de ter um circuito de menor custo sobre uma rede de $n$ clientes. 
Dado um grafo $G(I, A)$, onde $I$ é o conjunto de vértices, que nesses casos representam a localização dos clientes que devem ser atendidos, e $A$ o conjunto de arcos, então o PRV trata de obter as melhores rotas de atendimento para um número determinado de clientes, minimizando o custo ou o tempo de viagem com uma frota homogênea ou heterogênea com capacidades conhecidas.

Uma das premissas do problema é que cada cliente deve ser atendido exatamente uma vez, ou seja, um cliente que é incluído em uma rota não pode participar na formação de outra rota. Outra premissa é que todas as rotas programadas devem começar e terminar as viagens num ponto específico, seja este um depósito ou um centro de distribuição, originando circuitos conforme a Figura 3.1 (OMBUKI et al, 2006; YEUN et al, 2008).

Figura 3.1- Roteirização de veículos

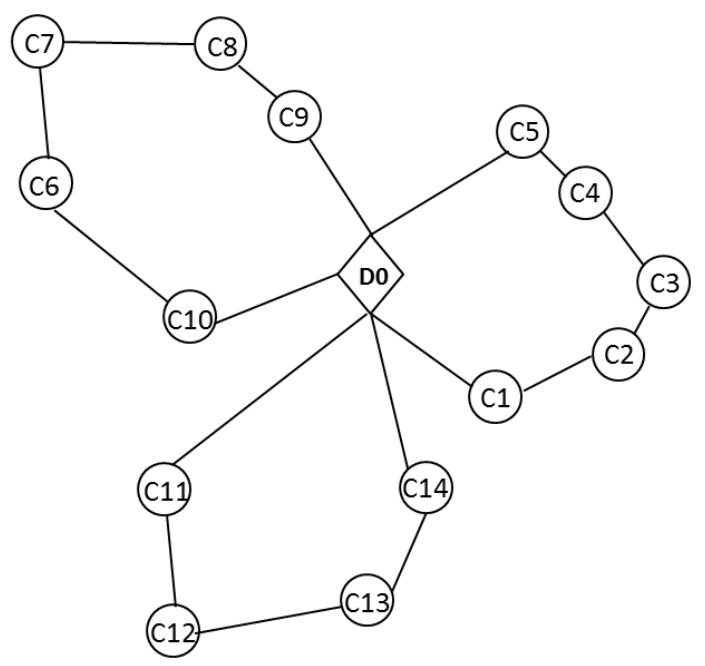

Fonte: Ombuki et al (2006)

O modelo geral de programação linear inteira binária do PRV, reportado como um problema de alta complexidade computacional, solucionado para grandes cenários com procedimentos meta-heurísticos (NAGY, 2007) é definido por Laporte (1992) como segue:

Função Objetivo:

$$
\operatorname{Min} C T=\sum_{(i, j) \in A, i \neq j} c_{i j} x_{i j}
$$

Minimizar o custo total de roteirização 


\section{Sujeito a:}

- Restrição de entrada de cada cliente no percurso;

$$
\sum_{j=1}^{n} x_{i j}=1, \quad \forall i \in I
$$

- Restrição de saída de cada cliente do percurso;

$$
\sum_{i=1}^{n} x_{i j}=1, \quad \forall j \in I
$$

- Restrição de eliminação de subciclos;

$$
\sum_{i=1}^{n} x_{i j} \leq|S|-v(S), \quad S: S \subseteq A-\{1\},|S| \geq 2
$$

- Restrição de não negatividade;

$$
x_{i j} \in\{0,1\}, \quad \forall i, j ; \quad i \neq j
$$

Onde:

$I \quad$ : Conjunto de clientes do grafo $G(I, A)$, incluído o depósito $0, i=0,1, \ldots, n$.

$A \quad$ : Conjunto de $\operatorname{arcos}(i, j) \in A, i \neq j$, do grafo $G(I, A)$.

$c_{i j} \quad$ : Custo de percorrer o trecho que vai do cliente $i$ ao cliente $j$.

$S \quad$ : Subconjunto de arcos.

$v(S)$ : Limite inferior apropriado sob a quantidade de veículos necessários para visitar todos os arcos de $S$ na solução ótima.

$x_{i j}$ : A variável binária que assume o valor 1 quando os clientes $i$ e $j$ são visitados , 0 em caso contrário.

Para atender outras exigências dos problemas reais, foram introduzidas várias variáveis, tais como:

a) Frota heterogênea; 
b) Demanda determinística e estocástica;

c) Janelas de tempo para o atendimento a cada cliente;

d) Restrições nos arcos (um só sentido ou dois sentidos) e;

e) Tipo de operação (coleta, entregue e/ou coleta-entrega), dentre outros.

A inclusão dessa série de variáveis e do aumento dos dados de entrada no PRV tem tornado esse problema ainda mais complexo, interessante e desafiador. No entanto, isso tem demandado mais esforços no sentido de desenvolver novas heurísticas que atendam todas as restrições do modelo, assim como novos recursos computacionais que possibilitem sua execução e validação para a obtenção de soluções satisfatórias à realidade do problema formulado.

Neste trabalho se apresenta duas variantes do modelo PRV. O primeiro é o problema de roteirização operando com frota homogênea e o segundo é o problema de roteirização com janela de tempo.

\subsubsection{Problema de Roteirização Operando com Frota Homogênea}

De acordo com Sungur et al. (2006), este tipo de problema, também conhecido como o Problema de Roteirização de Veículo Capacitado (PRVC) busca minimizar o custo de transporte utilizando uma frota homogênea de veículos, com capacidade $(q)$, que presta serviço a um conjunto de clientes $(I)$.

A premissa do problema é que somente um veículo pode visitar a um cliente uma única vez. A continuação é apresentada a formulação matemática do modelo que minimiza o custo total obtido no processo de geração da melhor rota para o atendimento aos clientes.

Função Objetivo:

$$
\operatorname{Min} C T=\sum_{(i, j) \in A,} c_{i \neq j} x_{i j}
$$

Minimizar o custo total de roteirização 
Sujeito a:

- Restrição de roteirização dos veículos;

$$
\sum_{i=1}^{n} x_{i j}=1, \quad \forall j \in I, \quad j \neq 0
$$

- Restrição de roteirização dos veículos;

$$
\sum_{j=1}^{n} x_{i j}=1, \quad \forall i \in I, \quad i \neq 0
$$

- Restrição de rotas viáveis que terminam no depósito $j=0$;

$$
\sum_{i=1}^{n} x_{i j} \leq Q, \quad j=0
$$

- Restrição de rotas viáveis que começam no depósito $i=0$;

$$
\sum_{j=1}^{n} x_{i j} \leq Q, \quad i=0
$$

- Restrição de rotas viáveis na rede;

$$
u_{j}-u_{i}+q_{k}\left(1-x_{i j}\right) \geq d_{j}, \quad \forall i \neq 0 \in I, \quad j \neq 0 \in I
$$

- Restrição de demanda atendida pelo veículo;

$$
d_{i} \leq u_{i}, \quad \forall i \neq 0 \in I
$$

- Restrição de demanda atendida segundo a capacidade do veículo;

$$
u_{i} \leq q_{k}, \quad \forall i \neq 0 \in I, \quad k \in K
$$

- Restrição de não negatividade das variáveis;

$$
\begin{aligned}
& x_{i j} \in\{0,1\}, \quad \forall i, j \in I \\
& u_{i} \geq 0, \quad \forall i \neq 0 \in I
\end{aligned}
$$

Onde:

I: Conjunto de clientes incluído o depósito $0 ; i=0,1,2, \ldots, n$. 
$K$ : Conjunto de veículos $k$; onde $k=1,2, \ldots, k^{\prime}$.

$c_{i j}$ : Custo do arco que se inicia no cliente $i$ e termina no cliente $j$.

$d_{i}$ : Demanda dos clientes $i$; onde $i=1,2, \ldots, n$.

Q: Quantidade de veículos que compõem a frota.

$q_{k}:$ Capacidade dos veículos $k$.

$x_{i j}$ : Variável binária que assume o valor 1 quando os clientes $i$ e $j$ são visitados , 0 em caso contrario.

$u_{i}$ : Variável que representa o fluxo de veículos depois da visita do veículo ao cliente $i$.

\subsubsection{Problema de Roteirização de Veículos com Janelas de Tempo}

Outra variante do PRV é aquela conhecida como Problema de Roteirização de Veículos com Janelas de Tempo (PRVJT). Para otimizar o uso da frota de veículos com parada para o atendimento dos clientes que têm associado uma janela de tempo $\left[a_{i}, b_{i}\right]$, o PRVJT procura minimizar a quantidade de veículos e a distância de viagem percorrida, considerando a capacidade dos veículos e o tempo de serviço numa rede dirigida $G=$ $(I, A)$, onde 0 e $n+1$ representam o depósito (OMBUKI et at, 2006). O problema é formulado como segue:

Função Objetivo:

$$
\operatorname{Min} C T=\sum_{(i, j) \in A,} c_{i \neq j, i \neq 0, j \neq n+1, j \neq 0 ; k \in K} x_{i j k}
$$

Minimizar custo total de roteirização

Sujeito a:

- Restrição1, somente um veículo pode visitar a um cliente uma única vez;

$$
\sum_{j=1, k=1, i \neq j}^{n, k^{\prime}} x_{i j k}=1, \quad \forall i \in I, \quad i \neq 0, \quad i \neq n+1
$$

- Restrição 2, a capacidade do veículo não deve ser excedida; 
$\sum_{(i, j) \in A, i \neq j, i \neq 0, i \neq n+1} d_{i} x_{i j k} \leq q_{k}, \quad \forall k \in K$

- Restrição3, cada veículo deve sair do depósito para visitar um cliente;

$$
\sum_{(i, j) \in A, i \neq j, i=0} x_{i j k}=1, \quad \forall k \in K
$$

- Restrição 4, estabelece o equilíbrio do modelo;

$$
\sum_{i=1, i \neq h}^{I} x_{i h k}-\sum_{j=1, h \neq j}^{I} x_{h j k}=0, \quad h \in I, \quad k \in K, \quad h \neq 0, \quad h \neq n+1
$$

- Restrição 5, estabelece que cada veículo deve retornar ao depósito;

$$
\sum_{(i, j) \in A, i \neq j, i \neq 0, j=n+1} x_{i j k}=1, \quad \forall k \in K
$$

- Restrição 6, o veículo $k$ somente pode ir onde o cliente $j$, se ele já visitou ao cliente $i$;

$$
y_{i k}+t_{i j}-M\left(1-x_{i j k}\right) \leq y_{j k}, \quad(i, j) \in A, k \in K, i \neq 0, i \neq n+1, i \neq j
$$

- Restrição 7, estabelece o limite inferior da janela de tempo para cada cliente;

$$
y_{i k} \geq a_{i}, \quad \forall i \in I, \quad k \in K, \quad i \neq 0, \quad i \neq n+1
$$

- Restrição 8, estabelece o limite superior da janela de tempo para cada cliente;

$$
y_{i k} \leq b_{i}, \quad \forall i \in I, \quad k \in K, \quad i \neq 0, \quad i \neq n+1
$$

- Restrição de não negatividade das variáveis;

$$
\begin{aligned}
& x_{i j} \in\{0,1\}, \quad \forall i, j \in I \\
& y_{k i} \geq 0, \quad \forall i \in I, \quad k \in K
\end{aligned}
$$

Onde:

I : Conjunto de clientes incluído o depósito $0 ; i=0,1,2, \ldots, n$.

$K$ : Conjunto de veículos que compõem a frota, onde $k=1,2, \ldots, k^{\prime}$.

$c_{i j}:$ Custo do arco que se inicia no nó i e termina no nó j. 
$d_{i}$ : Demanda dos clientes $i$.

$q_{k}:$ Capacidade dos veículos $k$

$t_{i j}$ : Tempo de percurso do arco entre os nós (clientes) $i$ e $j$.

$a_{i}$ : Limite inferior de tempo para o atendimento do cliente $i$

$b_{i} \quad$ : Limite superior de tempo para o atendimento do cliente $i$.

$x_{i j k}$ : Variável binária que assume o valor 1 se o veículo $k$ for atribuído para a rota selecionada, 0 caso contrário.

$y_{i k}$ : Variável inteira que estabelece que o veículo $k$ começa o atendimento no cliente $i$.

\subsection{MODELOS UTILIZADOS NOS PROBLEMAS DE REDES LOGÍSTICAS}

Uma proposta baseada num modelo de programação inteira mista não linear para o desenho de rede logística de distribuição integrada (direta e reversa) foi apresentada em (JEUNG, 2005). Neste modelo a função objetivo minimiza os custos totais, que representam os custos operacionais, os custos de funcionamento das facilidades fornecidas e os custos de fluxos diretos e reversos. A técnica de solução desenvolvida para solucionar o problema é um algoritmo genético.

Srivastava (2008) apresenta no nível metodológico uma estrutura conceitual combinando a modelagem descritiva com as técnicas de otimização para abordar o problema de logística reversa. Dessa forma, formula um modelo conceitual de logística reversa baseado em multiperíodo e com agregação de valor ao sistema (Figura 3.2).

O modelo está fundamentado em três níveis:

a) Retorno dos produtos pós-venda e pós-consumo;

b) Captação desses produtos nos centros de coleta;

c) Transporte desses produtos aos centros de manutenção e remodelação ou aos centros de manufatura. 
Figura 3.2- Modelo conceitual de logística reversa

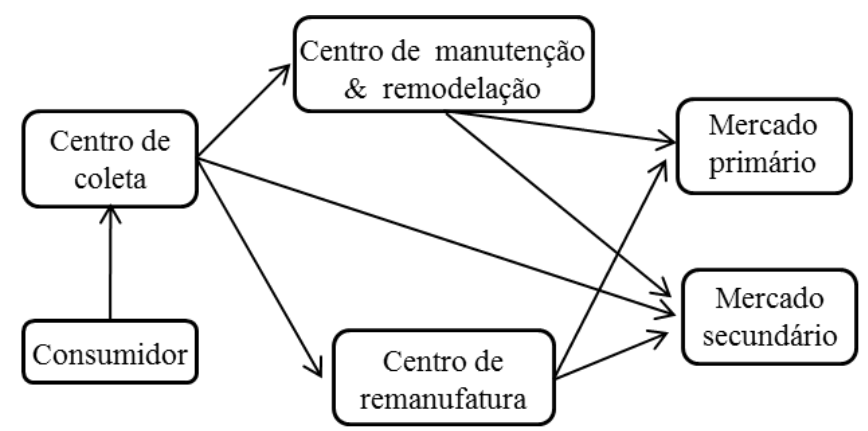

Fonte: Srivastava (2008)

A proposta de Srivastava (2008) parte do princípio que os consumidores retornam os produtos pós-venda e pós-consumo (aqueles factíveis de reciclagem) para os centros de coleta, ou seja, não existe coleta domiciliar. Nos centros de coleta, esses produtos passam por uma triagem e dependendo da sua avaliação, eles podem ser transportados para os centros de manutenção e remodelação (produtos para serem reparados e/ou reciclados) ou para os centros de manufatura (produtos com defeitos de fábrica para serem de novo manufaturados).

Desses locais, os produtos resultantes são encaminhados para os mercados primários ${ }^{21} \mathrm{e}$ secundários $^{22}$ para sua revenda. Ainda, existe a possibilidade de transportar certos produtos coletados nos centros de coleta diretamente ao mercado secundário, ou seja, produtos que não precisam de nenhum processamento, que ainda estão em bom estado e que podem ser vendidos diretamente no mercado.

A partir desse modelo conceitual, Srivastava (2008) propõe um modelo de programação linear inteira mista baseada na hierarquia das entidades participantes, ou seja, um modelo de otimização hierárquico (Figura 3.3). Assim, no seu modelo, ele procura primeiro minimizar os custos de investimentos de localização de centros de coleta sujeito a restrições de estratégias definidas previamente no problema e de acordo com as exigências dos clientes em ambos mercados. Já na otimização principal, o objetivo é a maximização dos lucros de transportar os produtos coletados para os centros de manutenção e remodelação, ou para os centros de manufatura, para posteriormente serem revendidos nos mercados primário ou secundário.

\footnotetext{
${ }^{21}$ Os mercados primários são aqueles onde se vendem produtos novos ou seminovos.

${ }^{22}$ Os mercados secundários vendem produtos reparados e/ou recuperados.
} 
Figura 3.3- Modelo de otimização hierárquico

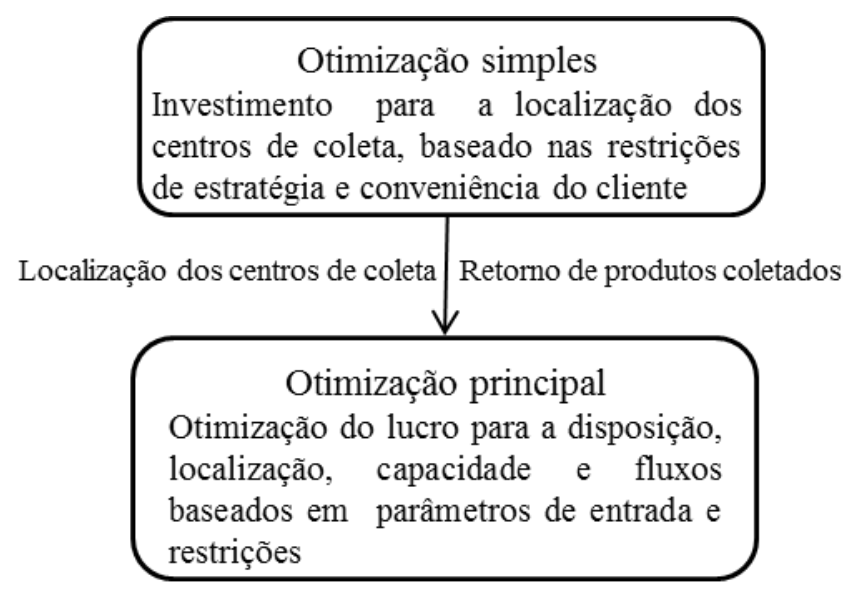

Fonte: Srivastava (2008)

\subsubsection{Modelo de Lee J. et al (2008)}

Um modelo de programação linear que minimiza o custo total para o transporte em uma rede de logística reversa foi proposto por Lee J. et al (2008). O modelo compreende três etapas:

- Etapa 1. Os RSU coletados nas estações de coleta (ec) são transportados para os centros de triagem $(c d)$.

- Etapa 2. Nos centros de triagem ( $c d$ ) é realizada uma classificação dos RSU sob três critérios, RSU que podem ser reutilizados são transportados para os centros de reciclagem ( $r$; RSU que precisarem de algum processo então são transportados para os centros de transformação $(c t)$ e; aqueles resíduos sem valor são transportados para os centros de eliminação $(e)$.

- Etapa 3. Os RSU processados nos centros de transformação (ct) são transportados para as fábricas $(f)$. Nesta etapa mantêm-se a seguinte premissa, se a quantidade de matéria-prima $(m)$ que vem dos centros de transformação $(c t)$ é menor do que a demanda das fábricas $(f)$, então estas devem comprar essa matéria prima de seus outros fornecedores. Mas se existe matéria-prima suficiente para atender a demanda das fábricas então, não se faz necessário os outros fornecedores. No entanto, o excesso deve ser distribuído aos centros de reciclagem $(r)$ e/ou centros de eliminação $(e)$. 
Na Figura 3.4 exibe-se a Rede Logística Reversa A proposta nesse modelo, cada nó mostra as capacidades de oferta e/ou demanda de cada unidade produtiva componente do processo logístico reverso. E a continuação apresenta-se a formulação matemática do referido modelo.

Figura 3.4 - Rede Logística Reversa A e as capacidades de oferta e/ou demanda de cada unidade produtiva

(1000

(p)

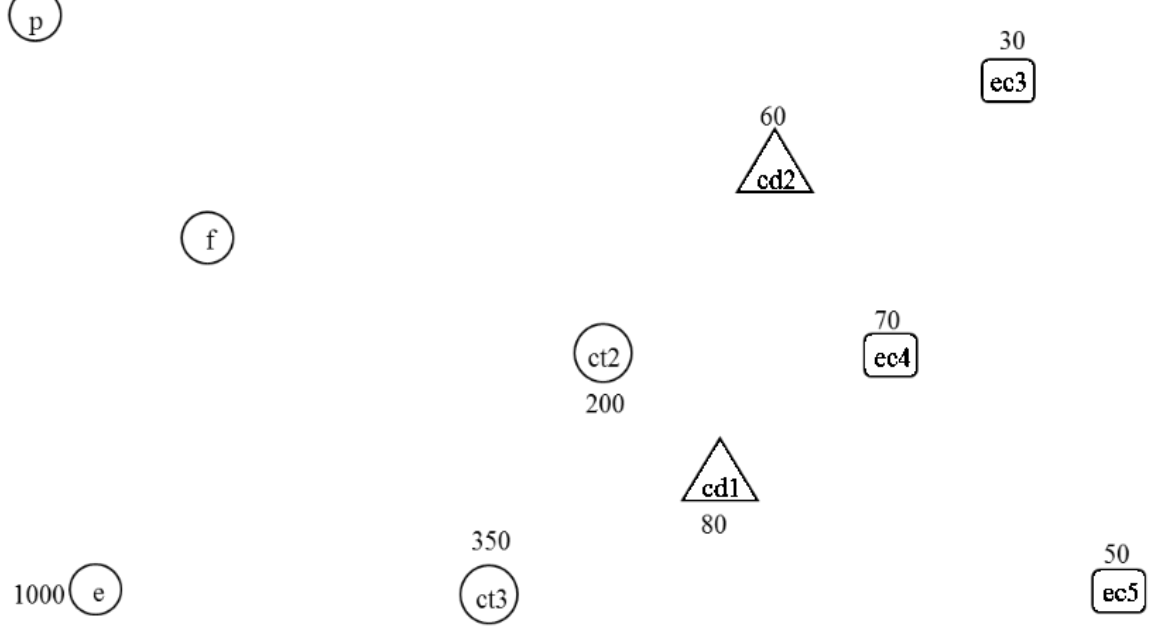

$\overbrace{\mathrm{cd} 3}^{110}$

(ct1) ecl

ec2

Fonte: Lee J. et al (2008)

Função Objetivo:

$$
\begin{aligned}
\operatorname{Min} C T= & \sum_{e c=1}^{n} \sum_{c d=1}^{n^{\prime}} c_{e c, c d} x_{e c, c d}+\sum_{c d=1}^{n^{\prime}} \sum_{c t=1}^{n^{\prime \prime}} \sum_{m=1}^{m \prime} c 1_{c d, c t, m} x 1_{c d, c t, m} \\
& +\sum_{c d=1}^{n^{\prime}} \sum_{m=1}^{m^{\prime}} c 2_{c d, r, m} x 2_{c d, r, m}+\sum_{c d=1}^{n^{\prime}} \sum_{m=1}^{m^{\prime}} c 3_{c d, e, m} x 3_{c d, e, m} \\
& +\sum_{c t=1}^{n^{\prime \prime}} \sum_{m=1}^{m^{\prime}} c 4_{c t, f, m} x 4_{c t, f, m}+\sum_{c t=1}^{n^{\prime \prime}} \sum_{m=1}^{m \prime} c 5_{c t, r, m} x 5_{c t, r, m}
\end{aligned}
$$




$$
+\sum_{c t=1}^{n^{\prime \prime}} \sum_{m=1}^{m \prime} c 6_{c t, e, m} x 6_{c t, e, m}+\sum_{m=1}^{m \prime} c 7_{p, f, m}
$$

Minimizar os custos totais de transporte dos resíduos sólidos coletados e inseridos no processo reverso desde as estações de coleta até o último componente da cadeia reversa

\section{Sujeito a:}

- Restrição 1, o fluxo total de carga (x) que sai de cada estação de coleta (ec) para os centros de triagem $(c d)$ deve ser menor ou igual que sua capacidade de armazenamento $(a)$;

$$
\sum_{e c=1}^{n} x_{e c, c d} \geq a_{e c}, \quad \forall e c \in E C
$$

- Restrição 2, o fluxo total de carga ( $x$ ) de todos os produtos $(m)$ que sai de cada centro de triagem $(c d)$ deve ser menor ou igual que sua capacidade de armazenamento $(b)$;

$$
\sum_{c d=1}^{n^{\prime}}\left(x 1_{c d, c t, m}+x 2_{c d, r, m}+x 3_{c d, e, m}\right) \leq b_{c d}, \quad \forall c d \in C D, \quad m \in M
$$

- Restrição 3, o fluxo total de carga ( $x$ ) de todos os produtos $(m)$ que sai de cada centro de transformação $(c t)$ deve ser menor ou igual que sua capacidade de armazenamento $(u)$;

$$
\sum_{c t=1}^{n^{\prime \prime}}\left(x 4_{c t, f, m}+x 5_{c t, r, m}+x 6_{c t, e, m}\right) \leq u_{c t, m}, \quad \forall m \in M
$$

- Restrição 4, a oferta de matéria-prima vindo do fornecedor (p) para a fábrica mais o somatório da oferta vindo dos centros de transformação $(c t)$ tem que ser maior ou igual à demanda da fábrica por essa determinada matéria-prima $(m)$;

$$
x 7_{p, f, m}+\sum_{c t=1}^{n^{\prime \prime}} x 4_{c t, f, m} \geq d_{m}, \quad \forall m \in M
$$

- Restrição de não negatividade das variáveis;

$$
x_{e c, c d}, x 1_{c d, c t, m}, x 2_{c d, r, m}, x 3_{c d, e, m}, x 4_{c t, f, m}, x 5_{c t, r, m}, x 6_{c t, e, m}, x 7_{p, f, m} \geq 0
$$


Ainda, para este modelo foram acrescentadas duas novas restrições para manter o equilíbrio no fluxo de transporte dos resíduos coletados.

$$
\begin{gathered}
\sum_{e c=1}^{n} x_{e c, c d}=\sum_{c t=1}^{n^{\prime \prime}} x 1_{c d, c t}, \quad \forall c d \in C D \\
\sum_{c d=1}^{n^{\prime}} x 1_{c d, c t}=\sum_{e=1}^{e \prime} x 5_{c t, e}, \quad \forall c t \in C T
\end{gathered}
$$

Onde:

EC : Conjunto de estações de coleta, $e c=1,2, \ldots, n$.

$C D \quad$ : Conjunto de centros de triagem, $c d=1,2, \ldots, n^{\prime}$.

CT : Conjunto de centros de transformação, $c t=1,2, \ldots, n "$.

$M \quad$ : Conjunto de matérias primas, $m=1,2, \ldots, m^{\prime}$.

CR : Conjunto de centros de reciclagem, $\mathrm{r}=1,2, \ldots, r^{\prime}$.

$a_{e c} \quad$ : Capacidade da estação de coleta $e c \in E C$.

$b_{c d} \quad:$ Capacidade do centro de triagem $c d \in C D$.

$u_{c t, m}:$ Capacidade do centro de transformação $c t \in C T$ para a matéria-prima $m \in M$.

$v_{r} \quad$ : Capacidade do centro de reciclagem $r \in C R$.

$d_{m} \quad$ : Demanda da fábrica $\mathrm{f} \in F$ em matéria-prima $m \in M$.

$c_{e c, c d}$ : Custo unitário de transporte da estação de coleta para o centro de triagem.

$c 1_{c d, c t, m}$ : Custo unitário de transporte da matéria prima $m$ do centro de triagem para o centro de transformação.

$c 2_{c d, r, m}$ : Custo unitário de transporte da matéria-prima $m$ do centro de triagem para o centro de reciclagem.

$c 3_{c d, e, m}$ : Custo unitário de transporte da matéria-prima $m$ do centro de triagem para o centro de eliminação.

$c 4_{c t, f, m}$ : Custo unitário de transporte da matéria-prima $m$ do centro de transformação para a fábrica. 
$c 5_{c t, r, m}$ : Custo de transporte da matéria-prima $m$ do centro de transformação para o centro de reciclagem.

$c 6_{c t, e, m}$ : Custo de transporte da matéria-prima $m$ do centro de transformação para o centro de eliminação.

$c 7_{p, f, m}$ : Custo unitário de transporte da matéria-prima $m$ do provedor para a fábrica $f$.

$x_{e c, c d}$ : Quantidade transportada da estação de coleta para o centro de triagem.

$x 1_{c d, c t, m}$ : Quantidade transportada do centro de triagem para o centro de transformação.

$x 2_{c d, r, m}:$ Quantidade transportada do centro de triagem para o centro de reciclagem.

$x 3_{c d, e, m}$ : Quantidade transportada do centro de triagem para o centro de eliminação.

$x 4_{c t, f, m}$ : Quantidade transportada do centro de transformação para a fábrica.

$x 5_{c t, r, m}$ : Quantidade transportada do centro de transformação para o centro de reciclagem.

$x 6_{c t, e, m}$ : Quantidade transportada do centro de transformação para o centro de eliminação.

$x 7_{p, f, m}:$ Quantidade transportada do fornecedor $(p)$ para a fábrica.

\subsubsection{Modelo de Saman et al (2009)}

Para resolver o modelo de logística reversa, Saman et al (2009) propõem um modelo de programação linear inteira mista para otimizar os custos de transporte e custos fixos de funcionamento das diferentes unidades produtivas que compõem a rede logística reversa. $\mathrm{O}$ modelo permite também, determinar o número necessário das diferentes unidades produtivas que compõem a rede.

O modelo desses autores também funciona em várias etapas: os RSU são entregues nos centros de atenção ao cliente $(l)$, que depois são enviadas as estações de coleta $(e c)$. Nas estações de coleta se realiza uma triagem. Os RSU's com possibilidades de serem reciclados ou recuperados são enviados aos centros de recuperação $(c r)$ e aqueles que não tem mais utilidade são encaminhados aos centros de eliminação (e). Uma estrutura da rede apresenta-se na Figura 3.5. 
Devido à complexidade do problema os autores fazem uso da metaheurística simulated annealing para obter soluções. O modelo matemático procura otimizar a rede logística reversa, buscando atender a demanda dos clientes que descartam seus RSU no sistema. O modelo de otimização trata de determinar, em função das capacidades estabelecidas ás unidades produtivas da rede, o número de unidades necessária de cada uma delas, assim como as quantidades de volume de carga que deve sair de cada uma delas de forma a minimizar os custos de transporte na rede. O modelo matemático proposto por Saman et al (2009) é explanado a seguir.

Figura 3.5 - Rede Logística Reversa A e as capacidades de oferta e/ou demanda de cada unidade produtiva

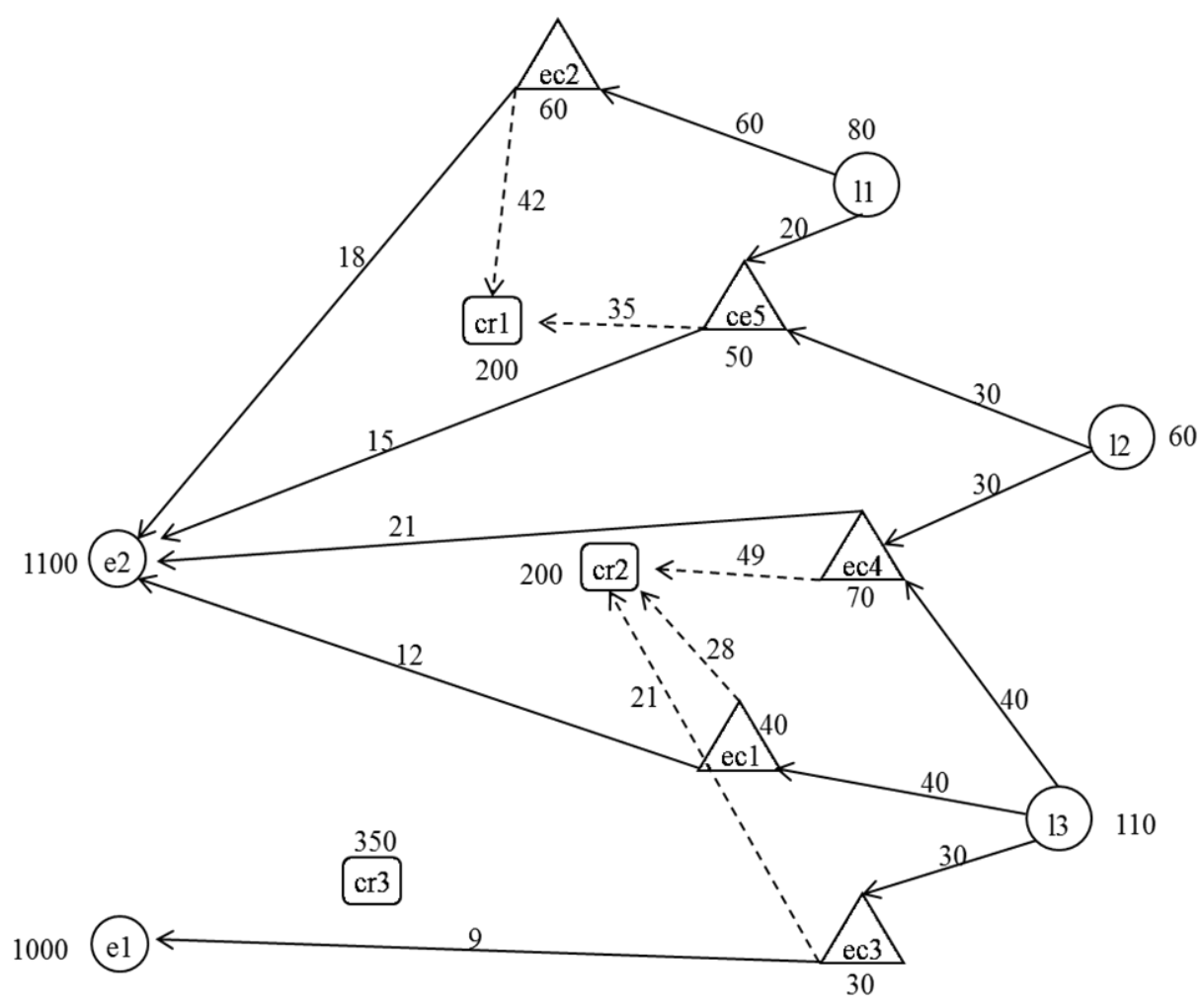

Fonte: Saman et al (2009)

Função Objetivo:

$$
\operatorname{Min} C T=\sum_{e c=1}^{n} f_{e c} y_{e c}+\sum_{l=1}^{l \prime} \sum_{e c=1}^{n} c f_{l, e c} x_{l, e c}
$$




$$
+\sum_{e c=1}^{n} \sum_{c r=1}^{r^{\prime \prime}} c s_{e c, c r} z_{e c, c r}+\sum_{e c=1}^{n} \sum_{e=1}^{e^{\prime}} c t_{e c, e} w_{e c, e}
$$

Minimizar os custos totais da instalação das estações de coleta, os custos de transporte entre os centros de atenção ao cliente, estações de coleta, de recuperação e de eliminação.

Sujeito a:

- Restrição 1, o volume de carga $(x)$ que é transportado dos centros de atenção ao cliente $(l)$ às estações de coletas $(e c)$ é igual ao volume $(r)$ coletados nos $(l)$;

$$
\sum_{e c=1}^{n} x_{l, e c}=r_{l}, \quad \forall l \in A
$$

- Restrição 2, o fluxo total de carga (z) que chega aos centros de recuperação (cr) é igual ao fluxo total de carga $(x)$ que sai dos centros de atenção ao cliente $(l)$ para as estações de coleta (ec) menos o fluxo de carga que é enviado aos centros de eliminação $(e)$, é uma restrição de equilíbrio de fluxo;

$$
\sum_{c r=1}^{r^{\prime \prime}} z_{e c, c r}=(1-d) \sum_{l=1}^{l^{\prime}} x_{l, e c}, \quad \forall e c \in E C
$$

- Restrição 3, o fluxo total de carga (w) que chega aos centros de eliminação (e) é igual ao volume médio dos resíduos classificados como não recuperáveis vindo dos centros de atenção ao cliente, é outra restrição de equilíbrio de fluxo;

$$
\sum_{e=1}^{e \prime} w_{e c, e}=d \sum_{l=1}^{l \prime} x_{l, e c}, \quad \forall e c \in E C
$$

- Restrição 4, o fluxo total de carga $(x)$ que sai dos centros de atenção ao cliente $(l)$ não deve exceder a capacidade das estações de coleta $(c c)$;

$$
\sum_{l=1}^{l \prime} x_{l, e c} \leq y_{e c} c c_{e c}, \quad \forall e c \in E C
$$

- Restrição 5, o fluxo total de carga (z) que sai das estações de coleta (ec) não deve exceder a capacidade dos centros de recuperação $(c r)$; 


$$
\sum_{e c=1}^{n} z_{e c, c r} \leq c r_{c r}, \quad \forall c r \in C R
$$

- Restrição 6, o fluxo total de carga (w) que sai das estações de coleta (ec) não deve exceder a capacidade dos centros de eliminação $(c e)$;

$$
\sum_{e c=1}^{n} w_{e c, e} \leq c e_{e}, \quad \forall e \in C E
$$

- Restrições de não negatividade das variáveis;

$$
\begin{aligned}
& x_{l, e c}, z_{e c, c r}, w_{e c, e} \geq 0, \quad \forall e c \in E C, c r \in C R, e \in C E, l \in A \\
& y_{e c} \in\{0,1\}, \quad \forall e c \in E C
\end{aligned}
$$

Onde:

EC : Conjunto de estações de coleta, $e c=1,2, \ldots, n$.

CR : Conjunto de centros de recuperação, $c r=1,2, \ldots, r^{\prime \prime}$.

CE : Conjunto de centros de eliminação, $e=1,2, \ldots, e^{\prime}$.

$A \quad$ : Conjunto de centros de atenção aos clientes, $l=1,2, \ldots, l^{\prime}$.

$d \quad$ : Percentagem do valor médio dos resíduos eliminados, ou seja, é aquele volume que as estações de coleta enviam para os centros de eliminação.

$r_{l} \quad$ : Quantidade de resíduos coletados nos centros de atenção ao cliente.

$f_{e c}$ : Custo fixo das estações de coleta.

$c f_{l, e c}$ : Custo de transporte dos resíduos movimentados do centro de atenção ao cliente para a estação de coleta.

$c s_{e c, c r}$ : Custo de transporte do resíduo recuperável da estação de coleta para o centro de recuperação.

$c t_{e c, e}$ : Custo de transporte dos resíduos em valor da estação de coleta para o centro de eliminação.

$c c_{e c}$ : Capacidade da estação de coleta.

$c r_{c r}$ : Capacidade do centro de recuperação. 
$c e_{e} \quad$ : Capacidade do centro de eliminação

$x_{l, e c}:$ Quantidade de resíduos transferidos do centro de atenção ao cliente para a estação de coleta.

$Z_{e c, c r}:$ Quantidade de resíduos transferidos da estação de coleta para o centro de recuperação.

$w_{e c, e}:$ Quantidade de resíduos sem valor transferidos da estação de coleta para o centro de eliminação.

$y_{e c}$ : Variável binária que assume valor 1 se a estação de coleta $e c$ for aberta ou 0 se não.

\subsection{MODELOS UTILIZADOS NOS PROBLEMAS DE LOGISTICA URBANA}

Como já foi enfatizada, a escolha dos modelos foi realizada em função da contribuição que estes podem dar a modelagem do problema proposto nessa tese. Assim, somente foram escolhidos dois modelos, o de Sterle (2010) e o de Qureshi et al (2010). Eles são explicados nos itens seguintes.

\subsubsection{Modelo de Sterle (2010)}

Sterle (2010) explica que é possível desenvolver um sistema de logística urbana em dois níveis, baseando-se numa extensão do PRV. O modelo consiste em concentrar a carga que chega para a área urbana em um determinado conjunto de plataformas $(C P)$, localizadas no cordão externo (limítrofe) da área urbana. Nessas plataformas ( $p)$ a carga é classificada segundo a localização geográfica do destinatário da carga e distribuída a um conjunto de centros menores $(C S)$ localizados nos bairros ou distritos pertencentes à área urbana. Esses centros são denominados pelo autor como unidades satélites $(s)$. Dessas unidades a carga passa a ser entregue a seus respectivos donos ou clientes $(c c)$, tal como se mostra na Figura 3.6.

Conforme Sterle (2010) o primeiro nível da rede compreende a distribuição da carga desde as plataformas até as unidades satélites, utilizando veículos de carga de maior porte (g). E 
o segundo nível, consiste em montar rotas desde estas unidades satélites até os clientes, usando para este caso veículos de menor porte (v). Assim, o modelo de localização e roteirização de veículos para a distribuição de carga proposto pelo autor, além de fazer a conexão dos dois níveis e estudar sua inter-relação e dependência, o modelo procura determinar a quantidade necessária de plataformas e de unidades satélites considerando o tamanho e dimensionamento da frota para a roteirização nos dois níveis.

Figura 3.6 - Estrutura de uma rede em dois níveis

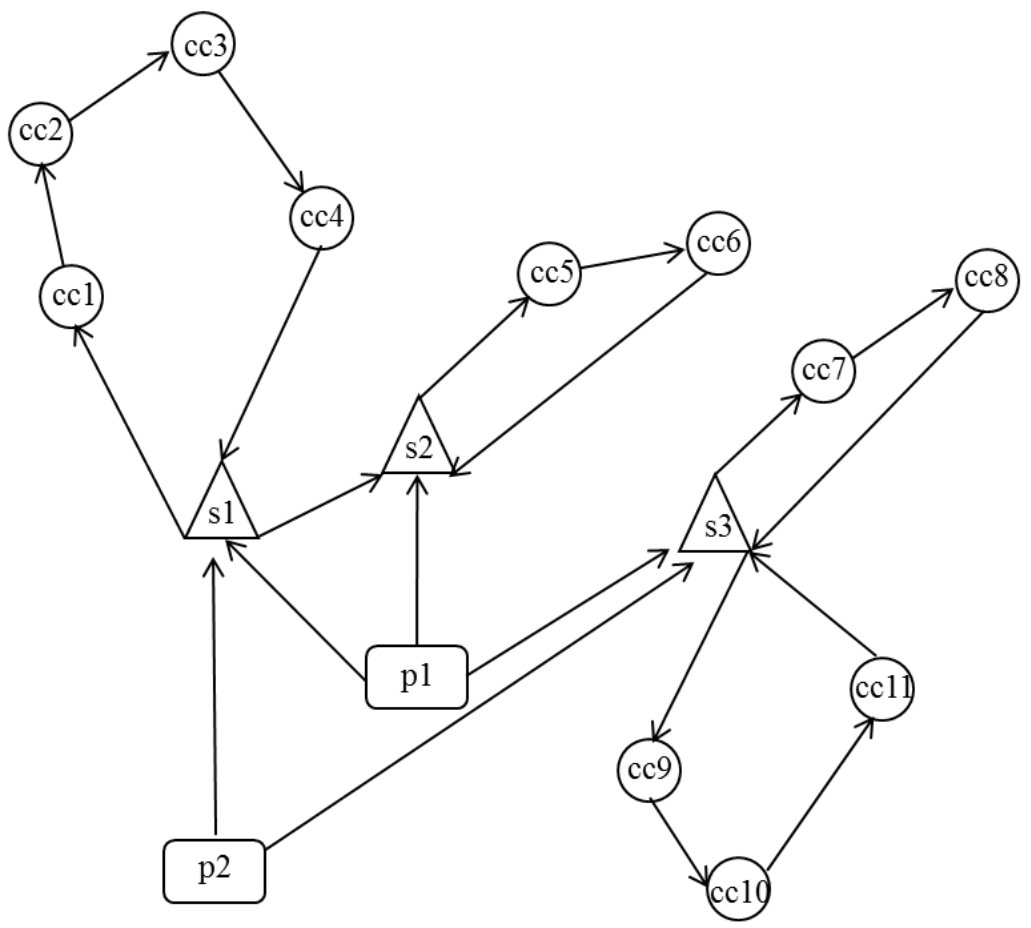

Fonte: Sterle (2010)

Devido a natureza combinatória do problema tem-se uma complexidade computacional para resolver o modelo, assim observa-se que quando mais componentes ou variáveis são acrescentados, o tempo de processamento para encontrar uma solução vai ficando bem maior. Dessa forma, Sterle (2010) propõe uma meta heurística (busca tabu) que resolve o problema em pouco tempo computacional, mas não garante que a solução seja ótima. $\mathrm{O}$ modelo matemático proposto pelo autor é definido a seguir.

Função Objetivo:

$$
\operatorname{Min} C T=\sum_{p \in C P} c 1_{p} Y 1_{p}+\sum_{s \in C S} c 2_{s} Y 2_{s}+\sum_{g \in G} c 3_{g} Z 1_{g}+\sum_{v \in V} c 4_{v} Z 2_{v}+
$$


$\sum_{i \in E 2, j \in E 2, v \in V: i \neq j} c 6_{i, j} x 2_{i, j, v}+\sum_{i \in E 1, j \in E 1, g \in G: i \neq j} c 5_{i, j} x 1_{i, j, g}$

Minimizar os custos de instalação das plataformas e das unidades satélites, os custos fixos dos veículos (v) e (g) e os custos de transporte nos dois níveis

Sujeito a:

- Restrição 1, cada cliente é atendido somente por um veículo menor (v) pertencente ao nível E2;

$$
\sum_{v \in V, j \in E 2: c c \neq j} X 2_{c c, j, v}=1, \quad \forall c c \in C C
$$

- Restrição 2, esta restrição estabelece o equilíbrio em cada ponto de entrega ao cliente, ou seja, todo veículo (v) que visita um cliente tem que obrigatoriamente sair depois do atendimento;

$$
\sum_{m \in E 2, m \neq j} X 2_{m, j, v}-\sum_{m \in E 2: j \neq m} X 2_{j, m, v}=0, \quad \forall j \in E 2, \quad v \in V
$$

- Restrição 3, elimina os possíveis subciclos que podem acontecer no processo de roteirização dos clientes;

$$
L 1_{i, v}-L 1_{j, v}+C C . X 2_{i, j, v} \leq C C-1, \quad \forall c c \in C C, j \in C C, \quad v \in V: i \neq j
$$

- Restrição 4, estabelece a existência de uma rota realizada por um veículo menor (v) atribuído a uma unidade satélite;

$$
\sum_{m \in E 2, j \in C S: m \neq j} X 2_{m, j, v} \leq 1, \quad \forall v \in V
$$

- Restrição 5, estabelece a existência de rotas no nível E1 se tiver unidades satélites abertas;

$$
\sum_{g \in G, j \in E 1: m \neq j} X 1_{m, j, g}=Y 2_{m}, \forall m \in C S
$$

- Restrição 6, esta restrição estabelece o equilíbrio em cada unidade satélite, ou seja, todo veículo $(g$ ) que visita uma unidade tem que obrigatoriamente sair depois do atendimento; 


$$
\sum_{m \in E 1: m \neq h} X 1_{m, h, g}-\sum_{m \in E 1, h \neq m} X 1_{h, m, g}=0, \quad \forall h \in E 1, g \in G(3.50)
$$

- Restrição 7, elimina os possíveis subciclos que podem acontecer no processo de roteirização das unidades satélites;

$$
L 2_{i, g}-L 2_{j, g}+C S . X 1_{i, j, g} \leq C S-1, \quad \forall i, j \in C S, g \in G, i \neq j
$$

- Restrição 8, constitui a existência de uma rota no nível 1 realizada por um veículo maior ( $g$ ) atribuído a uma plataforma;

$$
\sum_{m \in E 1, j \in C P: m \neq j} X 1_{m, j, g} \leq 1, \quad \forall g \in G
$$

- Restrição 9, estabelece o enlace entre a alocação de clientes a uma unidade satélite e o processo de roteirização;

$$
\sum_{h \in E 2: c c \neq h} X 2_{c c, h, v}+\sum_{h \in E 2: s \neq h} X 2_{s, h, v}-X 3_{s, c c} \leq 1, \forall c c \in C C, v \in V, s \in C S
$$

- Restrição 10, cada cliente deve ser atribuído a uma unidade satélite;

$$
\sum_{s \in C S} X 3_{s, c c}=1, \quad \forall c c \in C C
$$

- Restrição 11, estabelece o equilíbrio de fluxo de carga nas unidades satélites;

$$
\sum_{p \in C P, g \in G} F_{p, s, g}-\sum_{c c \in C C} d_{c c} X 3_{s, c c}=0, \quad \forall s \in C S
$$

- Restrição 12, o fluxo de carga que sai da plataforma deve menor ou igual que sua capacidade de armazenamento;

$$
\sum_{s \in C S, g \in G} F_{p, s, g}-k 1_{p} Y 1_{p} \leq 0, \quad \forall p \in C P
$$

- Restrição 13, o fluxo de carga que chega às unidades satélites tem que ser menor ou igual que sua capacidade de armazenamento; 


$$
\sum_{p \in C P, g \in G} F_{p, s, g}-k 2_{s} Y 2_{s} \leq 0, \quad \forall s \in C S
$$

- Restrição 14, garante que a carga que sai da plataforma chega à unidade satélite utilizando o mesmo veículo $(g)$;

$$
\begin{aligned}
& k 3_{g} \sum_{h \in E 1: s \neq h} X 1_{s, h, g}-F_{p, s, g} \geq 0, \quad \forall g \in G, s \in C S, p \in C P \\
& k 3_{g} \sum_{h \in E 1: p \neq h} X 1_{p, h, g}-F_{p, s, g} \geq 0, \quad \forall g \in G, s \in C S, p \in C P
\end{aligned}
$$

- Restrição 15, a carga alocada ao veículo (v) deve menor ou igual à sua capacidade;

$$
\sum_{c c \in C C} d_{c c} \sum_{j \in E 2: c c \neq j} X 2_{c c, j, v} \leq k 4_{v} Z 2_{v}, \quad \forall v \in V
$$

- Restrição 16, a quantidade de carga transferida pelo veículo $(g)$ deve menor que sua capacidade;

$$
\sum_{p \in C P, s \in C S} F_{p, s, g} \leq k 3_{g} Z 1_{g}, \quad \forall g \in G, v \in V
$$

- Restrições de não negatividade das variáveis;

$$
\begin{aligned}
& X 1_{i, j, g}, \in\{0,1\}, \quad \forall i, j \in E 1, g \in G \\
& X 2_{i, j, v} \in\{0,1\}, \quad \forall i, j \in E 2, v \in \\
& X 3_{s, c c}, \in\{0,1\}, \quad \forall s \in C S, c c \in C C \\
& Y 1_{p}, \in\{0,1\}, \quad \forall p \in C P \\
& Y 2_{s}, \in\{0,1\}, \quad \forall s \in C S \\
& Z 1_{g}, \in\{0,1\}, \quad \forall g \in G \\
& Z 2_{v}, \in\{0,1\}, \quad \forall v \in V \\
& F_{p, s, g} \geq 0, \quad \forall p \in C P, s \in C S, g \in G
\end{aligned}
$$


Onde:

CP : Conjunto de plataformas, $p=1,2, \ldots, p^{\prime}$.

CS : Conjunto de satélites, $s=1,2, \ldots, s^{\prime}$.

CC : Conjunto de clientes, $c c=1,2, \ldots, c^{\prime}$.

$G \quad$ : Conjunto de veículos maiores alocados às plataformas, $g=1,2, \ldots, g^{\prime}$.

$V \quad$ : Conjunto de veículos menores alocados às unidades satélites, $v=1,2, \ldots, v^{\prime}$.

$E 1=C P \cup C S:$ Nível 1.

E2 $=C S \cup C C:$ Nível 2.

$c 1_{p} \quad$ : Custo pelo funcionamento da plataforma.

$c 2_{s} \quad$ : Custo pelofuncionamento da unidade satélite.

$c 3_{g} \quad$ : Custo pelo uso do veículo $(g)$.

$c 4_{v} \quad$ : Custo pelo uso do veículo (v).

$c 5_{i, j} \quad$ : Custo de transporte no primeiro nível E1.

$c 6_{i, j} \quad$ : Custo de transporte no segundo nível E2.

$k 1_{p} \quad$ : Capacidade da plataforma $(p)$

$k 2_{s} \quad$ : Capacidade da unidade satélite $(s)$

$k 3_{g} \quad$ : Capacidade do veículo $(g)$.

$k 4_{v} \quad:$ Capacidade do veículo (v).

$d_{c c} \quad$ : Demanda do cliente $(c c)$

$X 1_{i, j, g}$ : Variável binária que assume o valor 1 se acontece roteirização no nível E1.

$X 2_{i, j, v}:$ Variável binariaque assume o valor 1 se existe roteirização no nível E2.

$X 3_{c c, s}$ : Variável binária que assume o valor 1se o cliente for atribuído para uma unidade satélite ou 0 , caso contrário.

$Y 1_{p} \quad$ : Variável binária que assume o valor 1 se uma plataforma for aberta.

$Y 2_{s} \quad$ : Variável binária que assume o valor 1 se uma unidade satélite for aberta.

$Z 1_{g}$ : Variável binária que assume o valor 1 se o veículo $(g)$ for usado, ou 0 se não. 
$Z 2_{v} \quad$ : Variável binária que assume o valor 1 se o veículo $(v)$ for usado, ou 0 se não.

$F_{p, s, g} \quad$ : Variável que representa a quantidade de produtos transportado da plataforma para a unidade satélite com o veículo $(g)$.

$L 1_{c c, v} \geq 0$ : Variável usada para a eliminação de subciclos no processo de roteirização do conjunto de clientes.

$L 2_{s, g} \geq 0$ : Variável usada para a eliminação de subciclos no processo de roteirização do conjunto das unidades satélites.

\subsubsection{Modelo de Qureshi et al (2010)}

O Modelo de Qureshi et al (2010) é uma variante do Problema de Roteirização e Programação de Veículos com Janelas de Tempo (PRVPJT) conhecido como o Problema de Roteirização e Programação de Veículos com Janelas de Tempo Meio Suave (PRVPJTMS). O modelo proposto pelo referido autor aplica penalidade ao veículo quando este se atrasa e chega depois do tempo estabelecido na janela de tempo do cliente.

A representação matemática do modelo de Qureshi et al (2010), apresentado abaixo, é semelhante ao PRVJT discutido na subsecção 3.1.2, mas a janela de tempo $\left[a_{i}, b_{i}\right]$ é estendida para $\left[a_{i}, b_{i}^{\prime}\right]$, onde $b_{i}<b_{i}^{\prime}$. Assim, o novo limite da janela de tempo está definido por:

$$
b_{i}^{\prime}=\min \left[b_{0}-t_{i 0}, b_{i}+\frac{c_{0 i}+c_{i 0}}{c_{l}}\right]
$$

Onde $\mathrm{c}_{l}$ representa a penalidade devido a um atraso na chegada. $\mathrm{O}$ custo da viagem é então definido por:

$$
c_{i j k}^{\prime}=\left\{\begin{array}{ccc}
c_{i j} & \text { se } & y_{i k} \leq b_{i} \\
c_{i j}+c_{l}\left(y_{i k}-b_{i}\right), & \text { se } & y_{i k}>b_{i}
\end{array}\right.
$$

Função Objetivo:

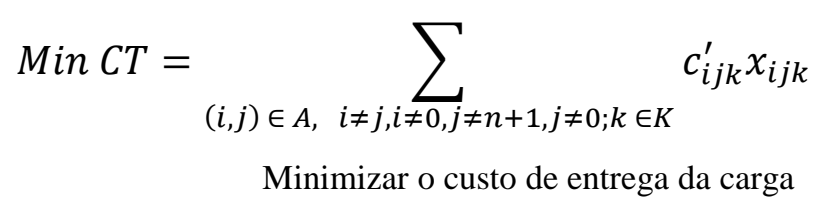


Sujeito a:

- Restrições de roteirização, Qureshi et al. (2010) utilizam as mesmas restrições expostas no item 3.1.2, ou seja, as do (PRVPJT) que correspondem as seguintes expressões;

$$
\text { (3.17), (3.18), (3.19), (3.20), (3.21), (3.22), (3.23) }
$$

- Restrição que estabelece o novo limite superior da janela de tempo;

$$
y_{i k} \leq b_{i}^{\prime}, \quad \forall i \in I, \quad k \in K, \quad i \neq 0, \quad i \neq n+1
$$

- Restrições de não negatividade das variáveis;

$$
\begin{aligned}
& x_{i j} \in\{0,1\}, \quad \forall i, j \in I \\
& y_{k i} \geq 0, \quad \forall i \in I, \quad k \in K
\end{aligned}
$$

\subsection{MODELO DE BADRAN (2006) PARA GESTÃO DE RSU}

Conforme Badran (2006) o gerenciamento dos RSU compreende o gerenciamento de três grandes sistemas. O primeiro é relacionado ao sistema físico-operacional, que começa com a otimização do processo de coleta dos resíduos, continua com o tratamento adequado (reciclagem e/ou reutilização) até a disposição final dos mesmos, seguindo as normas ambientais exigidas.

O segundo sistema diz respeito aos aspectos institucionais, onde o gerenciamento deve considerar todos os agentes que participam direta e indiretamente em todos os processos de forma a garantir o funcionamento do sistema, qualidade do serviço, a preservação do meio ambiente e o bem-estar da comunidade. Isso inclui a forma de relacionamento e participação de todos, contemplando programas de conscientização e responsabilidade social. O terceiro sistema refere-se ao sistema jurídico e regulatório.

Quanto ao sistema físico-operacional há várias propostas para otimizar os processos e determinar a quantidade necessária de estações. Um modelo de programação linear inteira mista para a seleção das estações de coleta necessárias numa região urbana ou cidade foi proposta por (BADRAN, 2006). 
Ele divide a região urbana em zonas (z), os RSU que são coletados nessas zonas são transportados as estações de coleta (ec). Nesse local, os RSU passam por uma triagem, os que são plausíveis de recuperação ou de reciclagem são transportados para os centros de triagem $(c d)$ e o resto é transportado para os aterros $(a)$, tal como é representado na Figura 3.7 .

Figura 3.7- Rede para o retorno dos RSU

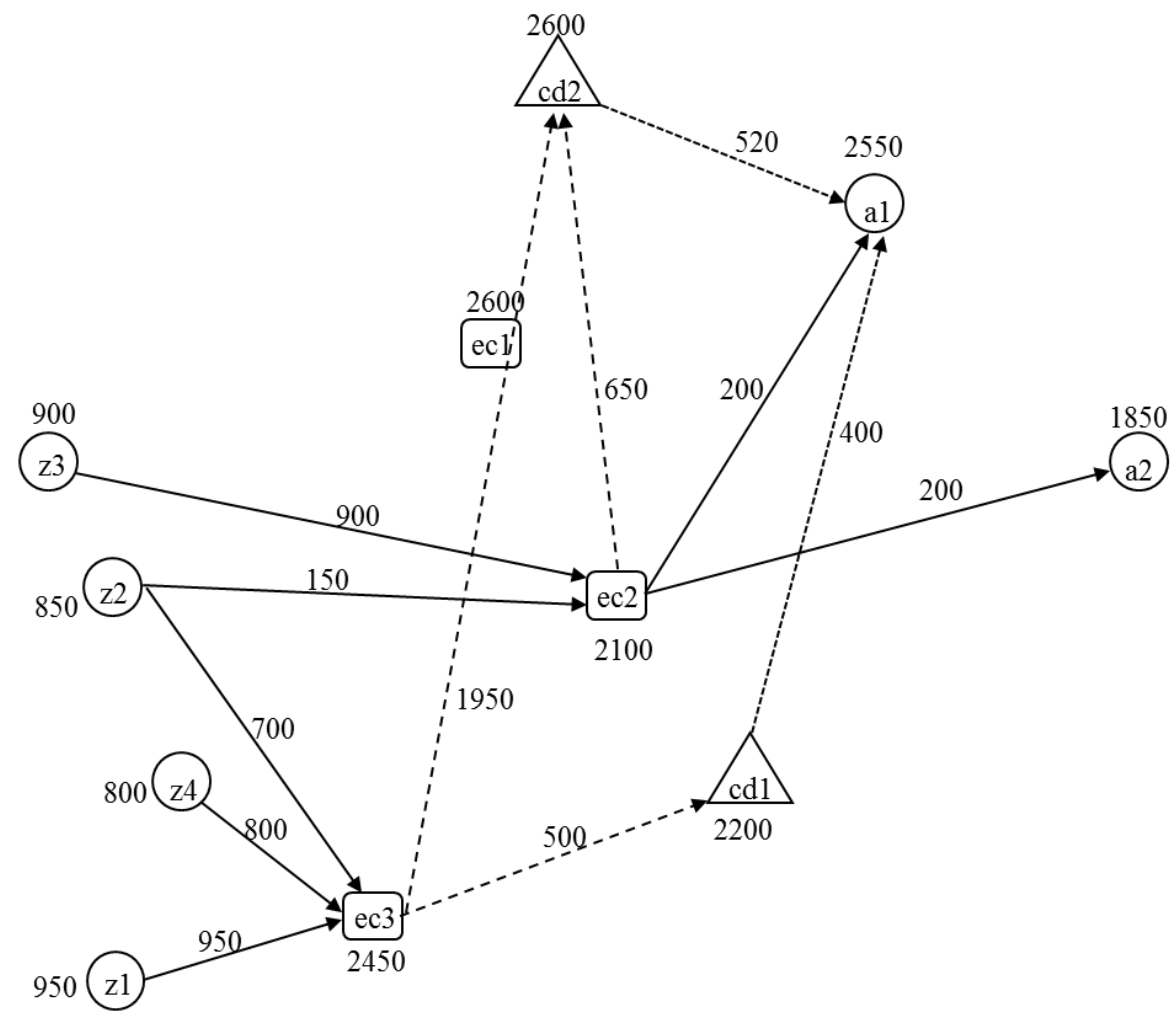

Fonte: Badran (2006)

Função Objetivo:

$$
\begin{aligned}
\operatorname{Min} C T= & \sum_{e c=1}^{n} c 2_{e c} e_{e c}+\sum_{c d=1}^{n^{\prime}} c 1_{c d}+\sum_{a=1}^{a^{\prime}} c 3_{a}+\sum_{e c=1}^{n} c 5_{e c} \sum_{z=1}^{z^{\prime}} f_{e c, z}+ \\
& \sum_{c d=1}^{n^{\prime}} c 4_{c d} \sum_{e c=1}^{n} y_{e c, c d}+\sum_{a=1}^{a \prime} c 6_{a} \sum_{e c=1}^{n^{\prime}} t_{e c, a}+\sum_{a=1}^{a \prime} c 6_{a} \sum_{c d=1}^{n \prime} x_{c d, a}+ \\
& \sum_{z=1}^{z \prime} \sum_{e c=1}^{n} c 10_{z, e c} f_{z, e c}+\sum_{e c=1}^{n} \sum_{c d=1}^{n} c 8_{e c, c d} y_{e c, c d}+ \\
& \sum_{e c=1}^{n} \sum_{a=1}^{a^{\prime}} c 9_{e c, a} t_{e c, a}+\sum_{c d=1}^{n^{\prime}} \sum_{a=1}^{\prime} c 7_{c d, a} x_{c d, a}
\end{aligned}
$$

Minimizar o custo total de transporte e de instalação da rede reversa 


\section{Sujeito a:}

-Restrição 1, a quantidade de RSU que é transportada para as estações de coleta é igual à quantidade que é gerada nas zonas;

$$
\sum_{e c=1}^{n} f_{z, e c}=Q_{z}, \quad \forall z \in Z
$$

- Restrição 2, a quantidade de RSU que as estações de coleta enviam aos aterros tem que ser menor ou igual as quantidades geradas nos hospitais e na construção;

$$
\sum_{e c=1}^{n} t_{e c, a} \leq U, \quad \forall a \in A
$$

- Restrição 3, estabelece o equilíbrio nas estações de coleta, ou seja, a quantidade de RSU que é coletada nas zonas e enviada as estações de coleta é igual à quantidade de RSU que recebem os centros de triagem mais a quantidade que recebem os aterros;

$$
\sum_{z=1}^{z \prime} f_{z, e c}-\left(\sum_{c d=1}^{n \prime} y_{e c, c d}+\sum_{a=1}^{a \prime} t_{e c, a}\right)=0, \quad \forall a \in A
$$

- Restrição 4, estabelece o equilíbrio nos centros de triagem;

$$
\sum_{e c=1}^{n} y_{e c, c d}-\left(\frac{1}{R_{c d}}\right) \sum_{a=1}^{a \prime} x_{c d, a}=0, \quad \forall c d \in C D
$$

- Restrição 5, a quantidade de RSU que é coletada nas zonas e enviada a uma estação de coleta proposta deve ser menor ou igual a sua capacidade de armazenamento;

$$
\sum_{z=1}^{Z \prime} f_{z, e c} \leq C 2_{e c} e_{e c}, \quad \forall e c \in E C
$$

- Restrição 6, a quantidade de RSU que as estações de coleta enviam a um centro de triagem tem que ser menor ou igual a sua capacidade;

$$
\sum_{e c=1}^{n} y_{e c, c d} \leq C 1_{c d}, \quad \forall c d \in C D
$$


- Restrição 7, a quantidade de RSU que as estações de coleta e os centros de triagem enviam aos aterros tem que ser menor ou igual à capacidade do aterro;

$$
\sum_{e c=1}^{n} t_{e c, a}+\sum_{c d=1}^{n \prime} x_{c d, a} \leq C 3_{a}, \quad \forall a \in A
$$

- Restrição 8, modela as atividades da estação de coleta selecionada;

$$
f_{z, e c}-M e_{e c} \leq 0, \quad \forall a \in A, \quad e c \in E C
$$

- Restrição 9, a quantidade de estações de coleta não pode ser maior do número proposto $\mathrm{W}$;

$$
\sum_{e c=1}^{n} e_{e c} \leq W
$$

- Restrições de não negatividades das variáveis;

$$
\begin{aligned}
& x_{c d, a}, y_{e c, c d}, z_{e c, a}, f_{i z, e c} \geq 0, \quad \forall a \in A, e c \in E C \\
& e_{e c} \in\{0,1\}, \forall e c \in E C
\end{aligned}
$$

Onde:

$C D \quad$ : Conjunto de centros de triagem, $c d=1,2, \ldots, n^{\prime}$.

A : Conjunto de aterros sanitários, $a=1,2, \ldots, a^{\prime}$.

EC : Conjunto de estações de coleta, $e c=1,2, \ldots, n$.

$Z \quad$ : Conjunto de zonas, $z=1,2, \ldots, z^{\prime}$.

$C_{1} \quad$ : Capacidade dos centros de triagem $c d \in C D$

$C_{2} \quad$ : Capacidade das estações de coleta $e c \in E C$.

$C_{3} \quad$ : Capacidade dos aterros sanitários $a \in A$.

$Q \quad$ : Quantidade de RSU gerados em $z \in Z$.

$c_{1}:$ Custo fixo dos centros de triagemcd $\in C D$.

$c_{2} \quad$ : Custo fixo das estações de coleta $e c \in E C$.

$c_{3}$ : Custo fixo dos aterros sanitários $a \in A$.

$c_{4} \quad$ : Custo variável dos centros de triagem $c d \in C D$. 
$c_{5}$ : Custo variável das estações de coleta ec $\in E C$.

$c_{6} \quad$ : Custo variável dos aterros sanitários $a \in A$.

$c_{7} \quad$ : Custo de transporte dos centros de triagem para os aterros sanitários.

$c_{8} \quad$ : Custo de transporte das estações de coleta para os centros de triagem.

$c_{9} \quad$ : Custo de transporte das estações de coleta para os aterros sanitários.

$c_{10}$ : Custo de transporte das zonas para as estações de coleta.

U : Quantidade de resíduos dos hospitais e resíduos de construção.

W : Quantidade de estações de coleta propostas.

$H \quad$ : Percentagem de resíduos que chega aos centros de triagem.

$x_{c d, a}$ : Quantidade de RSU transportado dos centros de triagem para os aterros sanitários.

$y_{e c, c d}$ : Quantidade de RSU transportado das estações de coleta para os centros de triagem.

$t_{e c, a}$ : Quantidade de RSU transportado das estações de coleta para os aterros sanitários.

$f_{z, e c}$ : Quantidade de RSU transportado das zonas para as estações de coleta.

$e_{e c}$ : Variável binária que assume o valor 1 , se a estação de coleta for aberta ou 0 , caso contrário.

\subsection{TESTE DOS MODELOS ESTUDADOS NO DISTRITO DE TRUJILLO}

Para conhecer o potencial dos modelos discutidos nos itens anteriores e saber como se comportam com dados que representam situações reais, escolheu-se um estudo de caso. $\mathrm{O}$ propósito dessa análise é aprofundar na modelagem de problemas de logística direta e reversa de RSU em ambiente urbano.

Como estudo de caso escolheu-se o Distrito de Trujillo de Peru ${ }^{23}$, que foi dividido em seis zonas, os cinco setores que formam a cidade e sua zona comercial (Figura 3.8). A zona comercial de Trujillo foi definida como uma zona por ser o maior centro gerador e atrator

\footnotetext{
${ }^{23}$ No capítulo 4 será apresentado com maior detalhe a caracterização do Distrito de Trujillo.
} 
de viagens do Distrito, praticamente aí é onde se realizam as principais atividades socioeconômicas da região urbana.

Os dados sobre as matrizes de distância, tempo e custo das viagens tanto dos clientes como das diferentes instalações propostas em todas as zonas do Distrito de Trujillo foram obtidos por meio do Serviço de Gestão Ambiental de Trujillo (SEGAT). Como a base de dados é muito grande não foi possível anexá-la a este documento.

Os dados dos clientes foram selecionados aleatoriamente do total de clientes que tem a zona comercial da cidade e, os dados das instalações propostas nas diferentes modelagens foram também fornecidos pela SEGAT e validados com outros órgãos locais que atuam em atividades similares e complementares.

Figura 3.8 - Zona comercial de Distrito de Trujillo

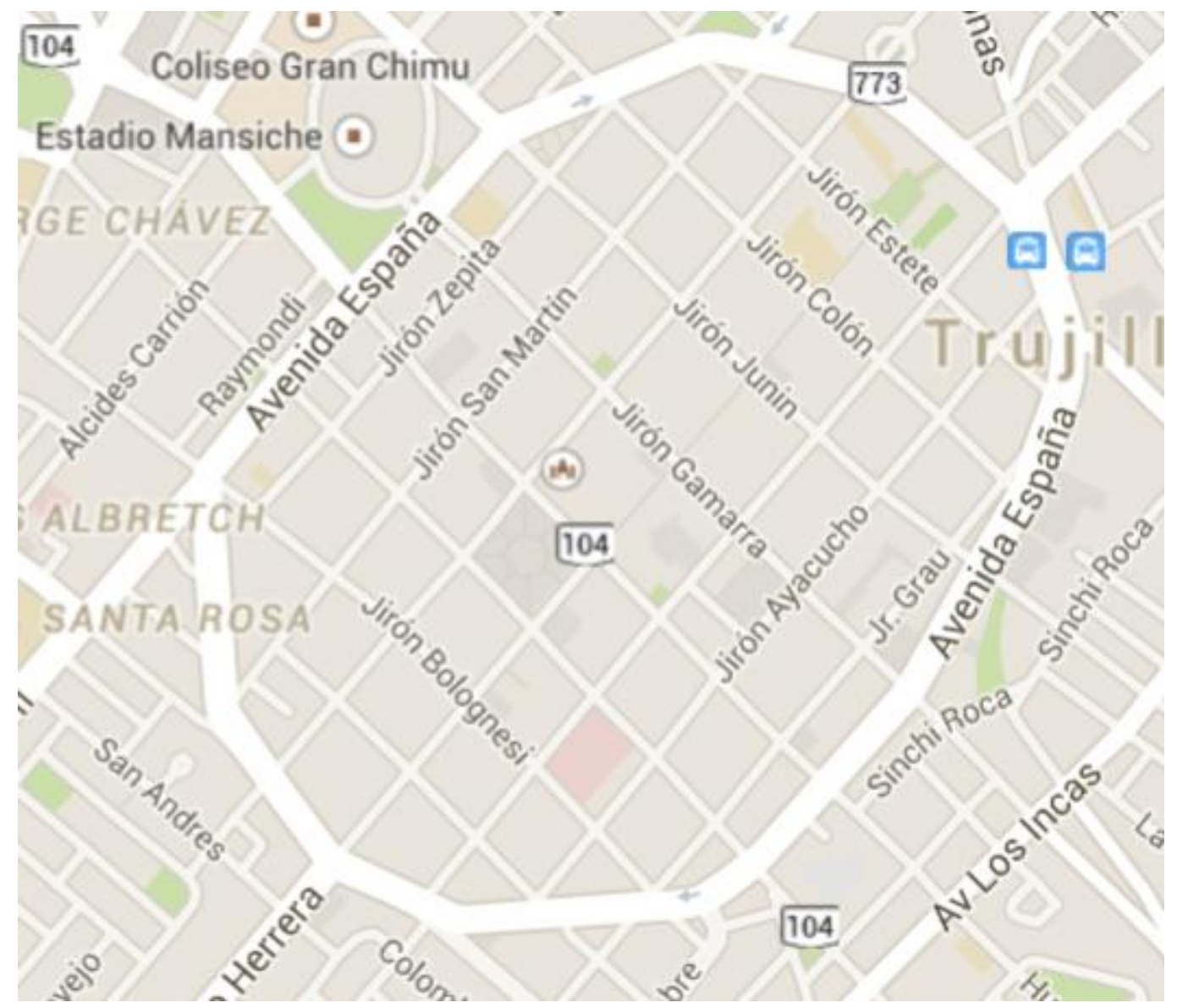

Fonte: Google Maps, 2015 


\subsubsection{Testes do Problema de Roteirização Operando com Frota Homogênea}

Com o propósito de testar este modelo foi feita a seguinte suposição, tem-se um número $N$ de clientes na zona comercial do Distrito de Trujillo que recebem produtos de um determinado depósito e deseja-se otimizar as atividades de distribuição usando uma frota homogênea que pode ter as seguintes capacidades10, 12 ou 14 toneladas. A demanda dos clientes pode variar entre 1 e 4 toneladas.

Os testes do modelo são feitos conforme a seguinte rotina:

a) Início do primeiro cenário;

b) Escolha da capacidade do veículo da frota homogênea;

c) Contagem do número de cenário;

d) Escolha do número de clientes a serem atendidos;

e) Escolha aleatória desses clientes na zona comercial;

f) Simulação do tamanho dos pedidos de cada cliente $d j$;

g) Localização desses clientes na zona comercial;

h) Montagem da matriz distância $D_{i j}$;

i) Montagem da matriz de custo, $c_{i, j}=f\left(D_{i, j}, d_{i}\right)$;

j) Execução do modelo;

k) Análise dos resultados obtidos: número de clientes por rota, custo do cenário obtido, tempo de execução do programa e número de variáveis geradas;

1) Os resultados do programa são válidos? O tempo de rodagem do programa está dentro do limite permitido? Se a resposta é sim, então gerar um novo cenário, executar de novo o passo (c) até o passo (k), manter constante a capacidade do veículo e aumentar o número de clientes; 
m) Se a resposta for não, então começar toda a rotina de novo, alterando a capacidade do veículo e iniciando com um pequeno grupo de clientes, ou seja, executar do passo (a) até o passou (1);

n) Já foram testados todos os tamanhos de veículos? Então parar os testes.

Com o objetivo de comparar o comportamento do modelo para as diferentes capacidades dos veículos, manteve-se constante o número de clientes para todos os cenários gerados em cada corrida. As Tabelas 3.1, 3.2 e 3.3 apresentam os resultados computacionais obtidos da implementação do modelo PRVC com o GLPK para cada veículo. E na Tabela 3.4 mostrase um quadro comparativo dos resultados obtidos nas três corridas.

Tabela 3.1 - Resultados obtidos no PRVC para veículos com 10 ton. de capacidade

\begin{tabular}{|c|c|c|c|c|c|}
\hline \multicolumn{6}{|c|}{ Veículos com capacidade de 10 toneladas } \\
\hline Cenários & Clientes & $\begin{array}{l}\text { Variáveis } \\
\text { geradas }\end{array}$ & $\begin{array}{c}\text { Tempo } \\
\text { (min) }\end{array}$ & $\begin{array}{c}\text { Custo gerado } \\
\text { (\$) }\end{array}$ & Rotas obtidas \\
\hline 1 & 5 & 36 & 0,000 & 52,8 & D0- P2-P1-P3-P4-P5-DO \\
\hline 2 & 7 & 64 & 0,006 & 100,2 & $\begin{array}{l}\text { D0-P6-P3-P4-P5-DO } \\
\text { D0-P7-P1-P2-D0 }\end{array}$ \\
\hline 3 & 9 & 100 & 0,008 & 94,4 & $\begin{array}{l}\text { D0-P6-P3-P4-P5-D0 } \\
\text { D0-P9-P1-P2-P7-P8-D0 }\end{array}$ \\
\hline 4 & 11 & 144 & 0,161 & 144,2 & $\begin{array}{l}\text { D0-P1-P2-P7-P8-D0 } \\
\text { D0-P6-P3-P4-P5-D0 } \\
\text { D0-P10-P11-P9-D0 }\end{array}$ \\
\hline 5 & 13 & 196 & 2,160 & 158,8 & $\begin{array}{l}\text { D0-P6-P3-P4-P5-D0 } \\
\text { D0-P9-P1-P2-P7-P8-D0 } \\
\text { D0-P11-P12-P13-P10-D0 }\end{array}$ \\
\hline 6 & 15 & 256 & 3,520 & 150,4 & $\begin{array}{l}\text { D0-P9-P1-P2-P7-P8-D0 } \\
\text { DO-P10-P11-P12-P13-P14-D0 } \\
\text { D0-P15-P6-P3-P4-P5-D0 }\end{array}$ \\
\hline 7 & 17 & 324 & 109.320 & 165,2 & $\begin{array}{l}\text { D0-P9-P1-P2-P7-P8-D0 } \\
\text { D0-P10-P11-P12-P13-P15-P16-P17-D0 } \\
\text { D0-P14-P6-P3-P4-P5-D0 }\end{array}$ \\
\hline
\end{tabular}

Fonte: Resultados computacionais obtidos com o GLPK

Da Tabela 3.4 pode-se observar o seguinte: o quadro de resultados para os três primeiros cenários manteve-se praticamente inalterado, já a situação começa a mudar a partir do quarto cenário. Para esse cenário, na segunda e terceira corrida que correspondem aos veículos de 12 e 14 toneladas respectivamente, o número de rotas cai para dois e como consequência reduz-se o custo de transporte, especialmente para o caso do veículo de 14 toneladas, diminuindo também, o tempo de processamento. 
Tabela 3.2 - Resultados obtidos no PRVC para veículos com 12 ton. de capacidade

\begin{tabular}{|c|c|c|c|c|c|}
\hline \multicolumn{6}{|c|}{ Veículos com capacidade de 12 toneladas } \\
\hline Cenários & Clientes & $\begin{array}{l}\text { Variáveis } \\
\text { geradas }\end{array}$ & $\begin{array}{c}\text { Tempo } \\
\text { (min) }\end{array}$ & $\begin{array}{c}\text { Custo gerado } \\
\text { (\$) }\end{array}$ & Rotas obtidas \\
\hline 1 & 5 & 36 & 0,000 & 52,8 & D0-P2- P1-P3-P4-P5-D0 \\
\hline 2 & 7 & 64 & 0,005 & 100,2 & $\begin{array}{l}\text { D0-P6-P3-P4-P5-D0 } \\
\text { D0-P7-P1-P2-DO }\end{array}$ \\
\hline 3 & 9 & 100 & 0,013 & 94,4 & $\begin{array}{l}\text { D0-P6-P3-P4-P5-D0 } \\
\text { D0-P9-P1-P2-P7-P8-DO }\end{array}$ \\
\hline 4 & 11 & 144 & 0,060 & 129,2 & $\begin{array}{l}\text { DO-P6-P3-P4-P5-P9-D0 } \\
\text { D0-P10-P11-P1-P2-P7-P8-D0 }\end{array}$ \\
\hline 5 & 13 & 196 & 1,120 & 150,2 & $\begin{array}{l}\text { D0-P9-P1-P2-P7-P8-D0 } \\
\text { D0-P10-P11-P12-DO } \\
\text { D0-P13-P6-P3-P4-P5-DO }\end{array}$ \\
\hline 6 & 15 & 256 & 9,000 & 150,4 & $\begin{array}{l}\text { D0-P9-P1-P2-P7-P8-D0 } \\
\text { D0-P10-P11-P12-P13-P14-D0 } \\
\text { DO-P15-P6-P3-P4-P5-D0 }\end{array}$ \\
\hline 7 & 17 & 324 & 31,020 & 161,4 & $\begin{array}{l}\text { D0-P9-P1-P2-P7-P8-D0 } \\
\text { D0-P10-P11-P12-P13-P15-P16-P17-D0 } \\
\text { D0-P14-P6-P3-P4-P5-D0 }\end{array}$ \\
\hline
\end{tabular}

Fonte: Resultados computacionais obtidos com o GLPK

Tabela 3.3 - Resultados obtidos no PRVC para veículos com 14 ton. de capacidade

\begin{tabular}{|c|c|c|c|c|c|}
\hline \multicolumn{6}{|c|}{ Veículos com capacidade de 14 toneladas } \\
\hline Cenários & Clientes & $\begin{array}{l}\text { Variáveis } \\
\text { geradas }\end{array}$ & $\begin{array}{l}\text { Tempo } \\
\text { (min) }\end{array}$ & $\begin{array}{c}\text { Custo gerado } \\
\text { (\$) }\end{array}$ & Rotas obtidas \\
\hline 1 & 5 & 36 & 0,000 & 52,8 & DO-P2-P1-P3-P4-P5-D0 \\
\hline 2 & 7 & 64 & 0,006 & 100,2 & $\begin{array}{l}\text { D0-P6-P3-P4-P5-D0 } \\
\text { D0-P7-P1-P2-D0 }\end{array}$ \\
\hline 3 & 9 & 100 & 0,011 & 94,4 & $\begin{array}{l}\text { D0-P6-P3-P4-P5-D0 } \\
\text { D0-P9-P1-P2-P7-P8-D0 }\end{array}$ \\
\hline 4 & 11 & 144 & 0,035 & 121,0 & $\begin{array}{l}\text { D0-P6-P3-P4-P5-D0 } \\
\text { D0-P10-P11-P9-P1-P2-P7-P8-D0 }\end{array}$ \\
\hline 5 & 13 & 196 & 0,208 & 131,4 & $\begin{array}{l}\text { D0-P7-P13-P6-P3-P4-P5-D0 } \\
\text { D0-P10-P11-P12-P8-P1-P2-P9-D0 }\end{array}$ \\
\hline 6 & 15 & 256 & 24,700 & 150,4 & $\begin{array}{l}\text { D0-P9-P1-P2-P7-P8-D0 } \\
\text { D0-P10-P11-P12-P13-P14-D0 } \\
\text { D0-P15-P6-P3-P4-P5-D0 }\end{array}$ \\
\hline 7 & 17 & 324 & 41,700 & 157,9 & $\begin{array}{l}\text { DO-P6-P3-P4-P5-P15-P16-P17-D0 } \\
\text { D0-P9-P1-P2-P7-P8-D0 } \\
\text { D0-P10-P11-P12-P13-P14-D0 }\end{array}$ \\
\hline 8 & 19 & 400 & 274,400 & 173,9 & $\begin{array}{l}\text { D0-P4-P5-P15-P16-P17-P18-P19-D0 } \\
\text { DO-P6-P3-P2-P7-P8-D0 } \\
\text { D0-P9-P1-P10-P11-P12-P13-P14-D0 }\end{array}$ \\
\hline
\end{tabular}

Fonte: Resultados computacionais obtidos com o GLPK 
Tabela 3.4 - Quadro comparativo dos resultados das três corridas

\begin{tabular}{c|c|c|c|c|c|c|c|c|c}
\hline & \multicolumn{3}{|c|}{ Veículo de 10 ton } & \multicolumn{3}{c|}{ Veículo de 12 ton } & \multicolumn{3}{c}{ Veículo de 14 ton } \\
\hline Cenário & $\begin{array}{c}\text { Tempo } \\
(\mathbf{m i n})\end{array}$ & $\begin{array}{c}\text { Custo } \\
\text { gerado } \\
\mathbf{( \$ )}\end{array}$ & $\begin{array}{c}\text { Rotas } \\
\text { obtidas }\end{array}$ & $\begin{array}{c}\text { Tempo } \\
(\mathbf{m i n})\end{array}$ & $\begin{array}{c}\text { Custo } \\
\text { gerado } \\
\mathbf{( \$ )}\end{array}$ & $\begin{array}{c}\text { Rotas } \\
\text { obtidas }\end{array}$ & $\begin{array}{c}\text { Tempo } \\
(\mathbf{m i n})\end{array}$ & $\begin{array}{c}\text { Custo } \\
\text { gerado } \\
\mathbf{( \$ )}\end{array}$ & $\begin{array}{c}\text { Rotas } \\
\text { obtidas }\end{array}$ \\
\hline 1 & 0,000 & 52,8 & 1 & 0,000 & 52,8 & 1 & 0,000 & 52,8 & 1 \\
\hline 2 & 0,006 & 100,2 & $2 / 4,3$ & 0,005 & 100,2 & $2 / 4,3$ & 0,006 & 100,2 & $2 / 4,3$ \\
\hline 3 & 0,008 & 94,4 & $2 / 4,5$ & 0,013 & 94,4 & $2 / 4,5$ & 0,011 & 94,4 & $2 / 4,5$ \\
\hline 4 & 0,161 & 144,2 & $3 / 4,4,3$ & 0,060 & 129,2 & $2 / 5,6$ & 0,035 & 121 & $2 / 4,7$ \\
\hline 5 & 2,160 & 158,8 & $3 / 4,5,4$ & 1,120 & 150,2 & $3 / 5,3,5$ & 0,208 & 131,4 & $2 / 6,7$ \\
\hline 7 & 3,520 & 150,4 & $3 / 5,5,5$ & 9,000 & 150,4 & $3 / 5,5,5$ & 24,700 & 150,4 & $3 / 5,5,5$ \\
\hline 8 & 109,320 & 165,2 & $3 / 5,7,5$ & 31,020 & 161,4 & $3 / 5,7,5$ & 41,700 & 157,9 & $3 / 7,5,5$ \\
\hline
\end{tabular}

Fonte: Resultados computacionais obtidos com o GLPK

No quinto cenário, a situação muda, nas duas primeiras corridas, manteve-se três rotas e para a terceira corrida duas, para este último caso, o custo de transporte diminui sensivelmente, assim como o tempo de processamento. No sexto cenário, os custos de transporte são iguais porque nas três corridas gerou-se 3 rotas com a mesma quantidade de clientes em cada rota, o que variou muito foi o tempo de processamento da terceira corrida, que teve um aumento significativo.

No sétimo cenário a situação não mudou muito, apenas teve-se uma mínima redução de custo do veículo com menor capacidade para o veículo de maior capacidade, já o tempo de processamento se inverteu. No oitavo cenário, quando se aumentou o número de clientes para 19, somente a terceira corrida conseguiu gerar um resultado.

Os resultados computacionais obtidos mostram o difícil que é resolver o problema de roteirização de veículos para grandes cenários, pois o tempo de processamento cresce em forma exponencial. Assim, para resolver problemas para cenários de 17 ou mais clientes é melhor usar uma meta heurística que talvez não garante a solução ótima, mas que, para este tipo de problema é a melhor alternativa. 


\subsubsection{Testes do Problema de Roteirização de Veículos com Janelas de Tempo}

Como premissa para aplicação deste modelo determina-se que os pedidos do conjunto de clientes selecionados da zona comercial de Trujillo devem ser atendidos de acordo com a seguinte janela de tempo, das $06 \mathrm{~h} 00 \mathrm{~min}$ até as $10 \mathrm{~h} 00 \mathrm{~min}$, que supostamente é o período que se tem o menor fluxo de veículos e pessoas nessa zona. Para execução do modelo com o GLPK é mantida a mesma base de dados e a lógica da rotina descrita no item anterior. No entanto, somente se fez uma corrida, ou seja, é utilizado só o veículo de 12 toneladas. Da Tabela 3.5 observa-se que os resultados não foram muito diferentes do problema testado no item anterior.

Tabela 3.5 - Resultados obtidos no PRVJT para veículos com 12 ton. de capacidade

\begin{tabular}{c|c|l|c|c|l}
\hline \multicolumn{2}{c|}{} & \multicolumn{5}{c}{ Veículos com capacidade de 12 toneladas } \\
\hline Cenário & Clientes & $\begin{array}{c}\text { Variáveis } \\
\text { geradas }\end{array}$ & $\begin{array}{c}\text { Tempo } \\
\mathbf{( m i n )}\end{array}$ & $\begin{array}{c}\text { Custo } \\
\text { gerado } \\
\mathbf{( \$ )}\end{array}$ & \multicolumn{1}{c}{ Rotas obtidas } \\
\hline 1 & 5 & $\begin{array}{l}\text { Inteiras: } 7 \\
\text { Binarias: } 40\end{array}$ & 0,000 & 44,8 & DO-P4-P5-P3-P2-P1-D0 \\
\hline 2 & 7 & $\begin{array}{l}\text { Inteiras: } 18 \\
\text { Binarias: } 140\end{array}$ & 0.001 & 75,0 & $\begin{array}{l}\text { D0-P2-P7-P1-D0 } \\
\text { D0-P6-P3-P4-P5-D0 }\end{array}$ \\
\hline 3 & 9 & $\begin{array}{l}\text { Inteiras: } 22 \\
\text { Binarias: } 216\end{array}$ & 0,011 & 84,8 & $\begin{array}{l}\text { D0-P9-P2-P7-P8-P1-D0 } \\
\text { D0-P6-P3-P4-P5-D0 }\end{array}$ \\
\hline \multirow{2}{*}{5} & 11 & $\begin{array}{l}\text { Inteiras: } 39 \\
\text { Binarias: } 462\end{array}$ & 1,250 & 129,4 & $\begin{array}{l}\text { D0-P6-P3-P4-P5-D0 } \\
\text { D0-P10-P11-P9-D0 } \\
\text { D0-P2-P7-P8-P1-D0 }\end{array}$ \\
\hline
\end{tabular}

Fonte: Resultados computacionais obtidos com o GLPK

\subsubsection{Teste do Modelo de Logística Reversa de Lee J. et al (2008)}

Para aplicação deste modelo no Distrito de Trujillo considera-se uma estação de coleta localizada no entorno da cidade (ecl), dois centros de triagem $(c d 1, c d 2)$, dois centros de transformação $(c t 1, c t 2)$, um centro de reciclagem $(r)$, um centro de eliminação (lixão Al) estabelecido fora da cidade, uma fábrica $(f)$ e um provedor $(p)$ que fornece matéria-prima para a fábrica quando for necessário (Figura 3.9). 
Como premissa, assume-se que os RSU já foram alocados na estação de coleta. Na Tabela 3.6 mostram-se os resultados da aplicação desse modelo.

Tabela 3.6 - Resultados obtidos com o modelo de Lee J. et al (2008)

\begin{tabular}{|c|c|c|c|c|c|c|c|c|c|c|}
\hline \multicolumn{5}{|c|}{$\begin{array}{l}\text { Capacidades dos diferentes } \\
\text { componentes do modelo } \\
\text { (ton) }\end{array}$} & \multicolumn{5}{|c|}{$\begin{array}{c}\text { Custo de transporte } \\
\text { (\$) }\end{array}$} & \multirow[t]{2}{*}{$\begin{array}{c}\text { Custo de } \\
\text { transporte (\$) }\end{array}$} \\
\hline EC & CD & CT & $\mathbf{R}$ & $\mathbf{F}$ & $e c-c d$ & cd-ct & $c t-f$ & $c t-r$ & $c t-e$ & \\
\hline ec $1: 3$ & $\begin{array}{l}\operatorname{cd} 1: 2 \\
\operatorname{cd} 2: 3\end{array}$ & $\begin{array}{l}\text { ct1: } 2 \\
\text { ct2: }\end{array}$ & r: 5 & f: 5 & 170,1 & 118,8 & 25,2 & 318,6 & 0 & 632,7 \\
\hline
\end{tabular}

Fonte: Resultados computacionais obtidos com o GLPK

Figura 3.9 - Alocação dos centros especializados

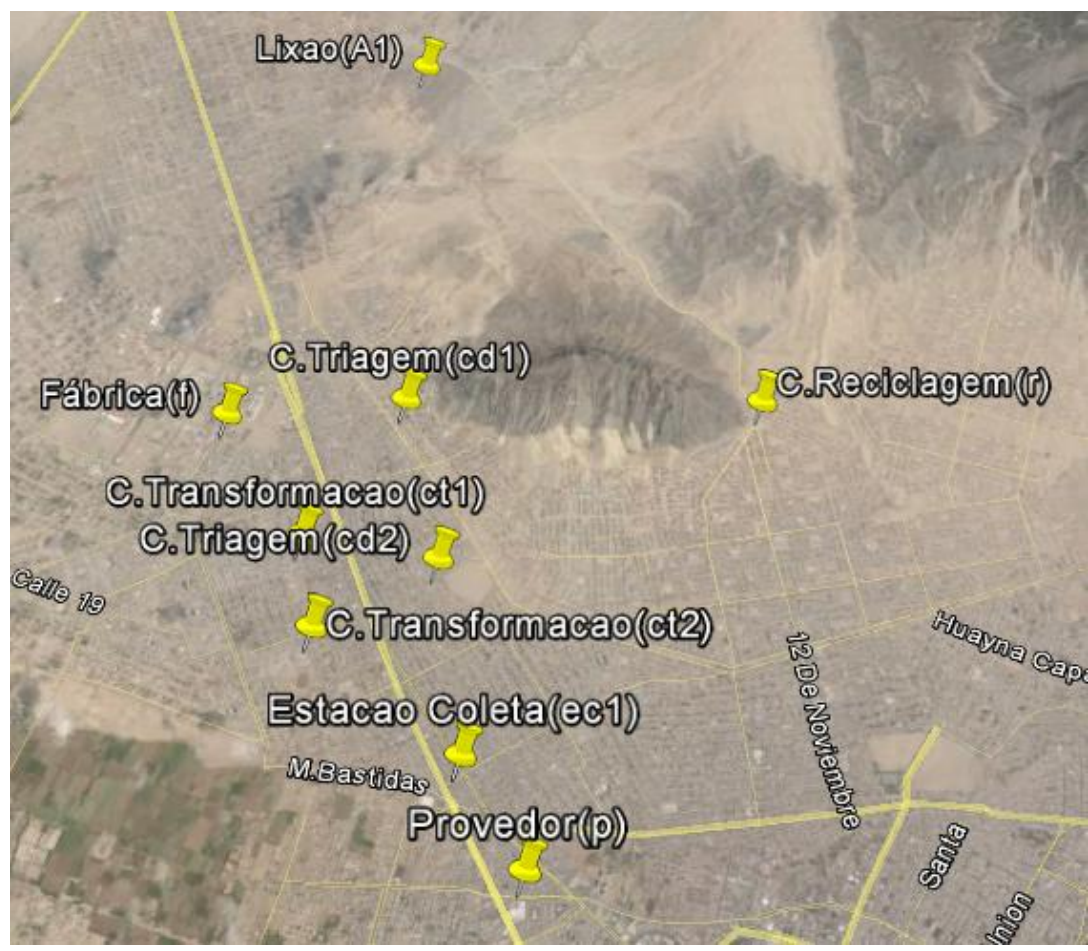

Fonte: Google, 2015

\subsubsection{Teste do Modelo de Logística Urbana de Sterle (2010)}

A cidade de Trujillo, como foi comentando anteriormente, é um grande polo gerador e atrator de viagens, recebe muitos produtos vindos das cidades do Norte (Pla2) e do Sul (Pla1). Baseada nesse fato propõe-se instalar dois grandes depósitos (plataformas) no limite externo da cidade e três unidades satélites (depósitos menores) mais perto da zona 
comercial da cidade. Esta é uma proposta muito utilizada em logística urbana para diminuir a circulação de veículos de grande porte dentro da área urbana.

Portanto, o objetivo é concentrar nas duas plataformas todos os produtos que vem das cidades vizinhas e do resto do pais. Assim, as cargas que vem das cidades localizadas no extremo sul da cidade serão recepcionadas pela plataforma sul e as que vêm das cidades do norte pela plataforma norte.

Depois de passar por uma triagem, as cargas serão transportadas às três unidades satélites usando uma frota de veículos com capacidade de 14 toneladas cada um. Dessas unidades satélites a carga será distribuída aos seus respectivos clientes por meio de outra frota de veículos com capacidade de 10 toneladas. Com essa configuração de rede (Figura 3.10) foi implementado o modelo de Sterle (2010) com o GLPK para minimizar custos, tanto de transporte como de instalação e dimensionamento da rede logística, incluindo a determinação do tamanho de ambas as frotas.

Figura 3.10 - Localização das plataformas, unidades satélites e clientes

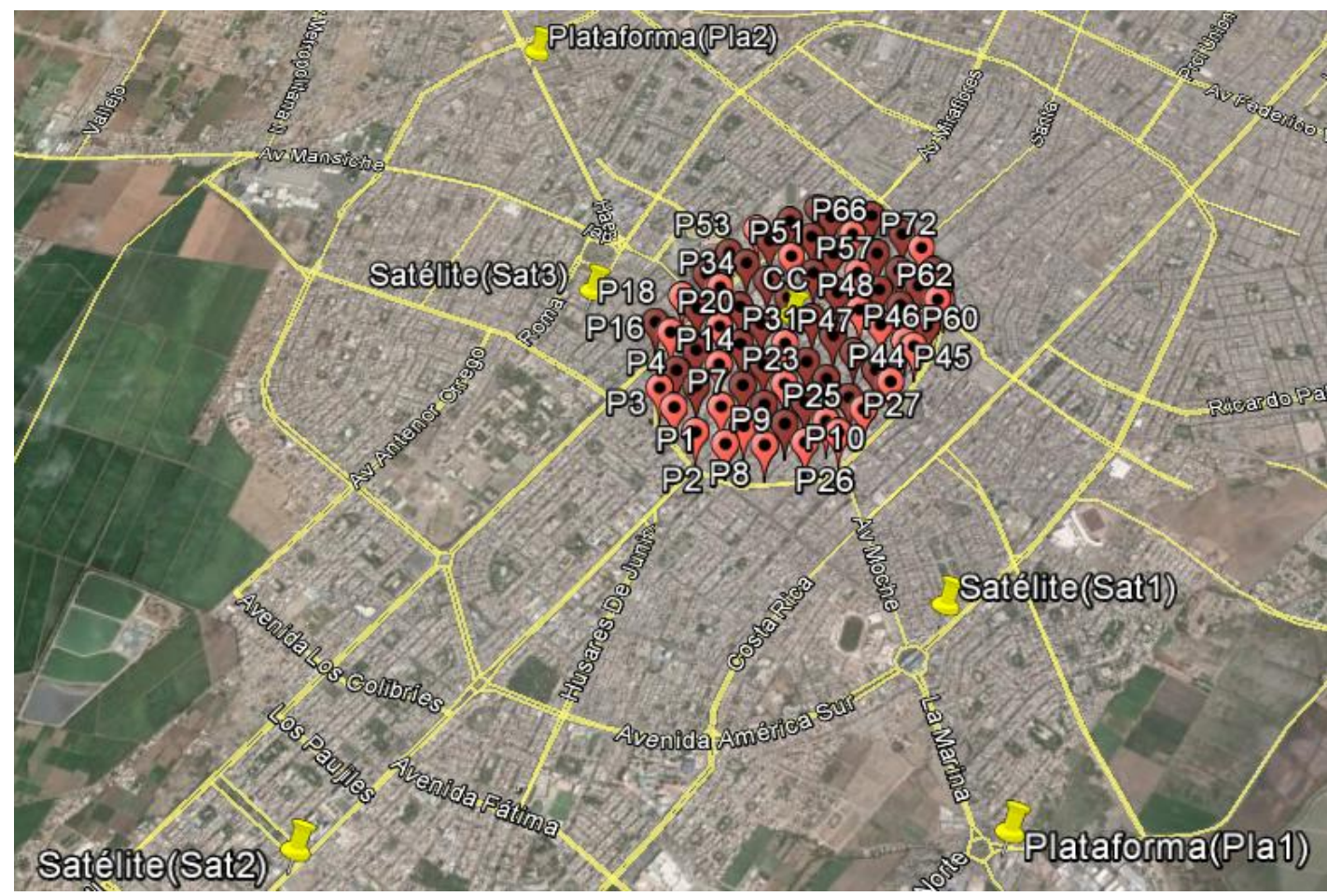

Fonte: Google, 2015

Seguindo a mesma lógica dos problemas anteriores simula-se inicialmente um cenário com cinco clientes e depois vai se construindo outros cenários aumentando o número de clientes 
até atingir um determinado limite de tempo de processamento considerado tolerável, neste caso, a execução do programa é abortado depois de passar o limite de 30 horas.

É importante ressaltar que este tipo de problema apresenta uma forte complexidade computacional, além de ser altamente combinatório, já que resolve duas classes de problema, roteirização e dimensionamento da rede. Devido a esta situação, Sterle (2010) também apresenta uma metaheurística para solucionar o problema para grandes cenários.

Os resultados apresentados na Tabela 3.7 mostram a composição da rede logística, os custos em ambos os níveis e os tempos de processamentos despendidos para cada cenário.

Tabela 3.7 - Resultados computacionais obtidos no modelo de Sterle (2010)

\begin{tabular}{|c|c|c|c|c|c|c|}
\hline \multirow[b]{2}{*}{$\begin{array}{c}\text { Cená- } \\
\text { rios }\end{array}$} & \multirow[b]{2}{*}{$\begin{array}{l}\text { Demanda dos } \\
\text { clientes (ton.) }\end{array}$} & \multirow[b]{2}{*}{$\begin{array}{c}\text { Tempo } \\
\text { (min) }\end{array}$} & \multicolumn{4}{|c|}{ Custo das rotas (\$) } \\
\hline & & & $\begin{array}{c}\text { Custo } \\
\text { no } \\
\text { nível } \\
1 \\
\end{array}$ & $\begin{array}{c}\text { Veículo: Rota no } \\
\text { nível } 1\end{array}$ & $\begin{array}{c}\text { Custo } \\
\text { no } \\
\text { nível } \\
2 \\
\end{array}$ & Veículo: Rota no nível 2 \\
\hline 1 & $\begin{array}{l}\text { P1: 1; P2: 2; P3: 2; } \\
\text { P4: 2; P5: } 1\end{array}$ & 0.12 & 624 & g4: pla1-sat1-pla1 & 43,42 & v1:sat1-P2-P1-P3-P4-P5-sat1 \\
\hline 2 & $\begin{array}{l}\text { P1: 1; P2: 2; P3: 2; } \\
\text { P4: 2; P5: 1; P6:4; } \\
\text { P7: } 3\end{array}$ & 56.54 & 1680 & $\begin{array}{l}\text { g3: pla1-sat1-pla1 } \\
\text { g4: pla2-sat3-pla2 }\end{array}$ & 64,35 & $\begin{array}{l}\text { v1:sat1-P6-P3-P4-P5-sat1 } \\
\text { v2: sat3-P2-P7-P1-sat3 }\end{array}$ \\
\hline 3 & $\begin{array}{l}\text { P1: 1; P2: 2; P3: 2; } \\
\text { P4: 2; P5: 1; P6:4; } \\
\text { P7: 3; P8: 2;P9:2 }\end{array}$ & 287.70 & 1680 & $\begin{array}{l}\text { g3: pla1-sat1-pla1 } \\
\text { g4: pla2-sat3-pla2 }\end{array}$ & 70,72 & $\begin{array}{l}\text { v1:sat1-P6-P3-P4-P5-sat1 } \\
\text { v2:sat3-P9-P2-P7-P8-P1- } \\
\quad \text { sat3 }\end{array}$ \\
\hline 4 & $\begin{array}{l}\text { P1: } 1 ; \text { P2: } 2 ; \text { P3: } 2 ; \\
\text { P4: } 2 ; \text { P5: } 1 ; \text { P6:4; } \\
\text { P7: } 3 ; \text { P8: } 2 ; \\
\text { P9:2;P10:1;P11: } 3\end{array}$ & 1848.57 & 1680 & $\begin{array}{l}\text { g3: pla1-sat1-pla1 } \\
\text { g4: pla2-sat3-pla2 }\end{array}$ & 93,46 & $\begin{array}{l}\text { v1:sat1-P6-P3-P4-P5-sat1 } \\
\text { v2:sat3-P9-P2-P7-P8-P1-sat3 } \\
\text { v3: sat3-P10-P11-sat3 }\end{array}$ \\
\hline
\end{tabular}

Fonte: Resultados obtidos com GLPK

\subsubsection{Teste do Modelo de Gestão de Resíduos Sólidos de Badran (2006)}

Deseja-se otimizar as atividades de coleta e entrega dos RSU gerados nos cinco setores do Distrito de Trujillo, utilizando para isso, a seguinte composição de rede logística reversa: uma estação de coleta, dois centros de triagem e um lixão ${ }^{24}$ (Figura 3.11). As cinco zonas geram 30, 30, 38, 22 e 31 toneladas de RSU respectivamente. Todo esse lixo é concentrado na estação de coleta, daí ele é enviado para os centros de triagem e logo, o que é

\footnotetext{
${ }^{24}$ É o que existe em Trujillo.
} 
considerado não utilizável é enviado ao lixão, o resto é encaminhado para reciclagem ou recuperação.

Os resultados da aplicação do modelo de Badran (2006) com o GLPK são mostrados na Figura 3.12. A execução do programa mostra um ótimo desempenho e resultados coerentes com a realidade. Do desenho da Figura 3.12 pode observa-se que o programa seleciona 51 toneladas para serem transportadas para o centro de triagem cd1 e 120 toneladas para $\mathrm{cd} 2$.

Desses valores, 27,9 e 96,0 toneladas respectivamente são selecionadas para serem transportados para o lixão, ou seja, 123,9 toneladas chegam ao fim de sua vida útil. Portanto, somente 27,1 toneladas são aproveitadas para algum processo de reciclagem ou reutilização, que representa $15,85 \%$ do total de RSU gerado pelas cinco zonas da cidade. Um valor muito baixo se comparado com os países desenvolvidos.

Figura 3.11 - Alocação dos setores e centros especializados

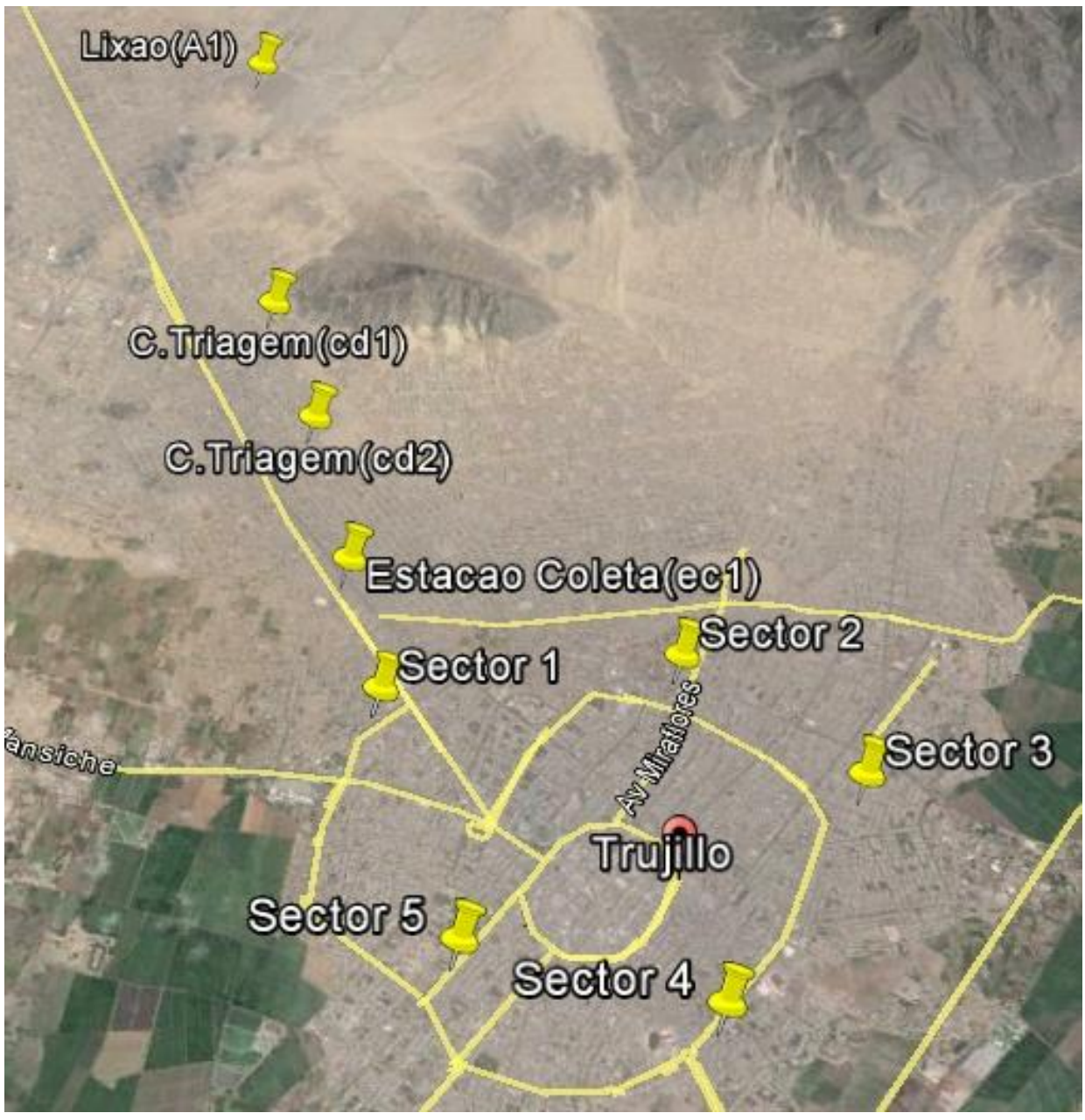

Fonte: Google, 2015 
Figura 3.12 - Distribuição dos resíduos gerados nos setores do Distrito de Trujillo

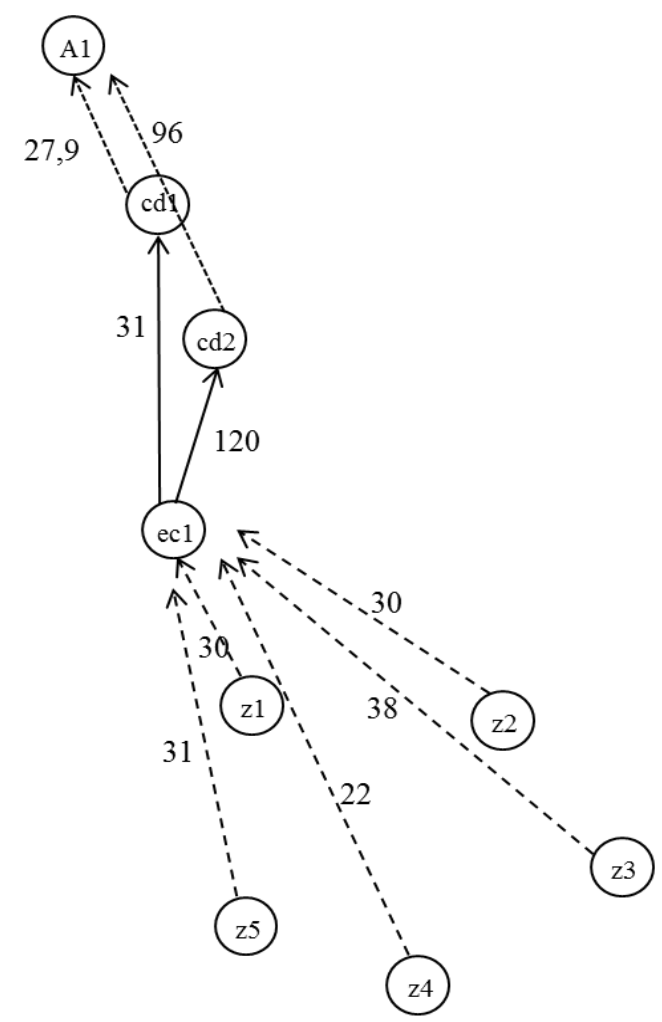

Fonte: Resultados obtidos com o GLPK 


\section{PROPOSTA DE MODELAGEM PARA COLETA E TRANSPORTE DE RSU}

Baseados nos conceitos discutidos nos Capítulos 2 e 3, assim como, da experiência obtida da análise de resultados dos modelos matemáticos estudados e programados com o GLPK são caracterizados os principais elementos que compõem o modelo proposto neste trabalho para a coleta e transporte de RSU em uma área urbana. Assim, estrutura-se uma rede logística reversa para os RSU considerando diferentes centros especializados ou unidades produtivas para atender as diferentes fases de processo da rede. Nesse processo de modelagem teve-se o cuidado de manter a proposta bastante próxima à realidade das cidades onde o modelo foi testado e validado.

\subsection{PROCESSO DA MODELAGEM}

O planejamento e modelagem do sistema de logística reversa de uma área urbana é uma fase importante e estratégica para obter no futuro, ótimos resultados no processo de gerenciamento e operação do sistema reverso de RSU. A modelagem permite determinar a localização de estações de coleta e de unidades especiais necessárias, assim como o fluxo que será movimentado ao longo da rede permitindo dimensionar todo o sistema e seus componentes.

O planejamento logístico vai além de definir somente infraestrutura e superestrutura do sistema, ela contribui para estruturar o sistema de controle operacional, gerencial e de inteligência para que o sistema logístico reverso funcione otimamente. Os diferentes agentes e membros da comunidade que participam em algumas ou em todas as atividades do processo logístico reverso passam a estar integrados e coordenados por esse sistema de informação, facilitando a comunicação em tempo real e interativa das informações e dos problemas, compartilhando experiências e soluções e propondo constantes melhorias ao sistema. Essa troca - troca de informação e de experiência entre os diferentes agentes e membros da comunidade só trazem benefícios e ganhos para todos.

Com a otimização do modelo de coleta de RSU pretende-se reorganizar o sistema reverso de uma cidade de forma a conseguir um melhor dimensionamento da rede, com a consequente diminuição do número de veículos que circulam na cidade. Em geral, a 
configuração de uma rede logística reversa de uma cidade segue a estrutura apresentada na Figura 4.1.

Figura 4.1-Esquema do processo de coleta e transporte de RSU

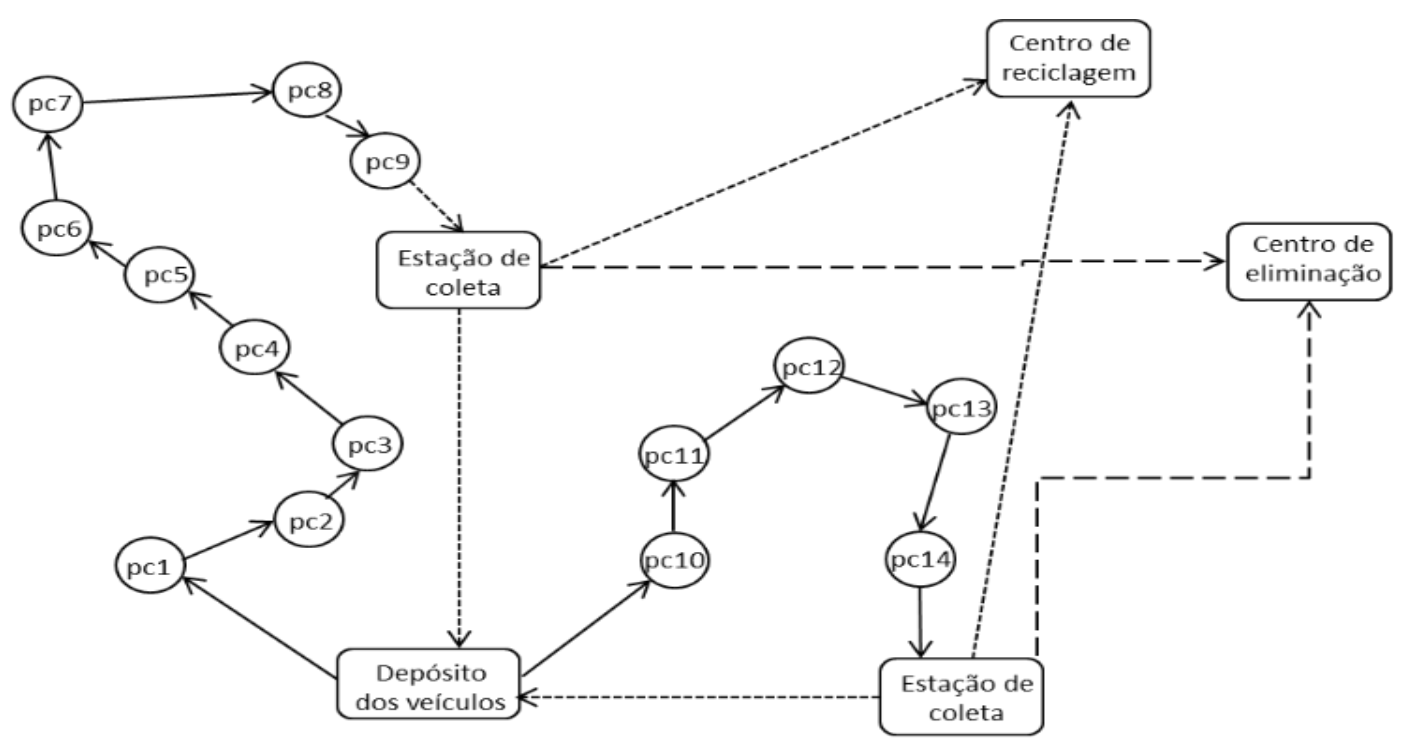

Fonte: Elaboração própria

Independente de como seja feita o processo de coleta e transporte dos RSU em uma cidade, esta tese propõe três etapas do processo de modelagem da rede logística reversa:

a) Roteirização da coleta dos RSU gerados nas zonas urbanas e transporte dos mesmos para as estações de coleta;

b) Transporte dos RSU das estações de coleta selecionadas até os centros especializados sob duas propostas diferentes, as quais se descrevem a continuação;

c) Teste e validação do modelo com a aplicação em um estudo de caso.

\section{Proposta I}

Dos pontos de coleta nas zonas residenciais, os resíduos sólidos são levados para as estações de coleta e logo transportados até os centros de eliminação para sua disposição final ou para os centros de triagem para sua classificação. Desse último local, os RSU são 
transportados para as fábricas para sua reutilização ou aos centros de transformação para passarem por um tratamento adequado para que possam ser reciclados e usados nas fábricas. Ainda, existe a possibilidade que neste último processo alguns resíduos sejam encaminhados para os centros de eliminação, como se mostra na Figura 4.2.

\section{Figura 4.2- Proposta do Caso I}

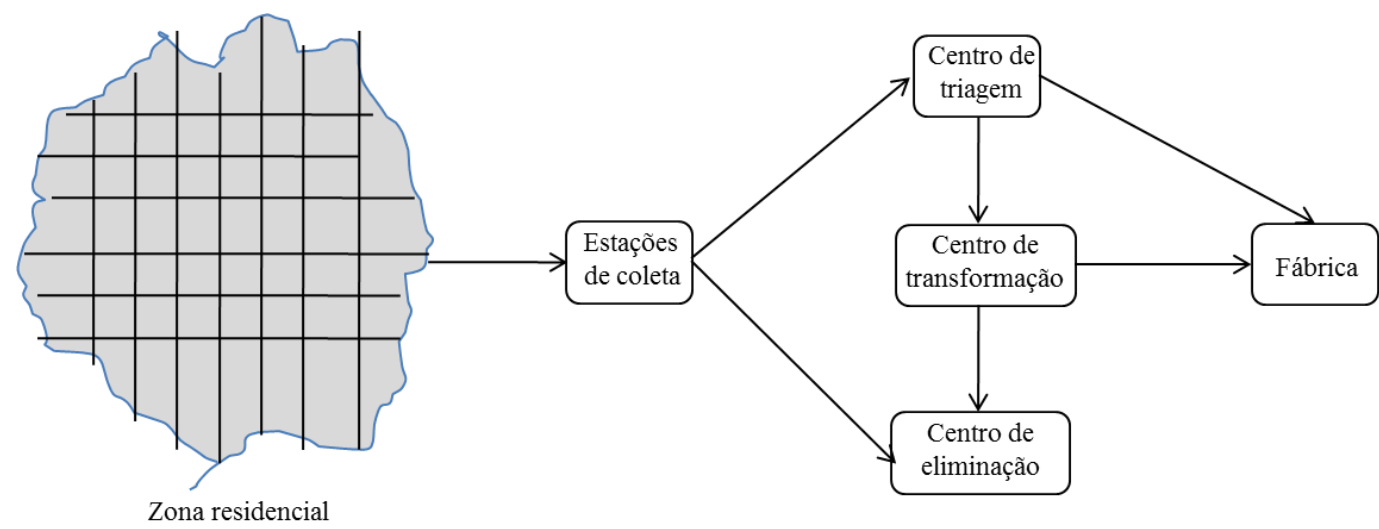

Fonte: Elaboração própria

\section{Proposta II}

Nesta segunda proposta são eliminados os centros de triagem. Os RSU são transportados diretamente das estações de coleta para os centros de eliminação para sua disposição final ou para os centros de transformação para que sejam reciclados e usados nas fábricas. Mas também, podem ser transportados diretamente das estações de coleta para as fábricas para que sejam reutilizados, conforme é mostrado na Figura 4.3.

Figura 4.3- Proposta do Caso II

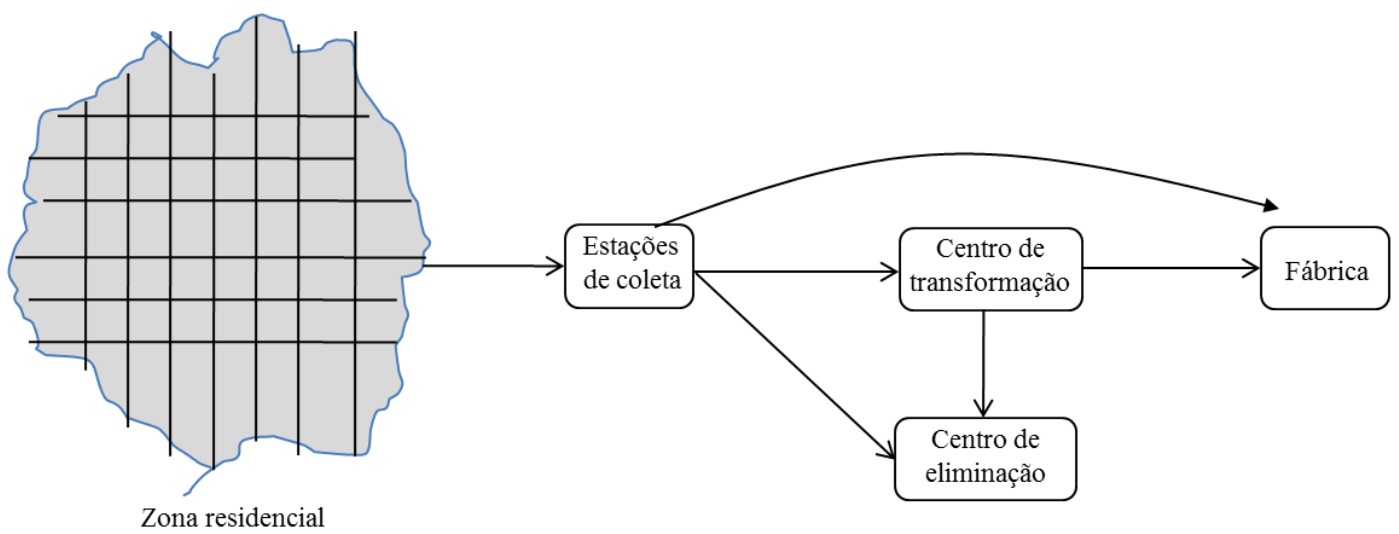

Fonte: Elaboração própria 


\subsection{PROCESSO DE ROTEIRIZAÇÃO E SELEÇÃO DAS ESTAÇÕES DE COLETA}

A primeira etapa do processo de modelagem da rede logística reversa consiste em formular o problema de roteirização e seleção das estações de coleta. Baseado no PRVJT e no modelo de Buhrkal et al (2012) formula-se um modelo que minimize o custo total obtido no processo de geração do melhor plano de roteirização, que atenda a demanda de todos os pontos de coleta e o transporte dos RSU coletados para as estações de coleta selecionadas.

A inserção de janelas de tempo no modelo é com o propósito de estabelecer períodos prefixados para a coleta de RSU nos pontos de coleta. Essa variável permitirá otimizar a frota ao longo do dia e estabelecer melhor as estações de coleta. Nesta classe de modelo, a contribuição dos cidadãos é essencial, já que retirarão os RSU das suas residências, no dia e no horário próximo à chegada do veículo coletor, evitando acumulo de lixo nos pontos de coleta.

Vários autores, entre eles, Buhrkal et al (2012) agregam um componente interessante em seus modelos matemáticos, que consiste em quantificar as emissões de $\mathrm{CO}_{2}$ dos veículos alocados em uma rota, mostrando sua relevância. Esse elemento somado à função objetivo do modelo influencia no processo de roteirização e seleção das estações de coleta, já que na medida em que aumenta o valor da emissão de $\mathrm{CO}_{2}$ pelo aumento do número de veículos circulando na rede viária, o modelo procura encontrar outra combinação que minimize os custos de transporte e de instalação das estações de coleta.

Tomando em consideração esse aspecto, passa-se a utilizar esse componente na formulação matemática do modelo proposto nesta tese, sendo definido ao final deste parágrafo. Para isso utiliza-se a equação matemática da Volvo Trucks ${ }^{25}$ (2010), sem entrar no mérito de

\footnotetext{
${ }^{25}$ Fórmula proposta pela Volvo Trucks (2010) para emissão de CO2 em kg/(ton-km): Onde:$$
\text { Emissao CO2 em } \frac{\mathrm{kg}}{\text { ton. } \mathrm{km}}=c c\left(\frac{\mathrm{em}_{k}}{q_{k}}\right)
$$

a) $\quad q_{k}=$ capacidade de carga dos veículos $k \in K$ em toneladas (ton.).

a) $\quad c c=0,275$ o consumo de combustível em litros por $\mathrm{km}(1 / \mathrm{km})$.

b) $e m_{k}=2,6$ a quantidade de emissão de $\mathrm{CO}_{2}$ gerada pelos veículos coletores $k \in K$ em quilogramas por litro $(\mathrm{kg} / \mathrm{l})$ de combustível.
} 
analisar e discutir sua formulação matemática, partindo da premissa que é uma pesquisa bem aceita pela comunidade científica de Peru.

Função Objetivo:

$$
\operatorname{Min} C T=\sum_{i, j=1 ; i \neq j}^{p^{\prime}} \sum_{k=1}^{k^{\prime}} c_{i, j} x_{i, j, k}+\sum_{e c=1}^{n} c f_{e c} y_{e c}+\sum_{i, j=1 ; i \neq j}^{p^{\prime}} \sum_{k=1}^{k^{\prime}} c c\left(\frac{e m_{k}}{q_{k}}\right) x_{i, j, k}
$$

Minimizar os custos de transporte na roteirização e transporte as estações de coleta + custos de abertura das estações de coleta selecionadas + quantificação das emissões de $\mathrm{CO}_{2}$ pelos veículos utilizados no processo de roteirização e transporte

Sujeito a:

- Restrição 1, garante que o veículo k deixa o depósito para iniciar uma rota;

$$
\sum_{j=1}^{h^{\prime}} x_{0, j, k}=1, \quad \forall k \in K
$$

- Restrição 2, garante que o veículo k depois, de visitar a última estação de coleta retorna ao depósito;

$$
\sum_{e c=1}^{n} x_{e c, 0, k}=1, \quad \forall k \in K
$$

- Restrição 3, cada ponto de coleta é atendido exatamente uma vez;

$$
\sum_{i=1 ; i \neq j}^{p^{\prime}} \sum_{k=1}^{k^{\prime}} x_{i, j, k}=1, \quad \forall j \in P C
$$

- Restrição 4, estabelece a conservação de fluxo entre pontos de coleta e estações de coleta;

$$
\sum_{i=1}^{p^{\prime}} x_{i, j, k}=\sum_{i=1}^{p^{\prime}} x_{j, i, k}, \quad \forall j \in P C \cup E C ; \quad k \in K
$$

- Restrição 5, estabelece as janelas de tempo para o atendimento nos pontos de coleta;

$$
a_{i} \leq W_{i, k} \leq b_{i}, \quad \forall i \in P C ; k \in K
$$


- Restrição 6, modela o tempo de atendimento nos pontos de coleta;

$$
W_{i, k}+s_{i}+t_{i, j} \leq W_{j, k}+100000\left(1-x_{i, j, k}\right) \quad \forall i, j \in P C \cup E C ; k \in K ; i \neq j
$$

- Restrição 7, estabelece que os veículos comecem o processo de coleta vazio e terminem vazios depois de concluir esse processo;

$$
\sum_{i=0, i=8}^{u} D_{i, k}=0, \quad \forall k \in K
$$

- Restrição 8, relação que estabelece o equilíbrio dos RSU acumulados nos pontos de coleta e nas estações de coleta;

$$
D_{i, k}+q_{i} \leq D_{j, k}+100000\left(1-x_{i, j, k}\right), \forall i \in P C \cup E C ; j \in N ; k \in K ; i \neq j
$$

- Restrição 9, a quantidade de RSU coletados tem que ser menor ou igual as capacidades dos veículos coletores;

$$
D_{i, k} \leq q_{k}, \quad \forall i \in P C ; k \in K
$$

- Restrição 10, estabelece que o atendimento dos pontos de coleta pelos veículos é limitado;

$$
\sum_{i=1}^{p^{\prime}} \sum_{j=1}^{h^{\prime}} x_{i, j, k} \leq S, \quad \forall k \in K
$$

- Restrição 11, somente é possível atribuir uma estação de coleta a um veículo, caso a estação fosse selecionada para oferecer atendimento;

$$
x_{i, e c, k} \leq y_{e c}, \quad \forall i \in N ; e c \in E C ; k \in K ; i \neq e c
$$

- Restrições de não negatividade das variáveis e das variáveis binárias;

$$
\begin{aligned}
& D_{i, k} \geq 0, \quad \forall i \in N ; k \in K \\
& W_{i, k} \geq 0, \quad \forall i \in N ; k \in K \\
& x_{i, j, k}=\{0,1\}, \quad \forall i, j \in N ; \quad k \in K \\
& y_{e c}=\{0,1\}, \quad \forall e c \in E C
\end{aligned}
$$


Onde:

I $\quad$ : Conjunto de depósitos, $i=0,1, \ldots, u$.

EC : Conjunto de estações de coleta, $i=1,2, \ldots, n$.

PC : Conjunto de pontos de coleta, $i=1,2, \ldots, h^{\prime}$.

$N \quad$ : Conjunto de pontos que compõem a rede $i=1,2, \ldots, p^{\prime}$ onde $I \cup E C \cup P$.

$K \quad$ : Conjunto de veículos homogêneos da frota designada para coleta, $k=1,2, \ldots, k^{\prime}$.

dist $_{i, j}$ : Distância entre os pontos que compõem a rede, $(i, j) \in N$.

$c_{i, j} \quad$ : Custo unitário de transporte.

$t_{i, j} \quad:$ Tempo de viagem.

$t a_{i} \quad$ : Tempo de atendimento em $i$.

$\left[a_{i} ; b_{i}\right]$ : Janela de tempo em $i \in N$.

$q_{i} \quad$ : Quantidade de RSU nos pontos de coleta i $\in P C$.

$q_{k} \quad$ : Capacidade dos veículos $k \in K$.

$c c_{k} \quad$ : Consumo de combustível do veículo em litros/Km.

$e m_{k}$ : Emissão de $\mathrm{CO}_{2}$ dos veículos $k \in K$ em gramas/litro.

$S \quad$ : Quantidade de pontos de coleta atendidos.

$c f_{e c}$ : Custo fixo de instalação de uma estação de coleta $e c \in E C$.

$x_{i, j, k}$ : Variável binária que assume valor 1 quando a rota $(i, j)$ é realizada pelo veículo $k$.

$y_{e c} \quad$ : Variável binária que assume valor 1 se a estação de coleta foi selecionada.

$D_{i, k} \quad$ : Cargaacumulada em $i \in N$ para ser transportada pelo veículo $k \in K$.

$W_{i, k} \quad:$ Tempo de atendimento inicial em $i \in N$ pelo veículo $k \in K$. 


\subsection{TRANSPORTE DOS RSU DAS ESTAÇÕES DE COLETA SELECIONADAS ATÉ OS CENTROS ESPECIALIZADOS}

Depois do processo de roteirização e seleção das estações de coleta pelo modelo da subseção 4.2, passa-se a analisar o processo de transporte dos RSU coletados nessas estações para os centros especializados, de acordo com os casos I e II propostos nas Figuras 4.2 e 4.3. O processo de transporte foi otimizado fazendo uma variação do modelo proposto em Lee J. et al. (2009).

\subsubsection{Modelo para o Caso I}

Apresenta-se um modelo que otimiza os custos de transporte dos RSU entre os diferentes centros especializados ou unidades produtivas que compõem a rede logística reversa, conforme mostrado na Figura 4.2. Ao modelo é agregado o componente de quantificação de emissões de $\mathrm{CO}_{2}$ produzidos pelos veículos no processo de transporte.

Função Objetivo:

$$
\begin{aligned}
\text { Min } C T= & \sum_{e c, c d=1}^{n, n^{\prime}} c_{e c, c d} x_{e c, c d}+\sum_{e c, e=1}^{n, e^{\prime}} c 1_{e c, e} x 1_{e c, e}+\sum_{c d, f=1}^{n^{\prime}, f^{\prime}} c 2_{c d, f} x 2_{c d, f} \\
& +\sum_{c d, c t=1}^{n \prime, n^{\prime \prime}} c 3_{c d, c t} x 3_{c d, c t}+\sum_{c t, f=1}^{n^{\prime \prime}, f^{\prime}} c 4_{c t, f} x 4_{c t, f}+\sum_{c t, e=1}^{n^{\prime \prime}, e \prime} c 5_{c t, e} x 5_{c t, e} \\
& +\sum_{k, i, j=1}^{k^{\prime}, m^{\prime}, m^{\prime}} f f_{k, i, j} Y_{k, i, j}+\frac{\sum_{e c, c d=1}^{n, n^{\prime}} \sum_{k=1}^{k^{\prime}} c c\left(\frac{e m_{k}}{q_{k}}\right)\left(Y_{k, e c, c d}\right)\left(D i s t_{E C_{C D}}\right)}{m}
\end{aligned}
$$

Minimizar os custos de transporte entre os centros especializado se reduzir as emissões de $\mathrm{CO}_{2}$

Sujeito a:

- Restrição 1, modela as capacidades das estações de coleta;

$$
\sum_{c d, e=1}^{n \prime, e \prime} x_{e c, c d} \leq a_{e c}, \quad \forall e c \in E C
$$


- Restrição 2, modela as capacidades dos centros triagem;

$$
\sum_{c d, f=1}^{n ", f \prime}\left(x 2_{c d, f}+x 3_{c d, c t}\right) \leq b_{c d}, \quad \forall c d \in C D, f \in F
$$

- Restrição 3, modela as capacidades dos centros de transformação;

$$
\sum_{f, e=1}^{f^{\prime}, e \prime}\left(x 4_{c t, f}+x 5_{c t, e}\right) \leq u_{c t}, \quad \forall c t \in C T
$$

- Restrição 4, limita o uso dos veículos para aquelas rotas selecionadas;

$$
\sum_{k=1}^{k^{\prime}} b_{-} b_{k, e c, c d} Y_{k, e c, c d} \leq x_{e c, c d}, \quad \forall e c, \in E C, c d \in C D
$$

- Restrição 5, mantem o equilíbrio do fluxo de carga nas estações de coleta, centros de triagem e centros de transformação;

$$
\sum_{e c=1}^{n} x_{e c, c d}=\sum_{c t=1}^{n^{\prime \prime}} x 3_{c d, c t}, \quad \forall c d \in C D
$$

- Restrição 6, mantem o equilíbrio do fluxo de carga nas estações de coleta, centros de triagem e fábricas;

$$
\sum_{e c=1}^{n} x_{e c, c d}=\sum_{f=1}^{f^{\prime}} x 2_{c d, f}, \quad \forall c d \in C D
$$

- Restrição 7, mantem o equilíbrio do fluxo de carga nos centros de triagem, transformação e fábricas;

$$
\sum_{c d=1}^{n \prime} x 3_{c d, c t}=\sum_{f=1}^{f^{\prime}} x 4_{c t, f}, \quad \forall c t \in C T
$$

- Restrição 8, mantem o equilíbrio do fluxo de carga nos centros de triagem, transformação e centros de eliminação;

$$
\sum_{c d=1}^{n^{\prime}} x 3_{c d, c t}=\sum_{e=1}^{e \prime} x 5_{c t, e}, \quad \forall c t \in C T
$$


- Restrições de não negatividade de todas as variáveis (inclusive as binárias);

$$
\begin{aligned}
& x_{e c, c d}, x 1_{e c, e}, x 2_{c d, f}, x 3_{c d, c t}, x 4_{c t, f}, x 5_{c t, e} \geq 0 \\
& Y_{k, i, j}=\{0,1\}, \forall k \in K, i, j \in N
\end{aligned}
$$

Onde:

EC : Conjunto de estações de coleta, $e c=1,2, \cdots, n$.

$C D \quad:$ Conjunto de centros de triagem, $c d=1,2, \cdots, n^{\prime}$.

CT : Conjunto de centros de transformação, $c t=1,2, \cdots, n "$.

F $\quad$ : Conjunto de fábricas, $f=1,2, \cdots, f^{\prime}$.

CE $\quad$ : Conjunto de centros de eliminação, $e=1,2, \cdots, e^{\prime}$.

$N \quad$ : Conjunto de nós que compõem a rede, $m=1,2, \cdots, m^{\prime}$, onde

$$
N=E C \cup C D \cup C T \cup F \cup C E
$$

$K \quad$ : Conjunto de veículos, $k=1,2, \cdots, k^{\prime}$.

$a_{e c} \quad:$ Capacidade das estações de coleta ec em toneladas.

$b_{c d} \quad:$ Capacidade do centro de triagem $c d$ em toneladas.

$u_{c t} \quad:$ Capacidade do centro de transformação $c t$ em toneladas.

$v_{e} \quad:$ Capacidade do centro de eliminação $e$ em toneladas.

Dist_EC_CD : Distância da ec para o $c d$.

Dist_EC_CE : Distância da $e c$ para o $e$.

Dist_CD_F $\quad$ : Distância do $c d$ para a $f$.

Dist_CD_CT : Distância do $c d$ para o $c t$.

Dist_CT_F : Distância do $c t$ para a $f$.

Dist_CT_CE : Distância do $c t$ para o $e$.

$c_{e c, c d} \quad$ : Custo de transporte da ec para ocd em \$.

$c 1_{e c, e} \quad:$ Custo de transporte da ec para o e em $\$$.

$c 2_{c d, f} \quad:$ Custo de transporte do $c d$ para a $f$ em $\$$. 


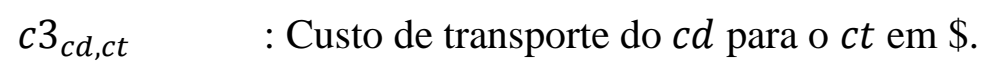

$c 4_{c t, f} \quad:$ Custo de transporte do $c t$ para a $f$ em $\$$.

$c 5_{c t, e} \quad:$ Custo de transporte do $c t$ para o $e$ em $\$$.

$b_{-} b_{k, i, j} \quad:$ Constante binária, onde 1 representa veículo na rota $(i, j)$, onde $i, j \in N$.

$f f_{k, i, j} \quad:$ Custo fixo dos veículos na rota $(i, j)$, onde $k \in K, i, j \in N$.

Q : Quantidade de veículos que compõem a frota.

$q_{k} \quad:$ Capacidade dos veículos transportadores em toneladas.

em $\quad:$ Emissão de $\mathrm{CO}_{2}$ dos veículos $k \in K$ em quilogramas/litro.

cc : Consumo de combustível do veículo em litros $/ \mathrm{km}$.

$x_{e c, c d} \quad:$ Quantidade transportada de RSU da ec para ocd em toneladas.

$x 1_{e c, e} \quad:$ Quantidade transportada de RSU da ec para o $e$ em toneladas.

$x 2_{c d, f} \quad:$ Quantidade transportada de RSU do $c d$ para a $f$ em toneladas.

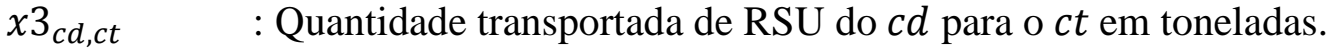

$x 4_{c t, f} \quad:$ Quantidade transportada de RSU do $c t$ para a $f$ em toneladas.

$x 5_{c t, e} \quad:$ Quantidade transportada de RSU do $c t$ para o $e$ em toneladas.

$Y_{k, i, j}=\{0,1\} \quad$ : Variável binária que assume o valor 1 se o veículo for atribuído à rota $(i, j)$, onde $i, j \in N$.

\subsubsection{Modelo para o caso II}

Apresenta-se nesta subseção uma variação do modelo anterior, mas sem considerar os centros de triagem, conforme mostrado na Figura 4.3. Além da quantificação das emissões de $\mathrm{CO}_{2}$. Espera-se com este modelo diminuir os custos de transporte da rede logística reversa, no entanto, neste caso é importante contar com a cooperação da população, já que se parte da premissa que existe coleta seletiva, o que permite fazer essa transferência direta dos RSU das estações de coleta às diferentes unidades produtivas. 
Função Objetivo:

$$
\begin{aligned}
\text { Min CT }= & \sum_{e c, c t=1}^{n, n^{\prime \prime}} c_{e c, c t} x_{e c . c t}+\sum_{e c, f=1}^{n, f \prime} c 1_{e c, f} x 1_{e c, f}+\sum_{e c, e=1}^{n, e \prime} c 2_{e c, e} x 2_{e c, e} \\
+ & \sum_{c t, f=1}^{n n^{\prime \prime} f^{\prime}} c 3_{c t, f} x 3_{c t, f}+\sum_{c t, e=1}^{n^{\prime \prime}, e \prime} c 4_{c t, e} x 4_{c t, e}+\sum_{k, i, j=1}^{k \prime, m \prime, m \prime} f f_{k, i, j} Y_{k, i, j} \\
+ & \frac{\sum_{e c, c t=1}^{n, n \prime} \sum_{k=1}^{k \prime} c c\left(\frac{e m_{k}}{q_{k}}\right)\left(Y_{k, e c, c t}\right)\left(D_{i s t} E C_{-} C T\right)}{m} \\
& \text { Minimizar os custos de transporte entre os centros especializados } \\
& \text { e reduzir as emissões de } \mathrm{CO}_{2}
\end{aligned}
$$

Sujeito a:

- Restrição 1, modela a capacidade das estações de coleta;

$$
\sum_{c t, f, e=1}^{n^{\prime \prime, f \prime, e \prime}}\left(x_{e c, c t}+x 1_{e c, f}+x 2_{e c, e}\right) \leq a_{e c}, \quad \forall e c \in E C
$$

- Restrição 2, modela a capacidade dos centros de transformação;

$$
\sum_{f, e=1}^{f \prime, e \prime}\left(x 3_{c t, f}+x 4_{c t, e}\right) \leq u_{c t}, \quad \forall c t \in C T
$$

- Restrição 3, limita o uso dos veículos às rotas selecionadas;

$$
\sum_{k=1}^{k \prime} b_{-} b_{k, e c, c t} Y_{k, e c, c t} \leq x_{e c, c t}, \quad \forall e c \in E C, c t \in C T
$$

- Restrição 4, estabelece o equilíbrio do fluxo de carga entre as estações de coleta, centros de transformação e fabrica;

$$
\sum_{e c=1}^{n} x_{e c, c t}=\sum_{f=1}^{f \prime} x 3_{c t, f}, \quad \forall c t \in C T
$$

- Restrição 5, estabelece o equilíbrio do fluxo de carga entre as estações de coleta, centros de transformação e centro de eliminação; 


$$
\sum_{e c=1}^{n} x_{e c, c t}=\sum_{e=1}^{e \prime} x 4_{c t, e}, \quad \forall c t \in C T
$$

- Restrições de não negatividade das variáveis e das variáveis binárias;

$$
\begin{aligned}
& x_{e c, c t}, x 1_{e c, f}, x 2_{e c, e}, x 3_{c t, f}, x 4_{c t, e} \geq 0 \\
& Y_{k, i, j}=\{0,1\}, \forall k \in K, i, j \in N(4.35)
\end{aligned}
$$

Onde:

EC : Conjunto de estações de coleta, $e c=1, \cdots, n$.

CT : Conjunto de centros de transformação, $c t=1, \cdots, n$.

F $\quad$ : Conjunto de fábricas, $f=1,2, \cdots f^{\prime}$.

CE : Conjunto de centros de eliminação, $e=1,2, \cdots e^{\prime}$.

$N \quad$ : Conjunto de nós que compõem a rede, $m=1,2, \cdots, m^{\prime}$, onde

$$
N=E C \cup C T \cup F \cup C E
$$

$\mathrm{K} \quad$ : Conjunto de veículos, $k=1,2, \cdots, k^{\prime}$.

$a_{e c} \quad$ : Capacidade das estações de coleta ec em toneladas.

$u_{c t} \quad$ : Capacidade do centro de transformação $c t$ em toneladas.

$v_{e} \quad:$ Capacidade do centro de eliminação $e$ em toneladas.

Dist_EC_CT : Distância entre a $e c$ e oc $t$.

$D i s t_{-} E C_{-} F$ : Distância entre a $e c$ e a $f$.

$D i s t_{-} E C_{-} C E$ : Distância entre a $e c$ e o $e$.

Dist_CT_F : Distância entre o $c t$ e a $f$.

Dist_CT_CE : Distância entre o $c t$ e o $e$.

$c_{e c, c t} \quad$ : Custo de transporte da ec para o $c t$ em $\$$.

$c 1_{e c, f} \quad$ : Custo de transporte da ec para a $f$ em $\$$.

$c 2_{e c, e} \quad:$ Custo de transporte da ec para o $e$ em $\$$.

$c 3_{c t, f} \quad:$ Custo de transporte da $c t$ para a $f$ em $\$$.

$c 4_{c t, e} \quad:$ Custo de transporte do $c t$ para o $e$ em $\$$.

$b_{-} b_{k, i, j} \quad$ : Constante binária, onde 1 representa veículo na rota $(i, j)$, onde $i, j \in N$.

$f f_{k, i, j} \quad$ : Custo fixo dos veículos na rota $(i, j)$, onde $k \in K, i, j \in N$.

$Q \quad$ : Quantidade de veículos que compõem a frota. 
$q_{k} \quad$ : Capacidade dos veículos em toneladas.

em $\quad:$ Emissão de $\mathrm{CO}_{2}$ dos veículos $k \in K$ em quilogramas/litro.

cc : Consumo de combustível do veículo em litros $/ \mathrm{km}$.

$x_{e c, c t} \quad$ : Quantidade transportada de RSU da ec para o $c t$ em toneladas.

$x 1_{e c, f} \quad$ : Quantidade transportada de RSU da ec para a $f$ em toneladas.

$x 2_{e c, e} \quad:$ Quantidade transportada de RSU da ec para o $e$ em toneladas.

$x 3_{c t, f} \quad$ : Quantidade transportada de RSU do $c t$ para a $f$ em toneladas.

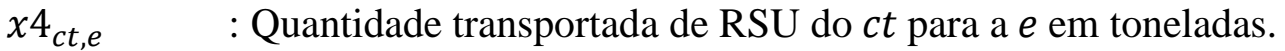

$Y_{k, i, j}=\{0,1\}$ : Variável binária assume o valor 1 se o veículo for atribuído à rota $(i, j)$, onde $i, j \in N$. Caso contrário 0 .

\subsection{ESTUDO DE CASO PARA O DISTRITO DE TRUJILLO NO PERU}

O último passo da modelagem é realizar os testes e validação dos modelos propostos nos itens anteriores em um estudo de caso. Para esse fim, utiliza-se a metodologia de programação linear inteira considerada computacionalmente como um problema NP hard. (KORTE, 2008). Os modelos programados com a ferramenta computacional GLPK utilizam como dados de entrada as informações do Distrito de Trujillo fornecida pelo Serviço de Gestão Ambiental de Trujillo (SEGAT, 2014).

Para aplicar o disposto na Lei Geral de Resíduos Sólidos 27314/2000 no Distrito de Trujillo e testar e validar os modelos propostos nesta tese foi necessário fazer uma série de levantamento de informações e estudos complementares.

\subsubsection{Distrito de Trujillo}

O Peru é um país localizado na América do Sul, sendo fronteiriço com Chile e Bolívia ao sul, com o Brasil a leste e Colômbia e Equador ao norte. A divisão política do Peru é constituída por 24 departamentos, uma Província Constitucional que é o Callao e a província sede da capital. Os departamentos estão constituídos por províncias, sendo um 
total de 180 (incluído o Callao). Estas por sua vez se integram por distritos, sendo um total de 1,747 .

Como estudo de caso foi escolhido o Distrito de Trujillo que pertence à Província de Trujillo no Departamento La Libertad (Figura 4.4). O Distrito de Trujillo, localizado a 34 metros acima do nível do mar, tem uma área de $39,36 \mathrm{~km}^{2}$ (2,2 \% da Província de Trujillo) e uma população de 317.900 habitantes (INEI, 2014). A densidade populacional é de 7.035 $\mathrm{hab} / \mathrm{km}^{2}$.

Para operacionalização da coleta dos RSU, o Serviço de Gestão Ambiental de Trujillo (SEGAT) divide o Distrito em cinco zonas, além do centro da cidade (CC). A Figura 4.5 mostra as zonas geradoras de RSU, a Tabela 4.1, a quantidade de residências por zona e a Tabela 4.2, o número de residências por classe econômica e social.

Tabela 4.1 - Quantidade de residências nas zonas geradoras de RSU

\begin{tabular}{c|c|c}
\hline $\begin{array}{c}\text { Zonas geradoras de } \\
\text { RSU }\end{array}$ & Residências & Percentagem \\
\hline 1 & 11.159 & $19 \%$ \\
\hline 2 & 11.231 & $20 \%$ \\
\hline 3 & 13.480 & $23 \%$ \\
\hline 4 & 8.630 & $15 \%$ \\
\hline 5 & 12.027 & $21 \%$ \\
\hline CC & 1.043 & $2 \%$ \\
\hline Total & $\mathbf{5 7 . 5 7 0}$ & $\mathbf{1 0 0 \%}$ \\
\hline \multicolumn{2}{|c|}{ Fonte: Huerta $(2012)$} & \\
\hline
\end{tabular}

Tabela 4.2 - Residências por classe econômica e social

\begin{tabular}{c|c|c|c}
\hline & Classe econômica & Residências & Percentagem \\
\hline & A & 6.158 & $10 \%$ \\
\hline & B & 37.835 & $66 \%$ \\
\hline & C & 13.577 & $24 \%$ \\
\hline & $\mathbf{5 7 . 5 7 0}$ & $\mathbf{5 7 . 5 7 0}$ & $\mathbf{1 0 0 \%}$ \\
\hline
\end{tabular}

Fonte: Huerta (2012) 
Figura 4.4- Localização geográfica do Distrito de Trujillo

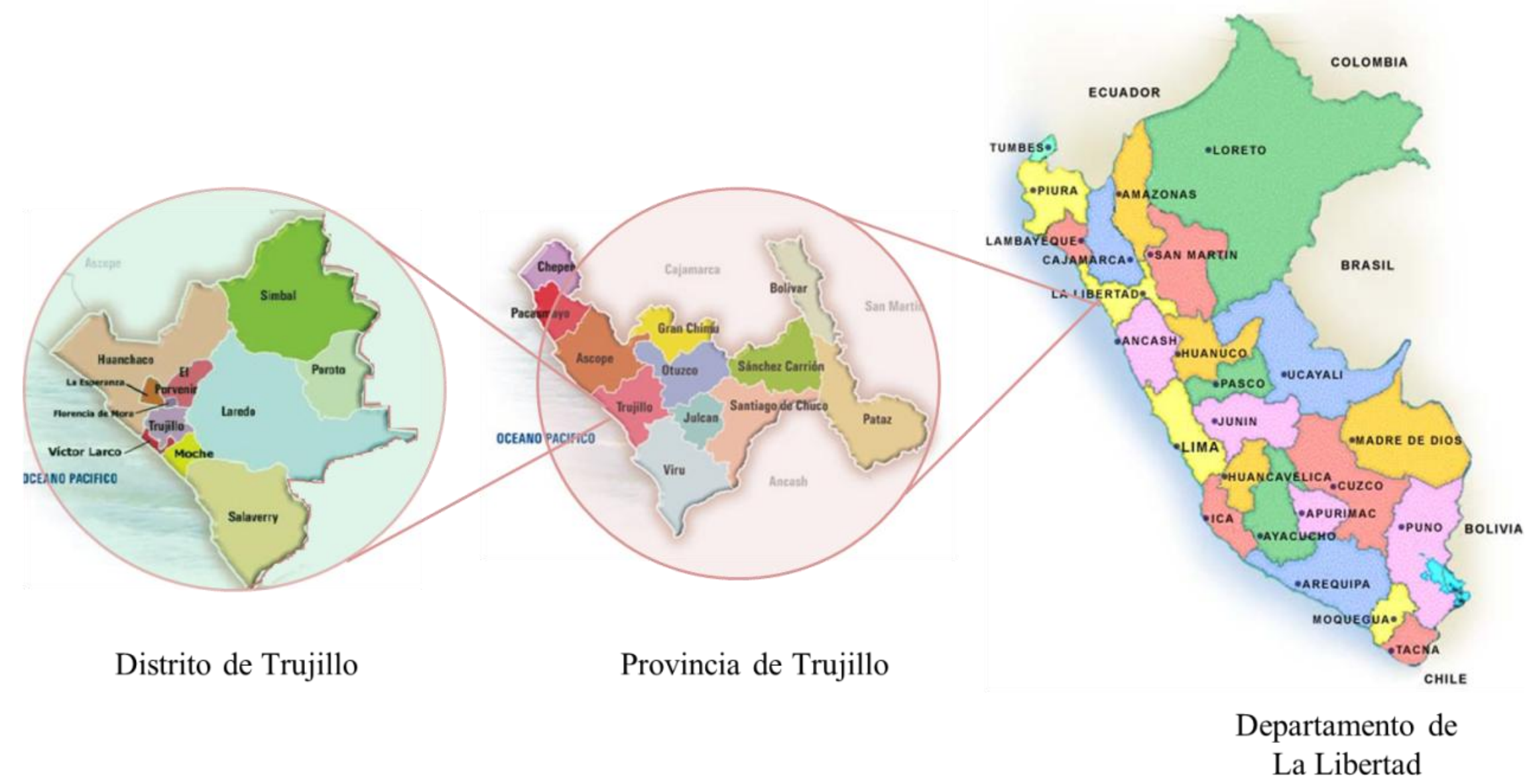

Fonte: Huerta (2012) 
Os estudos feitos no Distrito de Trujillo mostram que em média a geração de RSU por residência é 2,66 kg/residência/dia. A Tabela 4.3 apresenta a geração de resíduos em $\mathrm{kg} / \mathrm{residência/dia} \mathrm{por} \mathrm{zonas} \mathrm{segundo} \mathrm{a} \mathrm{classe} \mathrm{social} \mathrm{com} \mathrm{um} \mathrm{nível} \mathrm{de} \mathrm{confiança} \mathrm{de} 95 \%$.

Observa-se na Tabela 4.3 que as residências da zona 3 são as que produzem maior quantidade de RSU, em média 2,85 kg/dia. Isso se deve à maior concentração de pessoas por residência, isso é um caso muito comum na classe C. Uma série de puxadinhos vão sendo agregados à residência da família principal para alojar os descendentes, esse fenômeno afeta a demanda por serviços básicos e consequentemente aumenta a geração de RSU.

No caso da classe A a maior geração de RSU se dá pelo maior consumo de produtos. O total de RSU gerados no Distrito de Trujillo é de aproximadamente 153.772,33 kg/dia (Tabela 4.4), os quais são coletados por domicilio pela empresa responsável. Esta não conta com um plano de rotas que otimize o serviço de coleta. O sistema utilizado é empírico e intuitivo.

Tabela 4.3- Geração de RSU nas zonas por classe social em kg/residência/dia

\begin{tabular}{c|c|c|c|c}
\hline Zona & $\mathbf{A}$ & $\mathbf{B}$ & $\mathbf{C}$ & Média \\
\hline 1 & 3,16 & 2,44 & 3,06 & 2,68 \\
\hline 2 & - & 2,53 & 2,87 & 2,59 \\
\hline 3 & - & 2,85 & 2,85 & 2,85 \\
\hline 4 & - & 2,52 & 2,77 & 2,57 \\
\hline 5 & 2,55 & 2,46 & 2,87 & 2,62 \\
\hline CC & 2,56 & - & - & 2,56 \\
\hline Total média & $\mathbf{2 , 7 5}$ & $\mathbf{2 , 5 7}$ & $\mathbf{2 , 8 8}$ & $\mathbf{2 , 6 6}$ \\
\hline
\end{tabular}

No plano Integral de Gestão Ambiental de resíduos sólidos para a Província de Trujillo (2010-2020) reconhece-se que a coleta dos RSU tem chegado algumas vezes a $100 \%$ de cobertura, mas é realizada sem respeitar os horários estabelecidos. Isso se deve ao fato de que alguns veículos coletores já chegaram ao final da sua vida útil e a atual frota de veículos é insuficiente e inapropriada para a execução desse tipo de serviço (PIGARS, 2009). 
Figura 4.5- Zonas geradoras de RSU no Distrito de Trujillo

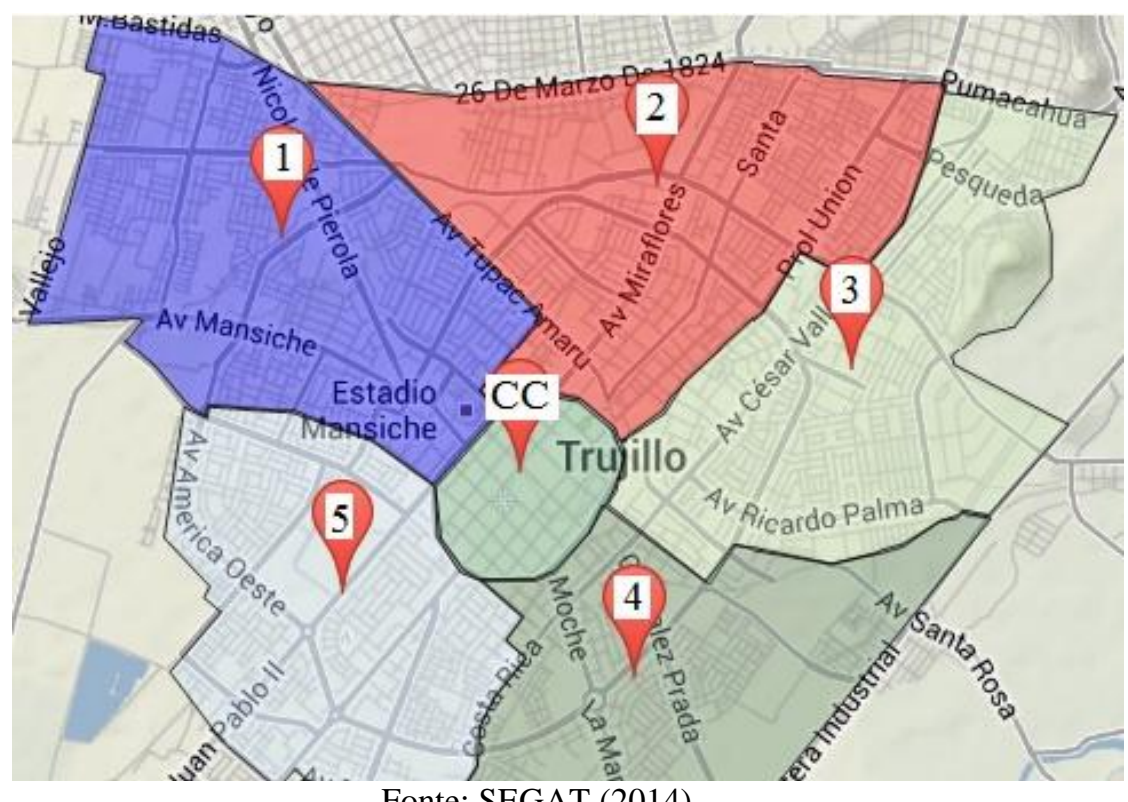

Fonte: SEGAT (2014)

Tabela 4.4 - Geração de RSU por zonas

\begin{tabular}{c|c}
\hline Zonas & $\begin{array}{c}\text { Quantidade gerada de RSU } \\
\text { (kg./dia) }\end{array}$ \\
\hline 1 & $29.906,12$ \\
\hline 2 & $29.088,29$ \\
\hline 3 & $38.418,00$ \\
\hline 4 & $22.179,10$ \\
\hline 5 & $31.510,74$ \\
\hline CC & $2.670,08$ \\
\hline Total & $\mathbf{1 5 3 . 7 7 2 . 3 3}$ \\
\hline
\end{tabular}

Fonte: Huerta (2012)

Depois do processo de coleta, os RSU são transportados direto para o lixão El Milagro. Trujillo não tem aterro sanitário, assim também não têm estações de coleta, centros de triagem e de transformação devidamente formalizados e controlados pelo Município. Existem algumas pequenas empresas informais que compram resíduos obtidos por catadores nas ruas. Vale ressaltar que perto do lixão El Milagro existe uma zona chamada de Parque Industrial que não é aproveitada totalmente para o processamento dos resíduos coletados para a reciclagem ou reutilização.

Para melhorar esse quadro, essa pesquisa propõe fazer o planejamento da rede logística reversa da Zona 5 do Distrito de Trujillo baseado nos modelos formulados no início deste 
Capitulo. Como a Zona 5 é muito extensa, questão que poderia vir inviabilizar os testes e validação dos modelos, está foi separada em três subzonas e modeladas separadamente. Assim, a primeira subzona compreende os subsetores de La Merced e La Arboleda_San Eloy, a segunda, o subsetor de San André e a terceira, o subsetor de Monserrate.

Baseado nos dados e relatórios da SEGAT, depoimentos de funcionários desse órgão gestor e na análise do atual plano de rotas para coleta domiciliar dos RSU nos subsetores a serem estudados, conclui-se que o atual sistema operacional, além de ser caro, não é funcional. Nesse sentido, propõe-se a instalação de um conjunto de pontos de coletas nos subsetores, acessíveis a população, para que ela colabore com a coleta seletiva, levando seus RSU até esses pontos coletores.

Talvez seja um tema polêmico, transferir essa responsabilidade à população. No entanto, neste trabalho não se abordará esse tema, somente é uma premissa que se coloca para objeto da modelagem, já que esse elemento dinamiza o sistema operacional da rede logística reversa proposta. A alocação geográfica dos centros especializados ou unidades produtivas propostas para todo o Distrito de Trujillo mostra-se na Figura 4.6.

Figura 4.6 - Localização geográfica dos centros especializados no Distrito de Trujillo

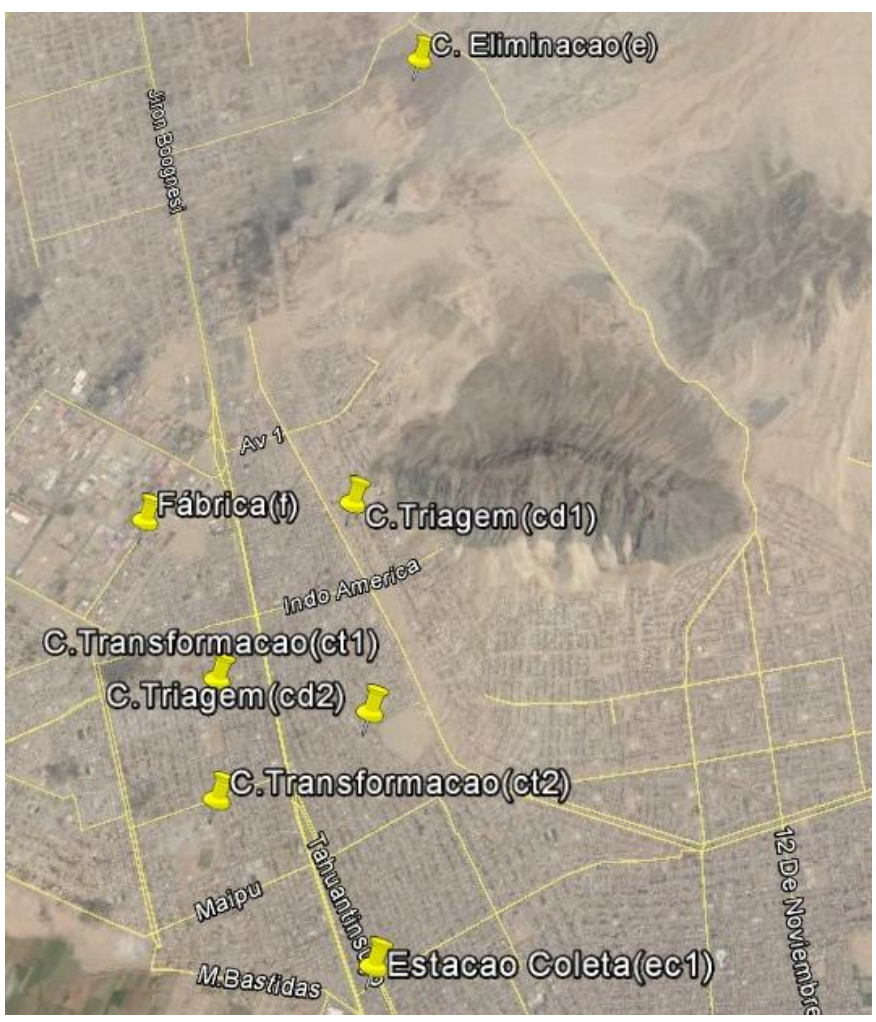

Fonte: Google Earth, 2015 


\subsubsection{Etapa 1: Aplicação do Modelo PRVJT nos Subsetores La Merced e La Arboleda_San Eloy}

A Figura 4.7 mostra a localização dos 37 pontos de coleta (pc1, .., pc37) propostos nestes subsetores, assim como os dados de geração de RSU (Tabela 4.5). Considera-se que o tempo de atendimento em cada ponto de coleta é aproximadamente de 4 minutos e a janela de tempo proposta está no intervalo de 7:00 às 10:00 horas.

Figura 4.7 - Subsetores La Merced e La Arboleda_San Eloy

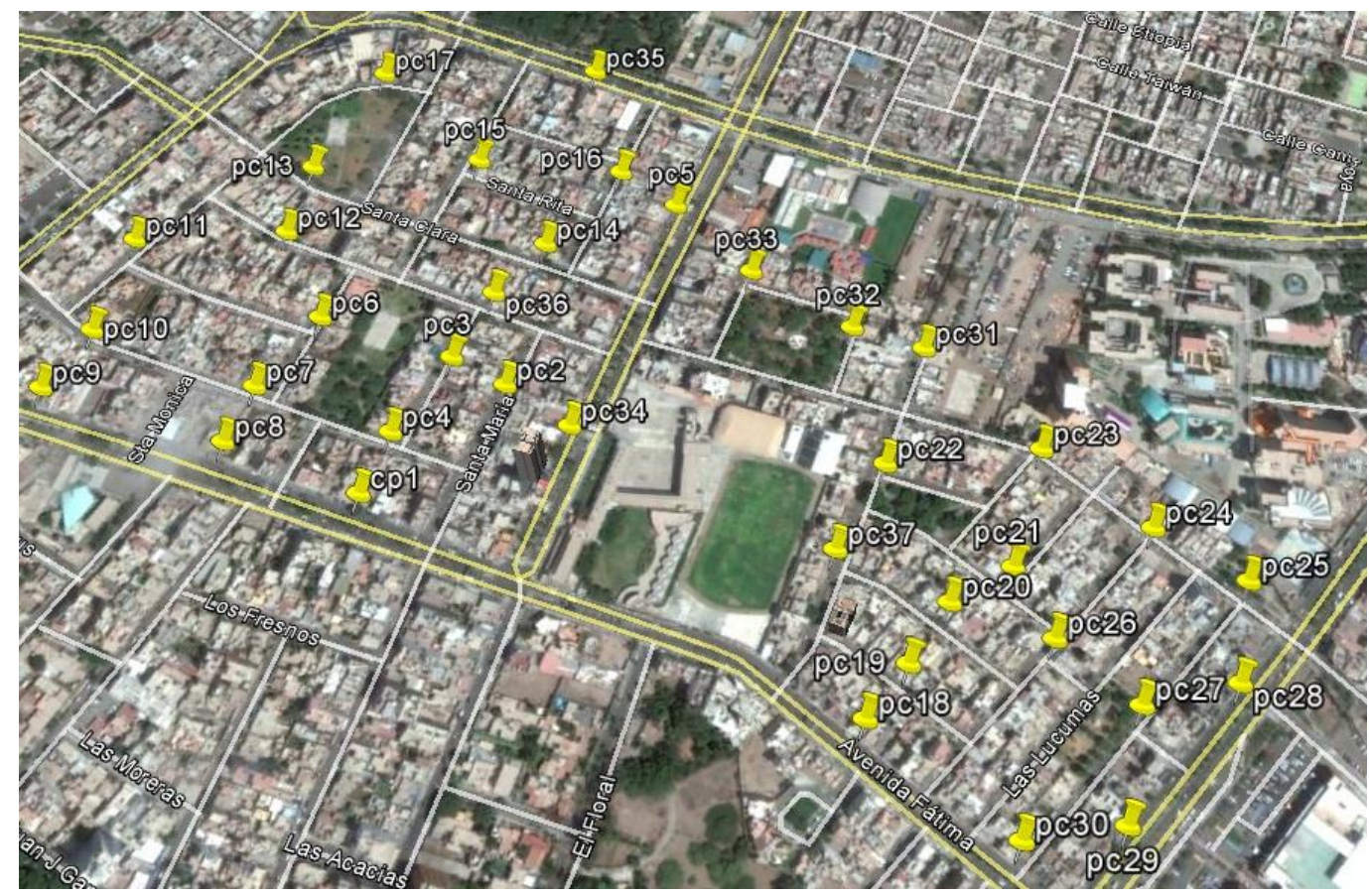

Fonte: Google Earth, 2015

Os resultados mostram que é possível o atendimento dos pontos de coleta somente com um veículo coletor e uma estação de coleta. Pode-se observar da Figura 4.8 a rota que faz o veículo. Ele sai do ponto D0 e volta ao mesmo depois de visitar todos os pontos coletores.

Tabela 4.5 - Dados de geração de RSU dos subsetores La Merced e La Arboleda_San Eloy

\begin{tabular}{c|c|c|c}
\hline Subsetores & Residências & $\begin{array}{c}\text { RSU gerado } \\
(\text { Kg/dia })\end{array}$ & $\begin{array}{c}\text { Pontos de } \\
\text { coleta }\end{array}$ \\
\hline La Merced & 589 & $1.566,74$ & 20 \\
\hline La Arboleda_San Eloy & 530 & $1.409,80$ & 17 \\
\hline Total & $\mathbf{1 . 1 1 9}$ & $\mathbf{2 . 9 7 7 , 5 4}$ & $\mathbf{3 7}$ \\
\hline
\end{tabular}

Fonte: (Huerta, 2012) 
Cada ponto de coleta tem uma capacidade de 90 quilogramas de armazenamento e a capacidade da frota de veículos coletores que tem o Município de Trujillo é de 7 toneladas. Com todas essas informações testou-se a primeira Etapa do Modelo Proposto.

Figura 4.8 - Roteirização nos Subsetores La Merced_La Arboleda_San Eloy

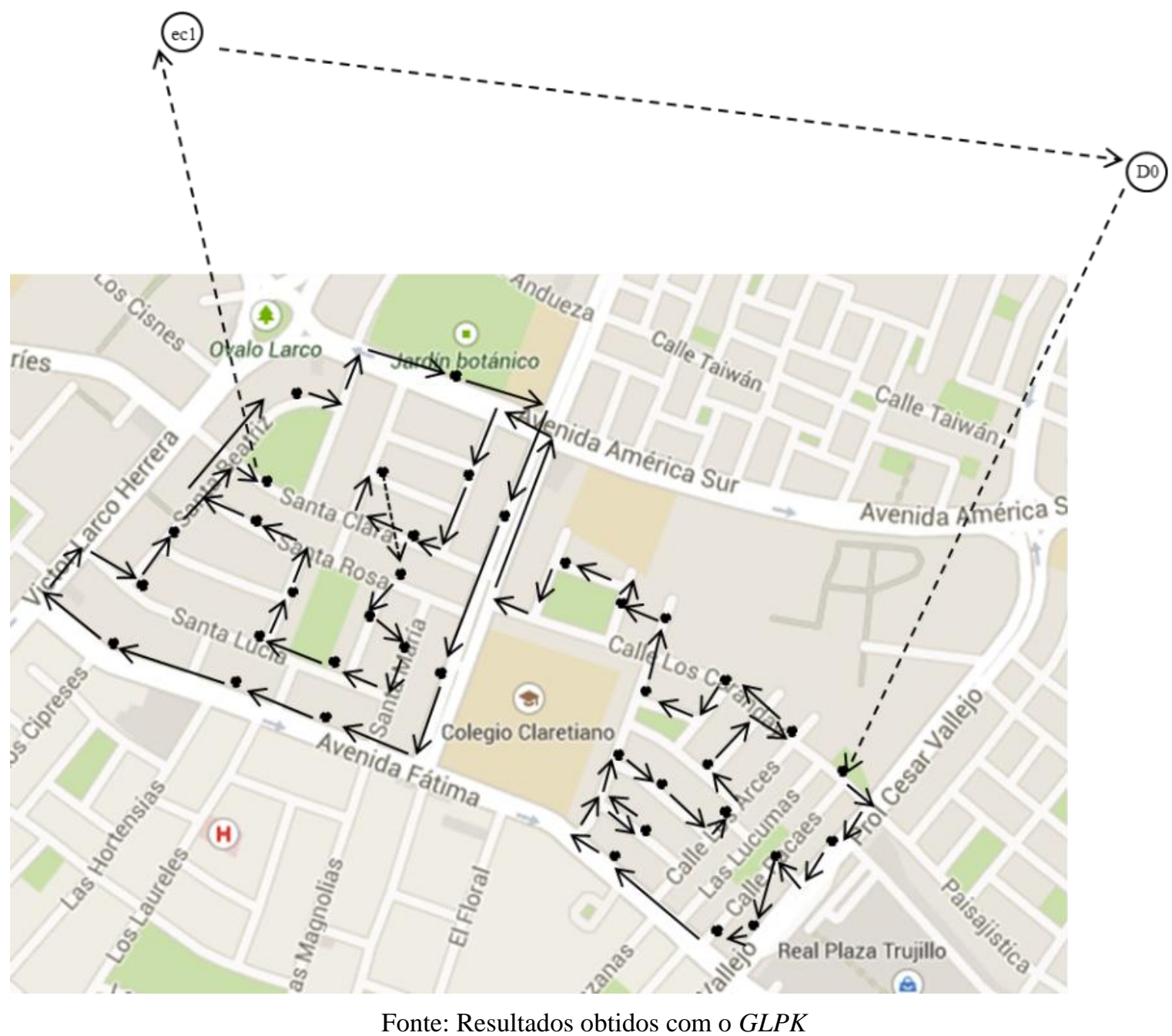

Na Tabela 4.6 mostra-se a ordem em que o veículo visita os pontos coletores. Como se pode observar, o veículo primeiro passa coletando os RSU de todos os pontos coletores, uma vez que visita o último ponto coletor se dirige à estação de coleta selecionada para descarregar e depois retorna ao D0.

O custo total de operação do sistema é de \$173.995, um valor bem aceito pelos especialistas da SEGAT, além de ser bem menor que o atual cenário. 
Tabela 4.6 - Resultados obtidos da Etapa 1 do processo de modelagem nos subsetores La Merced e Arboleda_San Eloy

\begin{tabular}{|c|c|c|c|c|c|}
\hline \multicolumn{6}{|c|}{$\begin{array}{l}\text { Custo total }(\$): 173.995,00 \\
\mathrm{CO}_{2} \text { gerado }(\mathrm{Kg} / \text { ton.-km): } 0,00398357142857143 \\
\text { Estação de coleta selecionada: } \mathbf{e c 1}\end{array}$} \\
\hline Rota & Veículo & Rota & Veículo & Rota & Veículo \\
\hline $\mathrm{pc} 25$ & $\mathrm{v} 1$ & pc23 pc22 & $\mathrm{v} 1$ & pc6 pc12 & $\mathrm{v} 1$ \\
\hline $\mathrm{pc} 25 \mathrm{pc} 28$ & $\mathrm{v} 1$ & pc22 pc31 & v1 & pc12 pc17 & $\mathrm{v} 1$ \\
\hline pc28 pc27 & $\mathrm{v} 1$ & pc31 pc32 & $\mathrm{v} 1$ & pc17 pc35 & $\mathrm{v} 1$ \\
\hline pc27 pc29 & $\mathrm{v} 1$ & pc32 pc33 & $\mathrm{v} 1$ & pc35 pc5 & $\mathrm{v} 1$ \\
\hline pc29 pc30 & $\mathrm{v} 1$ & pc33 pc16 & $\mathrm{v} 1$ & pc5 pc34 & $\mathrm{v} 1$ \\
\hline pc30 pc18 & $\mathrm{v} 1$ & $\mathrm{pc} 16 \mathrm{pc} 14$ & $\mathrm{v} 1$ & $\mathrm{pc} 34 \mathrm{pc} 1$ & $\mathrm{v} 1$ \\
\hline pc18 pc19 & $\mathrm{v} 1$ & pc14 pc15 & $\mathrm{v} 1$ & $\mathrm{pc} 1 \mathrm{pc} 8$ & $\mathrm{v} 1$ \\
\hline pc19 pc37 & $\mathrm{v} 1$ & $\mathrm{pc} 15 \mathrm{pc} 36$ & $\mathrm{v} 1$ & $\mathrm{pc} 8$ & $\mathrm{v} 1$ \\
\hline pc37 pc20 & $\mathrm{v} 1$ & pc36 pc3 & $\mathrm{v} 1$ & $\mathrm{pc} 9 \mathrm{pc} 10$ & $\mathrm{v} 1$ \\
\hline pc20 pc26 & $\mathrm{v} 1$ & $\mathrm{pc} 3 \quad \mathrm{pc} 2$ & $\mathrm{v} 1$ & $\mathrm{pc} 10 \mathrm{pc} 11$ & $\mathrm{v} 1$ \\
\hline pc26 pc21 & $\mathrm{v} 1$ & $\mathrm{pc} 4$ & $\mathrm{v} 1$ & $\mathrm{pc} 11 \mathrm{pc} 13$ & $\mathrm{v} 1$ \\
\hline $\mathrm{pc} 21 \mathrm{pc} 24$ & $\mathrm{v} 1$ & $\mathrm{pc} 4$ & $\mathrm{v} 1$ & $\mathrm{pc} 13 \mathrm{c} 1$ & $\mathrm{v} 1$ \\
\hline pc24 pc23 & v1 & $\mathrm{pc} 7$ & $\mathrm{v} 1$ & ec1 & v1 \\
\hline
\end{tabular}

\subsubsection{Etapa 2: Aplicação do Modelo de Transporte nos Subsetores La Merced e La Arboleda_San Eloy-Caso I}

Realizada a Etapa 1 de coleta dos RSU passa-se à Etapa 2 para prosseguir com o processo logístico reverso. Baseado na localização dos centros especializados ou unidades produtivas propostas na Figura 4.6 e considerando uma frota de veículos com capacidade de 14 toneladas é executado o programa computacional GLPK.

Os resultados gerados estão mostrados na Figura 4.9. Dos 2.977,54 kg de RSU coletados e alocados na $e c 1,2.577,00$ é transferido para o centro de triagem $c d l$, o restante, 400,54 kg é enviado para o $c d 2$. Daqui têm-se duas alternativas, se os RSU estão higienizados e prontos para utilização como matéria prima, eles são encaminhados diretos para a única fábrica da rede. Caso contrário, eles são transferidos aos centros de transformação.

O $c d 2$ envia seus 400,54 $\mathrm{kg}$ ao $c t 2$, o $c d 1$ remete $1.750,00 \mathrm{~kg}$ para o $c t 1$ e $827,00 \mathrm{~kg}$ para o ct2. Depois do processo de transformação, o $c t 1$ expede $1.700,00 \mathrm{~kg}$ para a fábrica e o $c t 2$, 
$1.200,00 \mathrm{~kg}$. Ou seja, a fábrica recebe em total $2.900,00 \mathrm{~kg}, 77,00 \mathrm{~kg}$ a menos que quando vem direto dos centros de triagem. Esses $77,00 \mathrm{~kg}$ são encaminhados para o centro de eliminação.

Figura 4.9 - Transporte dos RSU para os centros especializados, Caso I

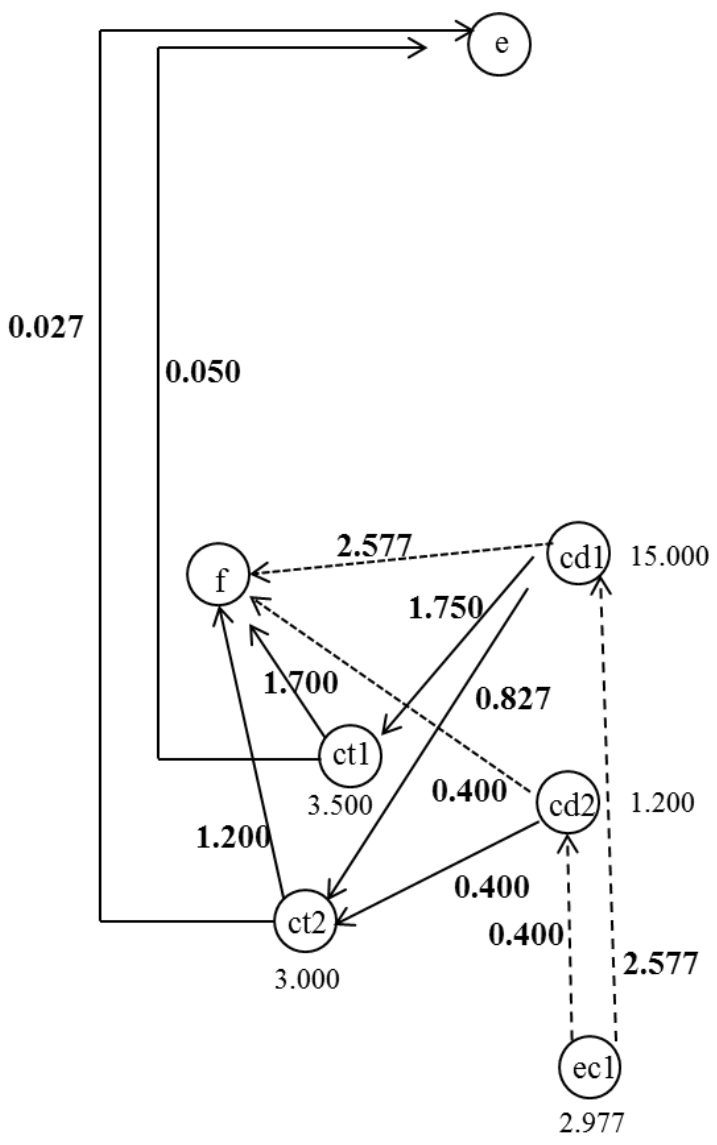

Nota: Os valores das unidades estão em decimais, notação em espanhol.

Fonte: Resultados obtidos com o GLPK

\subsubsection{Etapa 2: Aplicação do Modelo de Transporte nos Subsetores La Merced e La Arboleda_San Eloy-Caso II}

Neste caso II não existem os centros de triagem, assim dos $2.977,00 \mathrm{~kg}$ de RSU que recebe a estação de coleta $e c 1,1.227,00 \mathrm{~kg}$ são transportados para o centro de transformação $c t 1$ e o restante, $1.750,00 \mathrm{~kg}$ para o $c t 2$. Do centro de transformação $c t 1$ são remetidos $1.200 \mathrm{~kg}$ para a fábrica e $27,00 \mathrm{~kg}$ para o centro de eliminação. Do ct2 são enviados 1.700,00 kg à fábrica e 50,00 kg para o centro de eliminação (Figura 4.10). 
Figura 4.10 - Transporte dos RSU para os centros especializados, sem centro de triagem, Caso II

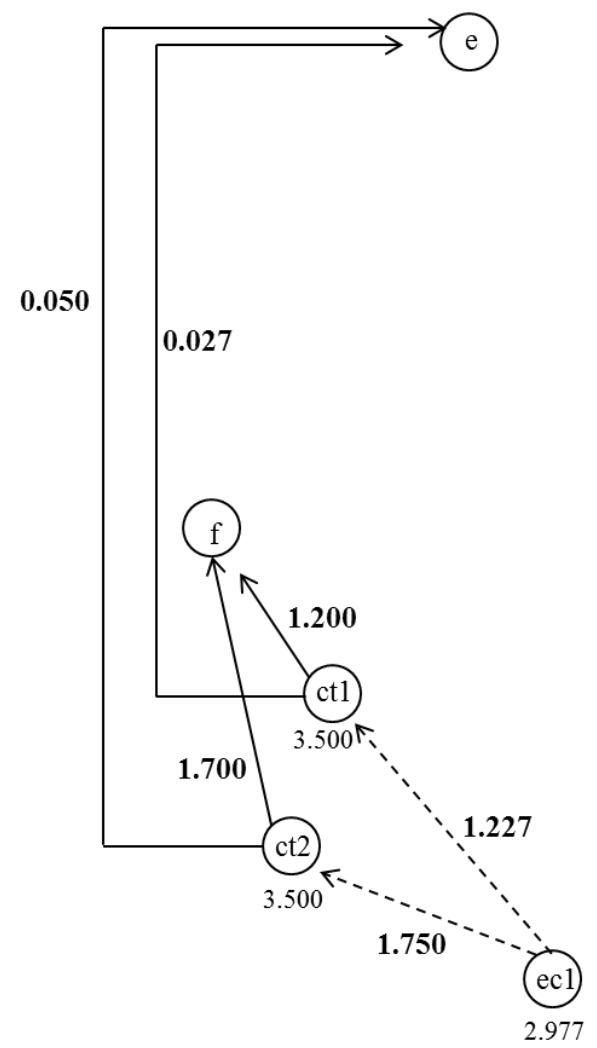

Nota: Os valores das unidades estão em decimais, notação em espanhol.

Fonte: Resultados obtidos com o GLPK

Observa-se que o fluxo de carga se movimentando na rede alcança o mesmo resultado que o Caso II, no entanto, os custos diferem sensivelmente. Nesta configuração de rede se têm dois nós a menos, isso representa uma redução de custo, tanto em transporte como em custos de capacidade instalada para que operem duas unidades produtivas. Além, de outra série de custos pertinentes a estes tipos de instalações.

O grande diferencial nos modelos propostos é a participação, cooperação e conscientização da população, assim como dos outros órgãos atuantes, principalmente, o papel que jogam as autoridades locais na sua capacidade de planejar, gerenciar e operar de forma integrada e coordenada todas as ações que se realizam para o melhoramento da qualidade do serviço de coleta e destinação final dos RSU, tendo como objetivo final o bem-estar da comunidade e a preservação do meio ambiente. A estruturação de um bom sistema de informação e de controle operacional é essencial no planejamento e gerenciamento da cadeia logística reversa. 


\subsubsection{Teste no Subsetor San André: Aplicação das Etapas 1 e 2 (Caso I e Caso II)}

Seguindo com a mesma metodologia das seções anteriores é realizado outro teste, desta vez o subsetor escolhido é San Andrés que tem 928 residências. Em média cada residência gera 2,66 kg/dia de RSU, fazendo um total de 2.468,00 kg/dia.

Para programar o modelo de coleta foram definidas janelas de tempo para o atendimento e veículos coletores com capacidades de 7 toneladas. Similar aos testes anteriores considerase que na cidade existem 43 pontos de coletas com capacidade de 90 quilogramas, onde parte-se do suposto que a população deposita os RSU. Ou seja, não existe coleta domiciliar.

Na Tabela 4.7 e Figura 4.11 são apresentados os resultados obtidos no processo de coleta, primeira etapa da modelagem, sendo que todos os pontos de coleta são atendidos com um veículo. O custo de operação do processo de coleta é de \$178.389,00.

Figura 4.11 - Roteirização no Subsetor San Andrés da zona 5

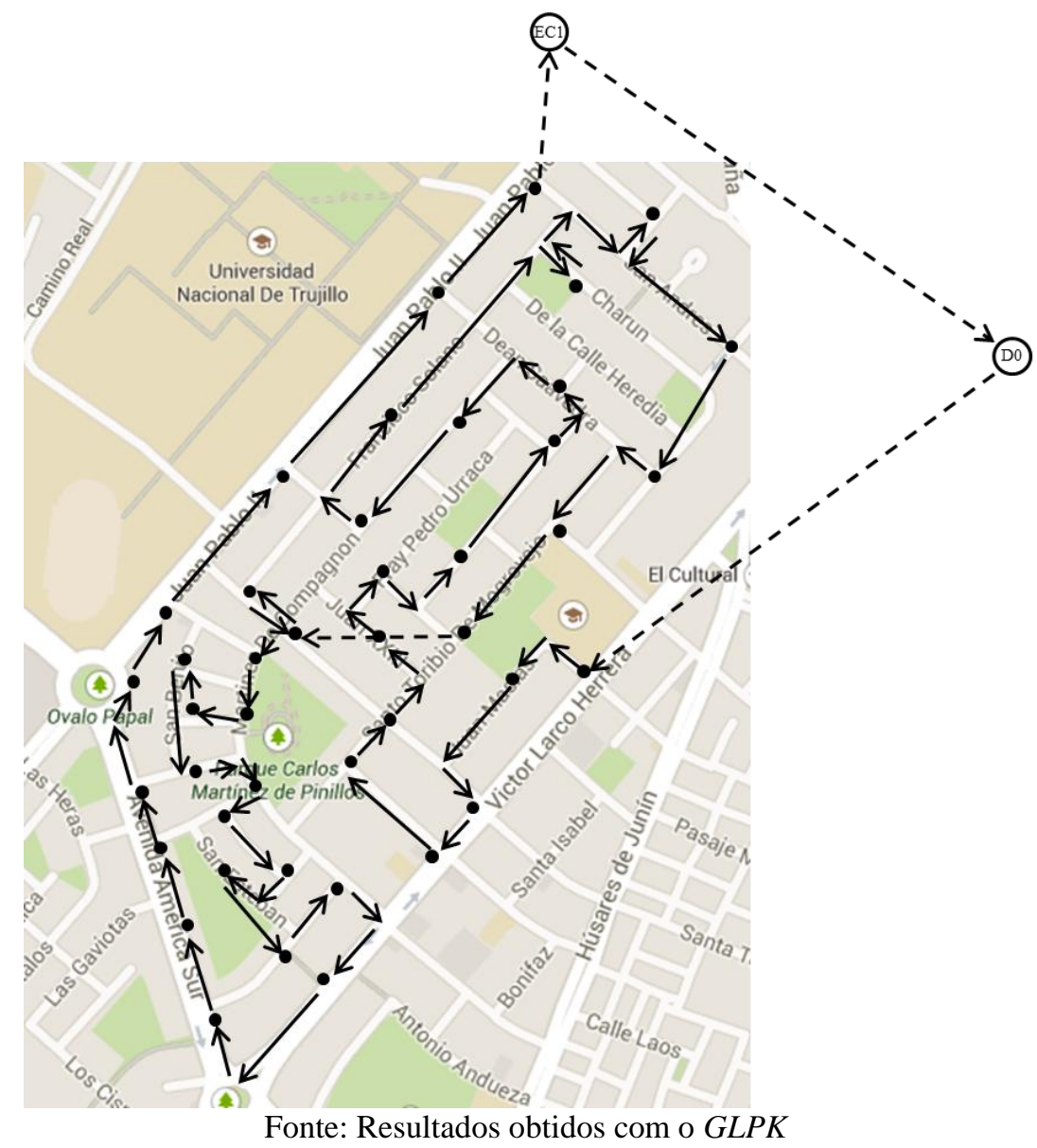


Tabela 4.7 - Resultados obtidos no subsetor San Andrés da zona 5

\begin{tabular}{|c|c|c|c|c|c|}
\hline \multicolumn{6}{|c|}{$\begin{array}{l}\text { Custo total }(\$): 178.389,00 \\
\text { C02 gerado }(\mathrm{Kg} / \mathrm{ton}-\mathrm{km}): 0,00459642857142857 \\
\text { Estação de coleta selecionada: } \text { ec1 }\end{array}$} \\
\hline Rota & Veículo & Rota & Veículo & Rota & Veículo \\
\hline D0 $\quad$ pc32 & v1 & pc41 pc43 & v1 & pc14 pc15 & v1 \\
\hline pc32 pc31 & v1 & pc43 pc42 & v1 & pc15 pc16 & v1 \\
\hline pc31 pc20 & $\mathrm{v} 1$ & $\mathrm{pc} 42 \mathrm{pc} 34$ & $\mathrm{v} 1$ & pc16 pc17 & $\mathrm{v} 1$ \\
\hline pc20 pc19 & v1 & pc34 pc33 & v1 & pc17 pc18 & v1 \\
\hline pc19 pc21 & $\mathrm{v} 1$ & pc33 pc30 & $\mathrm{v} 1$ & $\mathrm{pc} 18 \mathrm{pc} 1$ & $\mathrm{v} 1$ \\
\hline pc21 pc22 & $\mathrm{v} 1$ & pc30 pc23 & $\mathrm{v} 1$ & pc1 pc2 & $\mathrm{v} 1$ \\
\hline pc22 pc28 & $\mathrm{v} 1$ & pc23 pc24 & $\mathrm{v} 1$ & pc2 pc3 & $\mathrm{v} 1$ \\
\hline pc28 pc27 & $\mathrm{v} 1$ & pc24 pc10 & $\mathrm{v} 1$ & pc3 pc4 & $\mathrm{v} 1$ \\
\hline pc27 pc29 & v1 & pc10 pc11 & $\mathrm{v} 1$ & pc4 pc5 & $\mathrm{v} 1$ \\
\hline pc29 pc35 & v1 & pc11 c8 & $\mathrm{v} 1$ & pc5 pc6 & $\mathrm{v} 1$ \\
\hline pc35 pc39 & v1 & $\begin{array}{ll}\mathrm{pc} 8 & \mathrm{pc} 7\end{array}$ & v1 & pc6 pc25 & v1 \\
\hline pc39 pc36 & v1 & $\mathrm{pc} 9$ & $\mathrm{v} 1$ & pc25 pc38 & $\mathrm{v} 1$ \\
\hline pc36 pc26 & $\mathrm{v} 1$ & pc9 pc12 & $\mathrm{v} 1$ & pc38 pc40 & $\mathrm{v} 1$ \\
\hline pc26 pc37 & $\mathrm{v} 1$ & $\mathrm{pc} 12 \mathrm{pc} 13$ & $\mathrm{v} 1$ & pc40 ec1 & $\mathrm{v} 1$ \\
\hline pc37 pc41 & v1 & pc13 pc14 & v1 & ec1 D0 & v1 \\
\hline
\end{tabular}

Fonte: Resultados obtidos com o GLPK

Testada a Etapa 1 do processo de modelagem, passa-se a Etapa 2, Caso I e Caso II. Igual que no problema anterior, mante-se a mesma configuração das redes propostas.

Os resultados para o Caso I são os seguintes (Figura 4.12a):

- Dos 2.468,00 kg/dia coletados na estação de coleta, 2.068,00 kg são encaminhados ao $c d 1$ e o restante, $400,00 \mathrm{~kg}$, ao $c d 2$;

- Do $c d 1$ são selecionados $1.750,00 \mathrm{~kg}$ para ir ao $c t 1$ e 318,00 kg para o $c t 2$;

- Dos $1.750,00 \mathrm{~kg}$ recebidos pelo $c t 1,1.700,00 \mathrm{~kg}$ vão para a fábrica e 50,00 kg para o centro de eliminação;

- Também se tem a alternativa de enviar os $2.068,00 \mathrm{~kg}$ diretamente a fábrica sem passar pelos centros de transformação. Nesse caso, não se tem resíduo indo para o centro de eliminação;

- Do $c d 2$ podem ir os 400,00 diretamente a fábrica ou serem encaminhados ao $c t 2$ para processo de transformação; 
- O ct2 recebe em total $718,00 \mathrm{~kg}$, dos quais envia $648,00 \mathrm{~kg}$ para a fábrica e 70,00 kg para o centro de eliminação;

- O centro de eliminação recebe em total 120,00 kg/dia de RSU quando os RSU passam pelos centros de transformação.

Igual que no problema anterior observa-se que se tem uma redução considerável de RSU indo para os centros de eliminação, quando existe um sistema de coleta seletiva aliado a um bom sistema de logística reversa. E se todo o RSU é possível de reciclagem, então não se tem resíduo indo para o centro de eliminação.

Os resultados para o Caso II foram os seguintes (Figura 4.12b):

Figura 4.12 - Transporte de RSU coletados no subsetor San Andrés, para os centros especializados do Distrito de Trujillo, Caso I e Caso II

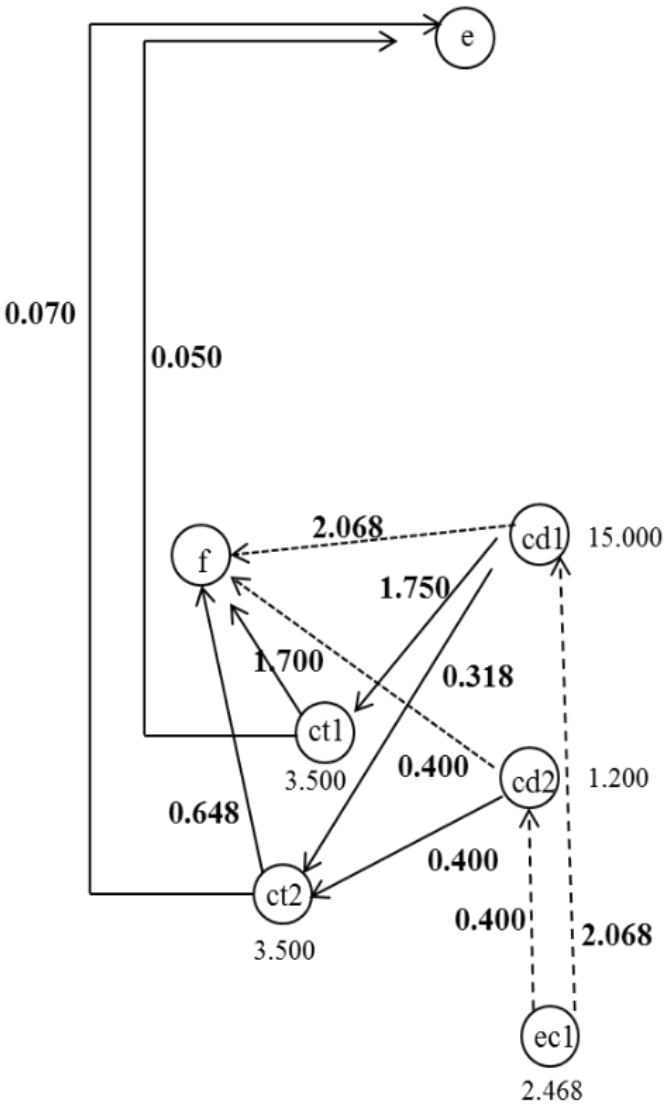

(a)

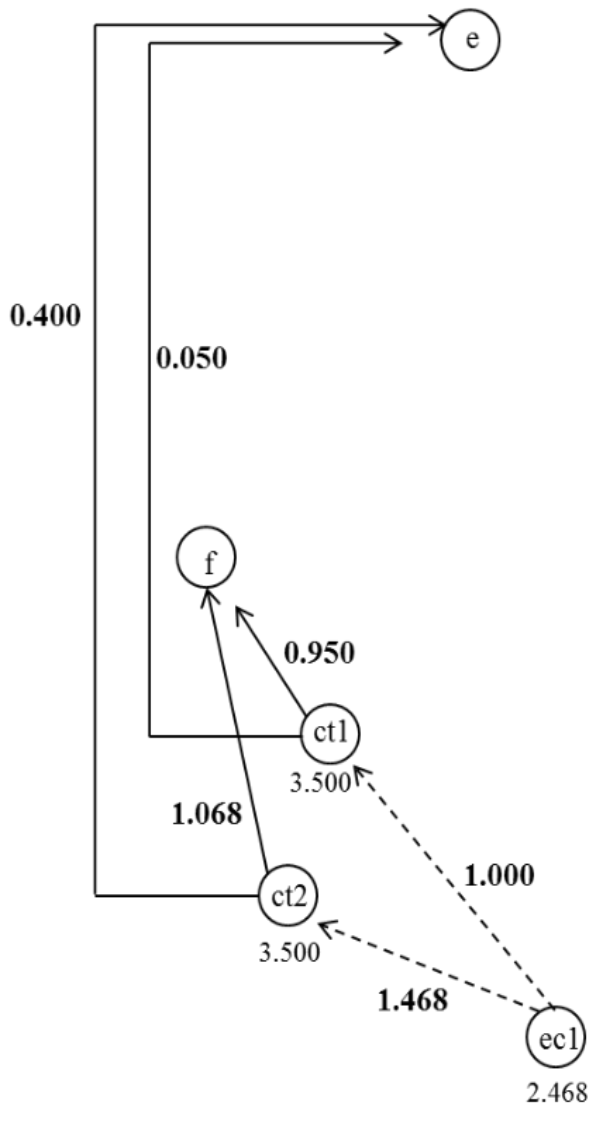

(b)

Nota: Os valores das unidades estão em decimais, notação em espanhol.

Fonte: Resultados obtidos com o GLPK 
- Dos 2.468,00 kg/dia coletados na estação de coleta, 1.000,00 kg são encaminhados ao $c t 1$ e o restante, $1.468,00 \mathrm{~kg}$, ao $c t 2$;

- Dos $1.000,00 \mathrm{~kg}$ recebidos pelo $c t 1,950,00 \mathrm{~kg}$ vão para a fábrica e 50,00 para o centro de eliminação;

- Do total que recebe o $c t 2,1.068,00 \mathrm{~kg}$ envia para a fábrica e $400 \mathrm{~kg}$ para o centro de eliminação;

- O centro de eliminação recebe em total $450 \mathrm{~kg} / \mathrm{dia}$ de RSU.

Neste segundo estudo de caso, subsetor San Andrés, obteve-se uma diferença na aplicação dos dois casos da Etapa 2. No primeiro estudo de caso (4.4.2; 4.4.3 e 4.4.4) a quantidade de RSU que recebe o centro de eliminação é igual para o Caso I e para o Caso II, já para o subsetor San Andrés, os valores diferem, isso se deve as premissas estabelecidas no problema quanto a probabilidade de reciclagem ou recuperação de RSU recebidos num centro de transformação. São valores experimentais, já que não se tem uma base confiável de dados para estimar essas porcentagens.

\subsubsection{Teste no Subsetor Monserrate: Aplicação das Etapas 1 e 2 (Caso I e Caso II)}

O subsetor Monserrate tem 2.000 residências que geram 4.920,00quilogramas de RSU por dia. Para este caso foram propostos 55 pontos de coleta. As premissas são similares aos dois estudos de casos anteriores.

Na Tabela 4.8 e Figura 4.13 são apresentados os resultados obtidos no processo de coleta, primeira etapa da modelagem, sendo que todos os pontos de coleta são atendidos com um veículo. O custo de operação do processo de coleta é de $\$ 154.396,00$.

Testada a Etapa 1 do processo de modelagem, passa-se a Etapa 2, Caso I e Caso II. Igual que no problema anterior, mante-se a mesma configuração das redes propostas.

Os resultados para o Caso I foram os seguintes (Figura 4.13a): 
Tabela 4.8 - Resultados obtidos no subsetor Monserrate da zona 5

\begin{tabular}{|c|c|c|c|c|c|}
\hline \multicolumn{6}{|c|}{$\begin{array}{l}\text { Custo total }(\$): 154.396,00 \\
\text { C02 gerado (Kg/ton-km): } 0,00582214285714285 \\
\text { Estação de coleta selecionada: ec1 }\end{array}$} \\
\hline Rota & Veículo & Rota & Veículo & Rota & Veículo \\
\hline D0 $\quad$ pc53 & $\mathrm{v} 1$ & pc9 $\mathrm{pc} 11$ & $\mathrm{v} 1$ & pc34 pc50 & $\mathrm{v} 1$ \\
\hline pc53 pc51 & v1 & pc11 pc6 & v1 & pc50 pc48 & v1 \\
\hline pc51 pc47 & v1 & pc6 $\mathrm{pc} 2$ & v1 & pc48 pc32 & v1 \\
\hline pc47 pc45 & v1 & $\mathrm{pc} 1$ & v1 & pc32 pc43 & v1 \\
\hline pc45 pc46 & v1 & pc3 & v1 & pc43 pc29 & v1 \\
\hline pc46 pc41 & v1 & pc5 & v1 & pc29 pc25 & v1 \\
\hline pc41 pc24 & v1 & pc8 & v1 & pc25 pc42 & v1 \\
\hline pc24 pc22 & v1 & pc8 $\mathrm{pc} 10$ & v1 & pc42 pc23 & v1 \\
\hline pc22 pc19 & v1 & pc10 pc12 & v1 & pc23 pc44 & v1 \\
\hline pc19 pc18 & v1 & pc12 pc13 & v1 & pc44 pc49 & v1 \\
\hline pc18 pc15 & v1 & pc13 pc27 & v1 & pc49 pc52 & v1 \\
\hline pc15 pc17 & v1 & pc27 pc26 & v1 & pc52 pc55 & v1 \\
\hline pc17 pc21 & v1 & pc26 pc28 & v1 & pc55 pc54 & v1 \\
\hline pc21 pc20 & v1 & pc28 pc30 & v1 & pc54 pc40 & v1 \\
\hline pc20 pc16 & v1 & pc30 pc31 & v1 & pc40 pc38 & v1 \\
\hline pc16 pc14 & $\mathrm{v} 1$ & pc31 pc36 & v1 & pc38 pc39 & v1 \\
\hline pc14 pc4 & v1 & pc36 pc35 & v1 & pc39 pc37 & v1 \\
\hline pc4 pc7 & v1 & pc35 pc33 & v1 & pc37 ec1 & v1 \\
\hline pc9 & v1 & pc33 pc34 & v1 & $\begin{array}{ll}\text { ec1 } & \text { D0 }\end{array}$ & $\mathrm{v} 1$ \\
\hline
\end{tabular}

Fonte: Resultados obtidos com o GLPK

- Dos 4.490,00 kg/dia coletados na estação de coleta, 4.120,00 kg são encaminhados ao $c d 1$ e o restante, $800,00 \mathrm{~kg}$, ao $c d 2$;

- Do $c d 1$ são selecionados 3.484,00 kg para ir ao $c t 1$ e 636,00 kg para o $c t 2$;

- Dos $3.484,00 \mathrm{~kg}$ recebidos pelo $c t 1,3.400,00 \mathrm{~kg}$ vão para a fábrica e 84,00 para $\mathrm{o}$ centro de eliminação;

- Também se tem a alternativa de enviar os 4.120,00 kg diretamente a fábrica, sem passar pelos centros de transformação. Nesse caso, não se tem resíduo indo para o centro de eliminação;

- Do $c d 2$ podem ir os 800,00 diretamente a fábrica ou serem encaminhados ao $c t 2$ para processo de transformação;

- O ct2 recebe em total $1.600,00 \mathrm{~kg}$, dos quais envia $1.400,00 \mathrm{~kg}$ para a fábrica e 36,00 kg para o centro de eliminação; 
- O centro de eliminação recebe em total $120,00 \mathrm{~kg} /$ dia de RSU quando os RSU passam pelos centros de transformação.

Figura 4.13 - Transporte de RSU coletados no subsetor Monserrate, para os centros especializados do Distrito de Trujillo, Caso I e Caso II

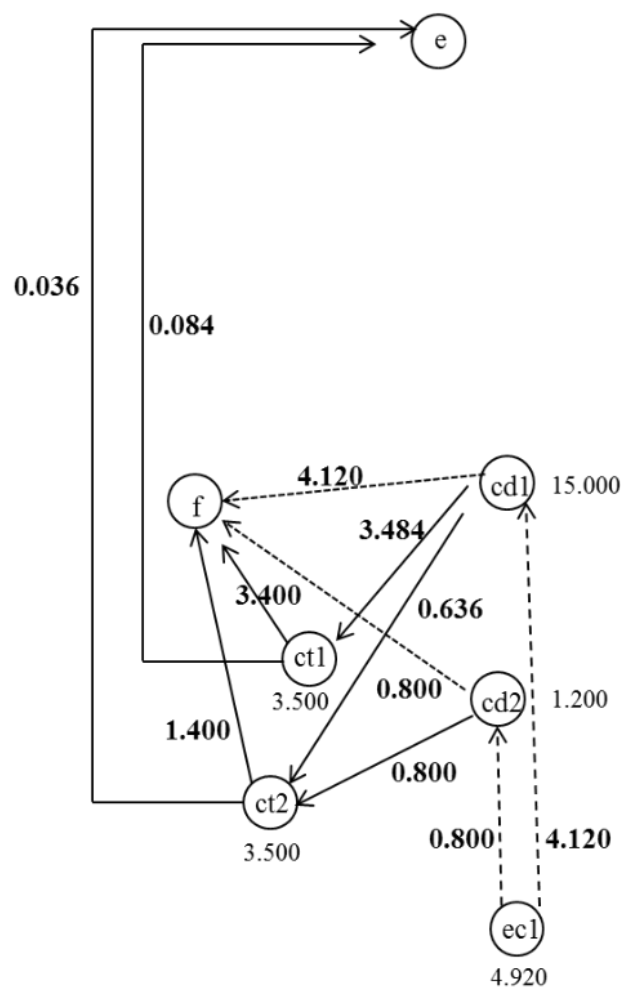

(a)

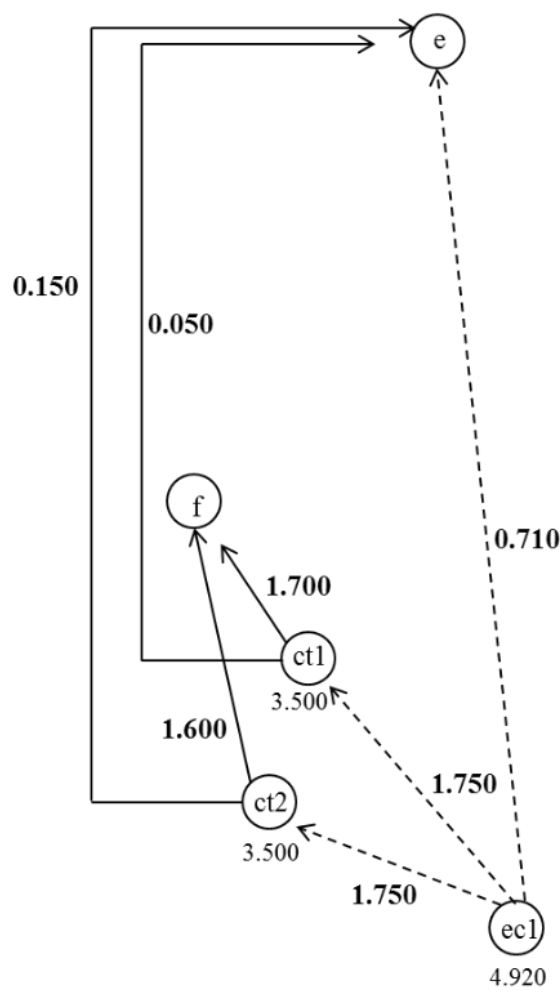

(b)

Nota: Os valores das unidades estão em decimais, notação em espanhol.

Fonte: Resultados obtidos com o GLPK

Igual que o problema anterior se observa que se tem uma redução considerável de RSU indo para os centros de eliminação, quando existe um sistema de coleta seletiva aliado a um bom sistema de logística reversa. E se todo o RSU é possível de entrar como matéria prima na fábrica sem passar por nenhum processo de reciclagem, então não se tem resíduo indo para o centro de eliminação.

Os resultados para o Caso II foram os seguintes (Figura 4.13b):

- Dos 4.490,00 kg/dia coletados na estação de coleta, $1.750,00 \mathrm{~kg}$ são encaminhados ao $c t 1,1.750,00 \mathrm{~kg}$ ao $c t 2$ e $1.420,00 \mathrm{~kg}(2 \times 710,00 \mathrm{~kg})$ ao centro de eliminação; 
- Dos $1.750,00 \mathrm{~kg}$ recebidos pelo $c t 1,1.700,00 \mathrm{~kg}$ vão para a fábrica e 50,00 para o centro de eliminação;

- Do total que recebe o $c t 2,1.600,00 \mathrm{~kg}$ envia para a fábrica e $150,00 \mathrm{~kg}$ para o centro de eliminação;

- O centro de eliminação recebe em total $1.620 \mathrm{~kg} / \mathrm{dia}$ de RSU.

Neste terceiro estudo de caso, obteve-se uma diferença na aplicação dos dois casos da Etapa 2. Isso se deve as premissas estabelecidas no problema quanto a probabilidade de reciclagem ou recuperação de RSU recebidos num centro de transformação. São valores experimentais, já que não se tem uma base confiável de dados para estimar essas porcentagens. 


\section{CONSIDERAÇÕES FINAIS}

A pesquisa bibliográfica revela que realmente existe uma preocupação dos governos federais com a destinação final dos resíduos sólidos, com o objetivo de preservar a saúde da população e o meio ambiente urbano e rural. Por exemplo, observa-se a criação, no caso do Brasil, da Lei 12.305/10 e, no Peru, da Lei 27.314/2000. No entanto, existe uma lacuna entre as metas propostas em ambas as leis com as metas reais dos governos locais. Isso se deve à falta de uma boa estrutura organizacional, gerencial e operacional dos governos locais capaz de atender às demandas locais e as necessidades da população.

A falta de quadros especializados, tanto nos governos centrais como locais, para realizar o planejamento e modelagem de uma rede logística reversa pode ser compensada com a contribuição de pesquisadores que atuam nesse campo de conhecimento. É muito difícil e dispendiosa a montagem de uma equipe que tenha toda a bagagem de conhecimento nas áreas das ciências da computação, de geoprocessamento, de modelagem matemática e de logística reversa, dentre outras. E essa é uma das principais justificativas que os governos, tanto federais e locais, argumentam diante da falta de realização do planejamento de uma rede logística reversa que funcione eficaz e eficientemente.

Portanto, como ficou demonstrado ao longo deste trabalho, é possível realizar a modelagem matemática desse tipo de problema com baixo investimento, assim como aplicá-lo em várias regiões, sem necessidade de grandes mudanças na modelagem proposta. A modelagem proposta calcula os fluxos na rede logística reversa, permitindo dimensionar a quantidade e capacidade das unidades produtivas e dos veículos.

Vale ressaltar que a ferramenta computacional $\mathrm{GLPK}^{26}$ foi importante na análise e implementação dos modelos desenvolvidos, já que permitiu realizar testes e validações com muita facilidade. E ajudou muito na criação de cenários alternativos que subsidiem na tomada de decisão. Assim, o uso do GLPK contribuiu na melhora dos modelos discutidos na tese e na análise dos estudos de casos como os que foram realizados na Cidade de Trujillo de Peru.

\footnotetext{
${ }^{26}$ Os modelos foram testados e implementados usando um Laptop SONY com processador INTEL (R) core i5 de 2.50 $\mathrm{GHz}$ de velocidade e 4 GB de memória, com o GLPK (ver anexos) rodando no sistema operativo Linux.
} 
No modelo de roteirização com o GLPK obtém-se como resultado o roteamento ótimo para o atendimento dos clientes (pontos de coleta) e alocação apropriada das estações de coleta, de forma a facilitar o acesso de veículos e reduzir os custos de transporte e os conflitos com o fluxo de tráfego da rede viária da cidade em estudo, por meio da seleção das melhores rotas.

Já no modelo de transporte, o GLPK mostra as quantidades de RSU coletadas das estações de coleta selecionadas que são transportadas para os centros especializados para seguir algum processo segundo seja o valor de tais resíduos. Uma contribuição adicional, foi a mensuração do $\mathrm{CO}_{2}$ gerado pelos veículos coletores e de transporte obtidos com o GLPK.

A modelagem proposta nesta tese baseia-se na não existência da coleta domiciliar, ou seja, parte-se da premissa que a população participa ativamente da coleta seletiva e leva seus RSU até um ponto de coleta. A partir desses pontos de coletas modela-se a rede logística reversa.

Essa premissa reduz sensivelmente os custos de coleta e de transporte dos RSU, fato que ficou demonstrado nos testes realizados, uma economia que tem seus reflexos em toda a rede, já que reduz a frota de veículos pesados circulando pelas vias urbanas. Recurso que a instituição responsável pode utilizá-lo para outras atividades.

Essa proposta pode despertar a dúvida se esse custo estaria sendo transferido ao consumidor que já paga pelo serviço de limpeza urbana. Do ponto de vista pragmático, pode-se dizer-se que não, já que, se ele se deslocou para comprar esse produto até um ponto de venda, então o mais natural é que uma vez consumido, usado, desgastado, etc. o retorne a esse mesmo ponto ou a um local de coleta que esteja próximo a uma das tantas rotas que ele sempre acostuma fazer ao longo do dia. Essa é uma prática que é comum em muitos países desenvolvidos.

Neste caso, o governo local desempenha um papel importante, porque tudo dependerá das políticas e intervenções dele, o que deverá fazer que o plano de ação e diretrizes cumpra as metas da Lei dos Resíduos Sólidos. 


\subsection{RECOMENDAÇÕES}

- Sugere-se o desenvolvimento de modelos com novas condições para ficar mais próximo a realidade.

- O problema de roteamento de veículos baseado na programação linear inteira pertence à classe de problemas $N P$ - hard, chamados de difíceis, sendo de alta complexidade computacional. Assim, para futuras pesquisas recomendasse o desenvolvimento de procedimentos computacionais meta-heurísticos tais como a pesquisa busca-tabu, simulated annealing, algoritmos genéticos, dentre outros, para assim diminuir o tempo de processamento em grandes cenários. 


\section{REFERÊNCIAS BIBLIOGRÁFICAS}

Abreu, P. H. (2015). Projeto de Acessibilidade para o Transporte de Carga e Coleta de Resíduos Sólidos nas Quadras Comerciais do Plano Piloto. Trabalho de Projeto Final, Publicação, Departamento de Engenharia Civil e Ambiental, Universidade de Brasília, Brasília, DF, 55 p.

Associação Brasileira de Empresas de Limpeza Pública e Resíduos - Especiais, ABRELPE. (2010). Panorama dos Resíduos Sólidos no Brasil 2009.

Associação Brasileira de Empresas de Limpeza Pública e Resíduos - Especiais, ABRELPE (2011). Panorama dos Resíduos Sólidos no Brasil 2010.

Associação Brasileira de Empresas de Limpeza Pública e Resíduos - Especiais, ABRELPE (2012). Panorama dos Resíduos Sólidos no Brasil 2011.

Associação Brasileira de Empresas de Limpeza Pública e Resíduos - Especiais, ABRELPE (2013). Panorama dos Resíduos Sólidos no Brasil 2012. Edição especial.

Associação Brasileira de Empresas de Limpeza Pública e Resíduos - Especiais, ABRELPE (2014). Panorama dos Resíduos Sólidos no Brasil 2013.

Agudelo-Vera, C.M.; Mels, A.R.; Keesman, K.J, Rijnaarts Huub, H.M. (2011). Resource management as a key factor for sustainable urban planning. Journal of Environmental; Management, Elsevier.

Badran, M.F.; El-Haggar, S.M. (2006). Optimization of municipal management in Port-Egypt. Waste Management, Elsevier.

Bartholomeu, D. B; Caixeta-Filho, J. V. et al. (org.) (2011). Logística ambiental de resíduos sólidos. Editora Atlas: São Paulo.

Benjelloun, A.; Crainic, T.G.; Bigras, Y. (2010). Towards a taxonomy of city logistics projects. The Sixth International Conference on City Logistics. Procedia Social and Behavioral Sciences, Elsevier.

Bugliarello, G. (2006). Urban sustainability: Dilemas, challenges and paradigms. Technology in Society, Elsevier.

Buhrkal, K.; Larsen, A.; Ropke, S. (2012). The waste collection vehicle routing problem with time windows in a city logistics context. Procedia Social and Behavioral Sciences, Elsevier.

Calderoni, Sabetai (2003). Os Bilhões Perdidos no Lixo. Humanitas. FFLCH/USP. $4^{\mathrm{a}}$ Ed. São Paulo.

Câmara dos Deputados (2012). Política Nacional de Resíduos Sólidos Lei 12.305/2010, 2a edição. Biblioteca digital da Câmara dos Deputados, Centro de documentação e informação, Edições câmara, Brasília.

Cerna, N. S. S. (2014). Contribuição para modelagem de um sistema de avaliação da qualidade dos elementos de infraestrutura de mobilidade urbana. Dissertação (Mestrado), Universidade de Brasília, Faculdade de Tecnologia, Programa de Pós-Graduação em Transporte.

Coelho, Hosmanny Mauro Goulart (2008). Aproveitamento energético do lixo urbano e de resíduos industriais. Textos Acadêmicos. Universidade Federal de Lavras.

Congreso de la Republica. (2000). Ley general de residuos sólidos No. 27314. Diário El Peruano. 
Crainic, T.G.; Ricciardi, N.; Storchi, G. (2009). Models for evaluating and planning city logistics systems. Centre interuniversitaire de recherché sur les réseaux d' entreprise, la logistique et le transport, CIRRELT.

Crainic, T.G.; Perboli, G.; Mancini, S.; Tadei, R. (2010). Two-Echelon vehicle routing problem: A satellite location analysis. The Sixth International Conference on City Logistics. Procedia Social and Behavioral Sciences, Elsevier.

Crainic, T.G.; Mancini, S.; Perboli, G.; Tadei, R. (2011). Heuristic for a two-echelon vehicle routing problem: A multi-start approach. Centre interuniversitaire de recherché sur les réseaux d' entreprise, la logistique et le transport, CIRRELT.

Da Silva Dutra, N.G. (2004). O enfoque de city logistics na distribuição urbana de encomenda. Tese de doutorado, Universidade Federal de Santa Catarina, Florianópolis.

De Brito, M.; Dekker, R. (2003). A framework for reverse logistics. Research in management, Erasmus research institute of management.

Dekker, R., Inderfurth, K., van Wassenhove, L. and Fleischmann, M. (2003). Quantitative Approaches for reverse logistics. Springer-Verlag, Berlin. Forthcoming.

Dicionário de Economia (2010). Disponível em http://introducaoaeconomia.files.wordpress.com/ 2010/03/dicionario-de-economia-sandroni.pdf.

Elwany, H.; Fors, N.; Harraz, N.; Galal, N. (2007). Reverse logistics network design: Review of models and solutions techniques. Proceedings of the 37th International Conference on Computers and Insdustrial Enginnering, Alexandria, Egypt.

ESA - UN (2013). World Population Prospects: The 2011 revision population data-base. Disponível em http://esa.un.org/unup. Acesso em 01/02/2013.

Galvão Novaes, A. (2007). Logística e gerenciamento da cadeia de distribuição: Estratégia, operações e avaliação. 3er edição. Campus Elsevier.

Ghiani, G.; Laporte, G.; Musmanno, R. (2004). Introduction to logistics systems planning and control. Jhon Wiley \& Sons.

Ghose, M.K.; Dikshit, A.K.; Sharma, S.K. (2006). A GIS based transportation model for solid waste disposal - A case study on Asansol munipality. Waste management, Elsevier.

Henriques, R. M. (2004).Aproveitamento energético dos RSU: uma abordagem tecnológica. Tese de Dissertação, COPPE/UFRJ, Rio de Janeiro.

Huerta, G.; Vásquez, J. (2012). Estudio de caracterización de los residuos sólidos urbanos, Distrito de Trujillo. Municipalidad Provincial de Trujillo.

INSTITUTO NACIONAL DE ESTADISTICA - INEI (2014a). Estado de la población peruana 2014. Disponível em http://www.inei.gob.pe/media/MenuRecursivo/publicaciones_digitales/ Est/Lib1157/libro.pdf. Acesso em 20/08/2014.

Instituto Nacional de Estadística e Informática - INEI. (2014b). Perú: Anuario de Estadísticasambientales. Lima, Perú.

IPEA (2012). Diagnóstico dos Resíduos Sólidos Industriais. Relatório de Pesquisa. Brasília.

Jeung Ko H.; Evans, G.W. (2005). A genetic algorithm-based heuristic for the dynamic integrated forward/reverse logistic network for 3PL. Computer \& Operations Research, Elsevier. 
John, V. M. (2000). Reciclagem de resíduos na construção civil: Contribuição para metodologia de pesquisa e desenvolvimento. São Paulo, 2000. 113p. Tese (Livre Docência) - Escola Politécnica da Universidade de São Paulo. Departamento de Engenharia de Construção Civil.

Korte, B., Vygen, J. (2008). Combinatorial optimization Theory and Algorithms, Fourth Edition. Springer Heidelberg Dordrecht London New York.

Laporte, Gilbert. (1992). The vehicle routing problem: An overview of exact and approximate algorithms. European Journal of Operational Research 59, 345-358. North-Holland.

Lee, J.; Gen, M.; Rhee, K. (2008). Reverse logistic network problem using priority-based genetic algorithm. International journal of information system for logistics and management.

Lee, J.; Gen, M.; Rhee, K. (2009). Network model and optimization of reverse logistics by hybrid genetic algorithm. Computer \& Industrial engineering, Elsevier.

Leite, Paulo Roberto (2003). Logística reversa: meio ambiente e competitividade. Pearson Prentice Hall.

Leite, Paulo Roberto. (2009) Logística Reversa. Meio ambiente e competitividade. 2a edição. Pearson. São Paulo.

Mambeli Barros, R. (2013). Tratado sobre Resíduos Sólidos: Gestão, uso e sustentabilidade. Editora Interciência, Rio de Janeiro.

Martel, A.; Rodrigues Vieira, D. (2008). Análise e projeto de redes logísticas. Editora Saravia.

Maroudas, E. (2011). City logistics for sustainability: The case of Stockholm. Royal Institute of Technology, School of Architecture and the Built Environment, Division of Transportation and Logistics.

Makhorin, A. (2008). Modeling language GNU MathProg. Draft Edition for GLPK, Version 4.34.

MDIC. Plano Brasil Maior. Disponível em http://www.brasilmaior.mdic.gov.br

Ministerio de Ambiente - MA. (2012). Informe anual de residuos sólidos municipales y no municipales en el Perú gestión 2012.

Ministério do Meio Ambiente - MMA. (2011). Plano Nacional de Resíduos Sólidos (PNRS).

Ministério do Meio Ambiente - MMA, PNUD (2010, Estudo sobre o Potencial de Geração de Energia a partir de Resíduos de Saneamento (lixo, esgoto), visando incrementar o uso de biogás como fonte alternativa de energia renovável. Resumo Executivo, São Paulo, 2010.

Monteiro, M. J.(2013). Logística Reversa: uma proposta de gestão integrada de resíduos sólidos nos setores comerciais. Dissertação. PPGT/UnB, Brasília.

Nagy, G.; Saïd S. (2007). Location-routing: Issues, models and methods. European journal of operational research, Elsevier.

Oliveira, C.P. (2014). Planejamento Integrado e Participativo de Coleta Seletiva nas Quadras Comerciais do Plano Piloto. Trabalho de Projeto Final, Publicação, Departamento de Engenharia Civil e Ambiental, Universidade de Brasília, Brasília, DF, 48 p.

Oliveira, L. B; Reis, M. M. e Pereira, A. S. (2006). Resíduos sólidos urbanos: lixo ou combustível? XXVII Congresso Interamericano de Engenharia Sanitária e Ambiental,ABES - Associação Brasileira de Engenharia Sanitária e Ambiental 1, III-007. 
Ombuki, B.; Ross, Brian J.; Hanshar, F. (2006). Multi-Objetive Genetic Algorithms for Vehicle Routing Problem with Time Windows. Applied Intelligence, Springer Science.

Petramas SAC (2015). Disponível em www.petramas.com. Acesso em 12/08/2015.

Plan Integral de Gestión Ambiental de Residuos Sólidos - PIGARS para la Provincia de Trujillo 2010-2020 (2009). Comisión Ambiental Municipal de Trujillo.

Qureshi, A.G.; Taniguchi, E.; Yamada, T. (2010). Exact solution for the vehicle routing problem with semi soft time windows and its application. Procedia Social and Behavioral Sciences, Elsevier.

Rezende, Fernanda Pinheiro (2006). Modelagem de uma rede logística de coleta de lixo em áreas urbanas. . Trabalho de Projeto Final, Publicação, Departamento de Engenharia Civil e Ambiental, Universidade de Brasília, Brasília, DF, 104p.

Saman, P.; Kianfar, K.; Karimi, B. (2009). Reverse logistics network design using simulated annealing. Springer-Verlag, London.

Santos, A. et al. (2009). Gestão Pública de Resíduo Sólido Urbano. Compostagem e Interface Agroflorestal. FEPAF, Botucatu, 2009.

Santos, E. M. (2008) Contribuição à Gestão da Distribuição de Cargas em Áreas Urbanas sob a Òtica do Conceito City Logistics. Dissertação, Universidade de Brasília, 2008.

Servicio de Gestión Ambiental de Trujillo - SEGAT (2014). Mapa de zonas de limpieza pública. Disponível em http://www.segat.gob.pe/. Acesso em 27/02/2014.

Silva, M.T.; Donel, F. Wollmann, A. R. e Cuellar, J. O. (2003). Planejamento como instrumento de implementação da coleta seletiva de resíduos sólidos urbanos. XXIII Encontro Nac. de Eng. de Produção - Ouro Preto, MG, Brasil, ENEGEP 2003 ABEPRO 1.

Silva, F. C.; Pires, A.M. et al (org.) (2009). Gestão Pública de Resíduo Sólido Urbano: Compostagem e Interface agro-florestal. FEPAF, Botucatu.

Srivastava, S.K. (2008). Network design for reverse logistics. OMEGA, The International Journal of Management Science, Elsevier.

Sterle, C. (2010). Location-Routing models and methods for freight distribution and infomobility in city logistics, Thèse de doctorat. Centre interuniversitaire de recherché sur les réseaux d' entreprise, la logistique et le transport, CIRRELT- 20010 - 38.

Subramanian A.; Satoru Ochi L. (2010). New lower bounds for the vehicle routing problem with simultaneous pick-up and delivery. Technical report - RT 01/10, Instituto de computação, Universidade Federal Fluminense.

Sungur Ilgaz; Ordoñez, F.; Dessouky M. (2006). A robust optimization approach for the capacitated vehicle routing problem with demand uncertainty. Industrial and systems engineering, University of Southern California.

Tamagawa, D.; Taniguchi, E.; Yamada, T. (2010). Evaluating city logistics measures using a multiagent model. The sixth international conference on city logistics. Procedia Social and Behavioral Sciences, Elsevier.

Tanguay, G.A.; Rajaonson, J.; Lefevre, J.; Lanoie, P. (2010). Measuring the sustainability of cities: An analysis of the use of local indicators. Ecological Indiators, Elsevier. 
Taniguchi, E.; Thompson, R.G.; Yamada, T.; van Duin, J.H.R. (2001). City logistics: Network modeling and intelligent transport. Pergamon.

Takai, E. (2009). The rol of operations research towards advanced logistics. Science \& Technology trends.

Toledo, P.; Marcos, R.. (2005). Transporte urbano de mercadorias, logistica urbana y city logistics. Grupo de estudos logísticos, Universidade Federal de Santa Catarina.

Valentin, A.; Spangenberg, J.H. (2000). A guie to community sustainability indicators. Environmental impacts assessment review, Elsevier.

Volvo Trucks (2012). Disponível em http://www.volvotrucks.com/SiteCollectionDocuments/ VTC/Corporate/About\%20us/Environment-2012/Emis_eng_20640_10005.pdf . Acesso em 01/11/2013.

Yeun, L.C.; Ismail, W.R.; Omar, K.; Zirour, M. (2008). Vehicle Routing Problem: Models and solutions. Journal of Quality measurement and analysis.

Zhang, Dongquing; Keat Tan, Soon; Gersberg, R. M. (2010). A comparison of municipal solid waste management in Berlin and Singapore. Waste management, Elsevier. 
ANEXOS 


\section{ANEXO A: Modelo de roteirização de veículos operando com frota homogênea}

set I; $\quad$ \# conjunto de nos incluído o deposito 0

set $\mathrm{K}$; $\quad$ \# Conjunto de veículos

param $\mathrm{f}:=20$;

param $\mathrm{d}\{\mathrm{i}$ in $\mathrm{I}\}$, integer;

param $\mathrm{D}\{\mathrm{i}$ in $\mathrm{I}, \mathrm{j}$ in $\mathrm{I}\}$;

param $c\{i$ in $I, j$ in $I\}:=f * D[i, j] * d[i]$ param $\mathrm{Q}:=20$;

param $\mathrm{q}\{\mathrm{k}$ in $\mathrm{K}\}$, integer;

$\operatorname{var} \mathrm{x}\{\mathrm{i}$ in $\mathrm{I}, \mathrm{j}$ in $\mathrm{I}\}$, binary;

var $\mathrm{u}\{\mathrm{i}$ in $\mathrm{I}: \mathrm{i} !=$ 'D0' $\}>=0$;
\# Frete em $\$ /$ ton. por km

\# demanda (delivery) dos clientes $\mathrm{i}=1,2, \ldots, 74$.

\# Matriz de distância.

\# Custo transporte em dólar.

\# Quantidade de veículos

\# capacidade dos veículos $\mathrm{k}=\mathrm{v} 1$, v2, v3, v4, v5.

\# Valor 1 se veiculo faz viagem de i para j. Senão 0. \# O fluxo no veiculo depois da visita ao cliente $i$.

minimize $Z$ : $\operatorname{sum}\{\mathrm{i}$ in $\mathrm{I}, \mathrm{j}$ in $\mathrm{I}\} \mathrm{c}[\mathrm{i}, \mathrm{j}]^{*} \mathrm{x}[\mathrm{i}, \mathrm{j}]$;

s.t. $\mathrm{R} \_1\left\{\mathrm{j}\right.$ in $\mathrm{I}: \mathrm{j} !=$ 'D $\left.0^{\prime}\right\}: \operatorname{sum}\{\mathrm{i}$ in $\mathrm{I}\} \mathrm{x}[\mathrm{i}, \mathrm{j}]=1$;

s.t. $R \_2\{i$ in $I: i !=$ 'D0' $\}$ : sum $\{j$ in $I\} x[i, j]=1$;

s.t. R_3 : $\operatorname{sum}\left\{\mathrm{i}\right.$ in $\mathrm{I}, \mathrm{j}$ in $\mathrm{I}: \mathrm{j}==$ 'D0' $^{\prime} \mathrm{x}[\mathrm{i}, \mathrm{j}]<=\mathrm{Q}$;

s.t. $R \_4: \operatorname{sum}\left\{i\right.$ in $I, j$ in $\left.I: i=={ }^{D} D 0^{\prime}\right\} x[i, j]<=Q$;

s.t. $\mathrm{R} \_5\{\mathrm{i}$ in $\mathrm{I}, \mathrm{j}$ in $\mathrm{I}, \mathrm{k}$ in $\mathrm{K}: \mathrm{i} !=$ 'D0' and $\mathrm{j} !=$ 'D0' $\}$ :

$\mathrm{u}[\mathrm{j}]-\mathrm{u}[\mathrm{i}]+\mathrm{q}[\mathrm{k}]^{*}(1-\mathrm{x}[\mathrm{i}, \mathrm{j}])>=\mathrm{d}[\mathrm{j}]$;

s.t. R_6 $\{$ i in I: i != 'D0' $\}$ : d $[\mathrm{i}]<=\mathrm{u}[\mathrm{i}]$;

s.t.R_7\{i in I, $\mathrm{k}$ in $\mathrm{K}: \mathrm{i} !=$ 'D0' $^{\prime}: \mathrm{u}[\mathrm{i}]<=\mathrm{q}[\mathrm{k}]$;

solve;

printf "Custo mínimo: \%s\n", sum $\{\mathrm{i}$ in $\mathrm{I}, \mathrm{j}$ in $\mathrm{I}\} \mathrm{c}[\mathrm{i}, \mathrm{j}]^{*} \mathrm{x}[\mathrm{i}, \mathrm{j}]$;

printf(" Cliente Cliente $\backslash n ")$;

printf "In" ;

printf $\{\mathrm{i}$ in I, j in I: $x[i, j]\}$ " \%2s \%14s $\ln ", \mathrm{i}, \mathrm{j}$;

printf "In"; 


\section{ANEXO B: Modelo de roteirização de veículos com janela de tempo}

set I;

\# conjunto de nos incluído o deposito '0' = '75'

set $\mathrm{K}$;

\# Conjunto de veículos

param $\mathrm{f}:=20$;

param $\mathrm{d}\{\mathrm{i}$ in $\mathrm{I}\}$;

param $D\{i$ in $I, j$ in $I: i !=j\}$;

\# Frete em \$/ton. por km

\# demanda dos clientes $\mathrm{i}=1,2,3,4,5,6$.

\# Matriz de distância entre os clientes.

param $\mathrm{c}\{\mathrm{i}$ in $\mathrm{I}, \mathrm{j}$ in $\mathrm{I}: \mathrm{i} !=\mathrm{j}\}:=\mathrm{f} * \mathrm{D}[\mathrm{i}, \mathrm{j}] * \mathrm{~d}[\mathrm{i}]$; \# Custo transporte em dólar.

param $\mathrm{q}\{\mathrm{k}$ in $\mathrm{K}\}$;

param $\mathrm{t}\{\mathrm{i}$ in $\mathrm{I}, \mathrm{j}$ in $\mathrm{I}: \mathrm{i} !=\mathrm{j}\}$;

param a $\{\mathrm{i}$ in $\mathrm{I}\}$;

\# capacidade dos veículos k = v1, v2, v3.

\# Matriz de tempo entre os clientes

tempo.

param $b\{\mathrm{i}$ in $\mathrm{I}\}$;

tempo.

\# Limite de tempo inferior da janela de

\# Limite de tempo superior da janela de

$\operatorname{var} x\{i$ in $I, j$ in $I, k$ in $K\}$, binary;

var $y\{\mathrm{i}$ in $\mathrm{I}, \mathrm{k}$ in $\mathrm{K}\}$ integer ;

\# 1 se veiculo e atribuído a rota. Senão 0.

\# veiculo k começa o serviço ao cliente.

minimize Z: sum $\{\mathrm{i}$ in $\mathrm{I}, \mathrm{j}$ in $\mathrm{I}, \mathrm{k}$ in $\mathrm{K}: \mathrm{i} !=\mathrm{j}\} \mathrm{c}[\mathrm{i}, \mathrm{j}]^{*} \mathrm{x}[\mathrm{i}, \mathrm{j}, \mathrm{k}]$;

s.t. $\mathrm{R} \_1\{\mathrm{i}$ in $\mathrm{I}:(\mathrm{i} !=0$ and $\mathrm{i} !=75)\}: \operatorname{sum}\{\mathrm{j}$ in $\mathrm{I}, \mathrm{k}$ in $\mathrm{K}: \mathrm{i} !=\mathrm{j}\} \mathrm{x}[\mathrm{i}, \mathrm{j}, \mathrm{k}]=1$;

s.t. R_2 $\{\mathrm{k}$ in $\mathrm{K}\}: \operatorname{sum}\{\mathrm{i}$ in $\mathrm{I}, \mathrm{j}$ in $\mathrm{I}:(\mathrm{i} !=0$ and $\mathrm{i} !=75$ and $\mathrm{i} !=\mathrm{j})\} \mathrm{d}[\mathrm{i}]^{*} \mathrm{x}[\mathrm{i}, \mathrm{j}, \mathrm{k}]<=\mathrm{q}[\mathrm{k}]$;

s.t. $R \_3\{\mathrm{k}$ in $\mathrm{K}\}: \operatorname{sum}\{\mathrm{i}$ in $\mathrm{I}, \mathrm{j}$ in $\mathrm{I}: \mathrm{i}==0$ and $\mathrm{j} !=75$ and $\left.\mathrm{i} !=\mathrm{j}\} \times \mathrm{i}, \mathrm{j}, \mathrm{k}\right]=1$;

s.t. R_4 $\{\mathrm{h}$ in $\mathrm{I}, \mathrm{k}$ in $\mathrm{K}:(\mathrm{h} !=0$ and $\mathrm{h} !=75)\}: \operatorname{sum}\{\mathrm{i}$ in $\mathrm{I}: \mathrm{i} !=\mathrm{h}\} \times \mathrm{x}, \mathrm{h}, \mathrm{k}]-\operatorname{sum}\{\mathrm{j}$ in $\mathrm{I}: \mathrm{h} !=$ $\mathrm{j}\} \mathrm{x}[\mathrm{h}, \mathrm{j}, \mathrm{k}]=0$;

s.t. R_5 $\{\mathrm{k}$ in $\mathrm{K}\}: \operatorname{sum}\{\mathrm{i}$ in $\mathrm{I}, \mathrm{j}$ in $\mathrm{I}: \mathrm{j}==75$ and $\mathrm{i} !=\mathrm{j}$ and $\mathrm{i}>0\} \mathrm{x}[\mathrm{i}, \mathrm{j}, \mathrm{k}]=1$;

s.t. $\mathrm{R} \_6\{\mathrm{i}$ in $\mathrm{I}, \mathrm{j}$ in $\mathrm{I}, \mathrm{k}$ in $\mathrm{K}: \mathrm{i} !=0$ and $\mathrm{i} !=75$ and $\mathrm{i} !=\mathrm{j}\}: \mathrm{y}[\mathrm{i}, \mathrm{k}]+\mathrm{t}[\mathrm{i}, \mathrm{j}]-10000^{*}(1-$ $\mathrm{x}[\mathrm{i}, \mathrm{j}, \mathrm{k}])<=\mathrm{y}[\mathrm{j}, \mathrm{k}]$;

s.t. $\mathrm{R}_{-} 7\{\mathrm{i}$ in $\mathrm{I}, \mathrm{k}$ in $\mathrm{K}: \mathrm{i} !=0$ and $\mathrm{i} !=75\}: \mathrm{y}[\mathrm{i}, \mathrm{k}]>=\mathrm{a}[\mathrm{i}]$;

s.t. $\mathrm{R} \_8\{\mathrm{i}$ in $\mathrm{I}, \mathrm{k}$ in $\mathrm{K}: \mathrm{i} !=0$ and $\mathrm{i} !=75\}: \mathrm{y}[\mathrm{i}, \mathrm{k}]<=\mathrm{b}[\mathrm{i}]$;

solve;

printf "Custo mínimo para os clusters e atribuição do veículos: \%s\n",

\#sum $\{\mathrm{i}$ in $\mathrm{I}, \mathrm{j}$ in $\mathrm{I}, \mathrm{k}$ in $\mathrm{K}: \mathrm{i} !=\mathrm{j}$ and $(\mathrm{i} !=0$ and $\mathrm{j} !=8)$ and $\mathrm{j}>0\} \mathrm{c}[\mathrm{i}, \mathrm{j}]^{*} \mathrm{x}[\mathrm{i}, \mathrm{j}, \mathrm{k}]$;

sum $\{i$ in $I, j$ in $I, k$ in $K: i !=j\} c[i, j]^{*} x[i, j, k]$;

printf(" Aresta Veiculo $\backslash n ")$;

printf "In" ;

printf $\{\mathrm{i}$ in $\mathrm{I}, \mathrm{j}$ in $\mathrm{I}, \mathrm{k}$ in $\mathrm{K}: \mathrm{x}[\mathrm{i}, \mathrm{j}, \mathrm{k}]\}$ " \%1s \%2s \%10s $\backslash \mathrm{n} ", \mathrm{i}, \mathrm{j}, \mathrm{k}$; 
set I;

set $\mathrm{J}$

set $\mathrm{K}$;

set F;

set R;

set $\mathrm{D}$;

set $\mathrm{S}$;
\# Conjunto de estacoes de coleta, $\mathrm{i}=1, \ldots$
\# Conjunto de Centros de desmontagem, $\mathrm{j}=1, \ldots$
\# Conjunto de Centros de transformação, $\mathrm{k}=1, \ldots$
\# Conjunto de fabricas
\# Conjunto de Centros de reciclagem
\# Conjunto de centros de eliminação
\# Conjunto de provedores

param a $\{\mathrm{i}$ in $\mathrm{I}\}$; param $b\{\mathrm{j}$ in $\mathrm{J}\}$; param $\mathrm{u}\{\mathrm{k}$ in $\mathrm{K}\}$; param $\mathrm{v}\{\mathrm{r}$ in $\mathrm{R}\}$; param $1\{\mathrm{~s}$ in $\mathrm{S}\}$; param $\mathrm{d}\{\mathrm{f}$ in $\mathrm{F}\}$; param distI_J $\{\mathrm{i}$ in $\mathrm{I}, \mathrm{j}$ in $\mathrm{J}\}$; param distJ_K $\{\mathrm{j}$ in $\mathrm{J}, \mathrm{k}$ in $\mathrm{K}\}$; param distJ_R $\{\mathrm{j}$ in $\mathrm{J}, \mathrm{r}$ in $\mathrm{R}\}$; param distJ_D $\{\mathrm{j}$ in $\mathrm{J}$, e in $\mathrm{D}\}$; param distK_D $\mathrm{D} k$ in $\mathrm{K}$, e in $\mathrm{D}\}$ eliminação

param distK_F $\{\mathrm{k}$ in $\mathrm{K}$, $\mathrm{f}$ in $\mathrm{F}\}$; \# Distancia de centro transformação para fabrica param distK_R $\{\mathrm{k}$ in $\mathrm{K}, \mathrm{r}$ in $\mathrm{R}\}$; \# Distancia centro transformação para centro reciclagem

param distS_F $\{\mathrm{s}$ in $\mathrm{S}, \mathrm{f}$ in $\mathrm{F}\}$; \# Distancia provedor para fabrica
\# Capacidade da estação de coleta i

\# Capacidade do centro de desmontagem $\mathrm{j}$

\# Capacidade do centro de transformação k

\# Capacidade do centro de reciclagem $\mathrm{r}$

\# Capacidade do provedor $\mathrm{s}$

\# Demanda da fabrica $f$ pela matéria $m$

\# Distancia de estacoes de coleta para centro triagem

\# Distancia de centro triagem para centro transformação

\# Distancia de centro triagem para centro reciclagem

\# Distancia de centro triagem para centro eliminação

\}; \# Distancia de centro transformação para centro

param c $\{\mathrm{i}$ in $\mathrm{I}, \mathrm{j}$ in $\mathrm{J}\}:=9 * \operatorname{dist} I \mathrm{~J}[\mathrm{i}, \mathrm{j}] * \mathrm{a}[\mathrm{i}]$;

param c1 $\{\mathrm{j}$ in $\mathrm{J}, \mathrm{k}$ in $\mathrm{K}\}:=9 *$ distJ_K[j, $\mathrm{k}] * \mathrm{~b}[\mathrm{j}]$;

param c $2\{\mathrm{j}$ in $\mathrm{J}, \mathrm{r}$ in $\mathrm{R}\}:=9^{*}$ distJ_R[j,r]*b[j];

param c3 $\{\mathrm{j}$ in $\mathrm{J}$, e in $\mathrm{D}\}:=9 *$ distJ_D[j,e]*b[j];

param $\mathrm{c} 4\{\mathrm{k}$ in $\mathrm{K}, \mathrm{f}$ in $\mathrm{F}\}:=9^{*}$ distK_F[k,f]* $\mathrm{u}[\mathrm{k}]$;

param c5 $\{\mathrm{k}$ in $\mathrm{K}, \mathrm{r}$ in $\mathrm{R}\}:=9 *$ distK_R $[\mathrm{k}, \mathrm{r}] * \mathrm{u}[\mathrm{k}]$;

param c6 $\{\mathrm{k}$ in $\mathrm{K}$, e in $\mathrm{D}\}:=9 *$ distK_D[k,e]*u[k];

param c7 $\{\mathrm{s}$ in $\mathrm{S}, \mathrm{f}$ in $\mathrm{F}\}:=9 *$ distS_F[s,f]*1[s];

$\operatorname{var} x\{\mathrm{i}$ in $\mathrm{I}, \mathrm{j}$ in $\mathrm{J}\},>=0$;

$\operatorname{var} \mathrm{x} 1\{\mathrm{j}$ in $\mathrm{J}, \mathrm{k}$ in $\mathrm{K}\},>=0$;

$\operatorname{var} x 2\{\mathrm{j}$ in $\mathrm{J}, \mathrm{r}$ in $\mathrm{R}\},>=0$;

$\operatorname{var} x 3\{\mathrm{j}$ in $\mathrm{J}, \mathrm{e}$ in $\mathrm{D}\},>=0$;

$\operatorname{var} \mathrm{x} 4\{\mathrm{k}$ in $\mathrm{K}, \mathrm{f}$ in $\mathrm{F}\},>=0$;

$\operatorname{var} \mathrm{x} 5\{\mathrm{k}$ in $\mathrm{K}, \mathrm{r}$ in $\mathrm{R}\},>=0$;

var $x 6\{k$ in $K$, e in $D\},>=0$;

$\operatorname{var} \mathrm{x} 7\{\mathrm{~s}$ in $\mathrm{S}, \mathrm{f}$ in $\mathrm{F}\},>=0$;

$\operatorname{minimize} \mathrm{Z}: \operatorname{sum}\{\mathrm{i}$ in $\mathrm{I}, \mathrm{j}$ in $\mathrm{J}\} \mathrm{c}[\mathrm{i}, \mathrm{j}] * \mathrm{x}[\mathrm{i}, \mathrm{j}]+\operatorname{sum}\{\mathrm{j}$ in $\mathrm{J}, \mathrm{k}$ in $\mathrm{K}\} \mathrm{c} 1[\mathrm{j}, \mathrm{k}]^{*} \mathrm{x} 1[\mathrm{j}, \mathrm{k}]+$ $\operatorname{sum}\{\mathrm{j}$ in $\mathrm{J}, \mathrm{r}$ in $\mathrm{R}\} \mathrm{c} 2[\mathrm{j}, \mathrm{r}]^{*} \mathrm{x} 2[\mathrm{j}, \mathrm{r}]+\operatorname{sum}\{\mathrm{j}$ in $\mathrm{J}, \mathrm{e}$ in $\mathrm{D}\} \mathrm{c} 3[\mathrm{j}, \mathrm{e}]^{*} \mathrm{x} 3[\mathrm{j}, \mathrm{e}]+$ $\operatorname{sum}\{\mathrm{k}$ in $\mathrm{K}, \mathrm{f}$ in $\mathrm{F}\} \mathrm{c} 4[\mathrm{k}, \mathrm{f}]{ }^{*} \mathrm{x} 4[\mathrm{k}, \mathrm{f}]+\operatorname{sum}\{\mathrm{k}$ in $\mathrm{K}, \mathrm{r}$ in $\mathrm{R}\} \mathrm{c} 5[\mathrm{k}, \mathrm{r}] * \mathrm{x} 5[\mathrm{k}, \mathrm{r}]+$ $\operatorname{sum}\{\mathrm{k}$ in $\mathrm{K}, \mathrm{e}$ in $\mathrm{D}\} \mathrm{c} 6[\mathrm{k}, \mathrm{e}]^{*} \mathrm{x} 6[\mathrm{k}, \mathrm{e}]+\operatorname{sum}\{\mathrm{s}$ in $\mathrm{S}, \mathrm{f}$ in $\mathrm{F}\} \mathrm{c} 7[\mathrm{~s}, \mathrm{f}]^{*} \mathrm{x} 7[\mathrm{~s}, \mathrm{f}]$; 
s.t. $R 2\{\mathrm{j}$ in $\mathrm{J}, \mathrm{r}$ in $\mathrm{R}$, e in $\mathrm{D}\}: \operatorname{sum}\{\mathrm{k}$ in $\mathrm{K}\}(\mathrm{x} 1[\mathrm{j}, \mathrm{k}])+\mathrm{x} 2[\mathrm{j}, \mathrm{r}]+\mathrm{x} 3[\mathrm{j}, \mathrm{e}]<=\mathrm{b}[\mathrm{j}]$;

s.t. $\mathrm{R} 3\{\mathrm{k}$ in $\mathrm{K}\}: \operatorname{sum}\{\mathrm{f}$ in $\mathrm{F}, \mathrm{r}$ in $\mathrm{R}$, e in $\mathrm{D}\}(\mathrm{x} 4[\mathrm{k}, \mathrm{f}]+\mathrm{x} 5[\mathrm{k}, \mathrm{r}]+\mathrm{x} 6[\mathrm{k}, \mathrm{e}])<=\mathrm{u}[\mathrm{k}]$;

s.t. $R 4\{s$ in $S, f$ in $F\}: x 7[s, f]+\operatorname{sum}\{k$ in $K\} x 4[k, f]>=d[f]$;

s.t. Equi_ $5\{\mathrm{j}$ in $\mathrm{J}\}: \operatorname{sum}\{\mathrm{i}$ in $\mathrm{I}\} \mathrm{x}[\mathrm{i}, \mathrm{j}]=\operatorname{sum}\{\mathrm{k}$ in $\mathrm{K}\} \mathrm{x} 1[\mathrm{j}, \mathrm{k}]$;

s.t. Equi_2 $\{\mathrm{k}$ in $\mathrm{K}\}: \operatorname{sum}\{\mathrm{j}$ in $\mathrm{J}\} \times 1[\mathrm{j}, \mathrm{k}]=\operatorname{sum}\{\mathrm{r}$ in $\mathrm{R}\} \times 5[\mathrm{k}, \mathrm{r}]$;

solve;

printf "In" ;

printf "Transporte da estacao coleta para centro desmontagem: $\% \operatorname{s} \ln ", \operatorname{sum}\{i$ in $I, j$ in $J\}$ $c[i, j] * x[i, j] ;$

printf "ln\n" ;

printf(" Estacao de coleta Centro de desmontagem Quantidade transportada $\backslash n ")$; printf "In" ;

printf $\{\mathrm{i}$ in $\mathrm{I}, \mathrm{j}$ in $\mathrm{J}: \mathrm{x}[\mathrm{i}, \mathrm{j}]\}$ " \%8s \%16s \%25g\n", $\mathrm{i}, \mathrm{j}, \mathrm{x}[\mathrm{i}, \mathrm{j}]$;

printf "In" ;

printf "Transporte do centro de desmontagem para centro transformacao: \%s $\backslash n$ ", $\operatorname{sum}\{\mathrm{j}$ in $\mathrm{J}, \mathrm{k}$ in $\mathrm{K}\} \mathrm{c} 1[\mathrm{j}, \mathrm{k}]^{*} \mathrm{x} 1[\mathrm{j}, \mathrm{k}]$;

printf "\n\n" ;

printf(" Centro de desmontagem Centro de transformacao Quantidade transportada $\ln ")$;

printf "\n" ;

printf $\{\mathrm{j}$ in $\mathrm{J}, \mathrm{k}$ in $\mathrm{K}: \mathrm{x} 1[\mathrm{j}, \mathrm{k}]\}$ " \%9s $\% 19 \mathrm{~s} \% 28 \mathrm{~g} \backslash \mathrm{n} ", \mathrm{j}, \mathrm{k}, \mathrm{x} 1[\mathrm{j}, \mathrm{k}]$;

printf "ln" ;

printf "Transporte do centro transformacao para fabrica: \%s $\backslash n$ ", $\operatorname{sum}\{\mathrm{k}$ in $\mathrm{K}, \mathrm{f}$ in $\mathrm{F}\} \mathrm{c} 4[\mathrm{k}, \mathrm{f}] * \mathrm{x} 4[\mathrm{k}, \mathrm{f}]$;

printf "\n\n" ;

printf(" Centro de transformacao Fabrica Quantidade transportada $\backslash n ")$;

printf "\n" ;

printf $\{\mathrm{k}$ in $\mathrm{K}, \mathrm{f}$ in $\mathrm{F}: \mathrm{x} 4[\mathrm{k}, \mathrm{f}]\}$ " \%10s $\% 15 \mathrm{~s} \% 19 \mathrm{~g} \backslash \mathrm{n} ", \mathrm{k}, \mathrm{f}, \mathrm{x} 4[\mathrm{k}, \mathrm{f}]$;

printf "ln" ;

printf "ln" ;

printf "Transporte do centro transformacao para Centro reciclagem: \%s $\backslash n$ ", $\operatorname{sum}\{\mathrm{k}$ in $\mathrm{K}, \mathrm{r}$ in $\mathrm{R}\} \mathrm{c} 5[\mathrm{k}, \mathrm{r}] * \mathrm{x} 5[\mathrm{k}, \mathrm{r}]$;

printf "\n\n" ;

printf(" Centro de transformacao Centro reciclagem Quantidade transportada $\backslash n ") ;$ printf "In" ;

printf $\{\mathrm{k}$ in $\mathrm{K}, \mathrm{r}$ in $\mathrm{R}: \mathrm{x} 5[\mathrm{k}, \mathrm{r}]\}$ " \%10s \%15s \%19g $\backslash \mathrm{n} ", \mathrm{k}, \mathrm{r}, \mathrm{x} 5[\mathrm{k}, \mathrm{r}]$;

printf "In" ;

printf "In" ;

printf "Transporte do centro transformacao para Centro eliminacao: \%s $\mathrm{n}$ ", $\operatorname{sum}\{\mathrm{k}$ in $\mathrm{K}, \mathrm{e}$ in $\mathrm{D}\} \mathrm{c} 6[\mathrm{k}, \mathrm{e}] * \mathrm{x} 6[\mathrm{k}, \mathrm{e}]$; 
printf "In\n" ;

printf(" Centro de transformacao Centro eliminacao Quantidade transportada $\backslash n ") ;$

printf "In" ;

printf $\{\mathrm{k}$ in $\mathrm{K}$, e in D: $\mathrm{x} 6[\mathrm{k}, \mathrm{e}]\} " \% 10 \mathrm{~s} \quad \% 15 \mathrm{~s} \quad \% 19 \mathrm{~g} \backslash \mathrm{n} ", \mathrm{k}, \mathrm{e}, \mathrm{x} 6[\mathrm{k}, \mathrm{e}]$;

printf "\n" ;

printf "In" ;

printf "Transporte do proveedor para fabrica: \%s\n", $\operatorname{sum}\{\mathrm{s}$ in $\mathrm{S}, \mathrm{f}$ in $\mathrm{F}\} \mathrm{c} 7[\mathrm{~s}, \mathrm{f}] * x 7[\mathrm{~s}, \mathrm{f}]$; printf "In\n" ;

printf(" Proveedor Fabrica Quantidade transportada $\backslash n ")$;

printf "In" ;

printf $\{\mathrm{s}$ in S, f in F: $x 7[\mathrm{~s}, \mathrm{f}]\} " \%$ " $\quad \% 7 \mathrm{~s} \quad \% 19 \mathrm{~g} \backslash \mathrm{n} ", \mathrm{~s}, \mathrm{f}, \mathrm{x} 7[\mathrm{~s}, \mathrm{f}]$;

printf "In" ; 
set P;

set $S$;

set C;

set $\mathrm{G}$;

set V;

set $\mathrm{E} 1:=\mathrm{P}$ union $\mathrm{S}$;

set $\mathrm{E} 2:=\mathrm{S}$ union $\mathrm{C}$;

param $\mathrm{C} 1\{\mathrm{p}$ in $\mathrm{P}\}$; param $\mathrm{C} 2\{\mathrm{~s}$ in $\mathrm{S}\}$; param $\mathrm{C} 3\{\mathrm{~g}$ in $\mathrm{G}\}$; param $\mathrm{C} 4\{\mathrm{v}$ in $\mathrm{V}\}$; param $\mathrm{K} 1\{\mathrm{p}$ in $\mathrm{P}\}$; param $\mathrm{K} 2\{\mathrm{i}$ in $\mathrm{E} 1\}$; param $\mathrm{K} 3\{\mathrm{~g}$ in $\mathrm{G}\}$; param $\mathrm{K} 4\{\mathrm{v}$ in $\mathrm{V}\}$; param $\mathrm{D}\{\mathrm{c}$ in $\mathrm{E} 2\}$;

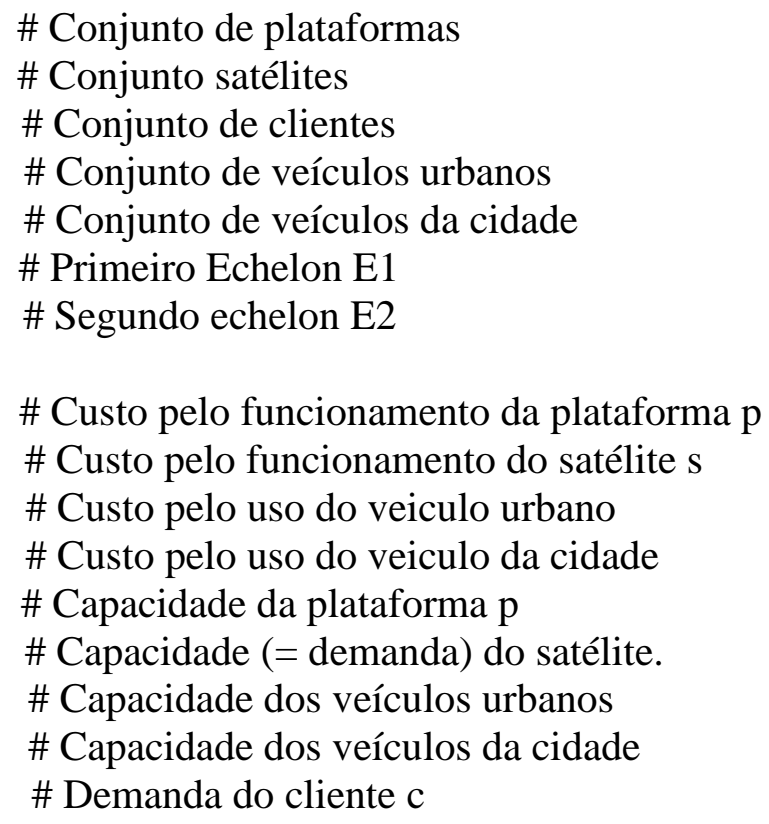

param distP_S $\{\mathrm{i}$ in E1, $\mathrm{j}$ in E1:i!=j\}; \#Distancia entre plataformas e satélites em Km. param distS_P $\{$ in E2, j in E2:i!=j\}; \# Distancia entre satélites e clientes em Km. param $\mathrm{C} 5\{\mathrm{i}$ in $\mathrm{E} 1, \mathrm{j}$ in $\mathrm{E} 1: \mathrm{i} !=\mathrm{j}\}:=16^{*}$ distP_S[i,j]*K2[i]; param C6 $\{\mathrm{i}$ in E2, j in E2:i!=j $\}:=13 *$ distS_P[i,j]*D[i];

$\operatorname{var} \mathrm{X} 1\{\mathrm{i}$ in $\mathrm{E} 1, \mathrm{j}$ in $\mathrm{E} 1, \mathrm{~g}$ in $\mathrm{G}: \mathrm{i} !=\mathrm{j}\}$, binary; \# Roteio em $\mathrm{E} 1$ com veiculo urbano $\mathrm{g}$ $\operatorname{var} \mathrm{X} 2\{\mathrm{i}$ in $\mathrm{E} 2, \mathrm{j}$ in $\mathrm{E} 2, \mathrm{v}$ in $\mathrm{V}: \mathrm{i} !=\mathrm{j}\}$, binary; \# Roteio em E2 com veiculo da cidade $\mathrm{v}$ $\operatorname{var} \mathrm{X} 3\{\mathrm{~s}$ in $\mathrm{S}, \mathrm{c}$ in $\mathrm{C}\}$, binary; $\operatorname{var} \mathrm{Y} 1\{\mathrm{p}$ in $\mathrm{P}\}$, binary; var $\mathrm{Y} 2\{\mathrm{~s}$ in $\mathrm{S}\}$, binary; $\operatorname{var} \mathrm{Z} 1\{\mathrm{~g}$ in $\mathrm{G}\}$, binary; $\operatorname{var} Z 2\{\mathrm{v}$ in $\mathrm{V}\}$, binary; $\operatorname{var} \mathrm{F}\{\mathrm{p}$ in $\mathrm{P}, \mathrm{s}$ in $\mathrm{S}, \mathrm{g}$ in $\mathrm{G}\}>=0$; \# cliente atribuído para um satélite \# Plataforma aberta em nodo i. \# Satélite aberta em nodo s \# Veiculo urbano usado \# Veiculo da cidade usado $\operatorname{var} \mathrm{L} 1\{\mathrm{i}$ in $\mathrm{C}, \mathrm{v}$ in $\mathrm{V}\}>=0$; $\operatorname{var} \mathrm{L} 2\{\mathrm{i}$ in $\mathrm{S}, \mathrm{g}$ in $\mathrm{G}\}>=0$; \# Quantidade transportada de P para S \# Em C \# em S

minimize JARM: $\operatorname{sum}\{\mathrm{p}$ in $\mathrm{P}\} \mathrm{C} 1[\mathrm{p}]^{*} \mathrm{Y} 1[\mathrm{p}]+\operatorname{sum}\{\mathrm{s}$ in $\mathrm{S}\} \mathrm{C} 2[\mathrm{~s}] * \mathrm{Y} 2[\mathrm{~s}]+$ $\operatorname{sum}\{\mathrm{g}$ in $\mathrm{G}\} \mathrm{C} 3[\mathrm{~g}] * \mathrm{Z} 1[\mathrm{~g}]+\operatorname{sum}\{\mathrm{v}$ in $\mathrm{V}\} \mathrm{C} 4[\mathrm{v}] * \mathrm{Z} 2[\mathrm{v}]+$ $\operatorname{sum}\{\mathrm{i}$ in $\mathrm{E} 2, \mathrm{j}$ in $\mathrm{E} 2, \mathrm{v}$ in $\mathrm{V}: \mathrm{i} !=\mathrm{j}\} \mathrm{C} 6[\mathrm{i}, \mathrm{j}] * \mathrm{X} 2[\mathrm{i}, \mathrm{j}, \mathrm{v}]+$ $\operatorname{sum}\{\mathrm{i}$ in E1, $\mathrm{j}$ in E1, g in G: $\mathrm{i} !=\mathrm{j}\} \mathrm{C} 5[\mathrm{i}, \mathrm{j}] * \mathrm{X} 1[\mathrm{i}, \mathrm{j}, \mathrm{g}]$;

s.t. $\mathrm{R} 1\{\mathrm{c}$ in $\mathrm{C}\}: \operatorname{sum}\{\mathrm{v}$ in $\mathrm{V}, \mathrm{j}$ in $\mathrm{E} 2: \mathrm{c} !=\mathrm{j}\} \mathrm{X} 2[\mathrm{c}, \mathrm{j}, \mathrm{v}]=1$;

s.t. $R 2\{j$ in $E 2, v$ in $V\}: \operatorname{sum}\{1$ in $E 2: 1 !=j\} X 2[1, j, v]-\operatorname{sum}\{1$ in $E 2: j !=1\} X 2[j, 1, v]=0$;

s.t. $\mathrm{R} 3\{\mathrm{i}$ in $\mathrm{C}, \mathrm{j}$ in $\mathrm{C}, \mathrm{v}$ in $\mathrm{V}: \mathrm{i} !=\mathrm{j}\}: \mathrm{L} 1[\mathrm{i}, \mathrm{v}]-\mathrm{L} 1[\mathrm{j}, \mathrm{v}]+(\operatorname{card}(\mathrm{C}))^{*} \mathrm{X} 2[\mathrm{i}, \mathrm{j}, \mathrm{v}]<=(\operatorname{card}(\mathrm{C})-$ $1)$;

s.t. $R 4\{v$ in $V\}: \operatorname{sum}\{1$ in E2, $\mathrm{j}$ in $\mathrm{S}: 1 !=\mathrm{j}\} \mathrm{X} 2[1, \mathrm{j}, \mathrm{v}]<=1$; 
s.t. $\mathrm{R} 5\{1$ in $\mathrm{S}\}: \operatorname{sum}\{\mathrm{g}$ in $\mathrm{G}, \mathrm{j}$ in $\mathrm{E} 1: 1 !=\mathrm{j}\} \mathrm{X} 1[1, \mathrm{j}, \mathrm{g}]=\mathrm{Y} 2[1]$;

s.t. $\mathrm{R} 6\{\mathrm{~h}$ in $\mathrm{E} 1, \mathrm{~g}$ in $\mathrm{G}\}: \operatorname{sum}\{1$ in $\mathrm{E} 1: 1 !=\mathrm{h}\} \mathrm{X} 1[1, \mathrm{~h}, \mathrm{~g}]-\operatorname{sum}\{1$ in $\mathrm{E} 1: \mathrm{h} !=\mathrm{l}\} \mathrm{X} 1[\mathrm{~h}, \mathrm{l,g}]=0$;

s.t. $R 7\{\mathrm{i}$ in $\mathrm{S}, \mathrm{j}$ in $\mathrm{S}, \mathrm{g}$ in $\mathrm{G}: \mathrm{i} !=\mathrm{j}\}: \mathrm{L} 2[\mathrm{i}, \mathrm{g}]-\mathrm{L} 2[\mathrm{j}, \mathrm{g}]+(\operatorname{card}(\mathrm{S}))^{*} \mathrm{X} 1[\mathrm{i}, \mathrm{j}, \mathrm{g}]<=(\operatorname{card}(\mathrm{S})-1)$;

s.t. $R 8\{g$ in $G\}: \operatorname{sum}\{1$ in $E 1, j$ in $P: 1 !=j\} X 1[1, j, g]<=1$;

s.t. $\mathrm{R} 9\{\mathrm{c}$ in $\mathrm{C}, \mathrm{v}$ in $\mathrm{V}, \mathrm{s}$ in $\mathrm{S}\}: \operatorname{sum}\{\mathrm{h}$ in $\mathrm{E} 2: \mathrm{c} !=\mathrm{h}\} \mathrm{X} 2[\mathrm{c}, \mathrm{h}, \mathrm{v}]+\operatorname{sum}\{\mathrm{h}$ in $\mathrm{E} 2: \mathrm{s} !=\mathrm{h}\}$ $\mathrm{X} 2[\mathrm{~s}, \mathrm{~h}, \mathrm{v}]-\mathrm{X} 3[\mathrm{~s}, \mathrm{c}]<=1$;

s.t. $\mathrm{R} 10\{\mathrm{c}$ in $\mathrm{C}\}: \operatorname{sum}\{\mathrm{s}$ in $\mathrm{S}\} \mathrm{X} 3[\mathrm{~s}, \mathrm{c}]=1$;

s.t. $\mathrm{R} 11\{\mathrm{~s}$ in $\mathrm{S}\}: \operatorname{sum}\{\mathrm{p}$ in $\mathrm{P}, \mathrm{g}$ in $\mathrm{G}\} \mathrm{F}[\mathrm{p}, \mathrm{s}, \mathrm{g}]-\operatorname{sum}\{\mathrm{c}$ in $\mathrm{C}\} \mathrm{D}[\mathrm{c}] * \mathrm{X} 3[\mathrm{~s}, \mathrm{c}]=0$;

s.t. $\mathrm{R} 12\{\mathrm{p}$ in $\mathrm{P}\}: \operatorname{sum}\{\mathrm{s}$ in $\mathrm{S}, \mathrm{g}$ in $\mathrm{G}\} \mathrm{F}[\mathrm{p}, \mathrm{s}, \mathrm{g}]-\mathrm{K} 1[\mathrm{p}]^{*} \mathrm{Y} 1[\mathrm{p}]<=0$;

s.t. $\mathrm{R} 13\{\mathrm{~s}$ in $\mathrm{S}\}: \operatorname{sum}\{\mathrm{p}$ in $\mathrm{P}, \mathrm{g}$ in $\mathrm{G}\} \mathrm{F}[\mathrm{p}, \mathrm{s}, \mathrm{g}]-\mathrm{K} 2[\mathrm{~s}] * \mathrm{Y} 2[\mathrm{~s}]<=0$;

s.t. R14 $\{\mathrm{g}$ in $\mathrm{G}, \mathrm{s}$ in $\mathrm{S}, \mathrm{p}$ in $\mathrm{P}\}: \mathrm{K} 3[\mathrm{~g}]^{*} \operatorname{sum}\{\mathrm{h}$ in $\mathrm{E} 1: \mathrm{s} !=\mathrm{h}\} \mathrm{X} 1[\mathrm{~s}, \mathrm{~h}, \mathrm{~g}]-\mathrm{F}[\mathrm{p}, \mathrm{s}, \mathrm{g}]>=0$;

s.t. R15 $\{\mathrm{g}$ in $\mathrm{G}, \mathrm{s}$ in $\mathrm{S}, \mathrm{p}$ in $\mathrm{P}\}: \mathrm{K} 3[\mathrm{~g}]^{*}$ sum $\{\mathrm{h}$ in $\mathrm{E} 1: \mathrm{p} !=\mathrm{h}\} \mathrm{X} 1[\mathrm{p}, \mathrm{h}, \mathrm{g}]-\mathrm{F}[\mathrm{p}, \mathrm{s}, \mathrm{g}]>=0$;

s.t. $R 16\{\mathrm{v}$ in $\mathrm{V}\}: \operatorname{sum}\{\mathrm{c}$ in $\mathrm{C}\} \mathrm{D}[\mathrm{c}]^{*} \operatorname{sum}\{\mathrm{j}$ in $\mathrm{E} 2: \mathrm{c} !=\mathrm{j}\} \mathrm{X} 2[\mathrm{c}, \mathrm{j}, \mathrm{v}]<=\mathrm{K} 4[\mathrm{v}]^{*} \mathrm{Z} 2[\mathrm{v}]$;

s.t. $\mathrm{R} 17\{\mathrm{~g}$ in $\mathrm{G}, \mathrm{v}$ in $\mathrm{V}\}: \operatorname{sum}\{\mathrm{p}$ in $\mathrm{P}, \mathrm{s}$ in $\mathrm{S}\} \mathrm{F}[\mathrm{p}, \mathrm{s}, \mathrm{g}]<=\mathrm{K} 3[\mathrm{~g}] * \mathrm{Z} 1[\mathrm{~g}]$;

solve;

printf "ln" ;

printf " Custo total: \%s\n", $\operatorname{sum}\{\mathrm{p}$ in P $\} \mathrm{C} 1[\mathrm{p}]^{*} \mathrm{Y} 1[\mathrm{p}]+\operatorname{sum}\{\mathrm{s}$ in S $\} \mathrm{C} 2[\mathrm{~s}]^{*} \mathrm{Y} 2[\mathrm{~s}]+$ $\operatorname{sum}\{\mathrm{g}$ in $\mathrm{G}\} \mathrm{C} 3[\mathrm{~g}] * \mathrm{Z} 1[\mathrm{~g}]+\operatorname{sum}\{\mathrm{v}$ in $\mathrm{V}\} \mathrm{C} 4[\mathrm{v}] * \mathrm{Z} 2[\mathrm{v}]+$ $\operatorname{sum}\{\mathrm{i}$ in $\mathrm{E} 2, \mathrm{j}$ in $\mathrm{E} 2, \mathrm{v}$ in $\mathrm{V}: \mathrm{i} !=\mathrm{j}\} \mathrm{C} 6[\mathrm{i}, \mathrm{j}] * \mathrm{X} 2[\mathrm{i}, \mathrm{j}, \mathrm{v}]+$

printf "\n\n" ; $\operatorname{sum}\{i$ in $E 1, j$ in $E 1, g$ in $G: i !=j\} C 5[i, j] * X 1[i, j, g]$;

printf " Custo de roteio em E1: \%sln", $\operatorname{sum}\{\mathrm{i}$ in E1, j in E1, g in G: $\mathrm{i} !=\mathrm{j}\}$ C5[i,j]*X1[i,j,g];

printf "In" ;

printf(" Roteio com veiculo urbano: $\lfloor n ")$;

printf "In" ;

printf $\{\mathrm{i}$ in E1, j in E1, g in G: i != j and X1[i,j,g] $\}$ " \%8s \%11s \%12sın", i, j, g; printf "ln\n" ;

printf " Custo de roteio em E2: \%s\n", $\operatorname{sum}\{\mathrm{i}$ in $E 2, j$ in $E 2, v$ in $V: i !=j\}$ C6[i,j]*X2[i,j,v];

printf "ln" ;

printf(" Roteio com veiculo da cidade: $\lfloor n ")$;

printf "In" ;

printf $\{\mathrm{i}$ in E2, j in E2, v in V: i != j and X2[i,j,v] $\}$ " \%8s \%11s \%12s $\ln ", \mathrm{i}, \mathrm{j}, \mathrm{v}$;

printf "ln\n" ; 
set $\mathrm{K}$;

set L;

set J;

set I;

set $\mathrm{KL}:=\mathrm{K}$ union $\mathrm{L}$;

set $\mathrm{JK}:=\mathrm{J}$ union $\mathrm{K}$;

set $\mathrm{JL}:=\mathrm{J}$ union $\mathrm{L}$;

set $\mathrm{IJ}:=\mathrm{I}$ union $\mathrm{J}$;

param $\mathrm{F}:=12$;

param $\mathrm{C}_{-} 1\{\mathrm{k}$ in $\mathrm{K}\}$;

param $\mathrm{C} \_2\{\mathrm{j}$ in $\mathrm{J}\}$;

param C_3 3 l in L $\}$;

param $\mathrm{Q}\{\mathrm{i}$ in $\mathrm{I}\}$;

param c_1 1 k in $\mathrm{K}\}$;

param c_2 $\{\mathrm{j}$ in $\mathrm{J}\}$;

param c_3 31 in L $\}$;

param c_4 4 k in $\mathrm{K}\}$;

param c_5 5 j in $\mathrm{J}\}$;

param c_6 $\{1$ in L $\}$;

param d_7 $7 \mathrm{i}$ in KL, $\mathrm{j}$ in KL:i! $=\mathrm{j}\}$;

param c_7 $\{\mathrm{i}$ in KL, j in KL: $\mathrm{i} !=\mathrm{j}\}:=\mathrm{F}^{*} \mathrm{~d}_{-} 7[\mathrm{i}, \mathrm{j}] * \mathrm{C}_{-} 1[\mathrm{j}]$;

param d_8 8 i in JK, $\mathrm{j}$ in JK: $\mathrm{i} !=\mathrm{j}\}$;

param c_8 $\{\mathrm{i}$ in JK, j in JK: $\mathrm{i} !=\mathrm{j}\}:=\mathrm{F} * \mathrm{~d} \_8[\mathrm{i}, \mathrm{j}] * \mathrm{C} \_2[\mathrm{j}]$;

param d_9 9 i in JL, $j$ in JL: $i !=j\}$;

param c_9 $\{$ i in JL, j in JL: $\mathrm{i} !=\mathrm{j}\}:=\mathrm{F} * \mathrm{~d} \_9[\mathrm{i}, \mathrm{j}] * \mathrm{C} \_2[\mathrm{j}]$;

param d_10 $\{\mathrm{i}$ in $\mathrm{IJ}, \mathrm{j}$ in $\mathrm{IJ}: \mathrm{i} !=\mathrm{j}\}$;

param c_10 $\{\mathrm{i}$ in $\mathrm{IJ}, \mathrm{j}$ in IJ: $\mathrm{i} !=\mathrm{j}\}:=\mathrm{F}^{*} \mathrm{~d} \_10[\mathrm{i}, \mathrm{j}]^{*} \mathrm{Q}[\mathrm{i}]$;

param U;

param T;

param $\mathrm{R}\{\mathrm{k}$ in $\mathrm{K}\}$;

param M;

$\operatorname{var} \mathrm{x}\{\mathrm{k}$ in $\mathrm{K}, \mathrm{l}$ in $\mathrm{L}\}>=0$;

$\operatorname{var} \mathrm{y}\{\mathrm{j}$ in $\mathrm{J}, \mathrm{k}$ in $\mathrm{K}\}>=0$;

$\operatorname{var} \mathrm{z}\{\mathrm{j}$ in $\mathrm{J}, \mathrm{l}$ in $\mathrm{L}\}>=0$;

$\operatorname{var} f\{i$ in $I, j$ in $J\}>=0$;

var $\mathrm{e}\{\mathrm{j}$ in $\mathrm{J}\}$, binary;

minimize Custo_Total: $\operatorname{sum}\{\mathrm{j}$ in $\mathrm{J}\}$ c_2[j] $* \mathrm{e}[\mathrm{j}]+\operatorname{sum}\{\mathrm{k}$ in $\mathrm{K}\} \mathrm{c} \_1[\mathrm{k}]+\operatorname{sum}\{1$ in $\mathrm{L}\}$ c_3[1]+ $\operatorname{sum}\{\mathrm{j}$ in $\mathrm{J}\} \mathrm{c} \_5[\mathrm{j}]^{*} \operatorname{sum}\{\mathrm{i}$ in $\mathrm{I}\} \mathrm{f}[\mathrm{i}, \mathrm{j}]+\operatorname{sum}\{\mathrm{k}$ in $\mathrm{K}\} \mathrm{c} \_4[\mathrm{k}]^{*} \operatorname{sum}\{\mathrm{j}$ in $\mathrm{J}\} \mathrm{y}[\mathrm{j}, \mathrm{k}]$

$+$

$\operatorname{sum}\{1$ in $L\}$ c_6[1]*sum $\{\mathrm{j}$ in $\mathrm{J}\} \mathrm{z}[\mathrm{j}, 1]+\operatorname{sum}\{1$ in $\mathrm{L}\} \mathrm{c} \_6[1] * \operatorname{sum}\{\mathrm{k}$ in $\mathrm{K}\} \mathrm{x}[\mathrm{k}, 1]+$ $\operatorname{sum}\{\mathrm{i}$ in $\mathrm{I}, \mathrm{j}$ in $\mathrm{J}\} \mathrm{c} \_10[\mathrm{i}, \mathrm{j}] * \mathrm{f}[\mathrm{i}, \mathrm{j}]+\operatorname{sum}\{\mathrm{j}$ in $\mathrm{J}, \mathrm{k}$ in $\mathrm{K}\} \mathrm{c} \_8[\mathrm{j}, \mathrm{k}] * \mathrm{y}[\mathrm{j}, \mathrm{k}]+$ $\operatorname{sum}\{\mathrm{j}$ in $\mathrm{J}, 1$ in $\left.\mathrm{L}\} \mathrm{c}_{-} 9[\mathrm{j}, \mathrm{l}]\right]^{*} \mathrm{z}[\mathrm{j}, 1]+\operatorname{sum}\{\mathrm{k}$ in $\mathrm{K}, 1$ in $\mathrm{L}\} \mathrm{c}_{-} 7[\mathrm{k}, 1] * \mathrm{x}[\mathrm{k}, 1]$;

s.t. Restriccion_1 $1\{\mathrm{i}$ in $\mathrm{I}\}: \operatorname{sum}\{\mathrm{j}$ in $\mathrm{J}\} \mathrm{f}[\mathrm{i}, \mathrm{j}]=\mathrm{Q}[\mathrm{i}]$; 
s.t. Restriccion_2\{l in L $\}: \operatorname{sum}\{\mathrm{j}$ in $\mathrm{J}\} \mathrm{z}[\mathrm{j}, 1]<=\mathrm{U}$;

s.t. Restriccion_3 3 in $J\}: \operatorname{sum}\{\mathrm{i}$ in $\mathrm{I}\} \mathrm{f}[\mathrm{i}, \mathrm{j}]-(\operatorname{sum}\{\mathrm{k}$ in $\mathrm{K}\} \mathrm{y}[\mathrm{j}, \mathrm{k}]+\operatorname{sum}\{1$ in $\mathrm{L}\} \mathrm{z}[\mathrm{j}, 1])=0$;

s.t. Restriccion_4\{k in $\mathrm{K}\}: \operatorname{sum}\{\mathrm{j}$ in $\mathrm{J}\} \mathrm{y}[\mathrm{j}, \mathrm{k}]-(1 / \mathrm{R}[\mathrm{k}])^{*} \operatorname{sum}\{1$ in $\mathrm{L}\} \mathrm{x}[\mathrm{k}, \mathrm{l}]=0$;

s.t. Restriccion_5 $\{\mathrm{j}$ in $\mathrm{J}\}: \operatorname{sum}\{\mathrm{i}$ in $\mathrm{I}\} \mathrm{f}[\mathrm{i}, \mathrm{j}]<=\mathrm{C} \_2[\mathrm{j}]^{*} \mathrm{e}[\mathrm{j}]$;

s.t. Restriccion_6 $\{\mathrm{k}$ in $\mathrm{K}\}: \operatorname{sum}\{\mathrm{j}$ in $\mathrm{J}\} \mathrm{y}[\mathrm{j}, \mathrm{k}]<=\mathrm{C} \_1[\mathrm{k}]$;

s.t. Restriccion_7 $\{1$ in $\mathrm{L}\}: \operatorname{sum}\{\mathrm{j}$ in $\mathrm{J}\} \mathrm{z}[\mathrm{j}, 1]+\operatorname{sum}\{\mathrm{k}$ in $\mathrm{K}\} \mathrm{x}[\mathrm{k}, \mathrm{l}]<=\mathrm{C} \_3[1]$;

s.t. Restriccion_8 $8 \mathrm{i}$ in $\mathrm{I}, \mathrm{j}$ in $\mathrm{J}\}: \mathrm{f}[\mathrm{i}, \mathrm{j}]-\mathrm{M}^{*} \mathrm{e}[\mathrm{j}]<=0$;

s.t. Restriccion_9: $\operatorname{sum}\{\mathrm{j}$ in $\mathrm{J}\}$ e $[\mathrm{j}]<=\mathrm{T}$;

solve;

printf "ln" ;

printf " Transporte das zonas para as estações de coleta: \%s $\backslash n ", \quad \operatorname{sum}\{\mathrm{i}$ in $\mathrm{I}, \mathrm{j}$ in $\mathbf{J}\}$ c_10[i,j]*f[i,j] ;

printf "\n\n" ;

printf(" Zona Estação de coleta Quantidade transportada $\backslash n ")$;

printf "In" ;

printf $\{\mathrm{i}$ in $\mathrm{I}, \mathrm{j}$ in J: $f[i, j]\}$ " \%1s \%10s \%23gln", i, j, f[i,j];

printf "In" ;

printf " Transporte das estações de coleta para centros de composição: \%s $\ln ", \operatorname{sum}\{\mathrm{j}$ in $\mathrm{J}$, $\mathrm{k}$ in $\mathrm{K}\} \mathrm{c} \_8[\mathrm{j}, \mathrm{k}]^{*} \mathrm{y}[\mathrm{j}, \mathrm{k}]$;

printf "\n\n" ;

printf(" Estação de coleta Centro de composição Quantidade transportada $\backslash n ")$;

printf "In" ;

printf $\{\mathrm{j}$ in $\mathrm{J}, \mathrm{k}$ in $\mathrm{K}: \mathrm{y}[\mathrm{j}, \mathrm{k}]\}$ " \%8s \%18s \%26g\n", j, k, y[j,k];

printf "ln" ;

printf " Transporte das estações de coleta para aterros sanitários: \% $\operatorname{sin",~} \operatorname{sum}\{\mathrm{j}$ in $\mathrm{J}, 1$ in L) c_9[j,1]*z[j,1] ;

printf "\n\n" ;

printf(" Estação de coleta aterro sanitário Quantidade transportada $\backslash n ")$;

printf "In" ;

printf $\{\mathrm{j}$ in $\mathrm{J}, 1$ in L: $\mathrm{z}[\mathrm{j}, 1]\}$ " \%9s $\quad \% 16 \mathrm{~s} \quad \% 22 \mathrm{~g} \backslash \mathrm{n} ", \mathrm{j}, 1, \mathrm{z}[\mathrm{j}, 1]$;

printf "\n" ;

printf " Transporte do centro de composição para aterro sanitário: \%s $\backslash n$ ", sum $\{\mathrm{k}$ in $\mathrm{K}, 1$ in L\} c_ $7[\mathrm{k}, 1] * x[\mathrm{k}, 1]$;

printf "\n\n" ;

printf(" Centro composição aterro sanitário Quantidade transportada $\backslash n$ ");

printf "ln" ;

printf $\{\mathrm{k}$ in $\mathrm{K}, 1$ in $\mathrm{L}: \mathrm{x}[\mathrm{k}, 1]\}$ " \%7s \%16s \%24g\n", $\mathrm{k}, 1, \mathrm{x}[\mathrm{k}, 1]$;

printf "In" ;

printf " Estações de coleta selecionadas: \%s $\backslash n$ ", $\operatorname{sum}\{\mathrm{j}$ in $\mathrm{J}\}$ c_2[j] * e[j] ;

printf "\n\n" ;

printf(" Estações de coleta $\backslash n ")$;

printf "\n" ;

printf $\{\mathrm{j}$ in $\mathrm{J}: \mathrm{e}[\mathrm{j}]\}$ " \%9s $\backslash \mathrm{n} ", \mathrm{j}, \mathrm{e}[\mathrm{j}]$;

printf "ln" ; 


\section{ANEXO F: Modelo de coleta dos RSU}

set I

\# conjunto de deposito $0=8$

set EC;

\# Conjunto de Estações de coleta

set $\mathrm{PC}$;

\# Conjunto de pontos de coleta

set $\mathrm{N}:=\mathrm{I}$ union $\mathrm{EC}$ union $\mathrm{PC}$;

\# Conjunto de pontos que compõem a rede

set $\mathrm{K}$;

\# Conjunto de veículos

param $\mathrm{f}:=3$;

\# Frete $\$ /$ ton por $\mathrm{km}$ percorrido

param dist $\{\mathrm{i}$ in $\mathrm{N}, \mathrm{j}$ in $\mathrm{N}: \mathrm{i} !=\mathrm{j}\}$; \# Distancia.

param ql $\{\mathrm{i}$ in $\mathrm{N}\}$;

\# Quantidade de lixo nos pontos de coleta.

param c $\{\mathrm{i}$ in $\mathrm{N}, \mathrm{j}$ in $\mathrm{N}: \mathrm{i} !=\mathrm{j}\}:=\mathrm{f}^{*} \operatorname{dist}[\mathrm{i}, \mathrm{j}]^{*} \mathrm{ql}[\mathrm{i}] ; \quad$ \# Custo transporte em $\$$.

param $\mathrm{t}\{\mathrm{i}$ in $\mathrm{N}, \mathrm{j}$ in $\mathrm{N}: \mathrm{i} !=\mathrm{j}\}$; \# Tempo de viagem em minutos.

param $\operatorname{ta}\{\mathrm{i}$ in $\mathrm{N}\}$;

param a $\{\mathrm{i}$ in $\mathrm{N}\}$;

\# Tempo de atendimento em cada ponto de coleta

param $b\{\mathrm{i}$ in $\mathrm{N}\}$;

param $\mathrm{q}\{\mathrm{k}$ in $\mathrm{K}\}$;

param cc: $=0.275$

\# Janela de tempo: Limite de tempo inferior.

\# Janela de tempo: Limite de tempo superior.

\# capacidade dos veículos em tn.

$(1 / \mathrm{km})$

\# Consumo de combustível do veiculo em litros por km

param em $\{\mathrm{k}$ in $\mathrm{K}\}$;

param $S:=80$

\# Emissão de CO2 dos veículos em gramas por litro (g/l).

param $\operatorname{cf}\{\mathrm{j}$ in $\mathrm{EC}\}$; \# Custo fixo pela instalação das estações de coleta.

$\operatorname{var} x\{i$ in $N, j$ in $N, k$ in $K\}$, binary; \# 1 se veiculo $k$ usa a rota $(i, j)$; senão 0 .

var $\mathrm{y}\{\mathrm{j}$ in $\mathrm{EC}\}$, binary;

\# Variável binaria: 1 se a ec e' selecionada. Senão 0.

$\operatorname{var} \mathrm{D}\{\mathrm{i}$ in $\mathrm{N}, \mathrm{k}$ in $\mathrm{K}\}>=0$;

\# Demanda acumulada em i para seu transp. no veiculo

$\mathrm{k}$.

$\operatorname{var} \mathrm{W}\{\mathrm{i}$ in $\mathrm{N}, \mathrm{k}$ in $\mathrm{K}\} ; \quad$ \# Tempo de atendimento inicial em i pelo veiculo $\mathrm{k}$.

minimize CT: $\operatorname{sum}\{i$ in $N, j$ in $N, k$ in $K: i ~ !=j\} c[i, j]^{*} x[i, j, k]+\operatorname{sum}\{j$ in $E C\} c f[j]^{*} y[j]+$ $\operatorname{sum}\{\mathrm{i}$ in $\mathrm{N}, \mathrm{j}$ in $\mathrm{N}, \mathrm{k}$ in $\mathrm{K}: \mathrm{i} !=\mathrm{j}\} \mathrm{cc}^{*}(\mathrm{em}[\mathrm{k}] / \mathrm{q}[\mathrm{k}])^{*} \mathrm{x}[\mathrm{i}, \mathrm{j}, \mathrm{k}]$;

s.t. $\mathrm{R} \_1\{\mathrm{k}$ in $\mathrm{K}\}: \operatorname{sum}\left\{\mathrm{i}\right.$ in $\mathrm{N}, \mathrm{j}$ in $\mathrm{PC}: \mathrm{i} !=\mathrm{j}$ and $\mathrm{i}==$ 'D0' $^{\mathrm{N}} \mathrm{x}[\mathrm{i}, \mathrm{j}, \mathrm{k}]=1$;

s.t. $R \_2\{k$ in $K\}: \operatorname{sum}\left\{i\right.$ in $E C, j$ in $N: i !=j$ and $j==$ 'D8' $^{\prime} x[i, j, k]=1$;

s.t. $\mathrm{R} \_3\{\mathrm{j}$ in $\mathrm{PC}\}: \operatorname{sum}\{\mathrm{i}$ in $\mathrm{N}, \mathrm{k}$ in $\mathrm{K}: \mathrm{i} !=\mathrm{j}\} \mathrm{x}[\mathrm{i}, \mathrm{j}, \mathrm{k}]=1$;

s.t. $\mathrm{R} \_4\{\mathrm{j}$ in $\mathrm{PC}$ union $\mathrm{EC}, \mathrm{k}$ in $\mathrm{K}\}: \operatorname{sum}\{\mathrm{i}$ in $\mathrm{N}\} \mathrm{x}[\mathrm{i}, \mathrm{j}, \mathrm{k}]=\operatorname{sum}\{\mathrm{i}$ in $\mathrm{N}\} \mathrm{x}[\mathrm{j}, \mathrm{i}, \mathrm{k}]$;

s.t. $\mathrm{R} \_5\{\mathrm{i}$ in $\mathrm{PC}, \mathrm{k}$ in $\mathrm{K}\}: \mathrm{a}[\mathrm{i}]<=\mathrm{W}[\mathrm{i}, \mathrm{k}]<=\mathrm{b}[\mathrm{i}]$;

s.t. $\mathrm{R} \_$6 $\mathrm{i}$ in $\mathrm{PC}$ union $\mathrm{EC}, \mathrm{j}$ in $\mathrm{PC}$ union $\mathrm{EC}, \mathrm{k}$ in $\left.\mathrm{K}: \mathrm{i} !=\mathrm{j}\right\}$ :

$\mathrm{W}[\mathrm{i}, \mathrm{k}]+\mathrm{ta}[\mathrm{i}]+\mathrm{t}[\mathrm{i}, \mathrm{j}]<=\mathrm{W}[\mathrm{j}, \mathrm{k}]+100000 *(1-\mathrm{x}[\mathrm{i}, \mathrm{j}, \mathrm{k}])$;

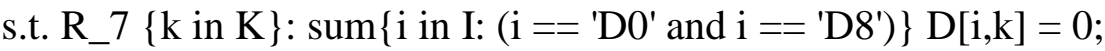

s.t. $\mathrm{R} \_8\{\mathrm{i}$ in $\mathrm{PC}$ union $\mathrm{EC}, \mathrm{j}$ in $\mathrm{N}, \mathrm{k}$ in $\mathrm{K}: \mathrm{i} !=\mathrm{j}\}$ :

$\mathrm{D}[\mathrm{i}, \mathrm{k}]+\mathrm{ql}[\mathrm{i}]<=\mathrm{D}[\mathrm{j}, \mathrm{k}]+100000 *(1-\mathrm{x}[\mathrm{i}, \mathrm{j}, \mathrm{k}])$; 
s.t. $\mathrm{R} \_9\{\mathrm{i}$ in $\mathrm{PC}, \mathrm{k}$ in $\mathrm{K}\}: \mathrm{D}[\mathrm{i}, \mathrm{k}]<=\mathrm{q}[\mathrm{k}]$;

s.t. $\mathrm{R} \_10\{\mathrm{k}$ in $\mathrm{K}\}: \operatorname{sum}\{\mathrm{i}$ in $\mathrm{N}, \mathrm{j}$ in $\mathrm{PC}\} \mathrm{x}[\mathrm{i}, \mathrm{j}, \mathrm{k}]<=\mathrm{S}$;

s.t. $\mathrm{R} 11\{\mathrm{i}$ in $\mathrm{N}, \mathrm{j}$ in $\mathrm{EC}, \mathrm{k}$ in $\mathrm{K}: \mathrm{i} !=\mathrm{j}\}: \mathrm{x}[\mathrm{i}, \mathrm{j}, \mathrm{k}]<=\mathrm{y}[\mathrm{j}]$;

solve;

printf "\n";

printf "

printf " CUSTO TOTAL (\$): \%sln", sum $\{\mathrm{i}$ in N, j in N, k in $\mathrm{K}: \mathrm{i} !=\mathrm{j}\} \mathrm{c}[\mathrm{i}, \mathrm{j}]{ }^{*} \mathrm{x}[\mathrm{i}, \mathrm{j}, \mathrm{k}]$;

printf "In" ;

printf " C02 GERADO (KG/TON-KM): \%s\n", $\quad \operatorname{sum}\{\mathrm{i}$ in $\mathrm{N}, \mathrm{j}$ in $\mathrm{N}, \mathrm{k}$ in $\mathrm{K}$ : $\mathrm{i} !=$ j\} $0.275^{*}(\mathrm{em}[\mathrm{k}] / \mathrm{q}[\mathrm{k}]) * \mathrm{x}[\mathrm{i}, \mathrm{j}, \mathrm{k}]$;

printf "In";

printf(" Estacoes de coleta selecionadas:");

printf $\{\mathrm{j}$ in EC: $y[j]\}$ " \%1s In", j;

printf " $\ln "$

printf "\n";

\#printf "In";

\#printf " ============================ $\operatorname{ln"~;~}$

\#printf " PERCORRIDO E VEICULOS USADOS $\backslash n "$ ";

\#printf " ============================ln" ;

printf(" Aresta Veiculo $\backslash n ")$;

printf "\n" ;

printf $\{\mathrm{i}$ in $\mathrm{N}, \mathrm{j}$ in $\mathrm{N}, \mathrm{k}$ in $\mathrm{K}: \mathrm{x}[\mathrm{i}, \mathrm{j}, \mathrm{k}]\}$ " \%1s \%2s \%9s \n", i, j, k;

printf "In $\backslash n "$; 
ANEXO G: Modelo de transporte dos RSU coletados para centros especializados: Caso I

set EC;

\# Conjunto de estações de coleta ec

set $\mathrm{CD}$;

\# Conjunto de Centros de desmontagem cd

set $\mathrm{CT}$;

\# Conjunto de Centros de transformação ct

set F;

\# Conjunto de fabricas $\mathrm{f}$

set $\mathrm{CE}$;

\# Conjunto de centros de eliminação e

set $\mathrm{N}$ := EC union $\mathrm{CD}$ union $\mathrm{CT}$ union $\mathrm{F}$ union $\mathrm{CE}$; \# Conjunto dos nodos da rede

set $\mathrm{K}$;

\# Conjunto de veículos.

param a $\{\mathrm{ec}$ in $\mathrm{EC}\}$;

\# Capacidade da estação de coleta ec

param $b\{c d$ in $C D\}$;

\# Capacidade do centro de desmontagem cd

param $\mathrm{u}\{\mathrm{ct}$ in $\mathrm{CT}\}$;

\# Capacidade do centro de transformação ct

param $\mathrm{v}\{\mathrm{e}$ in $\mathrm{CE}\}$

\# Capacidade do centro de eliminação e

param distEC_CD $\{$ ec in EC, cd in $\mathrm{CD}\}$; \# Distancia de estações de coleta para centro triagem

param distEC_CE $\{$ ec in EC, e in CE $\}$; \# Distancia de estações de coleta para CE.

param distCD_F $\{\mathrm{cd}$ in $\mathrm{CD}, \mathrm{f}$ in $\mathrm{F}\}$; \# Distancia de centro triagem para fabrica.

param distCD_CT $\{$ cd in CD, ct in CT $\}$; \# Distancia de centro triagem para centro transformação

param distCT_F $\{$ ct in CT, $\mathrm{f}$ in F\}; \# Distancia de centro transformação para fabrica

param distCT_CE $\{$ ct in $\mathrm{CT}$, e in $\mathrm{CE}\}$; \# Distancia de c. transformação para centro eliminação

param $\mathrm{c}\{\mathrm{ec}$ in $\mathrm{EC}$, cd in $\mathrm{CD}\}:=10 *$ distEC_CD[ec,cd]*a[ec]; \# Custo transporte de EC para CD

param c1 $\{$ ec in EC, e in $\mathrm{CE}\}:=10 *$ distEC_CE[ec,e]*a[ec]; \# Custo transporte de EC para $\mathrm{CE}$

param c $2\{\mathrm{~cd}$ in $\mathrm{CD}, \mathrm{f}$ in $\mathrm{F}\}:=10 *$ distCD_F[cd,f]*b[cd]; \# Custo transporte $\mathrm{CD}$ para $\mathrm{F}$ param c3 $\{\mathrm{cd}$ in $\mathrm{CD}$, ct in $\mathrm{CT}\}:=10 *$ distCD_CT[cd,ct]*b[cd]; \# Custo transporte CD para CT

param c4 $\{$ ct in $\mathrm{CT}$, f in $\mathrm{F}\}:=10^{*}$ distCT_F[ct,f]* $\mathrm{u}[\mathrm{ct}] ; \quad$ \# Custo transporte CT para $\mathrm{F}$ param c5 $\{$ ct in $\mathrm{CT}$, e in $\mathrm{CE}\}:=10 *$ distCT_CE[ct,e] ${ }^{*} \mathrm{u}[\mathrm{ct}]$; \# Custo transporte CT para CE param b_b $\{k$ in $K, i$ in $N, j$ in $N\}$, binary; \# Constante binaria, 1 se o veiculo esta na rota param ff $\{\mathrm{k}$ in $\mathrm{K}, \mathrm{i}$ in $\mathrm{N}, \mathrm{j}$ in $\mathrm{N}\}$; \# Custo fixo dos veículos nas rotas em $\mathrm{R} \$$.

param $\mathrm{m}:=3$;

param $\mathrm{q}\{\mathrm{k}$ in $\mathrm{K}\}$;

param $\operatorname{em}\{\mathrm{k}$ in $\mathrm{K}\}$;

\# Quantidade de veículos (Q).

\# Capacidade dos veículos transportadores em $\mathrm{Kg}$.

\# Emissão CO2 dos veículos em gramas por litro

(g/l).

param cc: $=0.275$;

\# Consumo de combustível do veículo em litros $/ \mathrm{km}$

var $\mathrm{x}\{\mathrm{ec}$ in $\mathrm{EC}, \mathrm{cd}$ in $\mathrm{CD}\},>=0$;

var $\mathrm{x} 1\{\mathrm{ec}$ in $\mathrm{EC}$, e in $\mathrm{CE}\},>=0$;

\# Quantidade transportada da EC para CD

\# Quantidade transportada da EC para CE

var $\mathrm{x} 2\{\mathrm{~cd}$ in $\mathrm{CD}, \mathrm{f}$ in $\mathrm{F}\},>=0$;

\# Quantidade transportada do CD para $\mathrm{F}$

var $\mathrm{x} 3\{\mathrm{~cd}$ in $\mathrm{CD}$, ct in $\mathrm{CT}\},>=0$;

\# Quantidade transportada do CD para CT

var $x 4\{$ ct in $C T, f$ in $F\},>=0$;

\# Quantidade transportada do CT para F

\# Quantidade transportada do CT para CE

$\operatorname{var} \mathrm{Y}\{\mathrm{k}$ in $\mathrm{K}, \mathrm{i}$ in $\mathrm{N}, \mathrm{j}$ in $\mathrm{N}\}$, binary; \# Valor 1: veiculo atribuído na rota, senão 0. 
$\operatorname{minimize} Z: \operatorname{sum}\{e c$ in $E C$, cd in $C D\} c[e c, c d]^{*} x[e c, c d]+\operatorname{sum}\{e c$ in $E C$, e in $\mathrm{CE}\} \mathrm{c} 1[\mathrm{ec}, \mathrm{e}] * \mathrm{x} 1[\mathrm{ec}, \mathrm{e}]+\operatorname{sum}\{\mathrm{cd}$ in $\mathrm{CD}, \mathrm{f}$ in $\mathrm{F}\} \mathrm{c} 2[\mathrm{~cd}, \mathrm{f}] * \mathrm{x} 2[\mathrm{~cd}, \mathrm{f}]+\operatorname{sum}\{\mathrm{cd}$ in $\mathrm{CD}, \mathrm{ct}$ in $\mathrm{CT}\}$ $\mathrm{c} 3[\mathrm{~cd}, \mathrm{ct}]^{*} \mathrm{x} 3[\mathrm{~cd}, \mathrm{ct}]+\operatorname{sum}\{\mathrm{ct}$ in $\mathrm{CT}, \mathrm{f}$ in $\mathrm{F}\} \mathrm{c} 4[\mathrm{ct}, \mathrm{f}]^{*} \mathrm{x} 4[\mathrm{ct}, \mathrm{f}]+\operatorname{sum}\{\mathrm{ct}$ in $\mathrm{CT}$, e in $\mathrm{CE}\} \mathrm{c} 5[\mathrm{ct}, \mathrm{e}]^{*} \mathrm{x} 5[\mathrm{ct}, \mathrm{e}]+\operatorname{sum}\{\mathrm{k}$ in $\mathrm{K}, \mathrm{i}$ in $\mathrm{N}, \mathrm{j}$ in $\mathrm{N}\} f f[\mathrm{k}, \mathrm{i}, \mathrm{j}] * \mathrm{Y}[\mathrm{k}, \mathrm{i}, \mathrm{j}]+$ $\operatorname{sum}\{\mathrm{ec}$ in $\mathrm{EC}$, cd in $\mathrm{CD}, \mathrm{k}$ in $\mathrm{K}$ : ec $!=$ cd $\} c^{*}(e m[k] / q[k]) * Y[k, e c, c d] * d i s t E C \_C D[e c, c d] / m$;

s.t. $\mathrm{R} 1\{\mathrm{ec}$ in $\mathrm{EC}\}: \operatorname{sum}\{\mathrm{cd}$ in $\mathrm{CD}$, e in $\mathrm{CE}\} \mathrm{x}[\mathrm{ec}, \mathrm{cd}]>=\mathrm{a}[\mathrm{ec}]$;

s.t. $\mathrm{R} 2\{\mathrm{~cd}$ in $\mathrm{CD}, \mathrm{f}$ in $\mathrm{F}\}: \operatorname{sum}\{\mathrm{ct}$ in $\mathrm{CT}\}(\mathrm{x} 2[\mathrm{~cd}, \mathrm{f}]+\mathrm{x} 3[\mathrm{~cd}, \mathrm{ct}])<=\mathrm{b}[\mathrm{cd}]$;

s.t. R3 $\{$ ct in $\mathrm{CT}\}: \operatorname{sum}\{\mathrm{f}$ in $\mathrm{F}, \mathrm{e}$ in $\mathrm{CE}\}(\mathrm{x} 4[\mathrm{ct}, \mathrm{f}]+\mathrm{x} 5[\mathrm{ct}, \mathrm{e}])<=\mathrm{u}[\mathrm{ct}]$;

s.t. $\mathrm{R} 4\{\mathrm{ec}$ in $\mathrm{EC}, \mathrm{cd}$ in $\mathrm{CD}: \mathrm{ec} !=\mathrm{cd}\}: \operatorname{sum}\{\mathrm{k}$ in $\mathrm{K}\} \mathrm{b} \_\mathrm{b}[\mathrm{k}, \mathrm{ec}, \mathrm{cd}]^{*} \mathrm{Y}[\mathrm{k}, \mathrm{ec}, \mathrm{cd}]<=\mathrm{x}[\mathrm{ec}, \mathrm{cd}]$;

s.t. $\mathrm{R} 5\{\mathrm{~cd}$ in $\mathrm{CD}\}: \operatorname{sum}\{\mathrm{ec}$ in $\mathrm{EC}\} \times[\mathrm{ec}, \mathrm{cd}]=\operatorname{sum}\{\mathrm{ct}$ in $\mathrm{CT}\} \times 3[\mathrm{~cd}, \mathrm{ct}]$;

s.t. $\mathrm{R} 6\{\mathrm{~cd}$ in $\mathrm{CD}\}: \operatorname{sum}\{\mathrm{ec}$ in $\mathrm{EC}\} \mathrm{x}[\mathrm{ec}, \mathrm{cd}]=\operatorname{sum}\{\mathrm{f}$ in $\mathrm{F}\} \mathrm{x} 2[\mathrm{~cd}, \mathrm{f}]$;

s.t. $\mathrm{R} 7\{\mathrm{ct}$ in $\mathrm{CT}\}: \operatorname{sum}\{\mathrm{cd}$ in $\mathrm{CD}\} \times 3[\mathrm{~cd}, \mathrm{ct}]=\operatorname{sum}\{\mathrm{f}$ in $\mathrm{F}\} \times \mathrm{x} 4[\mathrm{ct}, \mathrm{f}]$;

s.t. $\mathrm{R} 8\{\mathrm{ct}$ in $\mathrm{CT}\}: \operatorname{sum}\{\mathrm{cd}$ in $\mathrm{CD}\} \times 3[\mathrm{~cd}, \mathrm{ct}]=\operatorname{sum}\{\mathrm{e}$ in $\mathrm{CE}\} \times 5[\mathrm{ct}, \mathrm{e}]$

solve;

printf "ln" ;

printf "Transporte da estação coleta para centro desmontagem: \%s\n", sum $\{$ ec in EC, cd in CD $\}$ c[ec,cd]*x[ec,cd];

printf "\n\n" ;

printf(" Estação de coleta Centro de desmontagem Quantidade transportada $\backslash n ")$; printf "In" ;

printf $\{$ ec in EC, cd in CD: $x[e c, c d]\} " \quad \% 8 s \quad \% 16 \mathrm{~s} \quad \% 25 \mathrm{~g} \backslash \mathrm{n} ", \mathrm{ec}, \mathrm{cd}, \mathrm{x}[\mathrm{ec}, \mathrm{cd}]$;

printf "In" ;

printf "Transporte da estação coleta para centro eliminação: \%s\n", sum\{ec in EC, e in $\mathrm{CE}\} \mathrm{c} 1[\mathrm{ec}, \mathrm{e}]^{*} \times 1[\mathrm{ec}, \mathrm{e}]$;

printf "\n\n" ;

printf(" Estação de coleta Centro de desmontagem Quantidade transportada $\backslash n ")$; printf "In" ;

printf $\{\mathrm{ec}$ in EC, e in CE: $\mathrm{x} 1[\mathrm{ec}, \mathrm{e}]\} \quad \% 8 \mathrm{~s} \quad \% 16 \mathrm{~s} \quad \% 25 \mathrm{~g} \backslash \mathrm{n} ", \mathrm{ec}, \mathrm{e}, \mathrm{x} 1[\mathrm{ec}, \mathrm{e}]$

printf "In" ;

printf "Transporte do centro de desmontagem para fabrica: \%s $\backslash n$ ", $\operatorname{sum}\{\mathrm{cd}$ in $\mathrm{CD}, \mathrm{f}$ in $\mathrm{F}\} \mathrm{c} 2[\mathrm{~cd}, \mathrm{f}]^{*} \mathrm{x} 2[\mathrm{~cd}, \mathrm{f}]$;

printf "\n\n" ;

printf(" Centro de desmontagem Fabrica Quantidade transportada $\backslash n ")$;

printf "In" ;

printf $\{\mathrm{cd}$ in $\mathrm{CD}, \mathrm{f}$ in $\mathrm{F}: \mathrm{x} 2[\mathrm{~cd}, \mathrm{f}]\} " \quad \% 9 \mathrm{~s} \quad \% 19 \mathrm{~s} \quad \% 28 \mathrm{~g} \backslash \mathrm{n} ", \mathrm{~cd}, \mathrm{f}, \mathrm{x} 2[\mathrm{~cd}, \mathrm{f}]$;

printf "ln" ; 
printf "Transporte do C. desmontagem para C. transformação: \%s\n", sum \{cd in CD, ct in CT\} c3[cd,ct]*x3[cd,ct];

printf "\n\n" ;

printf(" Centro de desmontagem Centro de transformação Quantidade transportada $\ln ")$;

printf "\n" ;

printf $\{\mathrm{cd}$ in CD, ct in CT: $\mathrm{x} 3[\mathrm{~cd}, \mathrm{ct}]\} \quad \% 9 \mathrm{~s} \quad \% 19 \mathrm{~s} \% 28 \mathrm{~g} \backslash \mathrm{n} ", \mathrm{~cd}, \mathrm{ct}, \mathrm{x} 3[\mathrm{~cd}, \mathrm{ct}]$;

printf "\n" ;

printf "Transporte do centro transformação para fabrica: \%s\n", $\operatorname{sum}\{\mathrm{ct}$ in CT, $\mathrm{f}$ in F $\}$ c4[ct,f]*x4[ct,f];

printf "\n\n" ;

printf(" Centro de transformação Fabrica Quantidade transportada $\backslash n ")$;

printf "In" ;

printf $\{\mathrm{ct}$ in CT, f in F: $\mathrm{x} 4[\mathrm{ct}, \mathrm{f}]\}$ " \%10s $\% 15 \mathrm{~s} \quad \% 19 \mathrm{~g} \backslash \mathrm{n} ", \mathrm{ct}, \mathrm{f}, \mathrm{x} 4[\mathrm{ct}, \mathrm{f}]$;

printf "ln" ;

printf "Transporte do centro transformação para Centro eliminação: \%s\n", $\operatorname{sum}\{$ ct in CT, e in $\mathrm{CE}\} \mathrm{c} 5[\mathrm{ct}, \mathrm{e}]^{*} \mathrm{x} 5[\mathrm{ct}, \mathrm{e}]$;

printf "\n\n" ;

printf(" Centro de transformação Centro eliminação Quantidade transportada $\backslash n$ "); printf "\n" ;

printf $\{$ ct in CT, e in CE: x5[ct,e] $\} " \% 10 \mathrm{~s} \quad \% 15 \mathrm{~s} \% 19 \mathrm{~g} \backslash \mathrm{n} ", \mathrm{ct}, \mathrm{e}, \mathrm{x} 5$ [ct,e];

printf "In" ;

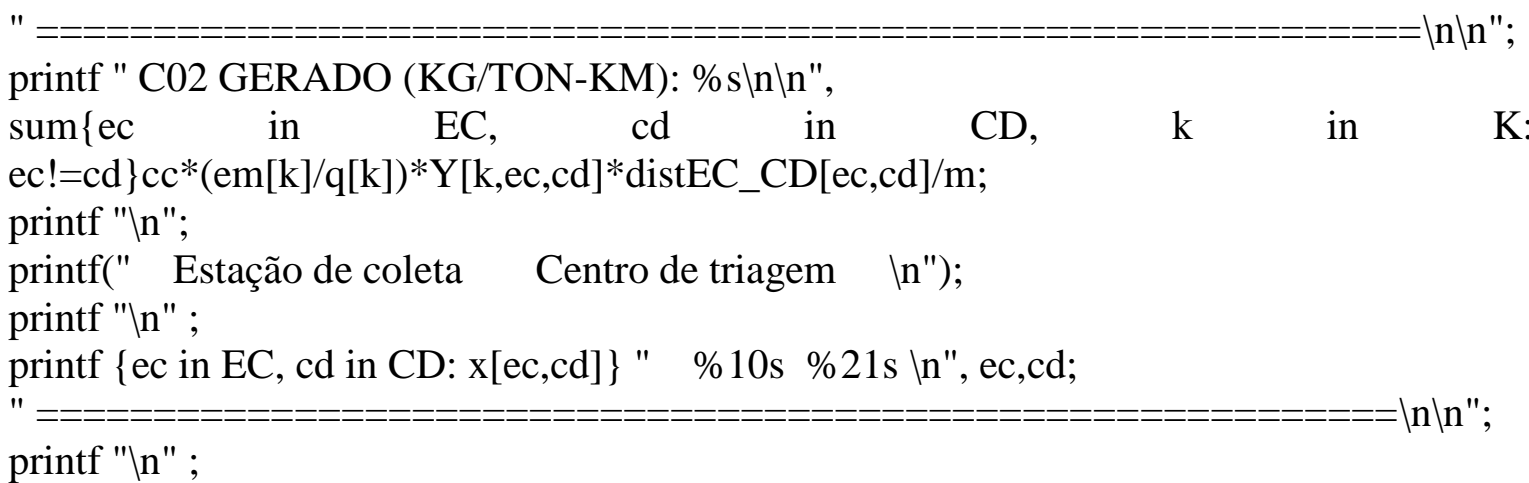




\section{ANEXO H: Modelo de transporte dos RSU para centros especializados: Caso II}

$\begin{array}{ll}\text { set EC; } & \text { \# Conjunto de estações de coleta ec } \\ \text { set CT; } & \text { \# Conjunto de Centros de transformação ct } \\ \text { set F; } & \text { \# Conjunto de fabricas f } \\ \text { set CE; } & \text { \# Conjunto de centros de eliminação e }\end{array}$

set $\mathrm{N}$ := EC union $\mathrm{CT}$ union $\mathrm{F}$ union $\mathrm{CE}$; \# Conjunto de todos os nodos da rede

set K; \# Conjunto de veículos.

param a $\{$ ec in EC $\}$; $\quad$ \# Capacidade da estação de coleta $\mathrm{i}$

param $\mathrm{u}\{$ ct in $\mathrm{CT}\}$; \# Capacidade do centro de transformação $\mathrm{k}$

param $v\{\mathrm{e}$ in $\mathrm{CE}\}$; $\quad$ \# Capacidade do centro de eliminação e

param DistEC_CT $\{$ ec in EC, ct in CT $\}$; \# Distancia entre EC para CT

param DistEC_F $\{$ ec in $\mathrm{EC}, \mathrm{f}$ in $\mathrm{F}\}$; \# Distancia entre EC para $\mathrm{F}$

param DistEC_CE $\{$ ec in EC, e in CE $\}$; \# Distancia de estações de coleta para CE.

param DistCT_F $\{$ ct in $\mathrm{CT}, \mathrm{f}$ in $\mathrm{F}\}$; \# Distancia de centro transformação para fabrica

param DistCT_CE $\{$ ct in CT, e in CE $\}$; \# Distancia de C. transformação para C. eliminação

param c $\{$ ec in EC, ct in CT $\}:=15^{*}$ DistEC_CT[ec,ct]*a[ec]; \# Custo transp. de EC para CT

param c1 1 ec in EC, $\mathrm{f}$ in $\mathrm{F}\}:=15^{*}$ DistEC_F[ec,f]*a[ec]; \# Custo transporte de EC para $\mathrm{F}$ param c2 $\{$ ec in EC, e in CE $\}:=15^{*}$ DistEC_CE[ec,e] $]^{*}$ a[ec]; \# Custo transp. de EC para $\mathrm{CE}$

param $\mathrm{c} 3\{\mathrm{ct}$ in $\mathrm{CT}, \mathrm{f}$ in $\mathrm{F}\}:=15^{*}$ DistCT_F[ct,f]*u[ct]; \# Custo transporte CT para $\mathrm{F}$ param c4 $\{$ ct in CT, e in CE $\}:=15^{*}$ DistCT_CE[ct,e]*u[ct]; \# Custo transporte CT para CE param $\mathrm{b} \_\mathrm{b}\{\mathrm{k}$ in $\mathrm{K}, \mathrm{i}$ in $\mathrm{N}, \mathrm{j}$ in $\mathrm{N}\}$, binary; \# Constante binaria, 1 se o veiculo esta na rota param ff $\{\mathrm{k}$ in $\mathrm{K}, \mathrm{i}$ in $\mathrm{N}, \mathrm{j}$ in $\mathrm{N}\}$;

param $\mathrm{m}:=3$;

param $\mathrm{q}\{\mathrm{k}$ in $\mathrm{K}\}$;

$\mathrm{Kg}$.

param $\operatorname{em}\{\mathrm{k}$ in $\mathrm{K}\}$;

\# Custo fixo dos veículos nas rotas em \$.

\# Quantidade de veículos.

\# Capacidade dos veículos transportadores em

$(\mathrm{g} / \mathrm{l})$.

param cc: $=0.275$

\# Emissão CO2 dos veículos em gramas por litro

$\operatorname{var} \mathrm{x}\{\mathrm{ec}$ in $\mathrm{EC}, \mathrm{ct}$ in $\mathrm{CT}\},>=0 ; \quad$ \# Quantidade transportada da EC para $\mathrm{CD}$

var $\mathrm{x} 1\{\mathrm{ec}$ in $\mathrm{EC}, \mathrm{f}$ in $\mathrm{F}\}>=0$; $\quad$ \# Quantidade transportada de EC para $\mathrm{CT}$

var $\mathrm{x} 2\{\mathrm{ec}$ in $\mathrm{EC}$, e in $\mathrm{CE}\},>=0$; \# Quantidade transportada da EC para CE

var $\mathrm{x} 3\{$ ct in $\mathrm{CT}, \mathrm{f}$ in $\mathrm{F}\},>=0$; \# Quantidade transportada do CT para $\mathrm{F}$

var $\mathrm{x} 4\{$ ct in $\mathrm{CT}$, e in $\mathrm{CE}\},>=0$; \# Quantidade transportada do CT para CE

var $\mathrm{Y}\{\mathrm{k}$ in $\mathrm{K}, \mathrm{i}$ in $\mathrm{N}, \mathrm{j}$ in $\mathrm{N}\}$, binary; \# Valor 1 se veiculo atribuído na rota, senão 0.

minimize Z: $\operatorname{sum}\{\mathrm{ec}$ in $\mathrm{EC}$, ct in $\mathrm{CT}\} \mathrm{c}[\mathrm{ec}, \mathrm{ct}] * \mathrm{x}[\mathrm{ec}, \mathrm{ct}]+$

$\operatorname{sum}\{\mathrm{ec}$ in $\mathrm{EC}, \mathrm{f}$ in $\mathrm{F}\} \mathrm{c} 1[\mathrm{ec}, \mathrm{f}]^{*} \mathrm{x} 1[\mathrm{ec}, \mathrm{f}]+\operatorname{sum}\{\mathrm{ec}$ in $\mathrm{EC}$, e in $\mathrm{CE}\} \mathrm{c} 2[\mathrm{ec}, \mathrm{e}]^{*} \mathrm{x} 2[\mathrm{ec}, \mathrm{e}]+$

$\operatorname{sum}\{\mathrm{ct}$ in $\mathrm{CT}, \mathrm{f}$ in $\mathrm{F}\} \mathrm{c} 3[\mathrm{ct}, \mathrm{f}]^{*} \mathrm{x} 3[\mathrm{ct}, \mathrm{f}]+\operatorname{sum}\{\mathrm{ct}$ in $\mathrm{CT}$, e in $\left.\mathrm{CE}\} \mathrm{c} 4[\mathrm{ct}, \mathrm{e}]^{*} \mathrm{x} 4[\mathrm{ct}, \mathrm{e}]\right)+$

$\operatorname{sum}\{k$ in $K, i$ in $N, j$ in $N\} f f[k, i, j] * Y[k, i, j]+$

$\operatorname{sum}\{\mathrm{ec}$ in EC, ct in CT, $\mathrm{k}$ in K: ec!=ct $\} \mathrm{cc}^{*}(\mathrm{em}[\mathrm{k}] / \mathrm{q}[\mathrm{k}]) * \mathrm{Y}[\mathrm{k}, \mathrm{ec}, \mathrm{ct}] *$ DistEC_CT[ec,ct]/m; s.t. $\mathrm{R} 1\{\mathrm{ec}$ in $\mathrm{EC}\}: \operatorname{sum}\{\mathrm{ct}$ in $\mathrm{CT}, \mathrm{f}$ in $\mathrm{F}, \mathrm{e}$ in $\mathrm{CE}\}(\mathrm{x}[\mathrm{ec}, \mathrm{ct}]+\mathrm{x} 1[\mathrm{ec}, \mathrm{f}]+\mathrm{x} 2[\mathrm{ec}, \mathrm{e}])<=\mathrm{a}[\mathrm{ec}]$; 
s.t. $\mathrm{R} 2\{$ ct in $\mathrm{CT}\}: \operatorname{sum}\{\mathrm{f}$ in $\mathrm{F}, \mathrm{e}$ in $\mathrm{CE}\}(\mathrm{x} 3[\mathrm{ct}, \mathrm{f}]+\mathrm{x} 4[\mathrm{ct}, \mathrm{e}])<=\mathrm{u}[\mathrm{ct}]$;

s.t. $\mathrm{R} 3\{\mathrm{ec}$ in $\mathrm{EC}$, ct in $\mathrm{CT}\}: \operatorname{sum}\{\mathrm{k}$ in $\mathrm{K}\} \mathrm{b} \_\mathrm{b}[\mathrm{k}, \mathrm{ec}, \mathrm{ct}] * \mathrm{Y}[\mathrm{k}, \mathrm{ec}, \mathrm{ct}]<=\mathrm{x}[\mathrm{ec}, \mathrm{ct}]$;

s.t. $\mathrm{R} 4\{\mathrm{ct}$ in $\mathrm{CT}\}: \operatorname{sum}\{\mathrm{ec}$ in $\mathrm{EC}\} \mathrm{x}[\mathrm{ec}, \mathrm{ct}]=\operatorname{sum}\{\mathrm{f}$ in $\mathrm{F}\} \mathrm{x} 3[\mathrm{ct}, \mathrm{f}]$;

s.t. $\mathrm{R} 5\{\mathrm{ct}$ in $\mathrm{CT}\}: \operatorname{sum}\{\mathrm{ec}$ in $\mathrm{EC}\} \mathrm{x}[\mathrm{ec}, \mathrm{ct}]=\operatorname{sum}\{\mathrm{e}$ in $\mathrm{CE}\} \mathrm{x} 4[\mathrm{ct}, \mathrm{e}]$;

solve;

printf "ln" ;

printf "Transporte da estação coleta para centro transformação: \%s\n", sum $\{$ ec in EC, ct in CT\} c[ec,ct $]^{*} x[\mathrm{ec}, \mathrm{ct}]$;

printf "\n\n" ;

printf(" Estação de coleta Centro de transformação Quantidade transportada $\backslash n ")$;

printf "In" ;

printf $\{\mathrm{ec}$ in EC, ct in CT: $\mathrm{x}[\mathrm{ec}, \mathrm{ct}]\} \quad \% 8 \mathrm{~s} \quad \% 16 \mathrm{~s} \quad \% 25 \mathrm{~g} \backslash \mathrm{n} ", \mathrm{ec}, \mathrm{ct}, \mathrm{x}[\mathrm{ec}, \mathrm{ct}]$;

printf "In" ;

printf "Transporte da estação coleta para fabrica: \%s\n", $\operatorname{sum}\{\mathrm{ec}$ in EC, f in F $\}$ $\mathrm{c} 1[\mathrm{ec}, \mathrm{f}] * \mathrm{x} 1[\mathrm{ec}, \mathrm{f}]$;

printf "\n\n" ;

printf(" Estação coleta Fabrica Quantidade transportada $\backslash n ")$;

printf "In" ;

printf $\{\mathrm{ec}$ in EC, f in F: $\mathrm{x} 1[\mathrm{ec}, \mathrm{f}]\}$ " \%9s $\% 19 \mathrm{~s} \quad \% 28 \mathrm{~g} \backslash n ", \mathrm{ec}, \mathrm{f}, \mathrm{x} 1[\mathrm{ec}, \mathrm{f}]$;

printf "ln" ;

printf "Transporte da estação coleta para Centro eliminação: \%s\n", sum\{ec in EC, e in $\mathrm{CE}\} \mathrm{c} 2[\mathrm{ec}, \mathrm{e}] *$ x2[ec,e];

printf "ln\n" ;

printf(" Estação coleta C. Eliminação Quantidade transportada $\backslash n ")$;

printf "\n" ;

printf $\{$ ec in EC, e in CE: $x 2[e c, e]\} " \quad \% 9 s \quad \% 19 s \quad \% 28 \mathrm{~g} \backslash n ", e c, e, x 2[e c, e] ;$

printf "\n" ;

printf "Transporte do centro transformação para fabrica: \%s\n", sum\{ct in CT, $\mathrm{f}$ in $\mathrm{F}\} \mathrm{c} 3[\mathrm{ct}, \mathrm{f}]^{*} \times 3[\mathrm{ct}, \mathrm{f}]$;

printf "In\n" ;

printf(" Centro de transformação Fabrica Quantidade transportada $\backslash n ")$;

printf "In" ;

printf $\{\mathrm{ct}$ in CT, f in F: $\mathrm{x} 3[\mathrm{ct}, \mathrm{f}]\}$ " \%10s $\% 15 \mathrm{~s} \quad \% 19 \mathrm{~g} \backslash \mathrm{n} ", \mathrm{ct}, \mathrm{f}, \mathrm{x} 3[\mathrm{ct}, \mathrm{f}]$;

printf "ln" ;

printf "Transporte do centro transformação para Centro eliminação: \%s\n", sum $\{$ ct in CT, e in $\mathrm{CE}\} \mathrm{c} 4[\mathrm{ct}, \mathrm{e}]^{*} \mathrm{x} 4[\mathrm{ct}, \mathrm{e}]$;

printf "\n\n" ;

printf(" Centro de transformação Centro eliminação Quantidade transportada $\backslash n ")$;

printf "In" ;

printf $\{$ ct in CT, e in CE: $x 4[c t, e]\} " \% 10$ s $\% 15 \mathrm{~s} \% 19 \mathrm{~g} \backslash n "$, ct, e, $\mathrm{x} 4$ [ct,e];

printf "ln" ;

printf

printf " C02 GERADO (KG/TON-KM): \%s\n\n", $=\ln \backslash n "$ 
$\operatorname{sum}\{\mathrm{ec}$ in $\mathrm{EC}$, ct in $\mathrm{CT}, \mathrm{k}$ in $\mathrm{K}: \mathrm{ec} !=\mathrm{ct}\} \mathrm{cc} *(\mathrm{em}[\mathrm{k}] / \mathrm{q}[\mathrm{k}])^{*} \mathrm{Y}[\mathrm{k}, \mathrm{ec}, \mathrm{ct}] * \operatorname{DistEC} \mathrm{CT}[\mathrm{ec}, \mathrm{ct}] / \mathrm{m}$; printf "In";

printf(" Estação de coleta Centro de transformação $\quad \ln$ "); printf "\n" ;

printf $\{\mathrm{ec}$ in EC, ct in CT: $\mathrm{x}[\mathrm{ec}, \mathrm{ct}]\} " \% 10 \mathrm{~s} \% 21 \mathrm{~s} \backslash \mathrm{n} ", \mathrm{ec}, \mathrm{ct}$;

printf

printf "\n" ; 
APÊNDICE 


\section{APÊNDICE A: Conceitos Utilizados}

1. Aterro sanitário: Técnica de disposição de resíduos sólidos urbanos no solo, sem causar danos à saúde pública e à sua segurança minimizando os impactos ambientais, método este que utiliza os princípios de engenharia (impermeabilização do solo, cercamento, ausência de catadores, sistema de drenagem de gases, águas pluviais e lixiviado) para confinar os resíduos e rejeitos à menor área possível e reduzi-los ao menor volume permissível, cobrindo-o com uma camada de terra na conclusão de cada jornada de trabalho, ou a intervalos menores, se necessário (PNRS, 2011).

2. Aterro controlado: Forma inadequada de disposição final de resíduos e rejeitos, no qual o único cuidado realizado é o recobrimento da massa de resíduos e rejeitos com terra (PNRS, 2011). Assim, a única vantagem em relação aos lixões é que os resíduos são cobertos com uma camada de solo ao final da jornada diária, com o intuito de atenuar a proliferação de vetores de doenças.

3. Clusters: Termo em inglês que significa "blocos" ou "agrupamentos", utilizado em vários contextos para designar o agrupamento de elementos comuns para um determinado fim. No setor industrial, o termo é usado quando se deseja, por exemplo, destacar agrupamentos ou ramos industriais dedicados à exportação que tenham alguma característica comum, como o fato de ser produtos de consumo de massa, bens duráveis, semiduráveis, etc. (Dicionário de Economia, 2010).

4. Coleta seletiva formal: coleta regular de resíduos realizada ou apoiada pela administração municipal por meio de organizações tais como cooperativa ou associação de catadores (PNRS, 2011).

5. Coleta seletiva informal: coleta de resíduo realizada por catadores autônomos dispersos pela cidade cuja quantidade não é contabilizada pelos órgãos municipais. Geralmente são vendidos para os sucateiros que comercializam diretamente com as indústrias (PNRS, 2011). 
6. Destinação final ambientalmente adequada: destinação de resíduos que inclui a reutilização, a reciclagem, a compostagem, a recuperação e o aproveitamento energético ou outras destinações admitidas pelos órgãos competentes do Sisnama, do SNVS e do Suasa, entre elas a disposição final, observando normas operacionais específicas de modo a evitar danos ou riscos à saúde pública e à segurança e a minimizar os impactos ambientais adversos (inciso VII, art. 3 da lei 10.305, de 2010).

7. Economia de Escala: na qual, quanto maior a produção, menores são os custos e maiores os lucros (Dicionário de Economia, 2010).

8. Gestão Integrada de resíduos sólidos: conjunto de ações voltadas para a busca de soluções para os resíduos sólidos, de forma a considerar as dimensões política, econômica, ambiental, cultural e social, com controle social e sob a premissa do desenvolvimento sustentável (XI, art.3 ${ }^{\circ}$, Lei nº 12.305, de 2010).

9. Gravimetria: Método analítico quantitativo cujo processo envolve a separação e pesagem de um elemento ou um composto do elemento na forma mais pura possível, segundo definido no Estudo sobre o Potencial de Geração de Energia a partir de Resíduos de Saneamento (lixo, esgoto), visando incrementar o uso de biogás como fonte alternativa de energia renovável. Resumo Executivo, PNUD, MMA, (2010).

10. Lixão: Forma inadequada de disposição final de resíduos e rejeitos, que consiste na descarga do material no solo sem qualquer técnica ou medida de controle (PNRS, 2011). Ou seja, é uma forma de disposição de RSU desordenada, sem compactação ou cobertura dos resíduos coletados, que gera elevada poluição do solo, ar e água, bem como facilita a proliferação de vetores de doenças.

11. Logística reversa de pós-venda: atividade de planejar, operar e controlar o fluxo de retorno dos produtos de pós-venda por motivos agrupados nas seguintes classificações: "garantia/qualidade"; "comerciais"; e "substituição de componentes". (Leite, 2009). 
12. Logística reversa pós-consumo: atividade de planejar, operar o controlar o fluxo de retorno dos produtos de pós-consumo ou de seus materiais constituintes, classificados em função de seu estado de vida e origem, em "condições de uso"; "fim de vida útil”; e "resíduos industriais". (Leite, 2009)

13. Reciclagem pré-consumo: reciclagem dos resíduos gerados nos processos produtivos. (PNRS, 2011).

14. Reciclagem pós-consumo: reciclagem de resíduos decorrente da utilização de um bem. (PNRS, 2011).

15. Reciclagem: processo de transformação dos resíduos sólidos que envolve a alteração de suas propriedades físicas, físico-químicas ou biológicas, com vistas à transformação em insumos ou novos produtos (XIV, art.3º, Lei nº 12.305, de 2010).

16. Redução: é a diminuição na geração de resíduo, pela redução do consumo ou a não geração de resíduo. (Silva e Pires, et al, 2009)

17. Rejeitos: resíduos sólidos que depois de esgotadas todas as possibilidades de tratamento e recuperação por processos tecnológicos disponíveis e economicamente viáveis, não apresentem outra possibilidade que não a disposição final ambientalmente adequada (PNRS, 2011).

18. Resíduos Sólidos: todomaterial, substância, objeto ou bem descartado resultante de atividades humanas em sociedade, a cuja destinação final se procede, se propõe proceder ou se está obrigado a proceder, nos estados solido ou semissólido, bem como gases contidos em recipientes e líquidos cujas particularidades tornem inviável o seu lançamento na rede pública de esgotos ou em corpos d água, ou exijam para isso soluções técnicas ou economicamente inviáveis em face da melhor tecnologia disponível (PNRS, 2011 e inciso XVI, art. 13, Lei nº 12.305, de 2010).

19. Resíduos sólidos urbanos: os originários de atividades domésticas em domicílios urbanos e os originários da varrição, limpeza de logradouros e vias públicas e outros serviços de limpeza urbana (alínea “c”, Inciso I, art. 13, da Lei 12.305, de 2010). 
20. Reutilização: consiste no reaproveitamento do resíduo, nas condições em que é descartado, sem qualquer alteração física de seu material, modificando ou não sua função original e submetendo-o a pouco ou nenhum tratamento, exigindo apenas limpeza, emelezamento, identificação, entre outras (Silva e Pires et al 2009). 